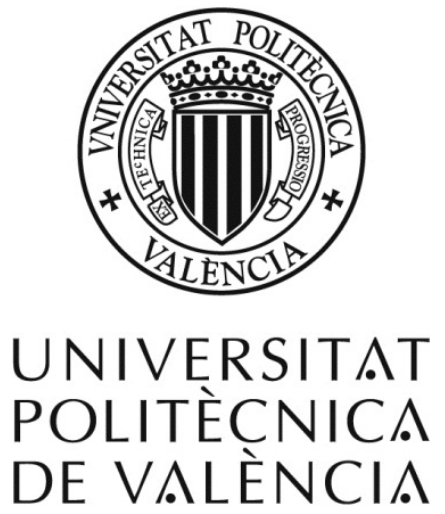

Departament de Lingüística Aplicada

\title{
ERROR IN THE LEARNING AND TEACHING OF ENGLISH AS A SECOND LANGUAGE AT HIGHER EDUCATION LEVEL
}

Author: Eva Maria Mestre Mestre Advisor: Maria Luisa Carrió Pastor

València, June 2011. 



\begin{abstract}
I un dia t'alçaràs
enmig de l'aire prim que he caminat

$i$ de les coses que el soroll amaga.

I escoltaran els ulls

guaitant des de les vores del silenci

alguna pluja tendra sobre els dits,

inacabada i fràgil.

Llavors sabràs que el món també batega

i gaudiràs dolors en la recerca

provant de ser fidel.
\end{abstract}

Severí Vila i Falgàs

A la família. El principi i la fi de tot.

A la meua. 

Les pàgines que segueixen són el resultat d'un llarg procés de treball, esforç i tossuderia. Han requerit dedicació amb avarícia, i han sigut el centre del meu pensament durant mesos i anys. Són, finalment, el fruit d'una idea, que ha anat madurant i prenent forma, que ha anat nodrint-se pel camí i ha crescut fins a convertir-se en el document que teniu a les mans. L'emoció que acompanya el moment de veure la tesi doctoral llesta per a defensar té múltiples causes: la satisfacció pel treball fet, l'entusiasme d'haver aconseguit arrodonir el projecte i sobretot la presa de consciència de tota l'ajuda rebuda en el camí. La llista és ben llarga, i per això, i perquè aquest és el resultat de la feina i la generositat de moltes persones, voldria dedicar aquest espai a regraciar-les.

Voldria primer donar les gràcies a la persona que ha dirigit aquesta tesi, la Dra. María Luisa Carrió Pastor. Gràcies, Marisa per haver confiat en mi des del primer moment. Gràcies per haver-me introduït en la maresma de l'error com a eina de millora en l'aprenentatge de les segones llengües. Per haver sigut ferma en el convenciment que el treball pagava la pena, per la motivació i el suport que m'has donat capítol rere capítol. Gràcies també per haver estat disponible en tot moment, per haver-me ajudat a posar ordre en el meu desordre i per la paciència.

Gràcies al Dr. Malcolm Coulthard per les converses i les discussions a Aston University, per les revisions setmanals davant un bon café anglés. Pels brillants comentaris sobre el plantejament i la metodologia que calia utilitzar en el treball que presente. Gràcies també a la Dra. Carmen Rosa Caldas-Coulthard, de la University of Birmingham. Gràcies a la Dra. Laurence Flucha i la Dra. Delphine Letort, de la Université du Maine, que em van donar suport a l'inici de la investigació, quan no era més que un projecte.

Vull donar les gràcies de manera especial a les persones que han fet el treball dur d'aquesta investigació. Les professores Carme Carrió i Verónica Pastor. Amigues generoses que no van dubtar un segon a oferir temps i saviesa per ajudar a fer aquest projecte una realitat. Elles són responsables de les correccions dels textos que han sigut la base de la investigació, i en són la justificació última. Sense elles, el treball simplement no s'hauria pogut fer. 
Gràcies a Lorraine Connor per la correcció lingüística d'aquest document, per no haver dubtat mai a l'hora de treballar de ferm per aconseguir complir els terminis i els requisits; per llegir i rellegir els texts fins quasi aprendre'ls de memòria. Per ser sempre minuciosa alhora que flexible.

Gràcies també a tots els companys de l'Escola Politècnica Superior de Gandia, especialment a Josep i a Cristina, perquè han sigut comprensius i esplèndids amb les meues circumstàncies, sovint especials i necessitades d'ajuda, de temps, de context. Gràcies pel suport diari, per l'amistat oferida des del primer dia, pels dinars al seminari, per les xerrades al corredor, pels riures. Sobretot gràcies pel respecte a la porta tancada -tan odiosa.

No vull oblidar en aquesta relació d'agraïments els alumnes. Els que han fet part d'aquesta investigació amb l'aportació de treballs escrits en anglés, i els que han seguit les meues classes enguany, per aportar cada any aire fresc i obrir-me portes a la reflexió i l'aprenentatge.

Als amics, clar. Gràcies a tots per haver sigut indulgents i pacients, per haver-me acompanyat en els bons moments i en els que no eren tan bons, per estar sempre disponibles. Pels pensaments collectius, les converses, els caps de setmana d'excursió, les visites sorpresa. I també gràcies per només preguntar quan devíeu.

Vull agrair especialment l'esforç que ha fet la meua família. La gran família, als dos costats de l'oceà. M'heu ensenyat tot el que sóc. Sempre m'heu donat suport i heu tingut plena confiança en mi. M'heu ajudat i heu arribat allà on jo no arribava, bé fóra emocionalment, intellectualment o en la pràctica quotidiana. A Ruth, sobretot, el meu model i punt de referència durant tants anys.

Gràcies a Sofia i a Andreu, la meua vida i la raó de tant d'esforç. Per les preguntes, els desacords, els riures, i tantes i tantes coses que no es poden escriure. He deixat a Rubén per al final. El millor company a tots els nivells imaginables, gràcies per tots. Sense tu, mai hauria arribat fins ací. Gràcies per l'estima, pel suport, per l'ajuda, per les converses, per les discussions de ciència, pels consells. Per deixar que aquest treball envaira la nostra quotidianitat. Per entendre-ho sempre. Per relegar tantes coses a un segon terme. Per caminar amb mi tot el camí. Gràcies. 
INDEXES 



\section{INDEXES}

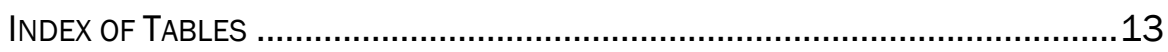

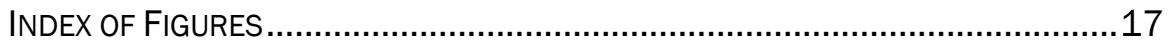

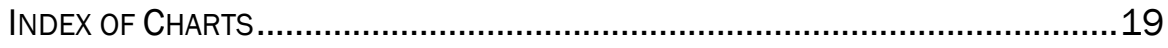

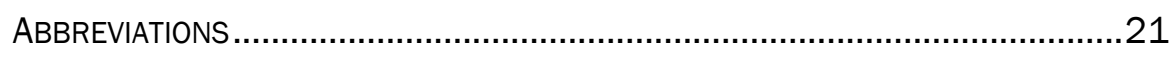

Item Abbreviation used in the analysis..................................................23

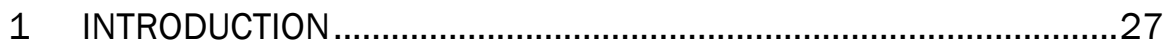

2 THEORETICAL BACKGROUND .......................................................

2.1 PRAGMATICS......................................................................... 42

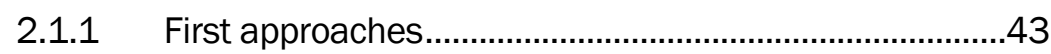

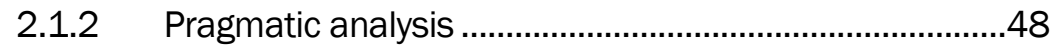

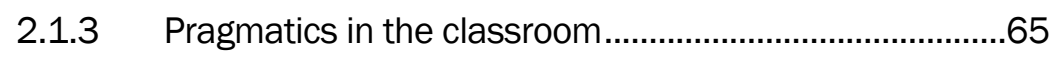

2.2 CONTRASTIVE ANALYSIS (CA) .............................................78

2.2.1 Definition and beginnings...............................................78

2.2.2 Aims and achievements ................................................8

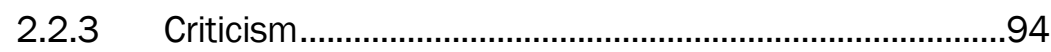

2.2.4 Present and future trends ..............................................97

2.3 ERROR ANALYSIS (EA) ....................................................... 108

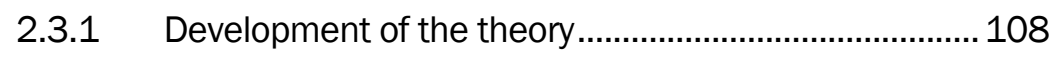

2.3.2 Present and future trends ............................................ 121

2.3.3 Types of errors ......................................................... 123

2.3.3.1 James' taxonomy .................................................. 124

2.3.3.2 Language transfer .............................................. 131

2.3.3.3 Grammatical errors ............................................ 136

2.3.3.4 Pragmatic errors ................................................. 143 
2.4 SECOND LANGUAGE ACQUISITION (SLA)............................ 150

2.4.1 Traditional methods ........................................................ 150

2.4.2 Content and Task-based methods ............................... 154

2.4.3 The Communicative Approach ....................................... 158

2.5 COMMON EUROPEAN FRAMEWORK FOR LANGUAGES (CEFR) ... 171

2.5.1 The Document ............................................................ 173

2.5.2 Pragmatics in the CEFR ................................................ 178

2.5.3 Description of competences ......................................... 184

2.5.4 Communicative activities: Written communication ..... 200

2.5.5 Errors in the CEFR ....................................................... 206

2.5.6 Proposals for error analysis based on the CEFR.......... 211

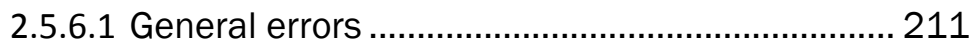

2.5.6.2 Written production .............................................. 216

2.5.6.3 Pragmatic errors ................................................. 221

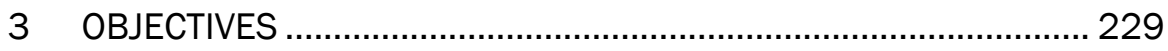

3.1 General objectives ............................................................ 230

3.2 Specific objectives........................................................... 232

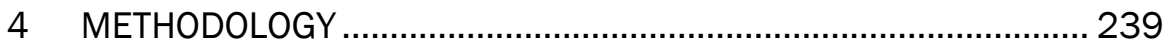

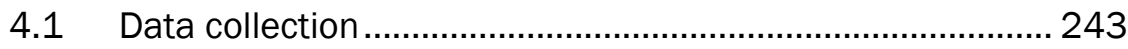

4.1.1 The students: origin of texts and level of proficiency... 244

4.1.2 The texts ........................................................................ 246

4.1.2.1General description of the texts.......................... 246

4.1.2.2Text types in the CEFR ......................................... 249

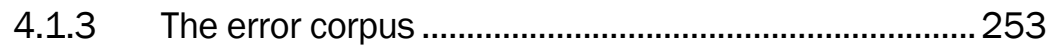

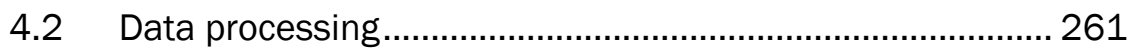

4.2.1 Correction process ....................................................... 261

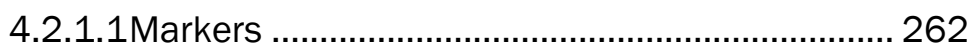

4.2.1.2Correction according to the CEFR ....................... 266

4.2.1.3Descriptors and text types..................................... 267 
4.2.2 Tagging .................................................................... 270

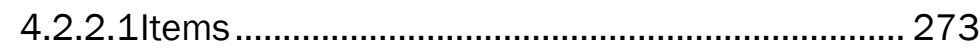

4.2.3 Foundation. A pilot study ............................................. 274

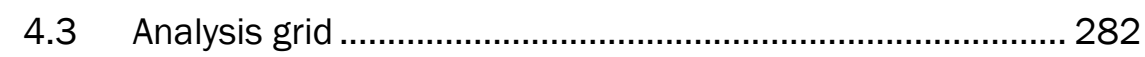

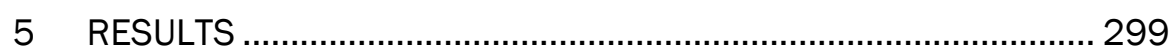

5.1 Setting of the study …..................................................... 300

5.2 Data obtained per markers................................................ 311

5.2.1 Coincidence in error detection .......................................313

5.2.2 Divergence in error detection......................................... 316

5.2.3 Exceptionality in error detection ....................................319

5.3 Analysis of items................................................................. 321

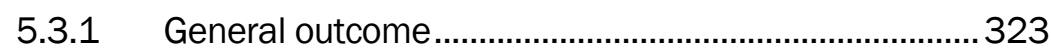

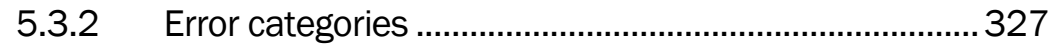

5.3.3 Items within error category.............................................330

5.4 Particularities of each genre................................................ 336

5.4.1 Impact of genre on error category ................................337

5.4.2 Distribution of errors within the text type......................343

5.5 Account of B1 level of proficiency …………........................ 351

5.6 Qualitative analysis of Pragmatic error categories............... 360

5.7 Limitations in the results of the present study ..................... 366

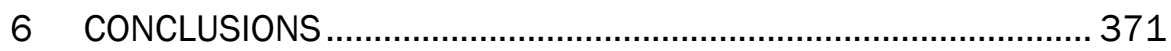

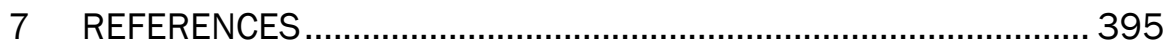

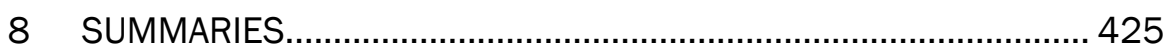

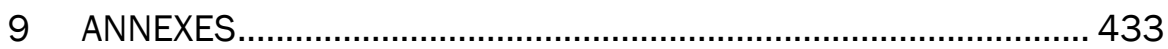


$-12-$ 


\section{INDEX OF TABLES}

Table 1. Studies examining the effect of pragmatic instruction from 1981 to 1997 based on Kasper (1997).

Table 2. Studies relating Pragmatics with the classroom 1993-2003 (Da Silva, 2003).

Table 3. Differences between traditional and communicative approach (Nunan, 1988). 166

Table 4. Self-assessment grid for writing. B2, C1, C2 levels (CE, 2001:26-27).

Table 5. External context of use: descriptive categories based on the CEFR (CE, 2001:48-49).

Table 6. Pragmatic competences. Discourse: Flexibility. B1 level (CE, 2001:124)

Table 7. Pragmatic competences. Discourse: Turn taking. B1 level (CE, 2001:124).

Table 8. Pragmatic competences. Discourse: Thematic development. B1 level. (CE, 2001:125).

Table 9. Pragmatic competences. Discourse: Coherence \& cohesion. B1 level. (CE, 2001:125). 189

Table 10. Functional competence. Qualitative factors: Propositional precision. (CE, 2001:129).

Table 11. Types of assessment (CE, 2001:183). 197

Table 12. Assessment: positive and negative criteria. (CEFR. Appendix A)....................................................................... 199

Table 13. Writing activities (CE, 2001:61)........................................... 201

Table 14. Overall written production activities (CE, 2001:61)............ 202

Table 15. Creative writing activities. (CE, 2001:62)............................. 202

Table 16. Overall written production activities. (CE, 2001:62)........... 202 
Table 17. The DIALANG scale for B1 level of proficiency (CE, 2001:233)

Table 18. Grammatical accuracy for B1 level of proficiency (CE, 2001:114).

Table 19. Orthographic competence for B1 level of proficiency (CE, 2001:114). 216

Table 20. Self-assessment grid for B1 level of overall writing (CE, 2001:26).

Table 21. Writing. Creative writing. B1 level (CE, 2001:62), ................ 218

Table 22. Writing. Reports and essays. B1 level (CE, 2001:62)......... 218

Table 23. Written production strategies. Planning (CE, 2001:64). ..... 219

Table 24. Written production strategies. Compensating (CE, 2001:64).

Table 25. Written production strategies. Monitoring and repair (CE, 2001:65). 219

Table 26. Written Production. Note-taking. (CE, 2001:96). 220

Table 27. Written Production. Processing text. (CE, 2001:96)............ 220

Table 28. Pragmatic competences. Flexibility (CE, 2001:124)............ 223

Table 29. Pragmatic competences. Turn taking (CE, 2001:124)........ 223

Table 30. Pragmatic competences. Thematic development. (CE, 2001:125). 223

Table 31. Pragmatic competences. Coherence and cohesion. (CE,

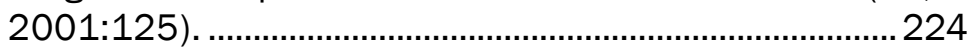

Table 32. Sociolinguistic appropriateness (CE, 2001:122), ................ 224

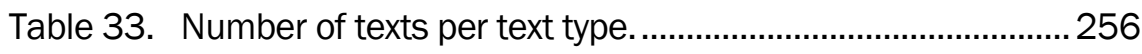

Table 34. Number of texts and codification............................................257

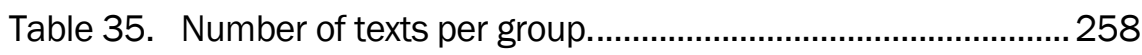

Table 36. Relationship between authorship and texts........................ 259

Table 37. Analysis grid. Tags used in the correction of the texts..........272

Table 38. Items for analysis based on CEFR. Texts. Rhetorical functions.

Table 39. Items for analysis based on the CEFR. Linguistic competences. 
Table 40. Items for analysis based on the CEFR. Pragmatic and Sociolinguistic competences.

Table 41. Items for analysis based on Pragmatic theories. 290

Table 42. Analysis grid. Items grouped and arranged for analysis (1).

Table 43. Analysis grid. Items grouped and arranged for analysis (2)

Table 44. Elements included in the analysis. 295

Table 45. Variables used in the analysis: Marker, Text, Item 301

Table 46. Descriptors used in the analysis. 305

Table 47. Analysis parameters. 306

Table 48. Combinations of variables. 310

Table 49. Most common errors in the corpus. 325

Table 50. Number of errors in each text type. 337

Table 51. Specific errors in summaries (1-10). 343

Table 52. Specific errors in opinions (1-10). 343

Table 53. Specific errors in letters (1-10). 343

Table 54. Specific errors in summaries (29-39). 345

Table 55. Specific errors in opinions (29-39). 345

Table 56. Specific errors in letters (29-39). 345

Table 57. Statistical calculation of means. 352

Table 58. Total of number of texts with a range of errors within the average. 355

Table 59. Error categories with less than 100 errors. Markers............ 362

Table 60. Error categories with less than 100 errors. Genres. 365

Table 61. Errors in average and in above average texts. 366 
$-16-$ 


\section{INDEX OF FIGURES}

Figure 1. Distinction between Pragmalinguistics and Sociopragmatics (Leech, 1983:11) ....................................................................63

Figure 2. Contrastive Rhetoric Studies (Connor, 2003).............................84

Figure 3. Applications of Contrastive Rhetoric Studies (Connor, 2003). 99

Figure 4. Swales' Four Move Model (1991)............................................ 103

Figure 5. Levels of error (James, 1998:130)......................................... 127

Figure 6. Carrió's classification of errors, based on Bachman

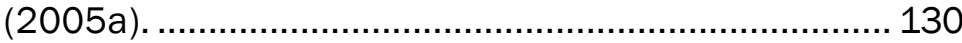

Figure 7. Levels of language proficiency as established in the CEFR. 175

Figure 8. Linguistic diversification and the curriculum. Summary.

(CE, 2001:176)

Figure 9. General schema for purchase of goods and services. (CE, 2001:127-128).

Figure 10. Politeness conventions. (CE, 2001:119-120)..................... 194

Figure 11. Communicative categories. (CE, 2001:179)........................ 196

Figure 12. Text types in CEFR (CE, 2001:95)...................................... 204

Figure 13. Errors and mistakes (CE, 2001:145-146)......................... 210

Figure 14. Grammatical elements for analysis. (CE, 2001:113)......... 214

Figure 15. Qualitative-Quantitative Continuum of Research Methodologies. Larsen-Freeman \& Long (1991:15)........... 242 
$-18-$ 


\section{INDEX OF CHARTS}

Chart 1. Results per marker in the total of errors.......................... 312

Chart 2. Grammatical competence per marker.................................... 315

Chart 3. Flexibility per marker. ....................................................... 315

Chart 4. Orthographic competence per marker. .................................. 315

Chart 5. Discourse competence per marker. ….............................. 315

Chart 6. Rhetorical functions per marker. ........................................ 317

Chart 7. Rhetorical effectiveness per marker. ................................. 317

Chart 8. Lexical competence per marker........................................... 318

Chart 9. Style and register per marker........................................... 320

Chart 10. Sociolinguistic competence per marker............................... 320

Chart 11. Relevance per marker..................................................... 320

Chart 12. Content knowledge per marker....................................... 320

Chart 13. Ranking of errors in the corpus. ....................................... 326

Chart 14. Distribution of error categories in the corpus................... 328

Chart 15. Ranking of error categories in the corpus......................... 329

Chart 16. Occurrences in grammatical competence items.............. 331

Chart 17. Occurrences in discourse competence items................... 331

Chart 18. Occurrences in orthographic competence items.............. 331

Chart 19. Occurrences in rhetorical effectiveness items. ................. 333

Chart 20. Occurrences in flexibility items....................................... 333

Chart 21. Occurrences in style and register items........................... 333

Chart 22. Occurrences in lexical competence items. ....................... 333

Chart 23. Occurrences in rhetorical functions items....................... 335 
Chart 24. Occurrences in content knowledge items. 335

Chart 25. Occurrences in sociolinguistic awareness items 335

Chart 26. Rhetorical functions in genres. 338

Chart 27. Grammatical competence in genres. 338

Chart 28. Lexical competence in genres. 339

Chart 29. Orthographic competence in genres. 339

Chart 30. Register and style in genres. 340

Chart 31. Flexibility in genres. 340

Chart 32. Rhetoric effectiveness in genres. 340

Chart 33. Relevance in genres. 340

Chart 34. Content knowledge in genres. 341

Chart 35. Discourse competence in genres. 341

Chart 36. Sociolinguistic competence in genres. 342

Chart 37. Error category distribution per genres in the corpus. 347

Chart 38. Error distribution in summaries in the corpus. 349

Chart 39. Error distribution in opinions in the corpus. 350

Chart 40. Error distribution in letters in the corpus. 351

Chart 41. Boxplot for texts and errors in the corpus. 354

Chart 42. Errors in average summaries in the corpus. 356

Chart 43. Errors in average opinions in the corpus. 356

Chart 44. Errors in average letters in the corpus. 357

Chart 45. Summaries. Total vs. average 358

Chart 46. Opinions. Total vs. average. 358

Chart 47. Letters. Total vs. average. 359

Chart 48. Total errors per markers in the corpus. Qualitative analysis. 363 


\section{ABBREVIATIONS}

$\begin{array}{ll}\text { AL } & \text { Applied Linguistics } \\ \text { CA } & \text { Contrastive Analysis } \\ \text { CARS } & \text { Create a Research Space } \\ \text { CE } & \text { Council of Europe } \\ \text { CEFR } & \text { Common European Framework of Reference for Languages } \\ \text { CR } & \text { Contrastive Rhetoric } \\ \text { DA } & \text { Discourse Analysis } \\ \text { EA } & \text { Error Analysis } \\ \text { ESL } & \text { English as a Second Language } \\ \text { ESP } & \text { English for Specific Purposes } \\ \text { GI } & \text { Group of items } \\ \text { I } & \text { Item } \\ \text { ICALL } & \text { Intelligent Computer-Assisted Language Learning } \\ \text { IL } & \text { Interlanguage } \\ \text { L1 } & \text { Mother Tongue } \\ \text { L2 } & \text { Second Language } \\ \text { M } & \text { Marker } \\ \text { MT } & \text { Mother Tongue } \\ \text { NES } & \text { Native English Speakers } \\ \text { NNES } & \text { Non-native English Speakers } \\ \text { NR } & \text { Norm Referencing Assessment } \\ \text { SLA } & \text { Second Language Acquisition } \\ \text { T } & \text { Text } \\ \text { TL } & \text { Target Language } \\ \text { TT } & \text { Text type } \\ \text { UG } & \text { Universal Grammar }\end{array}$


$-22-$ 


\section{ITEM ABBREVIATION USED IN THE ANALYSIS}

\begin{tabular}{|c|c|}
\hline CKG & General Content Knowledge \\
\hline CKS & Specific Content Knowledge \\
\hline DCC & Coherence and cohesion \\
\hline DSC & Connectors/transitions \\
\hline DSFOCUS & Main points \\
\hline DSS & Sequencing \\
\hline DSTH & Summarising (text types) \\
\hline DSV & Verb tense \\
\hline DSWO & Word order \\
\hline DVM & Extrapolate meaning \\
\hline GMT & Mother Tongue influence \\
\hline GP & Wrong patterns \\
\hline GSE & Grammatical errors simple sentencing \\
\hline LC & Collocations \\
\hline LF & Fixed expressions \\
\hline LI & Intensifiers \\
\hline LPOL & Polysemy \\
\hline LPV & Phrasal verbs \\
\hline $\mathrm{OL}$ & Layout \\
\hline OP & Punctuation \\
\hline OS & Spelling \\
\hline PRVC & Errors in common vocabulary \\
\hline PRVN & Insufficient vocabulary \\
\hline PRVWW & Errors in complex topics \\
\hline RAU & Considers Audience \\
\hline REL & Relationship amount effort/benefit \\
\hline $\mathrm{RF}$ & Formal Register \\
\hline RHA & Adequacy to own limitations \\
\hline RHAC & Accuracy \\
\hline RHF & Focus \\
\hline RHP & Precision \\
\hline $\mathrm{RHQ}$ & Rhetorical effectiveness \\
\hline RI & Informal Register \\
\hline RP & Paraphrases \\
\hline RS & Use of own words \\
\hline SOC & Cultural differences \\
\hline SOP & Politeness \\
\hline TP & Text purpose \\
\hline$\pi$ & Text type \\
\hline
\end{tabular}


$-24-$ 


\section{INTRODUCTION}





\section{INTRODUCTION}

This work was initially motivated by a drive to analyse the situation whereby students are now faced with the new legislation affecting all European Universities following the Bologna Declaration on the European space for Higher Education. The Agreement was originally signed in 1999 by twenty-nine European countries, to which 18 new countries were added. The legislation wished to promote a system of easily readable and comparable degrees, in order to promote the employability of European citizens and the international competitiveness of the European higher education system. The main tenet behind this was to construct the European Higher Education Area, and respond to globalisation in the field of education. Thus, the intention was to create a system that could unify all European Universities as much as possible in order to guarantee mobility both for students and for teachers. The deadline for implementation was 2010. The objectives pursued by it are detailed below (Bologna Declaration, 1999:4):

the adoption of a common framework of readable and comparable degrees, "also through the implementation of the Diploma Supplement"; the introduction of undergraduate and postgraduate levels in all countries, with first degrees no shorter than 3 years and relevant to the labour market;

ECTS-compatible credit systems also covering lifelong learning activities; 
- a European dimension in quality assurance, with comparable criteria and methods;

- the elimination of remaining obstacles to the free mobility of students (as well as trainees and graduates) and teachers (as well as researchers and higher education administrators).

This implied a revolution in most European Universities, which were compelled to reform their syllabuses and create scales capable of comparing and balancing their programmes with those of neighbouring European universities. The Bologna document bestowed the institutions with specific tasks to make mobility and university exchange real, and the responsibility for the implementation of the plan was mostly left to them (Bologna Declaration, 1999):

- profile their own curricula, in accordance with the emerging postBologna environment, in particular through the introduction of bachelor courses in systems where they have not traditionally existed, and through the creation of master courses meeting the needs of mobile postgraduate students from around the world;

activate their networks in key areas such as joint curriculum development, joint ventures overseas or worldwide mobility schemes;

- contribute individually and collectively to the next steps in the process.

In this sense, a significant part of the adaptation to the new environment and the European Framework of Reference was left to universities. Obviously, the transformation of their curricula also affected language learning; not only in the language classroom, but also in that it increased an awareness of the need to learn languages in order to make mobility a reality and not just a possibility. In this way, some Universities established as a requirement the necessity to demonstrate a certain level of language proficiency in order to obtain a University degree (Halbach, Lázaro Lafuente \& Pérez Guerra, 2010:1): 
Como consecuencia de la puesta en marcha del ambicioso y complejo plan denominado "Espacio Europeo de Educación Superior", la universidad española se ha visto inmersa en un proceso de cambio profundo que afecta tanto a la forma de concebir la enseñanza como a la estructura y contenidos de las titulaciones. En este contexto las universidades están implantando nuevos planes de estudios que exigen conocimientos mínimos de una lengua extranjera por parte de los estudiantes.

At an international level, Järvinen (2004) explains the importance of detecting the actual level of proficiency of students, assuming an A2 Level for comprehensive school, and upper levels for upper secondary school in Finland. This is also the minimum level of proficiency for undergraduate students in Italy and France (Randall, 2010; Hawkey, 2009). However, within the Spanish territory itself, the implementation of the requirements is neither very clear nor homogeneous ${ }^{1}$. At the specific University where the present study has been planned and developed, the Universitat Politècnica de València, the level established is B2 for all degrees. This requires the use of the Common European Framework of Reference for Languages (CEFR) as a measurement tool to establish the levels and to include foreign languages at the different stages in order to guarantee the obtainment of a B2 CEFR level. After having analysed the situation in the Spanish State, Halbach, Lázaro Lafuente \& Pérez Guerra (2010:16) make ten recommendations. Of interest to the present study is recommendation 6 , which prompts universities to:

\footnotetext{
1 According to Halbach, Lázaro Lafuente \& Pérez Guerra (2010), in Spain, this issue has been left to the discretion of the different autonomous communities or the universities themselves, with the exception of some degrees, such as training courses for primary or secondary school teacher. There are differences between the requirements demanded in the different territories. For instance, the Canary Islands or Catalonia Autonomous Communities require a B2 level of proficiency. However, University of Valladolid, University of León, University of Santiago, University of Valencia, University of Alicante and the University of Jaen all require a B1.
} 
El establecimiento de criterios, condiciones y procedimientos concretos y uniformes que han de seguir los centros universitarios (departamentos, centros de lenguas u otros órganos) a la hora de expedir certificados conducentes a la acreditación de niveles de inglés. La constatación por un órgano externo del mantenimiento de estos indicadores de calidad permitiría que se garantizaran las condiciones de homologación y transparencia, lo cual facilitaría el reconocimiento de estas certificaciones por parte de otras instituciones universitarias.

We are thereby required to work toward the establishment of specific and uniform criteria, conditions and procedures that enable students to obtain the required B2 level of proficiency. Although students can otherwise certify language knowledge, most universities include L2 courses on their curricula in order to guarantee that the expected level of proficiency is achieved by their students.

However, the level of proficiency possessed by students when they arrive at University is also unclear. Evidently, it cannot be identical in all individuals, but there should be some parameters and some standards in the secondary school curricula aimed at the obtainment of a certain level of aptitude. There is, at present, little information referring to this, since, as explained above, there is a great degree of diversity. In the Valencian Community, even though there are some recommendations in this regard ${ }^{2}$, the actual level of proficiency of students remains unclear.

2 As established by the Conselleria d'Educació (Regional Ministry of Education) for the level of proficiency that students should obtain in order to finish their High School studies and take the University Entrance Examination-ORDE de 17 de juny de 2009, de la Conselleria d'Educació, per la qual regula les matèries optatives en el Batxillerat. [2009/7863]-: "Al final del curs, l'alumne hauria d'haver adquirit amb poques paraules un nivell de competència situat aproximadament entre B1 i B2, segons es definix en el Marc comú europeu de referència per a les llengües". (By the end of the course, the student should have acquired a level of proficiency located at approximately between a B1 and a B2, according to the Common European Framework of Reference for Languages." 
In fact, the only researches that can help clarify this aspect are several studies related to the English exam in the University Entrance Examination (Iglesias Rábade, 1999).

At this point, the European Council published a manual for reference, aimed to establish the standardisation of levels and approaches to language teaching. In order to calibrate the students' levels of proficiency, and to approach teaching from a similar perspective, all forty-seven member states were invited to use the Common European Framework of Reference for Languages (CEFR). The present dissertation also studies this document, and looks at the specifications offered for the different levels of proficiency. It is crucial to ascertain whether the guidelines and descriptors offered in the document help clarify the specific levels of proficiency and the way in which these are achieved. It is also of interest to consider whether the document offers the means to work towards these proficiency levels or indications as to how the different issues should be approached.

The CEFR is based on the Communicative Approach (Nunan, 1993; Widdowson, 1978; 1979; 1996; Larsen-Freeman, 2000), upholding this methodology for language teaching. This language teaching method has been used over the past decades as an exceptional tool for the teaching of a foreign language. A thorough study of this renowned method is included in the present study, in order to identify the core issues and the theoretical implications it may present for the implementation of the CEFR document. 
Furthermore, since learning an L2 has become crucial within the European context, and this doctoral dissertation deals with the teaching of a foreign language in the classroom setting, research into Second Language Acquisition (SLA) was necessary. SLA was included in the present dissertation to advise on the possible chronology of a communicative approach, starting with traditional methods which then evolved into content and task-based methods, and finally to the view of language acquisition as a tool for communication (Hymes, 1971; Savignon, 1972; 2002; Sinclair \& Coulthard, 1975; Canale \& Swain, 1980; Bachman, 1990; Canale, 1983). In addition, other factors had to be taken into account in the analysis, such as learner idiosyncrasies, or the levels of proficiency, the student's motivation or the analysis of written texts from this perspective, sidestepping other possibilities. As Larsen-Freeman \& Long point out (1991:6-7):

SLA research must account for learner variables. Age is an example of one such learner variable. [...] SLA research must account for the acquisition of a second language by young learners who may have little proficiency in their native language, up to the acquisition of a second language by an older learner. [...] Of course, there are many other learner variables.

In defining communicative competence, Canale and Swain (1980) introduced three elements as the pillars of communication: (1) grammatical competence -linguistic knowledge and effective use of grammatical structures in communication, including syntactic, phonological, semantic and morphological knowledge; (2) sociolinguistic competence -appropriate use and understanding of texts in context, and (3) strategic competence, which they identify as the ability to repair. 
Albeit with a certain degree of overlapping with the sociolinguistic competence, in 1983, these same authors introduced discourse analysis as the fourth competence of this approach.

In 1990, this was rephrased by Bachman, who introduced a different categorisation for communicative competence, subdividing this into three: organisational competence, strategic competence, and pragmatic competence. While Bachman's organisational competence includes grammatical and contextual aspects, and the strategic competence includes planning and implementation, the pragmatic competence involves knowledge of both sociolinguistic and pragmatic aspects. As one of the main pillars of the Communicative Approach, the present dissertation focuses on the analysis of the student's written production from a pragmatic perspective. Extensive research has been carried out to analyse the definition, early theories and background development of the discipline, the detailed application of the theoretical approaches and, specifically, the use of pragmatics in the classroom.

Finally, the crucial milestone of the present dissertation is error. Written production has been studied from the point of view of error in order to measure whether the guidelines offered by the Common European Framework of Reference for Languages (CEFR) are useful for assessment and evaluation. It was also considered whether it was useful to set such guidelines as principles for study in class and whether these help improve the proposed levels of proficiency based on the errors students incurred when writing in English as a second language. 
The initial premises (Corder, 1967) proposed that L2 was analysed exclusively from the point of view of interference from the Mother Tongue (MT). Later on, these were expanded to include other types of errors not directly related to interference, but caused by other multifarious factors, (Dulay, Burt, \& Krashen, 1982), such as errors at a lexical level (Carter, 1998), or errors related to cohesion and coherence (Halliday \& Hasan, 1976). Additional issues were introduced in Error Analysis (EA), for instance by Mackinnon (1997), with considerations related to style and register and the appropriateness of different varieties of English.

The present study follows the recommendations initially made by Corder (1974; 1981) and subsequently by James (1998), which establish the correct steps to follow for the identification and subsequent correction of errors:

(1) Collect examples of utterances,

(2) Identify the errors,

(3) Describe the errors,

(4) Explain the errors encountered in the texts analysed.

The newest trends of Contrastive Analysis (CA) have been included in the present dissertation. They intend to explain errors, not to predict them, including transfer and cross-linguistic influence as a tool used to support this part of the analysis (Connor, Kurtes, 2005; Charles 2007; Ozturk 2007; Gonzálvez García 2009; Nir \& Berman, 2010). 
This doctoral dissertation is structured as follows: after this first introductory chapter, in which the general purpose and content of the work is established, the second chapter introduces the basis of the present research and is dedicated to the Theoretical Background. Four disciplines that have been considered crucial to the present investigation are included, as well as the Common European Framework of Reference for Languages. The different aspects that have an influence on the analysis have been studied and applied in the design and justification of this work. Since the investigation takes into account error produced by students of an L2 in a particular context and focuses on specific items of the global production, these disciplines, researches and points of view have been taken into account.

The first part is dedicated to Pragmatics. It offers a wide perspective of the discipline, from its foundation and the beginning of its consideration as an autonomous discipline (Foley \& Van Valin, 1984; Van Valin, 1993; Van Valin \& LaPolla, 1997), to the significant pragmatic theories that have been developed throughout the years to account for language in context (Grice, 1975; Sperber \& Wilson, 1985; 1995; Anscombre \& Ducrot, 1986; Van Eemeren \& Grootendorst, 1987; Lascarides \& Asher, 1993; Yule, 1996; Pietarinen, 2004). A substantial part has been dedicated to explore some analyses conducted in the classroom, similar in purpose or in content to the present one, aimed to analyse aspects related to L2 language teaching and learning (House \& Kasper, 1981; Wildner-Bassett, 1984; 1986; 1994; Billmyer, 1990; Olshtain \& Cohen, 1990; Bouton, 1994; Lyster, 1994; Takahashi, 1996; 2001; LoCastro, 1997; Wishnoff, 2000; Fukuya \& Clark, 2001; Liddicoat \& Crozet, 2001). 
Next follows Section 2.2, a review of Contrastive Analysis (CA). In this part, the beginnings of the discipline are explained, taking into account the first purposes of the research as a way to predict and decrease error production (Fries, 1945; Lado, 1957; Mathesius, 1964; Halliday, Mclntosh \& Strevents, 1964; Mackey, 1965; Catford, 1968; Nemser, 1971; Lee, 1974; Filipovi, 1975; James, 1980). A definition of the theory is introduced, explaining its different phases and the evolution it has undergone through the years, followed by an explanation of its aims and achievements (Oller, 1972; Harumitsu, 1988; Nunan, 1993; Carrió, 2005b), accompanied by a description of its criticism (Wardhaugh, 1970; Ellis, 1985). This part is completed with a prospection of present and future trends of the discipline, introducing changes of perspective for aspects considered overcome and new aspects taken into consideration, such as Contrastive Rhetoric (Chesterman, 1998; Connor, 2004; Li, 2008).

Section 2.3 introduces the contribution made by Error Analysis (EA). In this section, a view of the different perspectives developed by the theory throughout literature is included (Corder, 1967; Dulay \& Burt, 1974; Byram, 1988; James, 1998). It also gives account of present and future trends, (Olsen, 1999; Hamilton, 2001; Webber, 1993; Connor, 1996; James, 1998; Yates \& Kenkel, 2002). In addition, several types of classifications that have been proposed by different researchers are included in the document. The first taxonomy included in the study is James' taxonomy for errors (1998). Subsequently, there is a section dedicated to language interference as the first cause of error (Webber, 
1993) for NNE speakers. Next, grammatical errors are described as playing a significant part in the learning process (Rutherford \& SharwoodSmith, 1988; Carrió, 2005b). A special section is dedicated to pragmatic errors, which are the type studied in the present doctoral dissertation.

Following this, Section 2.4 refers to Second Language Acquisition. This part includes the different approaches that have been employed in teaching an L2 since the 1840s, with traditional methods based on translation, to the Reform Method promoted by Sauveur and Berlitz, and the subsequent Audiolingual Method (Hockett, 1959). Task based methods arrived in the 1970s grounded on Chomsky's theories surrounding Universal Grammar. This was the foundation for the Communicative Approach (Habermas, 1970; Jakobovits, 1970; Hymes, 1972; Savignon, 1972; Widdowson, 1978, 1979, 1983), and its implementation in specific rulings and syllabuses, which is the focus of the present text. The CEFR document focuses on this last proposal.

The final part (Section 2.5) is dedicated to the thorough analysis of the CEFR. This substantial section is dedicated to explaining the European document, which offers a framework for working at Higher Education levels. To begin with, the justification for the document is made. Then, a short section introduces the view given regarding pragmatics within the CEFR, including all relevant specifications. The competences, which an L2 student should have to prove at a given level of proficiency, are explained afterward. Subsequently, since the study completed for the dissertation focuses on written texts, the guidelines offered in the CEFR that relate to writing are analysed here. 
Chapter 3 includes a detailed explanation of the objectives of the present doctoral dissertation, both general and specific. These objectives are related to the consideration of error as a crucial element in language learning as well as to the study of the new proposals for teaching, taking into consideration all the actors in this learning and teaching process.

Subsequently, Chapter 4 is dedicated to the methodology used in the present dissertation. A significant amount of data has been used for analysis. In this chapter, two clearly differentiated parts can be identified. The first subchapter deals with data collection. This part presents a detailed explanation of the texts used for the analysis; their origin, characteristics, and usefulness for the research. It also explains the different items that have been included in the analysis following the CEFR. Then, a description of the way in which the error corpus has been constructed and prepared for analysis is given. The second subchapter introduces the processing of data. It explains three different variables used in the present research to meet the purposes established at its foundation; markers, items and text types.

Chapter 5 displays the results obtained in the consecutive analyses of the variables. Results are structured as follows: results per markers, results per items and results per text types. A qualitative analysis of results is also included.

Finally, the last part of this research (Chapter 6), introduces the conclusions and proposals for further work which derive from the present study. 
THEORETICAL BACKGROUND 



\section{THEORETICAL BACKGROUND}

The present work analyses texts produced by students of English during their learning process. In particular, undergraduates who are undertaking a University degree produced the group of texts chosen for the study. In them, the focus of interest will be set on the errors they incur into when writing in this second language. The entire idea of focusing on errors is thought to be useful to help identify patterns, if so, why are they produced, how can they be identified, and taken into account by teachers to then help the students in their learning process? In addition, can these errors help us identify the point in the learning process where they stand?

Several areas of knowledge have been included in this first section dedicated to the conceptual setting for the study. In broad terms, they are all inscribed within Applied Linguistics. First of all, Pragmatics offers the linguistic background for the analysis, since errors are analysed in their specific language use, and in the particular contexts the students produce them. The idea is to explore items, which might be considered errors from this viewpoint; and maybe they would not be from a different one. Secondly, as the study is based on the analysis of texts produced in a second language, an outline of contrastive linguistics is given. It also 
intends to help focus on error as analysis unit. Thirdly, a general presentation of Error Analysis is offered. This part presents a review through literature, to see what previous proposals have been made in this account and used in an academic setting. Next, since the language analysed has been learnt at school, an overview of the work carried out in the field of Second Language Acquisition is presented, in particular, the Communicative Approach. Finally, the tool that encircles all previous work in the standpoint presented here is the Common European Framework of Reference for Languages.

\subsection{PRAGMATICS}

We consider Pragmatics as the linguistic theoretical background from which this research stemmed. Since our interest centres on the study of language acquisition, and ways in which language teaching and use in the classroom can help students improve their language skills, our interest in the study of language in use necessitates an in-depth study. Indeed, it is crucial that we understand the foundations of Pragmatics. The first part in this section is dedicated to explaining the initial stages which led to the discipline of Pragmatics. To begin with, the discipline was grounded on different approaches, which focused on some specific parts of language use. This represented a departure from the traditional (structuralist) models, but did not yet include all the aspects that would later come to be studied under the Pragmatics perspective, such as specific linguistic conventions in language use, multiculturalism, or 
politeness. The second part of this section aims at offering an explanation of the discipline in its current form, by looking at some established and some more recent trends (ranging from Speech Act Theory, Grice's principles, different in-theories, etc.) several perspectives and contributions. Finally, an overview is offered of different studies carried out in the language classroom from a Pragmatic perspective, examining the usefulness of this approach for language teaching.

\subsubsection{First approaches}

We need to revisit Functionalism in order to set the context for Pragmatics. Functionalists believed that the central role of language is communication, in contrast to Chomsky's statement (1980:239) that "human language is a system for free expression of thought, essentially independent of stimulus control, need-satisfaction or instrumental purpose". This statement helps us understand the delimitation between the theories supported by the formalists, such as Chomsky, who focus upon form, and the functionalists, such as Dik or Haliday, who concentrate on structures and functions.

As stated above, functionalist theories deem that the primary function of language is communication, and, as such, study it in this context. Subsequently, linguistic functions are examined from either of these two perspectives; the Pragmatics and the Discourse perspective. The first concentrates on the meaning and the conditions of use of different speech acts, based on Searle's theory of speech $(1969 ; 1985)$ and 
Grice's $(1975 ; 1989)$ theory of conversation logics. The study of speech acts permits the interpretation of a sentence within a context. The discourse perspective is interested in describing the employment of grammatical devices and other linguistic tools in the construction of discourse.

This was explained by Foley and Van Valin in 1984, when they described the novelty, at that time, of the new theories in combination with several disciplines in order to illustrate real language utterances by focusing on the actual speech acts produced, and not by predicting them (Foley \& Van Valin, 1984:15):

\begin{abstract}
Functional theories [...] seek to describe language in terms of the types of speech activities in which language is used as well as the types of constructions which they are used in speech activities. They do not attempt to predict the actual tokens of speech events. In other words, the theories seek to describe the interaction of syntax semantics and Pragmatics in types of speech activities; they do not try to predict the occurrence of particular constructions in actual speech events.
\end{abstract}

Among the functionalists there exist many views. However, despite the abundant amount of approaches, there are only three explicitly articulated theories: the Functional Grammar, supported by Dik, 1978 and 1989, the Systemic Functional Grammar, mainly propounded by Halliday, 1967 and 1994, and the Role and Reference Grammar, the principles of which are explained by Foley and Van Valin, 1984; Van Valin 1993; and Van Valin and LaPolla, 1997, and have been explained by Butler, Mairal Usón, Martín Arista \& Ruiz de Mendoza (1999). 
These theories acknowledge the inadequacy of formalism or structuralism with varying degrees of divergence. The first and third approaches, in addition to pointing out this inadequacy of formalism, propose a functionalist analysis of structure. The second approach denies the veracity of structure per se, claiming that rules are based entirely on function. As an example, we can quote Dik (1991:247) in his description of a language and a language system including the conditions of use:

[...] language is considered in the first place as an instrument for communicative verbal interaction, and the basic assumption is that the various properties of natural languages should, wherever this is possible, be understood and explained in terms of the conditions imposed by their usage. The language system, therefore, is not considered as an autonomous set of rules and principles, the uses of which can only be considered in a secondary phase; rather it is assumed that the rules and principles composing the language system can only be adequately understood when they are analyzed in terms of conditions of use. In this sense, the study of language use (Pragmatics) precedes the study of the formal and semantic properties of linguistic expression.

Halliday (1985:xiii) had stated that language is a social and not an individual phenomenon, diverting the focus of attention from the individual production to the social: he is not interested in the particular utterances of one single speaker, but in how these need to be arranged so that they meets their objective:

Language has evolved to satisfy human needs and the way it is organized is functional with respect to these needs - it is not arbitrary. A functional grammar is essentially a "natural" grammar, in the sense that everything in it can be explained, ultimately, by reference to how language is used. 
Dik prioritised the study of language in use in real everyday situations above the rules and principles that govern it. This offers a new perspective in that the focus is no longer concentrated on the rules, but on the use given to those rules, on the practical implementations language offers. Likewise, as described Van Valin (1993:2) in Role and Reference Grammar:

\begin{abstract}
Language is a system, and grammar is a system in the traditional structuralist sense; what distinguishes the RRG conception [...] is the conviction that grammatical structure can only be understood with reference to its semantic and communicative functions. Syntax is not autonomous.
\end{abstract}

These functional approaches look to semantics and language use as the basis for explaining syntactic phenomena, and, as such, they are not theory-internal criteria (in the sense that they not only attempt to be selfexplanatory), but use different types of phenomena to explain syntax (which is considered non-autonomous and dependent).

Clearly, the label functional linguistics is a term for an assorted set of thoughts, objectives and methodologies. Conservative functionalists "yielded important insights regarding the pragmatic nature of many syntactic constraints" (El-dali, 2010), but they do not address the crucial question of the nature of structure in language, particularly syntactic, since they assume a generative account of structure. However, in defence of their theory, extreme functionalists "have uncovered many important generalizations about discourse structure, information flow, and the discourse functions of grammatical forms" (Van Valin, 
2000:319-337), but by rejecting the notion of language as a structural system they overlook the nature of linguistic structure.

The connection between Pragmatics and grammar is highlighted in research carried out within the Grammaticalisation Theory. In turn, this is based on Meillet's work, whereby grammaticalisation is defined as the process by which "a lexical unit or structure takes on a grammatical function, or [...] a grammatical unit takes on a more grammatical function" (Heine, Claudi \& Hünnemeyer, 1991:2).

A diagonally opposed view is that of Widdowson, who in 1979 affirmed that these proposed notional-functional categories were biased and incomplete (1979:254), requiring further language analysis leading to discourse itself, and introducing the notion of doing things with language:

\footnotetext{
They tell us nothing about the procedures people employ in the application of these rules when they are actually engaged in communicative activity. If we are to adopt a communicative approach to teaching which takes as its primary purpose the development of the ability to do things with language, then it is discourse which must be at the centre of our attention.
}

Thus, Widdowson claims that the focus of the linguistic analysis should be based on the process itself, on the actual procedures carried out to improve language proficiency. Therefore the emphasis should be set on the ability to use language appropriately with less emphasis given to the particular application of the rules which structure it. 


\subsubsection{Pragmatic analysis}

The behaviourist theories based on psychological philosophy followed on from the functional approaches. Consequently, with the introduction of the external, behavioural-contextual factor, syntax-centred Functionalism became Pragmatics. Regarding the origin of this discipline, Pietarinen argues that the philosopher Peirce is the father of modern Pragmatics. In the 1900s (Pietarinen, 2004:299): “Peirce proposed a three-part division of semeiotic inquiry into speculative grammar, logic proper (critic) and speculative rhetoric (methodeutic)". At this point in time, Morris and Carnap divided linguistics into syntax, semantics, and pragmatics, "by masking these classes on Peirce's trichotomy" (Pietarinen, 2004:299).

There are at least as many definitions of Pragmatics as there are pragmatists. For example, in Kempson's words (2001:398), it "is the study of communication - the study of how language is used. This study is based on the assumption of a division between knowledge of language and the way it is used". In this way, there is a clear distinction between what is common, theoretical knowledge and the particular use the individual makes of this knowledge.

Alcaraz (1990:117) characterised Pragmatics as:

(1) The use of language as a means of communication.

(2) The importance of language use focusing on functions rather than on forms.

(3) The study of the processes which occur in communication. 
(4) The importance of context and authentic language use.

(5) The interdisciplinary nature of Pragmatics.

(6) The application of linguistic theories based on the concept of communicative competence.

In any case, it is clear that the discipline focuses on the difference between the official meaning of a word or sentence, and the actual meaning the speaker intends to give it, and finally, the meaning perceived by the hearer derived from what the speaker said. Yule in his handbook on Pragmatics (1996:3-4) summarises this by saying that Pragmatics is the study of the relationships between linguistic forms and the human beings who use those forms, introducing the person behind the word. Focusing on the notion of studying meaning as communicated and interpreted, he illustrates the relevance of this by explaining that it consists of four different components; speaker meaning, contextual meaning, invisible meaning (more is conveyed than verbally imparted) and the expression of relative distance (there is shared experience between interlocutors).

Yule named these intentional interpretants (which later became known as speaker-meaning) effectual interpretants (hearer meaning) and immediate interpretants (both, the speaker and the hearer meaning; that is, the ordinary meaning of the sign). This harmonises with the distinction between the illocutionary and perlocutionary force of utterances. Morris, whose view of Pragmatics was concerned with the origin, use and effect of signs, as explained above, also used these ideas. He differed from Peirce in that he related the functions of signs to 
contexts defined using behavioural criteria. By doing this, he connected sign functions and the consequences those signs presented for interpretants.

After the behavioural approaches, Grice is acknowledged as the scholar responsible for redefining Pragmatics. In order to establish how people select the right interpretation of meanings, Grice (1975) proposed an approach to conversation which stated that there is a general assumption supporting interpretations and that the interpretation of utterances is guided by a cooperative principle whereby both speaker and hearer share a common goal: comprehension. As such, according to Grice, a number of maxims (aphorisms or axioms), adhered to by speakers are responsible for arranging and structuring this cooperative enterprise. These are the maxim of quality (do not say what you believe to be false or cannot support), the maxim of relevance (be relevant in your speech), the maxim of quantity (be as informative as required, but no more), the maxim of manner (be clear, concise, and orderly).

Although Pietarinen (2004:302) argues that Grice's principles were, if not based on, at least inspired by “[Peirce's] notion of honesty as one of the properties required to satisfy Grice's maxim of Quality", it is Grice's principles that were used and considered the foundations of modern Pragmatics. Indeed, this author also introduced the concept of implicature, which can be conventional or unconventional, and refers to the additional pieces of information that are implied but unspoken and which help us gain an accurate understanding of an utterance. 
This method of retrieving interpretation through a process of reasoning is a crucial aspect for conversation (communication). Conversational implicatures are derived from the rules of conversation, whereas nonconversational implicatures are derived from other kinds of causes (social, moral, or aesthetic). Conversational implicatures are generated by combining information contained in the utterance together with contextual and situational factors and conversation rules. According to Grice (1975; 1989), the former can be either generalised or particularised. Implicatures can be cancelled and thus are not an encoded principle of grammar, but the possible interpretations that are added to the established encoded and rule-governed maxims.

When the maxims are disregarded in communication (what Grice refers to as flouting), implicatures are produced. Grice establishes the following classification for the neglect of these maxims:

(1) Violating the cooperative principle (aimed at deceiving the listener),

(2) Signalling a violation (openly explaining that a maxim is being violated and the reason for this),

(3) Maxim clashing (ignoring one maxim to preserve another)

(4) Flouting a maxim to create a conversational implicature, (making it obvious that something else was implied in the utterance).

Generalised conversational implicatures seem so regular surface that they would appear to be the by-product of some form of pragmatic rule. Some authors have studied these using a rule-based approach. Indeed, the grammar of a language can be extended by a pragmatic component 
containing a set of default rules (Lascarides \& Asher, 1993). These authors use a formal model of discourse interpretation in which rhetorical structure and lexical and compositional semantics interact (Asher \& Lascarides, 2001:185):

[...] to determine truth conditions and for which we have developed or adapted various technical tools that turn out to be useful here: nonmonotonic or defeasible reasoning, semantic types and type shifting rules (Montague 1974, Sag and Wasow 1999, Pustejovsky 1995, Asher and Pustejovsky 2000). Many speech act types turn out from this perspective to be rhetorical relations.

Grice's theory appealed to linguists in that it underlined the existence of a clear separation between grammar-internal processes, which "characterise sentence structures, and arguably also a specification of their meanings, and the interpretation of utterances" (Kempson, 2001:405). However, Grice's maxims were often considered unclear, vague or difficult to interpret, due to the fact that some introduce subjective concepts (relevance, for instance) or ideas (manner) that are difficult to quantify.

Following this, in 1986, Anscombre and Ducrot constructed their Théorie de l'Argumentation dans la Langue based on the general idea that semantic meaning is obtained after solving the relationships between two postulates (Anscombre, 1989:13), and describing the task of the linguist as:

1) Quand on parle, il arrive que l'on fasse allusion au "monde réel" (ou en tout cas, à quelque chose présenté comme tel). En d'autres termes, la parole semble pouvoir être utilisée à des fins descriptives. 
2) Quand on parle, il arrive que l'on raisonne, que l'on argumente, que l'on déduise. II y a une fonction "rhétorique" de la parole, que l'on peut appeler inférentielle, à condition de ne pas limiter le sens de ce vocable à celui qu'il a dans les logiques habituelles.

3) La tâche du linguiste, en particulier quand il s'occupe de sémanticopragmatique, est de fournir une théorie de la "langue" apte à rendre compte des capacités discursives de la parole.

They propose the use of the term argumentation as the connection, the link holding discourse together. This is not understood in the formal rhetorical sense, but rather "following the rules of argumentation", as the linguistic means necessary to convince, and, as such, lead to a conclusion. To quote Anscombre (1989:20): “Tout énoncé est argument. Ce qui ne signifie pas qu'un énoncé vise nécessairement une conclusion particulière". Escandell (2006:95) provides a clear explanation for this concept of argumentation, which revisits classical Rhetoric:

[...] el término argumentar no debe entenderse como 'demostrar formalmente la validez de una conclusión, o la veracidad de una aserción', [sino] hacer admitir: se trata de presentar algo como si fuera una buena razón para llegar a una conclusión determinada.

The Argumentation Theory looks at the explicit linguistic means employed by speakers to direct their utterances in argumentation. These linguistic elements can be markers, operators and connectors (Anscombre, 1989:20): “Un opérateur argumentatif est un opérateur qui, appliqué à une phrase, modifie la classe des conclusions qui lui est attachée". This broad term (argumentative operator) includes a wide number of elements which, depending on the language, will be used to modify the general meaning of the discourse. Stemming from this, 
connectors would become a key feature in any Pragmatic analysis of the language. Bassano (1991:4) explains this:

[...] il existe dans les langues des morphèmes, ou des structures, qu'on définira essentiellement par leur valeur argumentative (bien qu'ils puissent avoir par ailleurs d'autres propriétés sémantiques), ou en d'autres termes par les contraintes qu'ils exercent sur les possibilités d'enchaînements discursifs. On considérera de tels morphèmes comme les opérateurs ou connecteurs argumentatifs de la langue, du moins si l'on s'en tient à l'étape de la théorie de l'argumentation - qui seule nous intéressera ici - où Anscombre et Ducrot définissaient des marques argumentatives privilégiées. Avec l'introduction des "topoï" notamment, l'argumentation investira la langue de façon encore plus radicale (cf. Anscombre \& Ducrot, 1986). Mais, dès lors que des termes tels que "presque" sont identifiés comme des opérateurs argumentatifs de base, il apparaît que l'argumentativité est présente dans le langage beaucoup plus fondamentalement qu'on n'aurait pu le penser à l'examen des seules marques traditionnellement considérées comme argumentatives.

Deriving from these proposals, Van Eemeren and Grootendorst's 1987 version of the Argumentation Theory, the Pragma-Dialectical Theory, is currently the most popular. These linguists began by studying argumentation as an instrument for solving differences of opinion. They define argumentation in terms of four principles:

(1) Externalisation: the need for both a standpoint and an opposition to the standpoint. Therefore, argumentation research must concentrate on commitments that can be externalised rather than on the internal, psychological elements of people.

(2) Socialisation: arguments are an expression of human thought processes. Two people try to reach an agreement. As such, argumentation forms part of a social context and not an individual context. 
(3) Functionalisation: this is aimed at facilitating the resolution of disagreement.

(4) Dialectification: this is only appropriate when effective arguments can be used by the participants to help support their case. Dialectical procedure is the term used to refer to a contextdepending element in efficient arguing to facilitate disagreement resolution.

Since there are many types of conflicts, and many ways of approaching them, the argumentation required for those types of situations can take various forms (Van Eemeren, 2002:20):

[...] a distinction between three main types of argumentation: (1) symptomatic (or 'sign') argumentation, (2) argumentation by comparison (or 'analogy'), and (3) causal (or 'teleological') argumentation. By way of illustration I shall present an example of symptomatic.

In the Anglo-Saxon context, Sperber and Wilson's Relevance Theory reexamined Grice's approach and expanded this (Sperber \& Wilson, 1985; 1995; 1998; 2002; Wilson \& Sperber, 2002). According to these authors, communication does not simply consist of packing thoughts or ideas in the form of words so that the listener can unpack and understand them. In other words, it cannot be assumed that communication equals the coding and decoding of information. Hence, it follows that language cannot be treated as a code. 
Additionally, they affirm that the environment and the context enrich abstract representations are linked to thought processes. As a consequence of this, the Relevance Theory is an attempt at the characterisation of pragmatic phenomena taking into consideration the cognitive concept of relevance, and thereby replaces Grice's cooperative principle, focusing exclusively on the speaker. Departing from the idea that it is necessary for an utterance to be relevant if comprehension is the aim, Sperber and Wilson launch their theory around the definition of an input relevance, and conclude that (Wilson \& Sperber, 2004:251):

[something] is relevant to an individual when it connects with background information [...] to yield conclusions that matter to him [...] when its processing in a context of available assumptions yields a POSITIVE COGNITIVE EFFECT ${ }^{3}$.

In so doing, they are proposing that an utterance, sound, memory... in order to reach a listener, in order to grasp the listener's attention, needs to connect her or him with whatever background information they may possess. They continue by describing the most important type of cognitive effect, which they refer to as contextual implication and propose several laws to assess relevance in terms of cognitive effects and processing effort. For instance, (Wilson \& Sperber, 2004:252):

Relevance of an input to an individual

a. Other things being equal, the greater the positive cognitive effects achieved by processing an input, the greater the relevance of the input to the individual at that time.

b. Other things being equal, the greater the processing effort expended, the lower the relevance of the input to the individual at that time.

${ }^{3}$ Authors' capitalisation. 
The principle of relevance constrains human cognition in the sense that not everything is deserving of effort. In other words, humans measure the effort required by communication and the results they obtain from this, striking a balance between effort and effect which individuals make when producing discourse is the constraint of maximising relevance. This assessment will therefore determine their decision-making in communication matters, both in terms of the actual speech act and its direct implications and in terms of what deductions can be made from these, both intended and implied. In line with Kempson's (2001:410411) explanation:

[...] the principle of balancing cognitive effort and inferential effect can be seen to underpin both the deduction of so-called implicatures and the fixing of context-dependent aspects of the proposition expressed. [...] Indeed it purports to explain why deduction of additional information is an unvarying consequence of interpreting an utterance, [...] Moreover it provides a natural distinction between implications which the hearer believes the speaker intended to convey (= implicatures), and those which she recovers from the utterance [...] (= contextual implications). (Sperber and Wilson 1995; Carston 1988).

Hereby, word meaning is understood as a set of procedures for interpretation, and the definition of interpretation is proposed in terms of structured representations (and the updating of these representations) of content. Furthermore, Kempson (2001:413) states that the process of interpretation must also be considered as:

[...] locality conditions have to be defined over a level of representation, and this can be construed as an encoded constraint on pragmatic interpretation only if the process of interpretation is also taken to be defined in terms of structure. 
This same view is also expressed by Wilson and Sperber (2004:254255); if word meaning is built through interpretation, then new concepts are created online from the presented word by means of interpretation processes: "[...] inferential communication is not just a matter of intending to affect the thoughts of an audience; it is a matter of getting them to recognise that one has this intention".

The existence of implicatures conveys the role of the hearer in any communication act, for which the hearer is partially responsible. With this in mind, as outlined above, pragmatists believe words should be regarded as procedures for interpretation, instead of having a predetermined and fixed given meaning. In Kempson's words (2001:423):

\begin{abstract}
The encoded specifications intrinsic to language are defined explicitly as the driving force in this incremental process of building up interpretations from a natural language sequence of words. Linguistic and non-linguistic processes of interpretation [...] freely interact.
\end{abstract}

The suggested viewpoint that the hearer's willingness to understand should not be taken for granted, nor assumed to be long lasting is an interesting one. Consequently, rising to meet this challenge, those encoded specifications uttered by the speaker should become the driving force that guarantees the attention of the hearer. Rephrasing this in the form of a recommendation, Kempson emphasises the need to uphold the principle of minimal effort. In this manner, the rule applicable to the hearer can be formulated as (2004:259): 
a. Follow a path of least effort in computing cognitive effects: Test interpretive hypotheses (disambiguations, reference resolutions, implicatures, etc.) in order of accessibility.

b. Stop when your expectations of relevance are satisfied.

Sperber and Wilson also refute the Gricean theory that truthfulness governs communication. Grice considered anything which did not conform to the maxim of Quality to be a deviation. The Relevance Theory does not comply with this: "where hearers are interested in truth. [...] even in these cases, hearers do not expect what is said to be strictly and literally true", and explains metaphor, hyperbole, etc. in the light of expectations of relevance. The theory rates these according to the relevance-effort balance by which communication is understood by the authors (Wilson \& Sperber, 2002:231):

\begin{abstract}
Given the characterisation of relevance in (1), aiming to maximise the relevance of the inputs one processes is simply a matter of making the most efficient use of the available processing resources. No doubt this is something we would all want to do, given a choice. Relevance theory claims that humans do have an automatic tendency to maximise relevance, not because we have a choice in the matter we rarely do but because of the way our cognitive systems have evolved.
\end{abstract}

This directly implies that the hearer expects the speaker to employ the best possible choice in terms of relevance in her or his utterances, and to facilitate the hearer's job at the other end of the communication act. It falls within the responsibility of the speaker, and not the hearer, to make communication valid (Wilson \& Sperber, 2002:234): 
What makes it reasonable for the hearer to follow a path of least effort is that the speaker is expected (within the limits of her abilities and preferences) to formulate her utterance in such a way as to diminish the hearer's effort.

The theory also dedicates significant attention to other items left unsolved by Grice's maxims, such as time, and the ways in which this governs the construction of discourse. Depending on whether it is respected or not, time has a direct consequence on the Relevance attached to a specific utterance. This time issue is referred to as the sequencing problem, the interval problem, and the cause-consequence problem (Wilson \& Sperber, 1998).

Although the Relevance Theory covers some (testimonial) work on the relationship with the social sciences, it mainly focuses on intra-dialogue relationship. It does not pay attention to language use based on external conventions or customs. Consequently, this model has been criticised because it omits the social aspects of communication. To cite an example, Mey \& Talbot (1986: 747-48) explicitly state that:

Intentionalist models of human agency are looking at only half the picture of language. A theory of social action, whether for language or any other form of behaviour, needs an account of both creative and conventional elements. (...) In an intentionalist model such as SW's an actor is a spontaneous individual consciously working on unique problems, rather than a social agent working on pre-existing conventions with resources available to him/her which s/he cannot be aware of. (...). SW disregard the perspective on the language use from which such use perpetuates historically constituted ways of saying and doing, a perspective from which types of interaction are predetermined. 
In this text, they overtly accuse Sperber and Wilson of studying language in isolation, without taking into account any external (social) factor. By so doing, they claim that the theory is incomplete as it does not consider use in general, and habitual use in particular, which, according to them, can be responsible for certain speech acts. Here Escandell (1996: 640) provides a different perspective, agreeing that social aspects need to be explained according to the structures and the meaning of the specific issues and their derived contexts. She concurs with Mey and Talbot (1988) that knowledge related to communication must not be studied as some abstract universal feature, but be based on previous experience common to both the speaker and the hearer:

[...] "social aspects of communication have to be explained in terms, not of inferential patterns working on universal principles, but of the structure and contents of specific knowledge" the emphasis is to be put especially on context, and not on inferential devices.

Aware of these critiques, Sperber and Wilson (1997:146) claim that communication is only social when considered a form of interaction, and that the crucial point is its existence as a code, as a system of signals, and not just simply the actual realisation of speech. Communication, they insist, is the responsibility of the speaker:

Relevance theory takes a different approach. It characterises communication as a different type of social process than does the code model. From the point of view of the code model, communication can be described as social because it is a form of interaction, but the abilities it presupposes in communicators are signal-oriented rather than otheroriented. All an encoder has to do is produce a signal; all a decoder has to attend to is a signal. This can happen without either communicator having any notion that there are other notions like itself, with mental states and capacities, or even that it is itself such being. 
To recapitulate a little, pragmatic principles are cognitive principles that enable us to enrich information through reasoning strategies. Although Sperber and Wilson state that communication does not require an actual performance from which to extract a context, many authors agree that it is the context which offers the knowledge necessary to perform a successful communication act. In any case, modelling the communication process furnishes us with the basis needed to explain what is actually involved in knowing a language (language competence). This differs from the view that linguistic ability should be a body of knowledge independent from the principles that determine the way language is used (language performance), since, either way, both the speaker and the listener must be aware of those rules and choose whether or not they wish to adhere to them. In other words, this is a reiteration of the importance of context and social awareness in the mastery of a language. These are not derived from knowledge of the grammatical aspects of a language, but need to be learned as independent units. In Bardovi-Harlig's words (1996:2):

\footnotetext{
A learner of high grammatical proficiency will not necessarily show concomitant pragmatic competence. We also have found at least at the higher levels of grammatical proficiency that learners show a wide range of pragmatic competence.
}

This statement is in concurs with the distinction made by both Leech (1983) and Thomas (1983) between a knowledge of general Pragmatics, defined by Leech (1983:10) as the study of "linguistic communication in terms of conversational principles", Pragmalinguistics, described as the grammatical aspect of Pragmatics, such as directness, indirectness, 
pragmatic routines, modification devices, etc., and Sociopragmatics (the relationship between linguistic action and social structure), as can be seen in Figure 1.

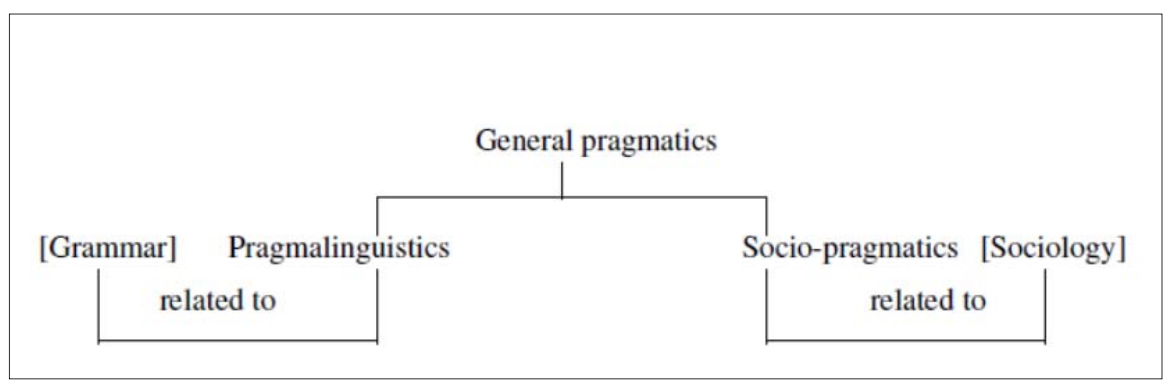

Figure 1. Distinction between Pragmalinguistics and Sociopragmatics (Leech, 1983:11).

Pragmalinguistics and Sociopragmatics are of particular interest to our study, since we deal with adult learners with prior knowledge of the standard communication routines (universal conversational pragmatic knowledge), which can be used by such learners when acquiring a second language (Kasper, 1997:1):

\begin{abstract}
Indeed, adult NNS do get a considerable amount of L2 pragmatic knowledge for free. This is because some pragmatic knowledge is universal, and other aspects may be successfully transferred from the learners' L1. To start with the pragmatic universals, learners know that conversations follow particular organizational principles - participants have to take turns at talk, and conversations and other speech events have specific internal structures. Learners know that pragmatic intent can be indirectly conveyed, and they can use context information and various knowledge sources to understand indirectly conveyed meaning.
\end{abstract}

However, it has been argued that learners of a new language need prolonged periods of training to be able to select the linguistic forms appropriate to particular social categories (Kasper \& Rose, 2002). These 
authors also claim that both pragmalinguistic and sociopragmatic aspects appear to be especially difficult in FL contexts, due to the fact that learners do not seem to be using prior knowledge to their advantage (Kasper, 1997:1):

Unfortunately, learners do not always make use of their free ride. It is well known from educational psychology that students do not always transfer available knowledge and strategies to new tasks. This is also true for some aspects of learners' universal or L1-based pragmatic knowledge. L2 recipients often tend towards literal interpretation, taking utterances at face value rather than inferring what is meant from what is said and underusing context information. Learners frequently underuse politeness marking in L2 even though they regularly mark their utterances for politeness in L1 (Kasper, 1981). Although highly context-sensitive in selecting pragmatic strategies in their own language, learners may underdifferentiate such context variables as social distance and social power in L2 (Fukushima, 1990; Tanaka, 1988).

This indeed focuses the attention on the specific issues that a learner must acquire in order to communicate effectively. However, although this should always be taken into account in the classroom, and although it is one of the major problems existing when learning a second language, Kasper (2001:522) insists that:

What is required is that teachers themselves have been sufficiently socialized to L2 pragmatic practices, that they can comfortably draw on those practices as part of their communicative and cultural repertoire, and that their metapragmatic awareness enables them to support students' learning of L2 pragmatics effectively.

Despite the fact that they may differ regarding the amount of time which must be dedicated to analyse and learn from a formal (standard) context, they agree on the idea that communication is not solely comprised of rules and structures. Indeed, also intention and volition 
play a part in it, which, in turn, requires specific knowledge in order to be successfully applied to personal (individual) communication. All these contributions help identify the way in which Pragmatics can frame the analysis we propose to make. The errors we wish to identify and analyse are not grammatical or lexical errors, but the types of pragmatic errors made by students. This implies that the items that we identity as errors must as such be related to a failure to communicate in the intended manner.

Next, the types of studies that have been conducted in the classroom setting to analyse pragmatic aspects from various perspectives are examined. By doing so, we plan to study, learn and assess how this method of analysis can help in the identification of errors.

\subsubsection{Pragmatics in the classroom}

In this section, we will be looking at specific studies carried out which associate Pragmatics to the study of a second language. These studies have specific features in common in that they combine two different fields of interest; on the one hand, the pragmatic approach taken towards the language understood as communication and, on the other, the context in which this is studied: English language classrooms. In 1997, Kasper completed a comparative research analysis of the different studies carried out in foreign language classes, in which the common feature was the actual setting for these studies - the classroom 
itself. Her study included all research papers that were completed between 1981 and 1997. It is reproduced in Table 1.

It could be seen that in the 1980s and 1990s, studies relating Pragmatics to the learning process within the classroom varied significantly and covered a wide range of features. However, it is clear that many were dedicated to the appreciation of explicit vs. implicit aspects (or inductive vs. deductive) by means of implicatures. It can also be seen that many of the studies focused on a specific act of communication (compliments, apologies), thereby extracting from it the information required for the study.

Table 1 is completed with Table 2, in which can be found Da Silva's 2003 study on interlanguage (IL) Pragmatics from an acquisitional perspective. Although this author is interested in the interlanguage attained by learners throughout their learning process, and centres on this, it obviously includes all research dedicated to the study of second language acquisition. Da Silva mentions several of the more recent studies that interrelate Pragmatics with the learning process, this time based on the language of the students and on the specific items studied. 


\begin{tabular}{|c|c|c|c|c|c|c|}
\hline STUDY & $\begin{array}{l}\text { TEACHING } \\
\text { GOAL }\end{array}$ & PROFICIENCY & LANGUAGES & $\begin{array}{l}\text { RESEARCH } \\
\text { GOAL }\end{array}$ & DESIGN & \begin{tabular}{|l} 
ASSESSMENT/ \\
PROCEDURE/ \\
INSTRUMENT
\end{tabular} \\
\hline $\begin{array}{l}\text { House \& } \\
\text { Kasper } \\
1981\end{array}$ & $\begin{array}{l}\text { Discourse } \\
\text { markers \& } \\
\text { strategies }\end{array}$ & Advanced & $\begin{array}{l}\text { L1 German } \\
\text { FL English }\end{array}$ & $\begin{array}{l}\text { explicit vs. } \\
\text { implicit }\end{array}$ & $\begin{array}{l}\text { pre-test/ post- } \\
\text { test control } \\
\text { group L2 } \\
\text { baseline }\end{array}$ & roleplay \\
\hline $\begin{array}{l}\text { Wildner- } \\
\text { Bassett } \\
1984 \\
1986\end{array}$ & $\begin{array}{l}\text { Pragmatic } \\
\text { routines }\end{array}$ & Intermediate & $\begin{array}{l}\text { L1 German } \\
\text { FL English }\end{array}$ & $\begin{array}{l}\text { eclectic vs. } \\
\text { suggestop } \\
\text { edia }\end{array}$ & $\begin{array}{l}\text { pre-test/ post- } \\
\text { test control } \\
\text { group }\end{array}$ & roleplay \\
\hline $\begin{array}{l}\text { Billmyer } \\
1990\end{array}$ & Compliment & $\begin{array}{l}\text { High } \\
\text { Intermediate }\end{array}$ & $\begin{array}{l}\text { L1 Japanese } \\
\text { SL English }\end{array}$ & $\begin{array}{l}+/- \\
\text { instruction }\end{array}$ & $\begin{array}{l}\text { pre-test/ post- } \\
\text { test control } \\
\text { group L2 } \\
\text { baseline }\end{array}$ & $\begin{array}{l}\text { elicited } \\
\text { conversation }\end{array}$ \\
\hline \begin{tabular}{|l|} 
Olshtain \& \\
Cohen \\
1990
\end{tabular} & Apology & Advanced & $\begin{array}{l}\text { L1 Hebrew } \\
\text { FL English }\end{array}$ & $\begin{array}{l}\text { teachabilit } \\
y\end{array}$ & $\begin{array}{l}\text { pre-test/ post- } \\
\text { test L2 } \\
\text { baseline }\end{array}$ & $\begin{array}{l}\text { discourse } \\
\text { completion } \\
\text { question. }\end{array}$ \\
\hline $\begin{array}{l}\text { Wildner- } \\
\text { Bassett } \\
1994\end{array}$ & $\begin{array}{l}\text { Pragmatic } \\
\text { routines \& } \\
\text { strategies }\end{array}$ & Beginning & $\begin{array}{l}\text { L1 English } \\
\text { SL German }\end{array}$ & $\begin{array}{l}\text { teachabilit } \\
\text { y to } \\
\text { beginning } \\
\text { FL } \\
\text { students }\end{array}$ & $\begin{array}{l}\text { pre-test/ post- } \\
\text { test }\end{array}$ & $\begin{array}{l}\text { questionnaires } \\
\text { role play }\end{array}$ \\
\hline $\begin{array}{l}\text { Bouton } \\
1994\end{array}$ & Implicature & Advanced & $\begin{array}{l}\text { L1 mixed SL } \\
\text { English }\end{array}$ & $\begin{array}{l}+/- \\
\text { instruction }\end{array}$ & $\begin{array}{l}\text { pre-test/ post- } \\
\text { test control } \\
\text { group }\end{array}$ & $\begin{array}{l}\text { multiple } \\
\text { choice } \\
\text { question }\end{array}$ \\
\hline $\begin{array}{l}\text { Kubota } \\
1995\end{array}$ & Implicature & Intermediate & $\begin{array}{l}\text { L1 Japanese } \\
\text { FL English }\end{array}$ & $\begin{array}{l}\text { deductive } \\
\text { vs. } \\
\text { inductive } \\
\text { vs. zero }\end{array}$ & $\begin{array}{l}\text { pre-test/ post- } \\
\text { test/ delayed } \\
\text { post-test } \\
\text { control group }\end{array}$ & $\begin{array}{l}\text { multiple } \\
\text { choice \& } \\
\text { sentence } \\
\text { combining } \\
\text { question }\end{array}$ \\
\hline $\begin{array}{l}\text { House } \\
1996\end{array}$ & $\begin{array}{l}\text { Pragmatic } \\
\text { fluency }\end{array}$ & Advanced & $\begin{array}{l}\text { L1 German } \\
\text { FL English }\end{array}$ & $\begin{array}{l}\text { explicit vs. } \\
\text { implicit }\end{array}$ & $\begin{array}{l}\text { pre-test/ post- } \\
\text { test control } \\
\text { group }\end{array}$ & roleplay \\
\hline $\begin{array}{l}\text { Morrow } \\
1996\end{array}$ & $\begin{array}{l}\text { Complaint \& } \\
\text { refusal }\end{array}$ & Intermediate & $\begin{array}{l}\text { L1 mixed SL } \\
\text { English }\end{array}$ & $\begin{array}{l}\text { teachabilit } \\
\text { y/ explicit }\end{array}$ & $\begin{array}{l}\text { pre-test/ post- } \\
\text { test/ delayed } \\
\text { post-test L2 } \\
\text { baseline }\end{array}$ & $\begin{array}{l}\text { roleplay } \\
\text { holistic ratings }\end{array}$ \\
\hline \begin{tabular}{|l|} 
Tateyama \\
et al. \\
1997 \\
\end{tabular} & $\begin{array}{l}\text { Pragmatic } \\
\text { routines }\end{array}$ & Beginning & $\begin{array}{l}\text { L1 English } \\
\text { FL Japanese }\end{array}$ & $\begin{array}{l}\text { explicit vs. } \\
\text { implicit }\end{array}$ & $\begin{array}{l}\text { pre-test/ post- } \\
\text { test control } \\
\text { group }\end{array}$ & multi-method \\
\hline
\end{tabular}

Table 1. Studies examining the effect of pragmatic instruction from 1981 to 1997 based on Kasper (1997). 


\begin{tabular}{|l|l|}
\hline INTERVENTIONAL STUDIES TO DATE \\
\hline Pragmatic routines & $\begin{array}{l}\text { Wildner-Bassett (1994), House (1996) and } \\
\text { Yoshimi (2001) }\end{array}$ \\
\hline Apologies & Olshtain \& Cohen (1990) and Tateyama (2001) \\
\hline Implicatures & Bouton (1994) and Kubota (1995) \\
\hline Compliments & $\begin{array}{l}\text { Billmyer (1990), LoCastro (2000), and Rose \& } \\
\text { Ng Kwai-fun (2001) }\end{array}$ \\
\hline Requests & $\begin{array}{l}\text { LoCastro (1997), Fukuya \& Clark (2001), and } \\
\text { Takahashi (2001) }\end{array}$ \\
\hline Socio/stylistic variation & Lyster (1994) \\
\hline Hedges in academic writing & Wishnoff (2000) \\
\hline Interactional norms & Liddicoat \& Crozet (2001) \\
\hline Refusals & $\begin{array}{l}\text { King and Silver (1993), Morrow (1996), and } \\
\text { Kondo (2001) }\end{array}$ \\
\hline
\end{tabular}

Table 2. Studies relating Pragmatics with the classroom 1993-2003 (Da Silva, 2003).

Table 2 covers many aspects related to communication, but not particularly to structures or to norms. A much broader approach is taken, and a discourse analysis from the point of view of proficiency is conducted taking just one of the particular issues. The studies are carried out using specific acts of communication, such as apologies or refusals. Compliments and Requests are particularly prolific. Once again, many authors study implicatures. If we compare both tables, the studies coincide in as far as they indicate a high level of interest in some specific genres, such as compliments or apologies, or academic writing. Since, by definition, Pragmatics studies language in use, research related to Pragmatics must necessarily consider what this presupposes with regards to the evolution and realisation of the discipline (which deals with performing language). That is to say, language must be studied 
taking actual realisations in order to be able to be explained from the Pragmatics viewpoint. This encounters some challenges when it comes to creating true SL environments. When Kasper analysed the results of these studies, she concluded that (Kasper, 1997:5):

\begin{abstract}
If we map the communicative actions in classic language classroom discourse against the pragmatic competence that nonnative speakers need to communicate in the world outside, it becomes immediately obvious that the language classroom in its classical format does not offer students what they need - not in terms of teacher's input, nor in terms of students' productive language use.
\end{abstract}

Noticeably, in some early studies, the consideration of the differences in language use between native English speakers (NES) and non-native English speakers (NNES) was crucial, as was the provision of appropriate contexts for these students which could be as life-like as possible in attempting to represent the real thing. This is not the case in our universities, where students have little access to English language spoken by natives (except in some -albeit not many- cases in which the teacher is a native English speaker). Kasper and Rose (2001:4) rephrase this as follows:

Participants in these studies are often foreign language learners, who may have little access to target-language input and even less opportunity for productive L2 use outside the classroom.

It can also be observed in Table 2 that a significant amount of research work has been dedicated to the study of specific items related to communication from a specific speech act perspective. For instance, we can identify studies which are committed to specific issues such as compliment, apology, etc. Other studies are identified here which 
consider what role Pragmatics should play in the second language learning process, that is, the way in which Pragmatics can help with procedures used in the second language classroom. Bardovi-Harlig (1996:28) insisted upon the idea of shared knowledge in second language production:

\begin{abstract}
The most important point is the accessibility of the notion of speech acts to both teachers and language learners. As speakers, as communicators, as language users, we know many of the terms already. We are aware of the intended effect of utterances, what we call the illocutionary force, and we can and do refer to illocutionary force in daily conversation.
\end{abstract}

Thus, after having concluded that many studies focus on the learners' pragmatic production, there are very few dedicated to perception and judgement. It can be inferred that students need to be conscious of the type of features they are required to master in order to be able to complete these tasks. From this, Bardovi-Harlig elicited the need to raise Pragmatics awareness (Bardovi-Harlig, 1996:29): "By increasing pragmatic awareness we mean a variety of things -we hope to help learners listen to interactions, to watch for reactions, to consider what may result from one choice of words over another". Other scholars (Erickson, 1979; Chick, 1996) agree that critical awareness training is superior to any sort of "direct teaching of culturally specific contextualization cues" in isolation (Chick, 1996:345).

While studying the differences in the use of the English language between native and non-native students, Bardovi-Harlig highlighted eight speech acts that should be afforded an in-depth revision, since these 
could account for the realisation strategies used by the language student; apologies, requests, complaints, disapproval, refusals, disagreement, gratitude, and compliments. In her own words (BardoviHarlig, 1996:28):

\begin{abstract}
Offering a model of an American manner of performing particular speech acts is only one part of increasing pragmatic awareness on the part of the learner. It is up to a learner whether he or she attempts American-style compliments, complaints, or closings, for example. A focus on Pragmatics in the classroom also offers learners tools to interpret and to respond to a variety of speech acts when they are addressed to them. Our chief goal is increased pragmatic awareness; this may include but is by no means limited to production alone.
\end{abstract}

These speech acts refer to Searle's 1976 classification of communicative acts categories (representatives, directives, commissives, expressives, and declarations), which are indications of requests, offers, invitations, refusals, suggestions, apologies, complaints, greetings, leave-takings, etc. Of these, one of the most prolific fields from the Pragmatics perspective is politeness. It is very fruitful, since considers two different cultures, viewed through two different languages. Several approaches study the differences in politeness awareness, polite gestures, or polite attitudes. The basic underlying notion is whether politeness can and should be taught through language, and, in particular, through a second language, and whether it relates to the person or to the language. In this context and in reference to politeness, Escandell (2006) suggests that all constructs are learnt. In her words: "ser cortés es también una cuestión de fijar adecuadamente los parámetros necesarios para evaluar correctamente los intercambios sociales". Again for this particular subject, context is 
crucial in the interpretation and correct use of polite conventions. Once more the idea of transferable knowledge is recurrent.

Escandell points to Janney's and Arndt's idea of including in the learning process other important issues such as standard social behaviour, etc.: “Growing up to become a normal member of a culture is largely a matter of learning how to perceive, think and behave as others in the culture do" (Janney \& Arndt, 1992:30). Politeness is thereby based on the previous suppositions that an individual has learnt concerning correct social behaviour, and, as such, represents a contextual effect; the learner needs to have learnt what is or what is not deemed polite in order to be able to use this appropriately. The authors insist that in social interaction, the individual's behaviour also depends on the knowledge acquired by the individual, as stated by Jackendoff (1992:74): “The way individuals are capable of acting out within a society depends on the way they are capable of internally representing the social context".

In this sense, and insisting on the role Pragmatics should take in the learning process, other views exist. For instance, Schmidt (1993) and Bialystok (1993) offer two parallel propositions: Schmidt (1993) argues that the initial stages of pragmatic awareness in second language acquisition should focus on relevant input. Bialystok in his account argues (1993:54) that the student should develop control to face a sufficient level of confidence with which to confront the different communication situations. He differentiates between adults and children, assuming that whereas the former have acquired their 
communicative abilities: the latter still need to work on them. Thus, children "need to explicate and expand their linguistic resources". Conversely, adults, as Bialystok explains (1993:34):

\footnotetext{
[...] make pragmatic errors, not only because they do not understand forms and structures, or because they do not have sufficient vocabulary to express their intentions, but because they choose incorrectly. They attend to the wrong possibility for meaning, they fail to attend to a social distinction that needs to be marked linguistically [...].
}

Thus, Bialystok (1993:54) also insists on the idea that Pragmatics will have to help adults to source different fields distinct from language in order to really master a language, and make use of previously acquired knowledge. Obviously, this side knowledge includes the linguistic competence to "develop the control strategies to attend to the intended interpretations in context" in addition to the social competence, to ensure that the speaker is able to "select the forms from the range of possibilities that satisfy the social and contextual needs of the communicative situations" and probably others related to intention and realisation. In accordance with this, Roberts (1998) and Truscott (1998) argue for the need to instruct the students and supply them with the metalinguistic tools, capable of ensuring that learners are in a position to discuss language. In support of this, some additional studies draw attention to the fact that communicative activities in the classroom encourage production practice without exposing the learners to sociolinguistic inputs, which could facilitate pragmatic acquisition (Porter, 1986; Kasper \& Schmidt, 1996). 
It is our opinion that exposure is crucial in actual language learning, since we agree with the need for pragmatic awareness raising, which has recently become an area of concern for many authors. For instance, Eslami-Rakesh (2005:199-200) explains that pragmatic competence consists of illocutionary competence, that is, knowledge of speech acts and speech functions, and sociolinguistic competence. The term sociolinguistic competence, which is included in this work, results in the ability to use language appropriately according to context. As such, it includes the ability to select communicative acts and appropriate strategies to implement them depending on the contextual features of the situation. In Bachman's model, pragmatic competence is not subordinated to knowledge of grammar and text organization but is coordinated to formal linguistic and textual knowledge and interacts with organizational competence in complex ways. Indeed, many authors (Thomas, 1983; Takahashi, 1996; 2001; Alcón \& Safont, 2008) concur by stating that there is a compelling need for students to be aware of language use in order for language to be learnt whilst considering this competence. Most studies consider Grice's differentiation between generalised implicatures (context-free inferences) and particularised implicatures (context-determined inferences). Traditionally, pragmatic studies have only focused on the second group. That is, those in which context determines the use and understanding of the utterance. However, attention should also be paid to the former group, which is integrated by those inferences typical amongst any group of language users. This refers to inferences that are not associated with one specific language, but with specific adeptness, knowledge and abilities which the 
users possess without even being aware of it. As Levinson states (2000:22) “[...] general expectations about how language is normally used. These expectations give rise to presumptions, default inferences, about both content and force".

Takahashi (2005:91) not only insists upon this need to make the student aware of the precise L2 features which will help him or her in future language development, but also emphasises the need for a more detailed research on the analysis of learning processes; "These findings stress the importance of a further, more systematic investigation into the focus of learners' attention in processing L2 implicit input". This author also underlines other factors affecting attention and awareness in L2 learning processes, such as grammatical sensitivity or sociopsychological factors. These aside, he also mentions motivation as a crucial aspect in the learning process. If the learning process is to be learner-centred, then the learner needs to play a decisive role in this. Motivation, Takahashi (2005:95) says is: "one of the ID variables that highly constrain pragmatic attention and awareness". In his study, he highlights the following as factors affecting motivation for Japanese learners: need for achievement, intrinsic motivation, external expectation, class anxiety, attitudes to Target Language (TL) community, self-devaluation, test anxiety, interest in TL culture and affiliative motives. In this it is implied that peer pressure (contextual stress), as well as self-image and self-expectations (motivation and attitude) play a key role particularly in the process of learning a second language. He establishes that, whereas there is a direct link between motivation and 
learning, this bond can be equally stated between proficiency and awareness; the greater the awareness of the learner in language uses and implementations, the greater the level of proficiency he or she will be able to achieve in that particular language (Takahashi, 2005:113114):
This suggests that, if we could increase learners' motivation in one way or another, we might be able to increase the chances that they notice pragmalinguistic features in implicit conditions. The non- significant correlation of awareness with proficiency suggests that motivation overrides proficiency in learners' attentional allocation.

Supporting this, Crooks and Schmidt (1991:484) argue that the allocation of attention may be initiated by one's voluntary decision and that "it is this kind of voluntary control of attention for which motivational factors are most obviously relevant". They connect this with what they refer to as personal relevance, which guarantees the attention of the individual providing the learner considers input relevant.

To reiterate the main points in this section, many pragmatic studies state that input is crucial to competent language learning. For many researchers, this input should be carefully considered and provided by native speakers. In those cases where it is not possible to obtain this input from the instructor, there should be direct contact with the target language. Students should be provided with real texts, listening activities, films, etc.

Implicit in this is the need to provide a context. Indeed, many researchers state that in order for a student to have significant first-hand information about a language, some social context must be provided. 
The student must be able to witness for her/himself the specific use of language in a real-life setting with its restrictions or limitations, and the possible implications contained in this. This is related to what is referred to as social awareness.

In turn, this is connected to pragmatic awareness, the understanding of how things work in a particular language, and which many claim to be the guarantee that students will attain language proficiency in real life situations. It is also combined with the use of previous knowledge which learners bring from their first language. Indeed, most communication events can be related in one way or another to expressions in the first language, and help establish both similarities and dissimilarities between languages. In any case, the first language is always used as a reference point, and helps when it comes to establishing the position of the new language uses.

Common to most research in this field is the study of speech acts. Many classroom studies focus on one particular aspect of communication to evaluate the proficiency students acquire throughout their learning process. Although there are several approaches, they coincide in the study of one of the specific language realisation strategies (related to Searle's Speech Acts): apologies, requests, complaints, etc. These can be based on several speech acts related to politeness (requests, refusals) or even politeness in the broad sense, or on intra-linguistic aspects (hedging, etc.). 


\subsection{CONTRASTIVE ANALYSIS (CA)}

The importance of Contrastive Analysis for our research is related to its relevance in second language acquisition, in particular to its interest in the way in which language is apprehended and understood when it is grounded on a different linguistic background. Besides, awareness and knowledge arising from this particular view are crucial for the consequent design and development of academic syllabuses as well as for the materials which will permit the learning of the target language.

Multilingualism and cross-cultural studies are keywords attached to this approach that make it enriching and attention grabbing in a globalised world. Indeed, the cross-cultural and multilingual views in the study of a second language proposed by CA also help in the recognition of problems that transcend linguistic production itself, and try to find answers in all the possible sources, both linguistic and non-linguistic.

\subsubsection{Definition and beginnings}

Contrastive Analysis (CA) was based on the behaviourist psychological principles aimed at obtaining methodological consequences of behaviour, although intended for linguistic purposes. Traditionally, CA included three types of analysis, Contrastive Analysis, Error Analysis and Interlanguage Analysis. The underlying idea was that consequences applicable to language teaching could be obtained from experience. 
Researchers sustained that, by observing frequencies of problems, and comparing the structures of the languages, there could be a prediction on probable areas of difficulty when a new language was to be learnt. Santos Gargallo (1993:16) summarises the launching of contrastive analysis based on the idea that:

[...] una comparación sistemática de dos lenguas, la lengua nativa y la lengua meta en todos los niveles de sus estructuras, generaría predicciones sobre las áreas de dificultad en el aprendizaje de dicha lengua meta y que, se podrían extraer consecuencias metodológicas [...].

The traditional definition of CA obviously refers to the comparison of two languages in order to ascertain which items in them are alike and which are different. From this, several consequences can be drawn. It has been explained by many authors, as Gomez-Gonzalez and Doval-Suarez (2005:19):

\begin{abstract}
The raison d'être of contrastive investigations is to compare (or contrast) linguistic and socio-cultural data across different languages (cross-linguistic/cultural perspective) or within individual languages (intra-linguistic/cultural perspective) in order to establish languagespecific, typological and/or universal patterns, categories and features. According to James (1980), this includes description and comparison.
\end{abstract}

Although Whorf used the actual expression in 1967, Kurtes explains a long journey in the naming of the discipline until the final term was coined and used generally to refer to it. There seemed to be certain amount of disparity in the naming of the discipline (Kurtes, 2006:830):

[...] this discipline was also referred to as 'parallel description' (Fries 1945), 'differential studies' (Lee 1974), 'differential description' (Mackey 1965), ‘dialinguistic analysis' (Nemser 1971), ‘analytical 
confrontation' (ibid.), ‘analytical comparison' (Mathesius 1964), 'interlingual comparison' (Filipovi 1975c), as well as 'comparative descriptive linguistics' (Halliday-Mclntosh-Strevents 1964), or 'descriptive comparison' (Catford 1968).

James (1980:63) explains that CA includes two different processes description and comparison-, subdivided into four basic steps, which include data assembling, description, data supplementing and formulation of contrasts. The first process, description, includes the collection of data from the two different languages in order to compare them. Then, there is a stage dedicated to the description of all the information that has been obtained. The second process is the comparison itself. First, data completion is finished, and then the actual formulation of contrasts takes place.

With regards the definition of the discipline, Charles Fries is recognised as the originator of the discipline, and gives a definition for it in the Preface to the 1978 edition of Lado's Linguistics Across Cultures. He highlights the idea that the learner who approaches an L2 does not come from nil, but has already a linguistic background. Consequently, he/she has a different perspective than that offered by the language he or she is trying to learn, and therefore than that of he or she who starts learning a first language for the first time:

[...] learning a second language [...] constitutes a very different task from learning the first language. The basic problems arise not out of any essential difficulty in the features of the new language themselves but primarily out of the "set" created by the first language habits. 
After Fries, Lado offers a clear definition of CA for the different processes involved in language acquisition, in which interference of the MT on the TL is assumed. These are the crucial aspects CA worried about, the contact between the target and the mother language, and the consequences (interferences) this could have on language learning. Lado describes both productive and receptive processes in terms of transfer and according to the MT of the learners (Lado, 1957:1):

\begin{abstract}
Individuals tend to transfer the forms and meanings and the distribution and forms and meanings of their native language and culture to the foreign language and culture- both productively when attempting to speak the language and to act in the culture and receptively when attempting to grasp and understand the language and the culture as practised by natives.
\end{abstract}

What is more, when he specifies the aims of the discipline, he highlights the positive aspects that can be obtained from comparison. He points at CA as a methodology, as the type of analysis that could be most generally productive in language analysis (Lado, 1957:vii): "the comparison of any two languages and cultures to discover and describe the problems that the speakers of one of the languages will have in learning the other". From this, he goes as far as saying that by means of CA it would be possible to predict, and consequently correct error patterns or potential problems encountered in the process of learning a second language. This was much criticized later on. (Lado, 1957:vii):

[...] assumption that we can predict and describe the patterns that will cause difficulty in learning, and those that will not cause difficulty, by comparing systematically the language and culture to be learned with the native language and culture of the student. 
A special mention must be given to one of the developments of $C A$, of considerable acceptance in recent years, which also bases analysis in learning by comparing, Contrastive Rhetoric (CR). It can be understood that it applies CA to written texts. It was well received by many researchers, who thought of if another way of studying the new views of discourse analysis and text linguistics, reaching beyond sentence level for composition analysis.

It was introduced by Kaplan in 1966 grounded on the idea that each language and culture has different intrinsic orders. With pedagogic purposes from the beginning (as compared to other formal views of text analysis), it aims at determining interferences, variations and errors produced in an L2. It does not pretend to predict, but to describe and correct if necessary. The idea supported by Kaplan was a reformulation of the Sapir-Whorf hypothesis, stating that not only language but also writing are specific for each culture. Because it includes different fields of knowledge (writing, culture, second language...), it is often considered too complicated to be able to offer clear, specific results. In Atkinson (2004:278) words:

[...] this is a field which combines at least three large areas, each enormously complex and variegated in itself: (1) writing (especially in EAP/ESP contexts); (2) learning and using second/additional languages (not to mention language itself); and (3) culture.

CR shares many features with CA, but uses L1 rhetoric devices to analyse the problems encountered in the production of $L 2$, and focuses on writing. Each language has its own unique rhetoric system, which 
represents different ways in which ideas are organised in that particular language. This includes both cultural and linguistic aspects. These must be taken into consideration as without them there can be no proficiency in second language writing: there are cultural as well as linguistic issues, i.e. rhetoric conventions, that play a key role in the identification of problems and proposals for improvement in second language production. One of the greatest defenders of the discipline is Connor. Her own definition of CR is (Connor, 1996:5):

\footnotetext{
Contrastive rhetoric is an area of research in second language acquisition that identifies problems in composition encountered by second language writers and, by referring to the rhetorical strategies of the first language, attempts to explain them.
}

Noteworthy is the fact that she refers exclusively to writers, not to learners, or speakers. CR focuses exclusively on written production. Of course it could be argued that this could be extended to any type of production in a second language.

From the very beginning in the discipline, there is clear awareness of the importance of writing if success in second language learning is expected. Lado (1957:93) referred to the problem of learning a language primarily through writing, and of writing itself as a challenging task: "And actually, the writing process constitutes a problem of its own, distinct from that of learning the foreign language". He based his statement on Bloomfield's (1933:21) assertion that "In order to study writing, we must know something about language, but the reverse is not true". By this, he implied that there could be some interference in the analysis of written 
texts if flaws are due to inadequacy on writing, and not lack of proficiency or fluency in a second language.

To complete the definition and description of the discipline, Connor also offers in the following Figure different contrastive rhetoric approaches that had been completed up to that moment. Figure 2 shows the evolution of these studies, and explains their focus of attention, pointing at differences in the approaches and settings (Connor, 2003:226):

1. Contrastive text linguistic studies examine, compare and contrast how texts are formed and interpreted in different languages and cultures using methods of written discourse analysis. (See Clyne, 1987; Connor \& Kaplan, 1987; Eggington, 1987; Hinds, 1983, 1987, 1990).

2. Studies of writing as cultural and educational activity investigate literacy development on L1 language and culture and examine effects on the development of L2 literacy. (See Carson, 1992; Purves, 1988).

3. Classroom-based contrastive studies examine cross-cultural patterns in process writing, collaborative revisions, and student-teacher conferences. (See Allaei \& Connor, 1990; Goldstein \& Conrad, 1990; Hull, Rose, Fraser, \& Castellano, 1991; Nelson \& Murphy, 1992).

4. Genre-specific investigations are applied to academic and professional writing. (See Bhatia, 1993; Connor, Davis, \& De Rycker, 1995; Jenkins \& Hinds, 1987; Mauranen, 1993; Swales, 1990; Tirkkonen-Condit, 1996; Ventola \& Mauranen, 1991).

Figure 2. Contrastive Rhetoric Studies (Connor, 2003).

We can see in the box an intermingling of disciplines and areas of study. For instance, the general framework in all the studies is CA in the sense that there is comparison, but the methodology used in the analysis of the texts can be discourse analysis or other. It can also be used to complete cross-cultural analysis, or genre specific investigations. Again, what all these studies have in common is that the focus of interest is set 
on two or more languages (CA), which are then compared in order to analyse the specific differences and find the reasons for errors, and learning processes.

In CA we can talk about three different periods: traditional, classical and modern. The first one goes from the end of the $19^{\text {th }} \mathrm{C}$ to the beginning of the $20^{\text {th }} \mathrm{C}$. During this time, focus was set on typological studies. For instance, with regard the study of language universals, Bloomfield (1933) stressed the importance of interlingual comparison. The second period includes approximately the years 1945-1965. CA was finally recognized as a scientific, pragmatic and academic discipline. This was the time of Fries, Lado, and others. Finally, the modern period knew the development of the discipline through academic projects, but also the decline and criticism.

With time, CA in turn subdivided into two distinct subareas. The theoretical area searches for similarities in the field of linguistic universals, whereas the practical (which follows the path started by Fries and Lado), which searches for similarities and differences between two languages which can be applicable to learning processes. Kurtes (2006:832) explains that the discussion on whether it should be more theoretical or more applied has been focused on three positions:

[...] (1) contrastive analysis is a method of contrastive linguistics, which is a branch of theoretical linguistics, and its results are relevant to both 'pure' (e.g. typological studies) and applied linguistics (e.g. language teaching methodology, translation studies, etc.); (2) being a branch of applied linguistics, the results of contrastive analysis are primarily relevant to foreign language teaching methodology; (3) there is no justifiable reason to insist on the distinction between the two. 
Worth mentioning is the work carried out by Ferguson, who largely promoted CA in Europe and US, by comparing English to different European languages. This view would be considered more theoretical since it left out the learning process and focused on the languages themselves. Despite the criticism undergone by CA, it was developed in Europe by the Prague Linguistic Circle. As had happened in the US, practical studies were replaced by theoretical studies. From 1970 onwards, CA was nearly abandoned almost by all linguists, after strong criticisms (Whitman \& Jackson, 1972; Taylor, 1986), which emphasized the unreliability of $\mathrm{CA}$.

The scope of the discipline was considered too narrow, and the discipline was criticised disregarding it as a useful tool in the study of language. In addition, in the 1960s and 1970s, the currents of CA, which were previously based on behaviourism, were replaced by Cognitivism, influenced by Chomsky's generative grammar. This claimed that deep structures in any language were connected through the idea of Universal Grammar, and that differences could only be found at surface structure level, in which the languages chose different words and structures to make those deep structures a reality.

Odlin (1989) declares that the major reason for the failure of CA theory lies in the fact that structural similarities and dissimilarities between two linguistic systems, and the processing of linguistic means in actual production and comprehension are two quite different things. Contrastive linguistics is concerned with the former, while acquisition has to do with the latter (Odlin, 1989:19): 
In other words, a comparison of the native and target languages would be useful for explaining why certain errors arise, but in the absence of actual data about learners' errors little if anything could be reliably predicted.

Two different versions of the discipline were developed, based on this idea that CA could only explain and never predict; the strong, and the weak version. The first claims that interference from the learner's MT hinders SLA, and that depending on his or her MT the learning process will be more or less difficult for the learner. This is to say, in the case of two similar languages, learners will encounter fewer difficulties than in the case of two languages that are very dissimilar, both in linguistic and cultural terms. This leads to the third aspect crucial in this strong version: these difficulties, and the errors that will be produced due to MT interference, can be predicted after analysis and research. As a result, CA can be used for the preparation of teaching materials, based on the features which show particular points of difficulty; taking into consideration how far apart the languages are, as well as what kind of interferences can be predicted and therefore corrected.

The weak version, however, was launched around the 1970s by Wardhaugh, who tried to prove that all theorists which had been claiming to be working with the strong version of the theory had actually been working with a weak version of the theory, and were not able to actually predict errors (Wardhaugh, 1970:126):

It seems therefore, not a little strange, given all the problems which the strong version of the contrastive analysis hypothesis creates, that so many linguists claim to use it in their work. None of them has actually conformed to its requirements in such work. 
He establishes that this is, in fact, an interested understanding of the weak version of the theory, and advocates for a weaker version, more realistic, and more sincere as to the possibilities of work and research. In doing so, he moves the focus of attention from the prediction of errors, to the observation and description of these errors, not as a second option, but as the main option which justifies the analysis (Wardhaugh, 1970:126):

\begin{abstract}
The weak version requires of the linguist only that he use the best linguistic knowledge available to him in order to account for observed difficulties in second language learning. It does not require what the strong version requires, the prediction of those difficulties, and, conversely, of those learning points which do not create any difficulties at all.
\end{abstract}

He also postulates the need to work with Error Analysis (EA) once these errors have been spotted and are in need of description. In this sense, he advocates for the joint use of both disciplines, questioning the efficiency of just using CA. What is more, CA is in fact considered (Johansson, 1975), as part of EA, in particular the part dedicated to the description of the errors.

\title{
2.2.2 Aims and achievements
}

$\mathrm{CA}$ has proved great usefulness in the development of intercultural communication (Nunan, 1993; Finch, 2003), mainly in the consideration of all factors that take place in communication. Many factors need to be taken into account in order to achieve effective communication. Apart 
from grammar, cultural and social aspects that permit the correct interpretation and use of language are also crucial in communication. In Nunan's words (1993:95):

In addition to having different expectations about how to do things with language, learners from different cultures have very different types of background knowledge, and this can impede communication.

In this sense, through comparison, CA can help in the determining of the cultural influences in discourses, which can lead either to language variations or to language errors. Cultural features can also cause interference in the mastering of an L2, in the cases in which the speaker is using L1 patterns in communication in L2. Indeed, it must be borne in mind that L2 always involves previous L1 knowledge as Lardiere points out (2009:175):

\begin{abstract}
Acquiring a second language grammar necessarily involves determining how to assemble the lexical items of the target language. I argue that this will require that the learner reconfigure or remap features from the way these are represented in the L1 into new formal configurations on possibly quite different types of lexical items in the $\mathrm{L} 2$.
\end{abstract}

This is not necessarily negative, since the learner can reconfigure already used rules and social norms to the new settings, and thus learn them more quickly. CA is also useful in the identification of problems caused by cultural interference, although not all errors are due to culture, and obviously, some flaws should find their origin in personal or other causes. 
Bearing in mind the primary interest and aim of CA, it is necessary to recall the importance of effective communication in an ever-greater interconnected world. Several studies in CA have been dedicated to the study of variations of the same language in different linguistic communities (Carrió, 2005a). This, in the case of English is particularly interesting for the future developments of English as a lingua franca.

Regarding language learning, Harumitsu (1988) related CA to the Communicative Approach to language learning, and claimed that it was necessary to interpret Interlanguage processes of learners. Previous studies had focused on specific aspects of language, such as syntactic and morphologic structures, because they were more likely to show errors useful to the linguist. However, to account for the Communicative Approach, CA was evidently useful (Harumitsu, 1988:75):

[...] communicative competence rather than grammatical competence is likely to reflect the authentic competency underlying the learners. $[\ldots]$ it is indispensable to analyze not merely learning strategy but also communicative strategy and discourse strategy as the target.

Indeed, with regards the pedagogical implications of CA, Guo and Zhuo explain that CA was intended at helping teachers teach better, and to do that, focus needed to be set on the acknowledgment of the existence of different groups of students with different needs, and centre on the differences these groups would have (Guo \& Zhuo, 2008:67):

1) The teacher needs to have prior knowledge about his/her students' $L 1$, if he is to respond the learner's difficulties. But what if the classroom contains learners from different linguistic backgrounds (as was and still is the case in the US)? 
2) Teaching will focus on linguistic differences. Similarities will be overlooked as they trigger positive transfer.

3) Teaching material will only be based on differences, hence the areas of predicted difficulties, between the $L 1$ and the $L 2$.

Undeniably, to complement this, Oller (1972:95) reminds us that traditionally CA has been considered a very useful tool in SLA. He quotes Fries (1945:9) when she stated that "the most efficient materials are those that are based upon a scientific description of the language to be learned, carefully compared with a parallel description of the native language of the learner". Then, always following Oller (1972:97), Fries gives some ideas as to the way this can be approached (Fries, 1945:153):

[...] the specific point at which interference will repeatedly occur, so that he may practice with awareness and concentration and monitor his own production with watchfulness until he finds himself producing the target language forms with ease and accuracy.

This, in Oller's opinion, is an exaggeration. Despite this, it does bring some light to the specific worth of the discipline, as a tool to face interference, one of the main errors considered when second language acquisition is studied, and which is thoroughly explained later on.

Apart from this, it must also be said that CA can provide a useful tool for NNES in their use of the language. Additionally, it ought to be pointed out that the infallibility of the Native English speaker, as that of any other language native speaker, is no longer taken for granted. Traditionally, NES have enjoyed a series of benefits derived from the mere fact that they were native speakers, as expressed by Carrió (2005a:62): 
[...] tradicionalmente, los escritores nativos ingleses han gozado de un mayor reconocimiento al expresar sus ideas que los no nativos, [...]. Los EN en un principio eran los que estaban en posesión de un dominio perfecto de la lengua, y por lo tanto, podían transmitirla perfectamente (Kramsh, 1998: 79), catalogando como escritura no ideal la variación de ese inglés ideal (Freeborn, French y Langford, 1993: 39). Actualmente se cuestiona la inefabilidad de los escritores nativos [...].

Obviously, it has long been considered the ideal concept of NES, as once was language. However, the language that is taught and learnt must not only be the ideal standard of the language, realistic and authentic in its implementation, from a communicative approach.

$\mathrm{CA}$ is also a reference field for contrasting variation among languages, or within language communities. Thus, looking at other specific studies, researchers in the field of English for Specific Purposes (ESP) have focused on rhetorical aspects or on the structure of academic English (Samraj, 2005; Yakhontova, 2006; Samraj \& Monk, 2008; Durrant, 2009).

Another area of interest is looking at how genres vary across languages (Bondi, 1999; Samraj, 2002; 2004; Freddi, 2005; Charles, 2007; Ozturk, 2007). Some studies focus on variation based on different linguistic or cultural backgrounds (Valero-Garcés, 1996; Moreno, 1997; Vassileva, 2001; Martín Martín, 2003; de Haan \& van Esch, 2005; Moreno \& Suárez, 2008; Hinkel, 2009; Schleef, 2009; Carrió, 2009a).

To sum up, the aims of CA as established are twofold. On the one hand, the analysis and prediction of the optimal steps in the learning process of a second language based on the strong version of the discipline, 
which defends its possibility for actually predict what progression an actual student can have. On the other, the questioning and description of the deviations of a speaker when trying to communicate in an L2, and the deduction of consequences (and subsequent applications) from this data. Seah (1981:iv) insisted on the usefulness of the process:

In relation to the Chinese ESL investigated, the above results indicate the following:

1) An a priori contrastive analysis proves valuable in locating and explaining problem areas. The phenomenon of objective linguistic difficulty is real [...].

2) An a posteriori error analysis provides data for verifying contrastive analysis and supplements it by revealing errors not predicted. Contrastive analysis and error analysis have to be jointly considered and employed for a better understanding and a more efficient treatment of difficulties in second language learning.

The underlying idea in most authors is that CA can be useful, but not as the only method for analysis to approach research on the teaching and learning of a second language. Indeed, many scholars stress the need for CA to be complemented by other disciplines, significantly EA (Oller, 1972:97):

In short, at the present time CA does have validity as a device for predicting some of the errors a second language learner will make. It thus provides a promising basis for investigating general properties of the mind and it seems to be a uniquely appropriate methodology for further study of the fundamental processes of transfer and interferences in learning tasks (both verbal and nonverbal). We should be careful not to underestimate its importance as a research tool but we should note that as a basis for a total foreign language program, CA is decidedly inappropriate. 
Actually, Odlin (1989) agrees with the idea that just because of similarity or dissimilarity, languages cannot be said to be more or less difficult to the learner. In fact, this generalisation is an oversimplification of the actual learning process. Any given learner of any language can find it easy to learn one specific feature of the target language, and very difficult to learn another. This leads us directly to the reasons why $\mathrm{CA}$, in particular the strong version of the discipline, was greatly criticised and discredited.

\subsubsection{Criticism}

Although some accomplishments were granted by CA and its findings, many points of criticism came to light early in the development of the discipline. These came from different perspectives of study, and questioned several issues. Carrió (2005a:55) summarises them as follows:

1) Los resultados parecían demasiado abstractos para su aplicación en la enseñanza de una L2; 2) se vislumbraba una difícil solución de los problemas planteados porque no todos los componentes eran lingüísticos; 3) existía una falta de definición de la teoría lingüística a seguir; 4) se ignoraba el componente psicológico y pragmático del aprendizaje.

In particular, and as has been explained above, many scholars have also questioned the idea that errors could be predicted ever since the 1970s. For instance, Wardhaugh (1970:23) strongly expressed his conviction that neither the strong nor the weak versions are useful to help in the teaching process: 
The claim that the best language-teaching materials are based on a contrast of the two competing linguistic systems has long been a popular one in language teaching. [...] The strong version of the hypothesis is untenable and even the weak version creates difficulties for the linguist.

Principally, he questions the fact that CA authors say they use the strong version for their works, and challenges the possibility of establishing a theory able to framework the studies as well as the use of linguistic universals (Wardhaugh, 1970:25),

[..] this version demands of linguists that they have available a set of linguistic universals formulated within a comprehensive linguistic theory which deals adequately with syntax, semantics, and phonology.

Apart from him, other researchers also establish that some of the items that are predicted as sure causes of error or difficulties are not so in the end. For instance, Banathy and Madarasz (1969) stressed the fact that not necessarily that which seems more dissimilar is more difficult to learn, so a direct link between language similarities and dissimilarities and effortlessness and difficulty cannot be established.

As said, CA has been used to analyse possible influence of the MT on the L2 ${ }^{4}$. However, the fact that interference of the MT on L2 learning has always been studied from the CA perspective with reference to the negative meaning of transfer between two languages had already been highlighted by Oller (1972 and Odlin (1989). This author argues, in contrast, that in some cases this not need be so, and there can be a positive influence derived from the command of a given language (for

${ }^{4}$ Section 2.3.3.2 is dedicated to studies and views on the concept of interference. 
instance the cases of language, context or cultural proximity), as stated by Odlin (1989:26):

\begin{abstract}
Native speakers of Spanish have a tremendous advantage over native speakers of Arabic in the acquisition of English vocabulary [...]. The term interference implies no more than what another term, negative transfer, does, but there is an advantage in using the latter term, since it can be contrasted with positive transfer, which is the facilitating influence of cognate vocabulary or any other similarities between the native and target languages.
\end{abstract}

Taking into consideration the actual results obtained in the analyses, as pointed out by Ellis (1985:29), many errors produced by students are not due to their mother tongue, nor to any influence of their culture or social habits.

In coincidence with some opinions gathered above, Sciarone (1970) explained that it is too simplistic to assume that some structures are easy and some others are difficult. Moreover, if this assertion is based on the degree of similarity between two languages, then it is completely artificial. Yet, questioning CA, Sciarone claimed that the process through which Second language is learnt cannot be compared to the acquisition of the first language. For this reason, interference from L1 should always be assumed as part of the acquisition process. Comparison should be carried out in specific ways, always paying careful attention to structures, and to the theoretical linguistic assumption that supports it. Thus, the contribution of CA depends highly both on the quality of the analysis and on the way it is carried out. Indeed, it needs a thorough theoretical background (Sciarone, 1970:118): "somebody who is thoroughly grounded in linguistics is needed; [...] one should carefully 
consider the theoretical points of departure that will guide the linguist in his analysis of language". However, this author also highlighted some positive points in relation to its support for language teaching (Sciarone, 1970:131):

It will be clear by now that the possibilities of CA are greatest in the first phase of the teaching of language. [...] If teaching is done on the basis of difference and similarities as they are systematized in the language to be learnt, the influence of the native language on the language to be learnt will grow smaller and smaller.

Also in relation to the application of CA to language teaching, Ritchie (1967) pointed out the inconvenience of just focusing on errors, advocating for a more general, broad view of language and language teaching. If teaching is only focused on errors; error detection and error correction, it can only conclude in "a patchwork of unfruitful, partial generalizations" and a consequent "lack of confidence in his intuitive grasp of the foreign language" (Ritchie, 1967:129).

\subsubsection{Present and future trends}

Chesterman (1998:90) contributed to CA with a functional vision, which offered a somehow different way of understanding the discipline. It was based on semantics, and the comparison of different ways of expressing the same concepts. The focus of the analysis was the comparison between different ways of communicating, and in this way he was able to establish similarities and differences between them. Subsequently, the idea was to quantify these similarities and differences. $\mathrm{He}$ 
distinguished between "similarity-as-trigger", defining it as "the notion of a particular relation [...] that impinges upon human perception, from matter to mind" (Chesterman, 1998:7) and “'similarity-as-attribution', going from mind to matter". The method proposed included at least six steps, which are explained by Kurtes (2005:835):

- Collecting primary data against which hypotheses are to be tested [...].

- Establishing comparability criterion based on a perceived similarity of any kind.

- Defining the nature of similarity and formulating the initial hypothesis.

- Hypothesis testing: determining the conditions under which the initial hypothesis can be accepted or rejected [...].

- Formulating the revised hypothesis.

- Testing of the revised hypothesis [...].

According to his proposal, the formulations could be tested in a corpus or in real language utterances. The work of the linguist was then to find the true and valid formulations to establish those similarities and differences. As can be understood from the explanation, here an inductive method is proposed for research, in which after having gathered the data, the similarity and dissimilarity criteria that will be used by the linguist for the comparison are set. Then, the hypothesis is reviewed and retested, and the process starts again.

Although CA methods and assumptions have been abandoned by most linguists, CR prevails as a useful tool to consider linguistic, cultural and social matters which affect communication. As explained by Atkinson (2004) above, some problems CR poses to the linguist are the complexity of intermingling all these three aspects to complete an analysis. In order to clarify the specific realisations that the discipline 
can have, Connor adapts Enkvist's 1997 Figure to show the applications of these studies throughout Europe (Connor, 2003:228):

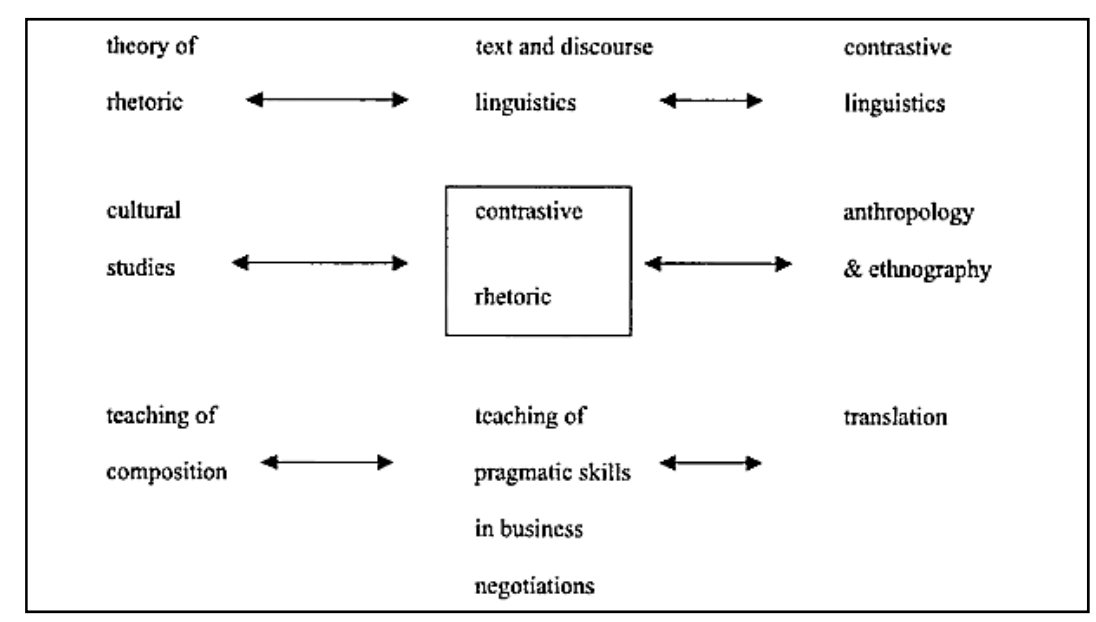

Figure 3. Applications of Contrastive Rhetoric Studies (Connor, 2003).

As can be seen, contrastive rhetoric is here related to very different disciplines, and is found convenient because it explores practical applications in many fields, which range from linguistic, to pragmatic, cultural or sociological. Connor (2004:273) also suggested changing the name into Intercultural Rhetoric:

\footnotetext{
I propose the term intercultural rhetoric to refer to what might previously have been called contrastive rhetoric or cross-cultural studies of writing. The term, in my definition, encompasses crosscultural studies (comparison of concept $A$ in culture one and two).
}

She emphasizes the fact that this term introduces new ethnographic views which take into consideration interaction, and at the same time permits the conservation of the traditional approaches (concerned with text and genre analysis and corpus analysis). 
Li (2008:16) analyses the term CR and concludes that, although it is linguistic "in at least three ways" (founded by a linguist, pursuing practical goals, and having texts as objects of study), "it analyzes the identifiable linguistic structures of texts, concentrating on those above the sentence level, and [...] its method is typically quantitative" and only a small fraction of works takes a cross-cultural perspective. In addition, "it is a particular perspective that the researcher brings to the examination of ESL writing" (Li, 2008:30).

Besides the use of the language, CR seeks now to analyse the processes the writers of any learned languages apply in the production of their texts. This is useful to analyse to which point they are errors or variations of the same language function or text. Thus, to retake the previous statement, CR mainly concentrates on discourse and nowadays is mainly focusing on genre. Many CA are based on contexts and genres, as well as audience and expectations (Connor, 2003:224):

\footnotetext{
Significant changes have taken place in contrastive rhetoric in the past 30-odd years. [...] [CR] has taken new directions in the following domains: (1) contrastive text linguistics, (2) the study of writing as a cultural-educational activity, (3) classroom based studies of writing, and (4) contrastive genre-specific studies, including a variety of genres composed for a variety of purposes [...].
}

This is useful not only in the analysis of the learner's language, but also in the actual definition of genres, functions and aims of the different texts produced in different languages. McCarthy (2001:45) focuses on structure, and state that CR can aim at obtaining the linguistic basic features which permit the coherent expression of our thoughts, the 
distinction between clearly structured and defined structures within the languages, and the linguistic competence of each speaker.

As far as future and present trends are concerned, James (2008) argues that there has recently been a renewal of $\mathrm{CA}$, although without strict acknowledgement to the work of Fries and Lado, and the previous Western tradition. Although it does not seem to find its roots, or at least its acknowledgment in the previous studies, this new trend is again based on some behaviourist concepts, such as training and finds its basis for instance on the work of Slobin (1996:89):

\footnotetext{
In brief, each native language has trained its speakers to pay different kinds of attention to events and experiences when talking about them. This training is carried out in childhood and is exceptionally resistant to restructuring in second language acquisition.
}

The new studies and the modernity of the discipline are based, always according to James (2008), on the following aspects:

(1) Culture learning. In the most commonly used approaches to SLA nowadays, i.e. the Communicative Approach, emphasis is set on cultural understanding. This will be the method used in the present research for the analysis of written texts. Hence the importance of learning the culture which supports and complements the target language together with the language itself in order to attain and complete real communication, as Widdowson and others point out in their encouragement of Communication as the goal of language learning. 
(2) Removal of the Audio-lingual Vetoes. Indeed, there are numerous recommendations to avoid certain kind of teaching strategies, such as the comparison between the two languages in contact (mother language, second language), in order to help learners stay away from confusion.

(3) Recuperation of the Sapir-Whorf hypothesis, in its weak relativist- version. This hypothesis maintains that languages shape our vision of the word.

Some remarks are made to the original formulation of the hypothesis. For instance, Slobin (1996) supports the thought that languages do not shape the way we think, but do shape the way we think of speaking. We can read about this in James' text (2008:7):

\begin{abstract}
He has compared how speakers of Spanish, German, and English encode their accounts of what is objectively the same series of events, and is able to make interesting generalisations, such as the following: "English speakers assert actions, implying results, whereas Spanish speakers assert results, implying actions". (Slobin, ibid. 84).
\end{abstract}

The fourth of these pillars of the new contrastive studies for the study of writing is CR. As seen, the discipline is still alive and productive, by means of combination with other fields of knowledge, such as cultural studies, translation, teaching, language policy or Pragmatics. It can even develop to obtain greater results with the use of the new technologies and the disciplines that are connected to these, such as Corpus Analysis in Linguistics or the Communicative Approach in Language Teaching.

Recent works in this sense are for instance Simpson's comparison (2000:307) of English and Spanish paragraphs, concluding that 
"didactic materials should be designed that emphasize the similarities (helping students positively transfer their previous knowledge into the second or foreign language) and that explain differences and help students avoid them when writing in the non-native language".

Particularly significant in this type of studies, mainly for its usefulness in the analysis of genre, is the work by Swales (1990). Indeed, this author emphasizes the need to analyse texts always taking into account their genre. It is his conviction that similar texts need to share similar aims, and similar structures: "A genre comprises a class of communicative events, the members of which share some set of communicative purposes" (Swales, 1990:58). In fact moves are text elements obligatory if the text is to be acceptable as an example of the genre. Very renowned is his Four Move proposal (Swales, 1991:141):

MOVE 1: establishing the field by centrality
MOVE 2: summarizing previous research
MOVE 3: preparing for present research (by indicating a
gap, raising a question or extending a finding)
MOVE 4: introduction of present research (by stating
the purpose or describing briefly present
research)

Figure 4. Swales' Four Move Model (1991).

In 1990, he revised this and simplified it, transforming it into the threemove, Create a Research Space (CARS) model. In it, the model is 
summarised: (1) set up a territory, (2) determine a niche, and (3) occupy it. Swales presented the final version of the CARS model in 2004.

The newest trends of CA have indeed to do with cross-culturality and pedagogy, and how can these be used in to improve teaching. Authors such as Sheen (1996), Connor (1996), James (1998) or Chesterman (1998) were convinced that the refusal of the reliability of CA came from its structuralist method, and not from its inappropriateness for the analysis. In this sense, Sheen claimed that, when it comes to minimise error rates, a deductive approach using CA input could be more effective than an inductive approach. He (1996:187) insists in the need to evaluate the efficacy of materials and teaching related to CA. He also argues that:

If cross-linguistic influence plays a crucial role in Second Language Acquisition (SLA) and, by extension, language learning in the formal classroom, it is plausible that teaching materials and methods should take it into account.

As for present and future trends, many studies based on CA are related to other fields of Applied Linguistics. Indeed, the principles of CA are combined with the pragmatic or cognitive currents. For instance, we can mention Cuenca's 2003 analysis of reformulation markers in Spanish, Catalan and English, taking pragmatics as the background for comparison, or Fischer and Drescher's 1996 study on the analysis of discourse particles from the point of view of translation. They are convinced that (Fischer \& Drescher, 1996:860): 
[...] contrastive analysis may indicate the sense spectrum of a certain discourse particle, support the criticism of traditional classification and furthermore show that, for instance, interjections do not just function as simple assertions of the speakers emotional state.

Atkinson, for instance, is firm in affirming that, although CR has been wrong in establishing identifications between culture and nation in the analysis carried out, it is a significant tool which will be necessary in all future work that takes into consideration culture (Atkinson, 2004:287):

\begin{abstract}
One of the distinctive characteristics of CR is that it actively uses the notion of culture to explain differences in written texts and writing practices. So far, however, CR has been seriously limited in this respect-the view of culture most widely assumed in accounting for textual forms and practices [...] the notion of culture is still a "great unknown" in CR studies, and increased attention to it and its analysis will do much to put the field on a more secure and betterrecognized academic footing, as well as to make it more relevant to our students' lives.
\end{abstract}

As far as the teaching and learning of a second language, recent analyses are very specific as for the kind of items they look into. Some quite recent studies focus on one particular item, as for instance demonstratives (Niimura \& Hayashi, 1996). This type of analysis is also useful to help enlighten lacks in the materials used in teaching (Niimura \& Hayashi, 1996; Gonzalvez Garcia, 2009). For instance, as a conclusion of their study, these authors claim the need for better models to teach demonstratives. In their case, they approach the analysis from a slightly different perspective, including aspects such as psychological proximity, thus combining the linguistic discipline with a more cognitive type of analysis (Niimura \& Hayashi, 1996:832): 
L2 learners would benefit from knowing the differences and similarities between the two languages: psychological, rather than mere physical, proximity is a determining factor in both language systems, but in English, focus, or the degree of attention on the referent, is the critical determinant whereas in Japanese the overriding factor is whether or not the referent is in the domain of the speaker's direct experience.

It seems apparent that language is no longer studied only within it, at least with regard to university learning. Other insights related to language teaching point to the need for acknowledging and recognising different registers, audiences and adequacies in the process of language mastering, as Hubert \& Bonzo (2010:520) mention:

It is currently unclear if U.S. university FL learners are being taught to recognize the fact that the audience for their TL writing may include language users whose rhetoric is different from their own linear organization. University FL learners could greatly benefit from their instructors' understanding and implementation of the tenets of CR, being potentially able to produce more readable, culturally-accurate and sensitive TL texts for an audience of more than just their university FL instructor(s).

Other possible combinations of $\mathrm{CA}$, as explained previously, are of course with EA. Many studies relate the need to analyse texts using jointly both disciplines. The well-known idea that errors should not be used merely as marks of failure but as indicators of the point in the learning process is for instance retaken by Kirkgöz (2010) to explain that interference can for instance be considered an error made at the early stages of the learning process of English as an L2.

As has been mentioned, the latest trends (Atkinson, 2004; Connor, 2004; Muñiz \& Carrió, 2007; Carrió, 2009b) focus on culture as the 
conducting thread in all types of contrastive analyses or at least take culture into account in their studies. Cross-cultural analyses are also developed in classroom environments and in relation to student's backgrounds. Much research also exists on the subject of cultural differences, and cross-culture studies, and in particular in fields related to teaching and learning (Connor, 2003; Lee, 2004; Hamid, 2007).

For instance Pisanski (2005) compares Slovene and English research articles, claiming for the need to teach academic English in more formal contexts within University. On their side, Loi and Sweetnam focus on genre types and Swales' moves to make a contrastive analysis of research articles between Chinese and English. They recommend the use of $\mathrm{CA}$ to teach students explicit strategies to produce effective writing (Loi \& Sweetnam, 2010:2815):

\begin{abstract}
Contrastive rhetorical studies are able to provide teachers and students with knowledge about the preferred patterns of writing (Connor, 2003) by uncovering specific rhetorical patterns, which might be culturally and contextually specific (Shim, 2005). Such knowledge could provide the basis for explicit strategies which Chinese ESL students might use to comprehend and produce effective English academic writing.
\end{abstract}

Thus, CA is considered highly useful in specific contexts both in research and in teaching, despite the strong criticism it underwent in the past. Due to the new technologies, contrastive analyses are more frequent due to the easier access to data (both public and specifically elaborated by the researchers), and so is data treatment, through the newest very specific and useful software programmes. 


\subsection{ERROR ANALYSIS (EA)}

In this section we explain the different stages involved in the development of Error Analysis. This theory is of long-standing in the study of second language acquisition. The assumptions supported by the theory have evolved from a very negative consideration of error, towards a more constructive and useful approach. To begin with, we take a look at the first stages in the development of the theory, followed by an examination of more recent studies. There is also a general presentation of errors. First of all, there will be a general description of James' taxonomy (1998), followed by the concept of language interference, which is the error type that greatly troubles scholars when looking at second language production. A general view of traditionally understood grammatical errors is also presented, since this has been the focal point of teachers for many years and has been studied from many perspectives.

To conclude, there will be a reflection on what Pragmatic errors are, that is, which items can be considered as errors from the point of view of Pragmatics. These errors will then be presented and assessed in the CEFR. The final sections will help define a case study and establish the type of errors to be considered and explained.

\subsubsection{Development of the theory}

Some authors considered EA to be the logical step following CA. It was regarded as an approach capable of advancing the analysis of the 
causes behind error production, particularly when dealing with second or foreign language acquisition and some specific problems in language use.

However, some consideration must be given to the fact that not all utterances that differ from one specific dialect or language variant should be treated as errors. They can be mere variations of a specific item, or they can be purposeful deviant utterances. The scope here of EA is much wider, and considers the authoritativeness of specific varieties of the language over others in the internal analysis of English. From our point of view, to state that EA only studies error is an oversimplification.

EA studies range from examination of the correct evolution and formation of utterances in English for the English-speaking communities, including errors due to ignorance and errors due to the manipulation of language, to standards and deviations or issues such as the study of English at schools in England. For instance EA scholars question to what extent social dialects should be respected if at all. Are these deviated uses or are the variations they include a part of the language? Should all students learn the same standard language at school? Should they be allowed to maintain and use their home languages?

Referring back to the origins of the theory, James (1998:1) defined language error as an "unsuccessful bit of language". From this, he derived that "Error Analysis is the process of determining the incidence, nature, causes and consequences of unsuccessful language" (James, 1998:1). If we were to take these words as the starting point for our particular research, it would be necessary to define or to decide upon 
that which is unsuccessful, and those utterances would qualify as being deviant, the term applied to these by many authors.

In 1967 EA was launched by Corder as a research analysis model related to the acquisition of a second language with his article "The Significance of Learners' Errors". Rejecting structuralism, Corder took as reference Chomsky's (1959) theory about mankind's innate ability to learn a language, which, in turn, refuted Skinner's -behaviouristtheory. Thus, following Chomsky, Corder assumed that language is learnt from generalisations about the structure of the target language based on the information available to the learner. This implied both a change in the learning theory and a modification in the way errors were examined, which became the centre of his work. The theory shifted the focus of interest to the $\mathrm{TL}$, or rather, the Interlanguage produced by the learner in his or her process of acquiring a new language. In particular, interest was placed on the learner's misunderstandings or misinterpretations. Attention was paid to the user, who, for some reason, had been unable to use the proper generalisation process, thus producing an erroneous utterance. Whereas some linguists approached EA as a mere complement to $\mathrm{CA}$, others considered that it was crucial for foreign language teaching, since it had a clear influence on the process of learning regardless of the field of knowledge: learners learn from their errors, as Dulay and Burt (1974:109) explain:

Language learning proceeds by the learner's exercise of those processing strategies in the form of linguistic rules which he gradually adjusts as he organizes more and more of the particular language he hears. 
In addition to this, EA studies the need to somehow consolidate English language since it is open to much influence due to many users, most of whom are NNES speakers (indeed, $80 \%$ of all communication events in English are carried out by NNS, according to Montalt, 2005:47). How many of those idiosyncrasies should be included in the general use of the language? How many can the language endure? Should language change only be considered in diachronic studies or historical linguistics in the so-called older Englishes, or else include variations occurring in the Outer Circle Englishes (the English of the colonies)?

Another aspect of this revision of authoritativeness is the representation of power in the use of language, specifically, the extent to which this is reflected in the communicative event. How much authority does nativeness assign to adequacy in the use of the language? Will native English always be considered as the sole standard model for an utterance?

These considerations lead us to the main focus of concern during these stages in the development of the theory. This is the significance and relevance of the $\mathrm{MT}$ in the acquisition of the second (third or subsequent) languages which was considered to be the point of departure in a process where the final outcome would never be free from the influence of the first linguistic knowledge.

James (1998:3) pointed out that "language teaching calls for the description of the language to be learnt, the FL", implying that the appropriate correct form of the foreign language should be defined and limited. However, according to the very author, language learning is 
studied as a process, once the TL has been described, the focus should shift to the learner's perspective, to how the new user perceives and uses the language being acquired. As is well known, this is what Selinker called interlanguage (IT), which Corder referred to as idiosyncratic dialect. Corder also studied learner performance and the result of that individual learning process, and called this performance analysis, which included not only error, but also correct utterances produced by the new language user. In short, both correct and incorrect utterances constituted the learner's performance.

As stated, Selinker (1972) coined the term interlanguage to refer to the systematic knowledge of an L2 independent of both the learner's L1 and the target language. Other terms that refer to the same basic idea are approximative system (Nemser, 1971) and transitional competence (Corder, 1967). Interlanguage is used with different but related meanings (Ellis, 1994:710):

(1) To refer to the series of interlocking systems which characterise acquisition,

(2) To refer to the system that is observed at a single stage of development (an interlanguage), and

(3) To refer to particular L1/L2 combinations (for example, L1 French/L2 English v. L1 Japanese/L2 English).

As a result of this, and because of the roots shared with CA, the approach chosen to study the learner's interlanguage involved a comparison of the second language and the interlanguage produced by 
the learner. However, subsequently, EA also took into account the study of the MT, since this was proven to affect the production of a second language. It defends the use of comparison as an effective tool in the process of error detection; this centres not so much on the fact that languages can be compared or that errors can be predicted, but on the focal point of how errors are produced, and on identifying the inflection point where these errors occur.

In relation to this, according to James (1998), it should be acknowledged that in the FL learning operation there is at least one more language involved: the learner's MT. Unquestionably, it is here that the MT plays a crucial role in the learning process. This also refers to any other language the user may be familiar with prior to learning the language under study and includes all linguistic skills and knowledge the user has before confronting the new learning process. This is what James calls prior linguistic knowledge.

In the previous years, Jain (1974:190) proposed the notion of independency of errors, implying that errors are not necessarily linked to the mother tongue. He points to age, learning strategies, degree of instruction, teaching techniques or the sociolinguistic circumstance of the student as key factors affecting production in a second language.

Further to this, Richards (1974) prefers to deal with errors that cannot be explained following a comparison between two languages because they belong to another category. He mentions other types of errors not necessarily due to external (extra-linguistic) factors, such as intralingual errors, derived from basic learning principles, generalisation, analogy or 
the incomplete application of rules, as well as developmental errors, which are those incorrect assumptions the learners make about the target language. In Richards' words (1974:173):

\footnotetext{
Rather than reflecting the learner's inability to separate two languages, intralingual and developmental errors reflect the learner's competence at a particular stage, and illustrate some of the general characteristics of language acquisition.
}

Richards' view presents a major change with regards the consideration of error, which justified the scope of CA. On the one hand, it does not consider all contact between languages as negative transference, since this implies the possible conveyance of old strategies to new situations (languages). On the other, the new model removes the systematic comparison of languages as the sole means of analysis and introduces, as Richards mentions, the idea that errors are evidence of the learning process, necessary for progress to occur.

As previously stated, error is a clear indication of the point in the learning process where the student stands, but it can also reveal how the teaching practice is being accomplished, and the steps taken in the learning and teaching process. Corder (1981) pointed out the importance of errors not only as negative inputs or as unsuccessful pieces of language, but also as significant pieces of information, which can help in the understanding of the learning process; i.e. the different stages the learner must go through to reach proficiency in a language. He refers to two different schools of thought, one, which considers error as proof of an incorrect teaching methodology, and the other which 
states that "we live in an imperfect world and consequently errors will always occur in spite of our best efforts" (Corder, 1967:163), errors will always appear and will always have to be corrected.

Mindful of this, Corder (1967) also introduced other major concepts in his article "The significance of learners' errors", in which the focus was shifted to the learner, both from the point of view of the materials (syllabuses) elaborated either by teachers or by linguists to encourage the learning process, and from that of effective progress in language learning. Thus, according to Corder (1967:165), the learner determines what input is, regardless of the aim or proposal of the teachers:

The simple fact of presenting a certain linguistic form to a learner in the classroom does not necessarily qualify it for the status of input, for the reason that input is "what goes in" not what is available for going in $[\ldots]$ is the learner who controls this input.

The direct implication of this is that syllabuses should be prepared with the student's needs in mind, and not the interests of the teacher or linguist: "we may learn to adapt ourselves to his needs rather than impose upon him our preconceptions of how he ought to learn, what he ought to learn and when he ought to learn it" (Corder, 1967:27). Corder also comments on Mager's concept of the learner's built-in syllabus (1961), which is a sequencing of the learner's own, believed to be possibly more efficient than a teacher-generated sequence. The evidence of this type of personal syllabus would be found in the systematic nature of errors, which Corder utilises to justify the difference between mistakes and errors (only possible in second language learning), establishing that "errors reveal the underlying knowledge of 
the language to date [...] the transitional competence of the learner at a specific moment in the learning process" (Corder, 1967:166).

This idea is of particular interest for our work since, as Richards reformulating Corder states, (1974:24) "errors of performance [mistakes] will characteristically be unsystematic and the errors of competence, systematic". What Corder was implying is that, by being aware of the type of errors a learner produces we can pinpoint the stage the learner has reached in his or her language learning process. Thus, the importance of errors is threefold (Corder, 1981):

(1) Firstly, for the teacher because they tell him how closer to the goal the learner has advanced;

(2) For the researcher, in that they provide evidence of how language is learned or acquired, and what strategies or procedures the learner is employing in his discovery of the language;

(3) And finally for the learner: he or she can learn from their mistakes.

In this sense, when it comes to error correction, Corder's suggestion is based on Carroll's proposal (1955) that the learner should not automatically be given the form needed to correct the error made, but be directed towards finding it for himself. In addition, while errors can be considered evidence of the learner's strategies for learning, it cannot be assumed that all correct utterances imply an appropriate understanding of the language and the capacity for language generation. In some cases, this is simply the result of mere repetition. 
Based on the same idea as CA with regard to the similarity and dissimilarity of languages, and the usefulness of comparison to help in the language learning process, Corder's conviction that the learner gains proficiency in a language by comparing old and new language knowledge is noteworthy $(1967: 168)$ :

[...] the task of the second language learner is a simpler one: that the only hypotheses he needs to test are: "Are the systems of the new language the same or different from those of the language I know? And if different, what is their nature?

Other scholars preferred the use of the term dialect to the term interlanguage when referring to the study of errors made by second language learners in their linguistic system, to the area in-between the native language and the target language. Indeed, some scholars, such as Jain (1974:202-203), highlighted the existence of an internal coherence among errors, advocating an in-built coherence and logic in the errors produced by learners:

Errors [...] show a consistent system, are internally principled and free from arbitrariness: they are therefore systematic. These systematic errors may be looked upon as rule-governed for they follow the rules of whatever grammar the learner has.

This statement is based on two considerations (Corder, 1971:158):

(1) Firstly that the spontaneous discourse of the learner is systematic, (rule governed),

(2) Secondly, this coincides to certain degree with the target language, hence the term dialect. 
Corder also talks about other types of dialects, which in this case are not internal integral parts of the learning process, but specific to a language, existing within it. It is interesting to point out that he attaches the same status to these dialects, whether internal to the learning process, or established in the language itself. Among these can be mentioned social dialects (linked to a social group), or idiosyncratic dialects, those that refer to child talk, poetry, or learners' language (Corder, 1971:161):

\begin{abstract}
It is regular, systematic, meaningful, i.e. it has a grammar, and is, in principle, describable in terms of a set of rules, some sub-set of which is a sub-set of the rules of the target social dialect. His dialect is unstable [...] not shared by a social group [...] and lastly, many of its sentences present problems of interpretation.
\end{abstract}

The language learning process was described as an individual evolution through various stages, involving the construction of a personal interlanguage, evidence of this dynamic process, and a transitional competence. Specifically, Corder proposed as a rule for EA that every learner sentence should be considered to be idiosyncratic until proven otherwise. Based on this, he established the belief that learners' dialects were personal constructs and processes, and that while it may be true to say that certain tendencies are typical of certain learners from the same linguistic background, it cannot be true to state that all learners from that background will have such tendencies. As noted by Kohn (1986:23):

[...] for the analysis of (inter)language processes, group knowledge is of absolutely no importance. It is the learner's own autonomous and functional knowledge and his own certainty or uncertainty which determines his interlanguage behaviour. 
At the beginning of the 1980s, Corder redirected the objective of EA towards an assessment of the global competence of the student, (both grammatical and communicative). In the original version, EA (Santos Gargallo 1993:87):

[...] recopilaba datos para ofrecer listados de errores que clasificaba haciendo uso de taxonomías gramaticales con el objetivo de analizar y medir la competencia gramatical del estudiante y su habilidad para producir instancias correctas desde el punto de vista de la norma lingüística.

To review this, Corder (1980) proposed a type of language analysis that could also include the correct instances produced by the students, and which would offer information about their communicative competence. This, in short, implied the inclusion of correct utterances capable of offering information about the communicative competence of the user. Other criteria were then necessary in order to evaluate the type of error. In the case of English as a foreign language, Byram's Incompleteness hypothesis (1988:17) should not be overlooked. This author highlights "the unattainable ideal of the native speaker"; that is, he explains that very rarely does a student of English as a foreign language master the use of the language in the same way as a native speaker. Consequently, regardless of the level of knowledge and use, some errors will persist, and this needs to be analysed.

Enkvist (in Santos Gargallo, 1993:88-89) proposed three criteria in the assessment of errors: correct utterances had to meet the requirements of:

(1) Grammaticality, (coinciding with the grammar of the language), 
(2) Acceptability (suitable for expressing the speaker's value judgement),

(3) Adequacy (capable of transmitting the desired meaning in a particular context).

Other linguists have added the effect on the listener, and have included intelligibility (can the message be understood), and comprehensibility (can the message be understood by the listener). Any deviation from these results in error.

James (1998) dedicated a significant part of his work to the definition, identification and classification of errors. In his studies, he did this both for English for second language users, and for English for first language users. He first referred to ignorance as the cause of errors made by second language users, which he always analysed by comparing the production of L2 speakers to that of L1 speakers, and not to the ideal standard language. He rated all errors according to the degree of deviance they represented, and distinguished four categories in ignorance representations by the learner: grammaticality, acceptability, correctness, strangeness and infelicity. For James, grammaticality is synonymous with well-formedness, and leaves no room for questioning (1998:65):

Appeal to grammaticality is an attempt to be objective, to take decisions such as whether some bit of language is erroneous or not out of the orbit of human whim. So, if we can point to a bit of language and say that there are no circumstances where this could ever be said in this way, we are dealing with ungrammaticality. 
Contrary to this, acceptability is a practical notion, and not a theoretical one. "When non-linguistic factors militate against the use of a form, we attribute this to unacceptability" (James, 1998:66).

\subsubsection{Present and future trends}

More recent trends in the study of error consider linguistic background as crucial to the understanding of error. As explained by Hamilton (2001), in order to deal with error in an appropriate and efficient manner, it must be put into context, and it must take into account the abilities of the learners and listeners. Learners must prove able to communicate, whereas listeners must be capable of listening and understanding. These capabilities provide a background for understanding the communication act (Hamilton, 2001:86):

\footnotetext{
On the one hand, they highlight the way in which people can manage the most complex social interactions, even in the face of formidable linguistic and cultural obstacles. On the other, they show an essential human capacity for placing oneself in another's shoes.
}

This new approach to error as part of the communication process concurs with the new methods in second language acquisition, in particular the communicative approach, which is learner-centred, and proposes the creation of customised curricula, focusing on the actual needs of the speakers. Due to this, the strategies used by the students to solve what they consider to be an error in their attempt to communicate are examined in the analysis of errors, that is, their actual 
learner self-perception. Often, learners try to communicate using approaches that help them say what they want to say using nonstandard means. Olsen (1999:193) has described this:

[...] there are two main types of strategies used by learners: achievement strategies and avoidance strategies. In the first case the learners produce language by using alternatives for the words or structures that they do not know, whereas the second type involves reducing the original message by leaving out what is problematic.

The study of error is now focused on very specific aspects. For instance, several studies have been dedicated to the study of lexical errors, which are based on the conviction that grammar structures are the most difficult aspects to be correctly reproduced in a second language (Al-Jarf, 2000; Carrió \& Seiz, 2000; Levinson, Lessard \& Walter, 2000; Carrió, 2004; Carrió, 2009b; Carrió \& Mestre, 2010). Apart from acknowledging that the study of lexical errors is particularly prolific in the analysis of SLA, they agree that error no longer needs to be regarded as a negative aspect, but on the contrary (Carrió, 2004:27):

Como consecuencia, el análisis e interpretación de los distintos errores que se cometen en una producción ha de contemplar el error no como un fenómeno indeseable en la lengua, sino como una fuente de información que ayuda a mejorar el aprendizaje y producción de una L2 como han demostrado Webber (1993); Connor (1996); James (1998) o Yates y Kenkel (2002).

Other perspectives that are currently being explored include EA in combination with complementary disciplines which can offer different standpoints for the study. To give an example, this applies to the present dissertation which puts forward the analysis of errors under the 
framework of Pragmatics. A similar study was carried out by Wang (2007), when he proposed to study pragmatic errors from an EA viewpoint, using the work of Leech and Grice to qualify this (Wang, 2007:42). He stressed the fact that student's instruction is mainly focused on grammar, and that this leads them to incur errors that can be considered to be pragmatic:

Their focus in English learning has been directed toward grammar rather than the actual use of the language. Over a long period of time, emphasis in English writing has been laid only on linguistic accuracy and structure while pragmatic pertinence has been lamentably ignored.

Indeed, much SLA classroom work has been based on grammar for many years, as is explained later on. Then, other linguistic aspects were introduced in the language learning syllabus.

\subsubsection{Types of errors}

What we consider to be error depends greatly on what we focus when describing error. Perhaps our interest rests on the well-formedness of the structures we use; perhaps it rests on the pronunciation, or maybe on the topic of conversation. In any case, if we wish to establish the sources of error, and the ways in which they are produced, it is necessary that we also take a look at the types of errors we encounter, and try to identify in which ways these are similar and in which ways they differ. With regard to this, James (1998:95) insists that the system used for the description of learner errors should be characterised firstly, as 
well developed and highly elaborated, and secondly, as simple, selfexplanatory and easily learnable. Providing that we are governed by this rule, we can analyse error in language from different perspectives, allowing us to focus on whatever issue is central to our interest, and on whatever linguistic approach is better suited for that purpose. Many are the methods, the views and the approaches used, but in this dissertation focus is set on James' taxonomy, language transfer and grammatical and pragmatic errors.

\subsubsection{James' taxonomy}

As far as the analysis itself is concerned, EA has helped in the understanding of error not as merely an unwanted phenomenon in language, but as a source of information which can help improve learning and production in L2. Errors detected in written texts facilitate knowledge of written production and help us to understand the mechanisms that the speaker of a foreign language adopts. As a result, by interpreting these error patterns, several strategies can be designed to improve written production in an L2 and several aspects should be considered when analysing errors.

Burt and Kiparsky (1972:8), for example, categorised errors depending on the consequences these errors would have on the on-going learning process, "what the person who says them has to learn about English". To give some examples, other approaches to errors have involved compiling lists, and elaborating dictionaries of errors (Fitikides, 1936; Alexander, 
1994; Turton, 1995), and dictionaries of false friends (Hill, 1982; Holmes \& Ramos, 1993; Kirk-Greene, 1992).

Some years later, after taking all this into consideration, Dulay, Burt and Krashen (1982:145) described four error taxonomies. The first two taxonomies "classify errors according to some observable surface feature of the error itself, without reference to its underlying cause or source" and were included within the same group. These were labelled descriptive taxonomies, and include the Linguistic Category Classification and the Surface Structure Taxonomy. Here the classification of errors is carried out depending on the language component or the linguistic constituent (or both), which were affected by the error. This would involve errors related to phonology, syntax and morphology, semantics and lexicon, and finally discourse (Dulay et al., 1982:146). The linguistic category is often used in combination with some other taxonomy for research and is also useful for organising the collected data. Taking this rationale, the surface strategy taxonomy deals with errors related to omissions, additions, misformations (illformations), or misorderings (word or sentence disordering).

The first important aspect of EA is identification. The correct identification of errors helps to define whether these have arisen due to cognitive, linguistic or socio-communicative lapses. Many studies concerning error have focused on the nature and classification of error (Lado, 1957; James, 1998; Ellis, 1985; 1994), but very few have analysed the ability to identify and interpret error in a second language (Rifkin \& Roberts, 1995; Carrió, 2004; 2005a; Hamid, 2007). 
The second important aspect of EA is that errors produced in a second language are a result of different causes. According to James, depending on the reason for these, errors fall into two main categories (James, 1998; Larsen-Freeman \& Long, 1992):

(1) Interlingual errors, which are due to first language interference upon the second (learnt) language.

(2) Intralingual errors, which are produced regardless of the mother tongue and are due to a deficiency in the learning process.

The third important aspect in EA is error classification. Lexical errors have traditionally been catalogued according to formal aspects of vocabulary or to semantic aspects related to meaning. The formal classification of lexical errors (James 1998:145) encompasses:

(1) Misselection (wrong word choice).

(2) Misformation (words that are non-existent in the L2 but exist in L1).

(3) Distortion (words that are non-existent in both the L2 and the L1).

Concerning the semantic errors in lexis, there are two main types: confusion of sense relations (a word being used in contexts where a similar word should be used) and collocational errors (the choice of a word to accompany another is inappropriate).

Figure 5 illustrates James' 1998 categorisation of errors depending on the level of language in which they are produced: 


\begin{tabular}{|c|c|c|}
\hline & Errors in encoding in speaking (Mispronunciations) & \\
\hline 2. & Errors in encoding in writing (Misspellings) & $\begin{array}{l}\text { SUBSTANCE } \\
\text { ERRORS }\end{array}$ \\
\hline 3. & Errors in decoding in hearing (Misperceptions) & \\
\hline 4. & Errors in decoding in reading (Miscues) & \\
\hline 5. & Errors in composing spoken text (Misspeaking) & \\
\hline 6. & Errors in composing written text (Miswriting) & TEXT \\
\hline & & ERRORS \\
\hline 7. & Errors in understanding spoken text (Mishearing) & \\
\hline 8. & Errors in understanding written text (Misreading) & \\
\hline 9. & Errors in formulating spoken discourse (Misrepresenting) & \\
\hline 10. & Errors in formulating written discourse (Miscomposing) & DISCOURSE \\
\hline & & \\
\hline 12 . & Errors in processing Written discourse (Misinterpretation) & \\
\hline
\end{tabular}

Figure 5. Levels of error (James, 1998:130).

Apart from these superficial errors that affect the surface of the message, two other taxonomies were considered; the Comparative Taxonomy and the Communicative Effect Taxonomy, which deal with error causes and error gravities. Thus, the Comparative Taxonomy classifies errors produced in an L2 by comparing these structures to those produced by children at the various stages of acquiring a language as their L1. Two main error categories are dealt with in this taxonomy: (1) developmental errors, and (2) interlingual errors. Also included are (3) ambiguous errors, and (4) the grab bag category of other errors (Dulay et al., 1982:163-164).

Finally, the Communicative Effect Taxonomy is concerned with the effect of errors on the interlocutor. These "errors that affect the overall organization of the sentence hinder successful communication, while 
errors that affect a single element of the sentence usually do not hinder communication". The former are referred to as global errors and the latter as local errors (Dulay et al., 1982:189).

The tools provided by EA and CA have mainly been used to analyse the development of written and spoken language use in a second language in terms of sentence level grammatical accuracy (Corder, 1967; James, 1980). In this context, Corder (1988:273) had proposed that errors inform the teacher about the progression of the learners, provide researchers with evidence, and serve as feedback for the learners. Other developments have broadened this approach. Archibald (1994) examines errors that affect the discourse structure of students' writing. Since our interest lies in error from the point of view of language in use, we hereby focus on the last block of errors - those produced at the discourse level. According to James himself (1998:161), these errors are produced in the realm of discourse and pragmatics (James' emphasis).

Within discourse errors, James distinguishes between production errors (coherence and pragmatic errors), and receptive errors. Within errors related to coherence is for instance topical coherence, which refers to the "need for the components of a discourse to be relevant to its general topic" (James, 1998:162), whereas relational coherence refers to the "requirement for the propositions constituting a discourse to be related to each other", (James, 1998:162). Finally, sequential coherence refers to the "need for constitutive propositions to be arranged in some effective order", (James, 1998:162). This can apply to foreign language 
users, who may produce utterances that would have never been selected by native speakers. This is what Austin (1962) referred to in his Speech Act Theory as infelicities ${ }^{5}$.

James considers two types of pragmatic errors at the level of discourse. The first one is referred to as pragmalinguistic deviations. They refer to errors not only in language, but also in the knowledge available of externally related factors. In his words (James, 1998:164): “Unlike text errors, they arise whenever speakers misencode [...] a message, not to the detriment of its meaning but to the detriment of its pragmatic force" (James' emphasis).

The second group included in this are sociopragmatic failures, which comprise errors due to cultural conflicts, which: "[...] result from cultureclashes, from cultural differences of view concerning what is appropriate social (and sociolinguistic) behaviour in certain settings" (James, 1998:165).

James distinguishes between taboos (topics off-limit), differences in imposition sizes (how much can be expected or asked of the interlocutor), values (how truthful are the utterances likely to be and what degree of deviation can be deemed acceptable), appropriate power and social distance.

\footnotetext{
5 In his How to do things with words (1962), Austin explains that statements uttered in the wrong context must be considered infelicitous. This erroneous context can arise due to many reasons; the convention for the utterance must be a common one, all participants must execute the procedure correctly, completely and truly, and the persons involved must conduct themselves accordingly afterward.
} 
Other approaches are related to the learning strategies used by the learner to acquire language. Indeed, Selinker (1972) referred to overgeneralisation and simplification as pervasive learning strategies. Richards (1974), in support of this, talked about overgeneralisation, ignorance of rule restriction, incomplete rule application and hypothesizing false concepts as learning strategies.

Following on from James' initial proposals and a consideration of his premises, there have been multiple suggestions for EA. For instance, as can be seen in Figure 6 below, Carrió (2005a) incorporated Bachman's classification of errors into her own analysis, and expanded certain aspects of it. Bachman's classification can be observed in black, while those particular aspects that were considered in Carriós investigation appear in blue in the Figure. These relate to errors found in academic writing, specifically in scientific papers.

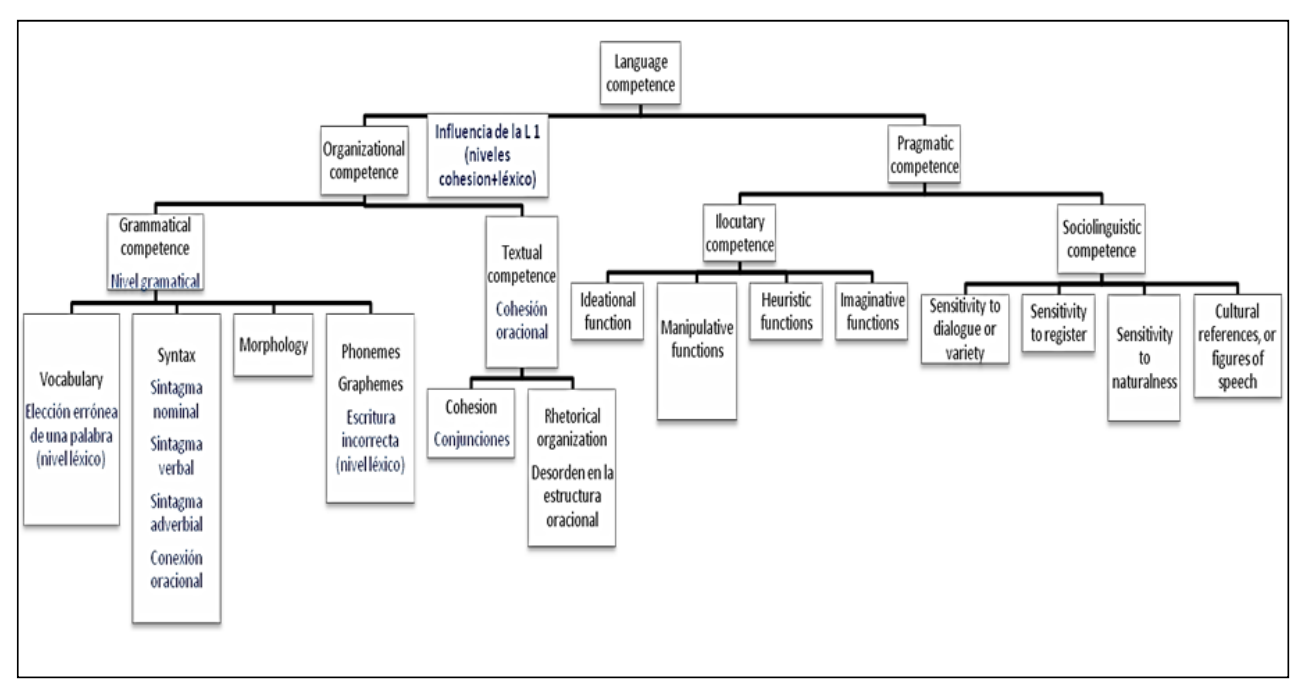

Figure 6. Carrió’s classification of errors, based on Bachman (2005a). 
Taking Bachman's initial division between the organisational and the pragmatic competences, Carrió centres her analysis on the first group, and aims to analyse L1 influence on cohesion and lexicon, while taking into account both the grammatical competence and the textual competence.

\subsubsection{Language transfer}

Depending on how rooted errors are, they can also be classified if we consider the reasons behind them. In the case of students learning a second language, the first cause of error to be pointed out is the interference of the Mother Tongue (MT) on the target language. Broadly speaking, there is reference to errors due to MT interference on the L2.

Several approaches have been expounded in the literature to study the possible influences between languages in contact. In connection with this we must recall Martinet's words when he defined interference in terms of languages in contact; "L'interférence se manifeste sur tous les plans des langues en contact et à tous les degrés" (Martinet, 1996:171).

Traditionally, the most widely studied errors in L2 production are those related to the comparison between languages, and analysed from this point of view. Webber (1993) states that the most common causes of error in non-native English speakers (NNES) are to be found in lexicon and arise due to L1 interference. 
Initially, error was merely considered to be a deviation from the norm, and thus interpreted as a language representation which required correction. For instance, the behaviourist approach considered that transfer between the first and the second language would always exist, and that this would always be negative as a result of old habits obstructing the formation of new habits. This, in fact, is the root of behaviourism: to connect actions and reactions in sociolinguistic processes. This tenet would justify the reasoning that in order to attain a new system (a new language), the first should be removed. This would be impossible in the case of L1 and L2. These theories claimed that any influence of L1 on L2 was negative and had to be eliminated, as explained by Ellis (1985:20):

\begin{abstract}
Up to the end of the 1960s, views of language learning were derived from a theory of learning in general [...] two key notions can be identified in these discussions: "habits" and "errors". Behaviourist psychology set out to explain behaviour by observing the responses that took place when particular stimuli were present... The association of a particular response with a particular stimulus constituted a habit.
\end{abstract}

Richards had referred to these types of errors as interferences, which had negative connotations, implying that the MT would unavoidably hamper the correct use of the L2. Additionally, he (1971:214) claimed that the learning process itself had an influence on the results obtained when attempting to master the L2:

Interference from the mother tongue is clearly a major source of difficulty in second language learning, and contrastive analysis has proved valuable in locating areas of interlanguage interference. Many errors, however, derive from the strategies employed by the learner in language acquisition, and from the mutual interference of items within 
the target language. These cannot be accounted for by contrastive analysis. Teaching techniques and procedures should take account of the structural and developmental conflicts that can come about in language learning.

Without a doubt, from the very beginning, EA and CA had set out to spot, analyse and theoretically predict errors that could be attributed to MT influence in specific areas. Subsequently, other views pointed to the possibility of looking at MT transfer in a different light, and although it was considered to be one of the factors which most influence learning and production in a second language, this did not necessarily present only negative interpretations (Odlin, 1989:25):

\footnotetext{
The behaviorist notion of transfer is quite different from the notion of native language influence [...] For one thing, the behaviorist notion of transfer often implies the extinction of earlier habits, whereas the acquisition of a second language need not [...] lead to any replacement of the learner's primary language.
}

The idea that an L1 is always a negative influence on an L2 has been reviewed by several authors (Ellis, 1985; Odlin, 1989), who consider it too pessimistic to use it as a working principle. There is a certain degree of consensus surrounding the fact that there exists a movement or translation of elements between different languages used by the same individual.

However, agreement is not reached on qualifying this phenomenon in terms of positive or negative influences. In some cases, this is considered to represent an advantage for the L2 over the L1 learner, whereas in other instances this is actually seen as a problem, resulting in difficulty in language learning. Odlin (1989:26) has highlighted the 
fact that interference has always been studied with reference to the negative meaning of transfer between two languages. In contrast, they argue that in some cases this may not necessarily be so, and that there could be a positive influence derived from the command of a given language (for instance in the case of language, context or cultural proximity). This should lead to a change in the term used, since, as stated by Odlin (1989:26), this has connotations that precede any possible analysis to decide whether any influence is positive or negative:

\begin{abstract}
Native speakers of Spanish have a tremendous advantage over native speakers of Arabic in the acquisition of English vocabulary [...]. The term interference implies no more than what another term, negative transfer, does, but there is an advantage in using the latter term, since it can be contrasted with positive transfer, which is the facilitating influence of cognate vocabulary or any other similarities between the native and target languages.
\end{abstract}

Thus, although interference is a term used by other schools (contrastive analysis, error analysis, etc.), which may not consider it to be necessarily problematic in the learning process, the negative behaviourist meaning prevails. In an attempt to avoid this perception, advocating the use of the term transfer instead of interference, some scholars state that transfer includes some aspects that interference omits (Odlin, 1989:26):

Transfer is not simply interference. With or without any behaviorist connotations, the notion of interference does seem applicable in the description of some aspects of second language performance, such as phonetic inaccuracies [...]. Nevertheless, much of the influence of the native language [...] can be very helpful, especially when the differences between two languages are relatively few. 
Nevertheless, as on many other occasions the terminology used to study a language reflects problems, and in the terminology of second language research, as in many other disciplines and specific aspects of study, the term transfer is as problematic as any. What is apparent throughout this discussion is that the starting point of the second language learner is completely different to that of the first language learner, or even the bilingual speaker. In any case, in the study of Second Language Acquisition (SLA), transfer is mainly considered as one of the factors that most influence its learning and production.

In the case of bilingual speakers, some scholars as, for instance, Fehringer and Fry (2007:45) are convinced that there is greater hesitation in L2 due to interference from the mother tongue, even when taking into account that hesitation exists in both languages. In this, they coincide with the authors claiming L1 negative interference in L2 production:

Thus, it is hypothesised that a speaker's performance in L2 should exhibit a slightly greater rate of hesitation phenomena than that shown in the mother tongue, as he/she will need to buy a little more processing time in L2 than in L1.

Backer and Hansen Bricker (2010:75) coincide on this negative interference, pointing out that not only language structures can be transferred from L1 to L2, but also what they call issues. By this they imply that learners may be unsure of certain aspects of their L1 and subsequently transfer these to the L2: 
Second language (L2) writers especially need written feedback because they often have issues not only with native language (L1) interference but also an incomplete understanding of their L2 (Ferris 2002; Hyland and Hyland 2001; Matsuda et al. 2006; Thonus 1999).

Other types of negative interferences are mentioned by Xie and Jiang (2007:11) when revealing the importance of cross-linguistic cultural interference, which, according to them, is crucial in producing the correct utterance and understanding: "Cultural interference can cause either linguistic errors or inappropriateness in the context. In addition, it sometimes hinders communication, so it should be taken seriously". This is closely connected with the category of errors of interest in this study, Pragmalinguistic and Sociopragmatic errors in L2 production, as will be seen in the results chapter.

\subsubsection{Grammatical errors}

Among the many aspects studied in the teaching and learning of the second language, grammatical errors produced by students have been a central theme in the structuralist theory for many years. Nowadays, this might seem a little outdated, but that is not the case. In actual fact, grammar is still considered to be crucial in the teaching of language, being complementary to other teaching approaches. Some immersion studies (Swain, 1985; Lightbown, 1992; Lyster, 1998) have shown that "comprehension of meaning and content by itself [...] does not necessarily culminate in a native-like grammar".

Some authors insist on the importance of grammar in the learning process, which the new communicative approaches have seen relegated 
to second and third places. Terrell (1991) insists that one of the main components of communicative competence is the grammatical component, and that this risks being overlooked in the new teaching methodologies. Regarding this, Rutherford and Sharwood-Smith (1988) argue that attention to grammar has an influence in the acquisition process. These authors support the creation of what they call grammatical awareness raising, in both the inductive and deductive approaches. The importance of this approach is that it highlights the need for students to recognise grammatical structures and, eventually, errors in order for them to be capable of reproducing the former and correcting the latter.

Several studies focus on certain specific grammatical aspects to analyse production in a second language. For instance, Carrió (2004) analyses vocabulary, syntax, phonemes and grammar in her corpus. Some of her conclusions have led her to affirm this (Carrió, 2004:24):

Varios autores (Al-Jarf, 2000; Levinson, Lessard y Walter, 2000; Carrió y Seiz, 2000) han determinado que existe una clara dificultad en la producción adecuada de las estructuras gramaticales de una segunda lengua, ya que este tipo de error es el más frecuente.

It is now common to make use of support software for these analyses. Indeed, there exist many programmes that help in the analysis of one particular item in a corpus. With regard to grammatical errors written by students of English, Gaskell and Cobb (2004) propose the use of software to establish concordances for error analysis and correction, since in Cobb's opinion (1997) "concordancing was an underresearched tool for second language learning". However, after having 
examined errors produced by students, and having marked these errors in the texts analysed, the authors argue that there was a lack of presentable information regarding: (1) whether any learners could actually learn anything from concordances; (2) whether any apart from very advanced learners could even use concordances at all; and (3) whether task specification or interface modification might facilitate use among intermediate learners.

To solve this, other studies, such as Cobb and Horst's (2004:303), included larger and wider corpora. These are concerned with the fact that learners may not be able to understand and analyse, and more importantly, correct their errors from the input received: “[...] while concordances for lexical and even collocational information are quite easy for learners to interpret and for instructors to set up [...], grammatical concordances may be less so". This implies that the spotting a grammatical problem does not necessarily lead to the identification of the underlying cause.

Due to the fact that learners have gone through the process of learning the grammar of their first language, Gaskell and Cobb (2004) state that L2 grammar is learned the same way L1 grammar, through practice in matching meanings and situations to the corresponding words and structures, an aspect previously pointed out by Ellis (2002). The approach supported by Gaskell and Cobb (2004) claims that examplebased acquisition theory can be useful if the following requirements are carried out: 
(1) Vastly increase the number of examples [...],

(2) Organise these samples so their patterns are highlighted,

(3) Get learners to attend to the examples, and

(4) Give systematic feedback on the success of interpreting the examples.

However, caution is expressed when considering the correlation between an increase in understanding and an increase in grammar.

This is in line with Reid's conviction that errors in writing reveal the students' underlying problems, suggesting several basic causes of errors (Reid, 1998:122-123):

(1) First language interference.

(2) Overgeneralisation of English language rules.

(3) High level of difficulty of the language structure.

(4) Production errors (mistakes).

In 1996, Truscott took a very radical stance against the focus on grammatical errors and advocated in favour of the rejection of grammar correction in the L2 writing classroom. Truscott's thesis (1996:328) centred on his argument that grammar correction is both ineffective and harmful and therefore has no place in the classroom:

[...] grammar correction has no place in writing courses and should be abandoned. The reasons are: (a) Research evidence shows that grammar correction is ineffective; (b) this lack of effectiveness is exactly what should be expected, given the nature of the correction process and the nature of language learning; (c) grammar correction has significant harmful effects; and (d) the various arguments offered for continuing it all lack merit. 
Although this is considered extreme, it has helped diminish the importance assigned to grammar in communication in an L2. At least, there is greater scepticism as to the actual effectiveness of error corrections (Yates \& Kenkel, 2002).

Indeed, the newer approaches to ESL teaching promote greater focus on communication and less on grammatical issues (correctness). This has shifted the focus of interest from grammar to other linguistic aspects of communication. For instance, some authors have studied the relationship between grammar and Pragmatics. They have approached this matter from different perspectives. Different groups of theories are established depending on the way in which they interpret this relationship between grammar and pragmatics. To give an example, Németh and Bibok (2010) arrange these approaches into four categories. The first group considers that grammar and pragmatics are not separate from each other. Subsequently, all issues usually studied under the scope of Pragmatics are considered to come under the remit of grammar. Holistic cognitive grammars (Rumelhart \& McClelland, 1986) or functional grammars (García Velasco \& Portero Muñoz, 2002) would fall under this category. The second group considers Pragmatics to be a functional perspective, and not an additional component of a theory language (Mey, 1993; Verschueren, 1999). For them, Pragmatics affects all levels of language and looks at linguistic phenomena at any level depending on the causes and effects of the linguistic choices made by communicators. A third group would include Pragmatics as a component of grammar. For instance Levinson's theory (2000) of 
generalised conversational implicatures, relating syntax and Pragmatics, belongs to this group. The fourth group of theories considers Pragmatics to be outside grammar. Here, for example, the theories of Sperber and Wilson (1995; 1997; 2002; 2004) would apply, as these authors consider Pragmatics to be a component of cognition.

Newer trends emphasise the need for students to learn about the particular errors they make. It is not only important that learners know their errors, but, quite the opposite, they also need to understand and be made aware of them, and, furthermore, the causes behind them. Gao explains this in relation to recommendations given to teachers for error correction and teaching derived from this (Gao, 2009:60):

\footnotetext{
Therefore, before the correction of actual errors, special efforts from the teacher are demanded in establishing for the learner the limitation of rule generalization. In this way, correction of actual errors will have effect and will be rewarding.

Some basic grammatical items, such as English tense, should be reviewed, not through the teacher's explanation, but through errorbased remedial program. Each assignment should be more targetoriented instead of blind practice [...].
}

From this perspective, it is crucial to expand the learner's knowledge as much as possible. Further recommendations increased attention to writing, the encouragement of learners' (grammatical error) selfdiscovery and self-correction of grammatical errors, rather than a mere listing or naming of errors. This reinforces Lee's view by stating that it is crucial for students to recognise their own errors, helping them to find these and discriminate between error and non-error. This approach will also show learners how to avoid making errors depending on the 
situation and the level of proficiency. She claims that error correction should also be learner-centred, and that teachers should work towards facilitating this error spotting and correction in the interests of the students (Lee, 1997:473):

To help error detection it is important that teachers provide error feedback to facilitate error location, and vary the degree of salience of error feedback according to the proficiency of the learners. Also, teachers need to re-consider the use of grammatical terminology in error feedback, and devise ways to bridge the gap between teachers' and students' understanding of the grammatical concepts involved. Finally, it is important that teachers determine their priorities in error correction, according to the needs and proficiency of their students.

Yates and Kenkel (2002:45) also agree that the students' views together with previous grammatical and non-grammatical knowledge should be taken into consideration, and that teachers should focus on this knowledge for their error correction in order to ensure that students understand their corrections:

[...] we are struck by how most of the received pedagogy in this second language domain remains influenced by first language pedagogy. [...] teachers must approach commenting on their students' papers from the students' perspective. This means remembering the grammatical and pragmatic knowledge which underlies the interlanguage constructions that occur in L2 learner texts.

These two authors (Yates \& Kenkel, 2002:32) centre their study on sentence-level errors. In order to explore them, they take as a starting point Leki's 1992 work, in which she explains this type of error. Even when grammar-based, there still remain some problems that can only be explained at sentence level, thus approaching more recent postulates which support discourse or pragmatic analyses. As a conclusion of her 
work, Leki classifies these potential language items including count and non-count nouns, adjectives which function as nouns, articles, noun determiner agreement, aspect markers, modals, tense sequence, verb forms and complements, adjective, adverb and noun clauses, reported speech, non-referential pronoun subjects, fragments, run-on sentences and prepositions. She offers solutions to the possible problems posed by these components (Leki, 1992:113 in Yates \& Kenkel, 2002):

\footnotetext{
Teachers who would like to help students correct sentence-level errors might begin to get a picture of the students' interlanguage by asking them to explain their reason for constructing a phrase or sentence as they did. Sometimes students have internalized an incorrect version of a grammar rule.
}

To all appearances, it is becoming widely accepted that focus should be extended from grammar and accuracy to include other aspects which are also consubstantial to language proficiency. Students are not only expected to know the language, but also to be aware of any possible shortcomings they may have, and to discover their needs, and the ways in which these should be confronted in order to obtain better results.

\subsubsection{Pragmatic errors}

Even though words encode information, speakers do more with words than simply inform, and even when conveying information, utterers often convey more than their words encode. Obviously, error can be analysed from a pragmatic point of view, these errors being related to either wrong use or misinterpretation. 
As explained later in this dissertation, the Speech Act Theory can help us analyse utterances that seem to contravene Gricean maxims and can also help us examine utterances from the perspective of their function, rather than their form. Bachman (1990) defined pragmatic competence as the ability to use language in socially appropriate ways, and referred to it as illocutionary competence, defining the illocutionary act as a speech act in which the words imply a different meaning from the stated one, and included several functions:

(1) The ideational function: the function of language to express one's ideas.

(2) The manipulative function: the function of language to get someone to do what you would like him/her to do,

(3) The heuristic function: the function of language to solve problems, especially using a trial-and-error method, and

(4) The imaginative function: the function of language to express imaginary ideas.

Recently, the analysis of pragmatic errors has mainly focused on oral communication. Indeed, many pragmatic studies relate errors (infelicities) to a lack of competence in the recognition and use of speech acts. With reference to this, Austin distinguished four types of errors related to performative speech acts. James (1998:76) termed these as follows:

1) A gap arises when the speaker lacks in his L2 repertoire the linguistic means for performing the desired speech act. [...] 
2) A misapplication arises when the act performed is rightly executed - but by the wrong person, or to an inappropriate addressee, or under the wrong circumstances.

3) A flaw arises when the right language is used by the right person in the appropriate setting, but the linguistic execution is imperfect. This is the situation that arises when a purely formal error has unforeseen pragmatic consequences.

4) We have a hitch when the execution of the speech act is cut short.

These types of infelicities help us identify what exactly has been misinterpreted or misused and why. They are very helpful in determining the reasons behind errors. They imply that either the user has not acquired the necessary level of proficiency in the language, or that the user is not aware of the context in which this language can be used. Another possibility is that the user chooses badly when deciding on the language to use.

Verschueren's approach (1999:69-70) to Pragmatics and language almost approximates this when he expresses that language use can be defined as the making of choices at several levels, and moments of speech. Following the previous analytical proposal, in the cases in which those choices were not correct, errors would have appeared. In particular, Verschueren (1999) mentions choices at different structure levels, strategies and forms, at different degrees of consciousness, and from options that are not equivalent (that is, transversally) in the production and interpretation of utterances. Three notions are used to explain this choice making (Verschueren, 1999:69):

(1) Variability, which "defines the range of possibility from which choices can be made". 
(2) Negotiability, which is "responsible for the fact that choices are not made mechanically.

(3) Adaptability, "which enables human beings to make negotiable linguistic choices [...] as to approach points of satisfaction for communicative needs".

All these possibilities regarding choices render language a flexible and organic object of study. Verschueren (1999:70) proposes that "the general concern for the study of linguistic Pragmatics is to understand the meaningful functioning of language as a dynamic process operating on context-structure relationships at various levels of salience."

With respect to this, information needs to be gathered as to what is the function of the different communication activities within language, seen as a progression under development, and not as a closed and finished item. In addition, language does not operate in isolation, but in relationship to contexts which award it different levels of consciousness or awareness (salience). When an utterance is analysed from a pragmatic perspective, certain issues always arise, such as the universality or the specificity of language, language variation, degree of correction, etc. We find Wang's (2007:40) account of what defines a pragmatic error useful for our work:

By pragmatic errors I mean words, expressions, sentences or even paragraphs that, though grammatically acceptable, do not fit the given situation, fail to express the intended meaning of the writer, or cause misunderstanding or displeasure of the targeted reader [...]. They violate certain principles of communication and consequently cause failure or disharmony in intercultural communication. 
Such information as knowledge of the structures and types of utterance (genres) that can be expected in communication is learnt. Indeed, in the same way speakers have a vision of what they wish to say, so too do listeners know what they can anticipate as the next step in a speech act, based on what they recognise about the structure, the context, and the meaning (Sinclair, 2006:135):

Structure thus plays two important roles in the interpretation of texts. It helps in the identification of components, and it allows the reader or listener to prospect ahead and make informed guesses about what is likely to come. So instead of the listener hearing a burst of sound and then trying to work out what it means, the listener will be halfexpecting one of a few options, and will only need to confirm which one it is. In these circumstances it is possible to interpret a sound wave which hardly contains enough information to signal its meaning.

Pragmatic studies have often focused on very specific issues concerning language use. For example, there are many studies which are related to the treatment of courtesy and politeness. In general, all these approaches identify courtesy as a (universal) phenomenon that takes its linguistic form in communicative interaction, having a relational aim and a cognitive foundation. As explained, this issue is approached from several angles, with the common objective being to demonstrate whether courtesy can be taught. Is it or is it not a social convention? Should this subject be taught in combination with language? Is it a cultural or a cross-cultural subject?

Landone (2009) lists the characteristics that identify politeness from the pragmatic point of view. She considers it: 
(1) A rational strategy to help control social aggressiveness,

(2) A solidarity principle between interlocutors,

(3) A system to mark positions and relationships,

(4) A tool to manage the interpersonal relationship in communication,

(5) The management of a conversational contract,

(6) Part of the normal system of information processing and

(7) As part of a selfish need for social appreciation.

Escandell-Vidal (1996) takes a cognitive approach to politeness. She questions the traditional proposal regarding the universality of language, and the long-established relationship between indirectness and politeness. She takes as her starting point the problem posed by the contradiction between the universality and culture-specificity of language, and in particular, politeness. Her first consideration $(1996: 633)$ is that:

[...] the claim that a basic inventory of speech acts and politeness strategies was shared by all languages was a natural consequence of the idea that both verbal interaction and politeness principles were founded on strictly rational principles [...] if languages show such a degree of variation in other crucial aspects, why should politeness be an exception?

From this, she concludes that politeness exploits general processing devices in language use as well as particular pieces of knowledge. Based on Sperber (1995), who expressed that many basic conceptual thought processes are governed by domain-specific competences, she states that "the theory of politeness will therefore be a theory of the faculty of social cognition, and will have to account for the structure and 
properties of the knowledge that governs interaction" (Escandell-Vidal, 1996:646). With this, she implies that pragmatic universals can exist as the result of the interaction of a few general principles in the particular case of each language. This suggests that some competences (related to politeness) coincide in more than one language, whereas others can be taught.

Also in relation to the possibility of learning politeness, or studying politeness as an approach to language mastery, many recent studies have been dedicated to the possibility of learning Pragmatics itself. Indeed, it is widely acknowledged that it is not an easy task for users to recognise, classify and modify pragmatic issues, not even when making correct use of the language, even for L1 users. Crandall and Basturkmen (2004:38) add that pragmatic errors are also usually very difficult to spot, because they are not necessarily associated to language.

\begin{abstract}
While native speakers are usually able to identify a grammatical error produced by a non-native speaker as a language problem, they are less likely to identify a pragmatic error as such. Instead, the non-native speaker may be seen as rude (ibid.). Possible reasons for these difficulties include the transfer of inappropriate norms or language from the learner's first language, and misconceptions about the target language.
\end{abstract}

They insist that the transfer of norms applicable to L1 (such as different understandings of the language, the world, the relationships, etc.) is one of the main causes of pragmatic errors. One of the underlying problems is that communicative activities proposed in the classroom support the practice of $\mathrm{L} 2$ production, but do not facilitate pragmatic acquisition (Erickson, 1979; Porter, 1986; Wishnoff, 2000). 


\subsection{SECOND LANGUAGE ACQUISITION (SLA)}

Second language acquisition has been studied from a wide range of perspectives. Indeed, as an area of concern for several disciplines (teaching, pedagogy, language, psychology, anthropology, or even politics), many have been the approaches aiming to understand the processes which take place inside the mind and which result in the learning of a language different than one's own. It is a much applied field of linguistics and its perspective is very broad. It studies language learning in different settings such as language acquisition in a bilingual community, or language learning in a formal setting. It also looks into the learning of subsequent languages after the second.

In an increasingly global world, language learning has become crucial for students in education and in future work prospections. Progressively, more attention has been paid to this aspect from different fields, in order to investigate the reasons that lead to success or failure in this field. This chapter is dedicated to the consideration of SLA as a crucial discipline in the understanding and explanation of errors made by students in an L2.

\subsubsection{Traditional methods}

Throughout the past two centuries, a myriad of methods have been applied for language teaching, a first group being integrated by what we now consider traditional methods. The first, most widely-known of these 
traditional approaches is the grammar-translation method. It is also called the classical method, because it is implemented following the technique used for the teaching of classical languages, and applied to modern languages. It governed language teaching for about a century from the 1840s onwards. It focuses on the grammatical, morphological and syntactic analyses of the language, and the writing and reading skills. Richards and Rodgers (2001:5-6) summarise its key features as:

1) The goal of foreign language study is to learn a language in order to read its literature or in order to benefit from the mental discipline and intellectual development [...]

2) Reading and writing are the major focus [...]

3) Vocabulary selection is based solely on the reading texts used, and words are taught through bilingual word lists, dictionary study, and memorization [...]

4) The sentence is the basic unit of teaching and language practice [...]

5) Accuracy is emphasized [...]

6) Grammar is taught deductively -that is, by presentation and study of grammar rules, which are then practiced through translation exercises [...]

7) The student's native language is the medium of instruction. It is used to explain new items and to enable comparisons.

After a long period of preponderance, and because of the new needs of society, the Reform Movement set out to review this approach to the study of a foreign language. This group of linguists, led by Sauveur and Berlitz, advocated for a more natural approach to language teaching, based on the way children learn to talk. Indeed, the approach proposed by Sauveur and Berlitz 6 became very popular and was the foundation for the Direct Method (the best known of all natural methods). It was based

\footnotetext{
6 Saveur and Berlitz used in language schools in the United States oral interaction in the target language as common teaching practice, following Gouin's methodology based on the observation of child language learning. This became known as the Natural Method.
} 
on the exclusive use of the target language in class, and only using examples of everyday vocabulary. Communication skills were built on exchanges between teachers and students introduced orally, and grammar was taught inductively. Vocabulary was taught through demonstration, and accompanied of significant practice of listening and speaking skills, and correct pronunciation (Richards \& Rodgers, 2001). The drawbacks and criticism to this approach refer to the method's dependency on the teacher, who is the constant focus of attention throughout the class, and the need for native speakers, or native-like fluent teachers in the classrooms.

Between the 1950s and the 1980s a great amount of approaches and methods related to the teaching of languages appeared, as for instance the Audiolingual and the Situational Methods, which then converged in the Communicative Approach, or the Silent Way, the Natural Approach and Total Physical Response, which coexisted with these, although at a lower scale of application.

In particular, the Audiolingual Method appeared to counteract the lack of a precise basis in applied linguistic theory of the Natural Method, of which it was accused by the Reform Movement. It was launched at the Michigan University English Language Institute based on structural linguistics and behaviourism. It was taught during the 1940s and 1960s, and maintained that language was a collection of isolated learnable structures. 
Grammar (structure) was the starting point, and pattern practice was the basic technique used by professors. It also held that language learning is mainly based on habit formation. According to this, errors were avoided, since they reinforced incorrect habits. They insisted on repetition as the only means for learning: "it is these basic patterns that constitute the learner's task. They require drill, drill, and more drill, and only enough vocabulary to make such drill possible" (Hockett, 1959 in Richards \& Rodgers, 2001:52). For them, focus needed to be set on mastery of speech and writing (phonological and grammatical structures). From the learning principles of the method emerged the psychological foundations and practices (Rivers, in Richards \& Rodgers, 2001:57):

1) Foreign language learning is basically a process of mechanical habit formation. [...]

2) Language skills are learned more effectively if the items to be learned in the target language are presented in spoken form before they are seen in written form. [...]

3) Analogy provides a better foundation for language learning than analysis. [...]

4) The meanings that the words of a language have for the native speaker can be learned only in a linguistic and cultural context.

The main attack to audiolingual beliefs came from the side of Chomsky (1966:153), who stated that language does not rely on habit. On the contrary, he asserted that "ordinary linguistic behaviour characteristically involves innovation, formation of new sentences and patterns in accordance with rules of great abstractness and intricacy". 


\subsubsection{Content and Task-based methods}

In the 1970s, the focus was moved towards dexterity and content. As a consequence, Content-Based instruction, Task-Based Language Teaching, or Competency-Based Instruction emerged. The first focuses on the topic or subject matter; during the lesson students are focused on learning about a topic using the language they are trying to learn, rather than their native language, as a tool for developing knowledge and so they develop their linguistic ability in the target language. The second, task-Based approaches are more flexible. In them, "content and tasks are developed in tandem" (Nunan, 1989:16). The last one, Competency based instruction advocates defining educational goals as precise measurable descriptions of knowledge, skills, and behaviours students should possess at the end of a course of study.

In this context, Chomsky's explanation of the way we acquire an L1 (1980), and consequently an L2, greatly influence the conception and approach to the teaching of languages. Indeed, Chomsky's Universal Grammar (UG) offers an interesting view for our research, in particular the way in which a speaker accesses the language he or she attempts to master. Even though Chomsky mainly studied First Language Acquisition, part of his theory was dedicated to explain its relation to SLA. One of the most controversial points in Chomsky's UG is that for him language is genetic in the human being: "[...] universal grammar is part of the genotype specifying one aspect of the initial state of the human mind and brain..." (Chomsky, 1980:82). According to this, a UG is 
present in the child's mind as a system of principles and parameters. As a response to the environment, and to the stimuli received (although not in a bonding manner, but in a free manner), the child creates a core grammar of his/her own. Parameter setting allows the child to acquire language variation, which implies that the child also acquires parts of the language that depart from the core, that is, exceptions in the language. Chomsky stated that, "what we know innately are the principles of the various subsystems of $S_{0}$ and the manner of their interaction, and the parameters associated to these principles" (Chomsky, 1986:150). As we can see, he is not so much interested in the result (the level of adequacy, the fluency in the use of the language) as in the device, the machinery that lies behind the process and permits it.

An important issue in this theory is the Poverty of the stimulus argument. In Cook and Newson's words (1996:86): “the nature of language knowledge is such that it could not have been acquired from the actual samples of language available to the human child". Chomsky uses this argument to justify the establishment of parameters in the child's mind, which then will permit their filling thus producing new bits of language.

As to whether second language learners have direct or indirect access to the UG or no access at all, and approach this learning by other means (grammar books, drills, etc.), many opinions exist, pointing that other aspects must be taken into account. For instance, Cook and Newson (1996:295-6) point out that: 
[...] the problem in choosing between these three models of access is that they might be true for different learners, or different aspects of language for the same learner, L2 learning depends on an interaction between learner and situation, unlike first language acquisition.

On this subject, Chomsky's UG considers three aspects: the nature of language representation, learning and use (Cook, 1994 in Skehan, 1998:76). This view is focuses on the principle-based first language acquisition. These principles being invariant features, which all languages share, and parameters (functions) which enable the speaker to generalise known utterances and structures and create new ones based on these.

Thus, one of the principles of language acquisition is structure dependence; that is, the existence of structures that hold the elements within them; words are not isolated elements, on the contrary, they fall into structures. This is general for all the languages, and children know this when they approach one. A resulting problem is the individualisation of these units, and their management. This description implies that learning is the process of inserting data into these structures. Consequently, as only a set of combinations is possible, the learning process is simplified. In addition, the existence of parameters also simplifies language learning, since it helps the generalisation or the narrowing of possible applicable features.

Nonetheless, what needs to be analysed is the relevance of the UG approach in the acquisition of a second language, and whether this mechanism would also be followed when we learn a second language. Wells (1985) explains second language acquisition as the reinvention of 
language. Some critiques were expressed to this approach, because there is little evidence to support it (Schachter, 1996; Cook, 1994). In fact, Skehan (1998) points out some problems yet to be solved in these explanations, as the lack of correlation between the change in one parameter and its causing an adjustment of all others. This author also indicates that UG focuses on issues of concern for linguists, not for learners or speakers. Finally, the last drawback of this theory, highlighted in relation to second language acquisition, seems to be the little importance given by the UG to language teaching. Indeed, language teaching is not one of the priorities of this approach. This is very useful to describe formal language competence, but not so much so to explain language acquisition. However, thanks to Chomsky's work, applied linguists started to see language learning as a cognitive process of hypothesis testing, thus introducing the notion of the learner's interlanguage, which helped locate the learner at the specific point in the learning process.

As a reaction to this characterization of the linguistic competence of the ideal native speaker, Hymes (1972) labelled Chomsky's distinction between competence and performance as too simple to describe language behaviour and therefore his view of performance is an incomplete reflection of competence.

Due to this, he proposed the term communicative competence, Hymes (1972). This term was meant to represent the capability to use language in a social context, to observe sociolinguistic norms of appropriateness and was introduced into discussions of language use and second or 
foreign language learning in the early 1970s (Habermas, 1970; Jakobovits, 1970; Hymes, 1972; Savignon, 1972). In this context, according to Savignon (2002:1), competence is defined in terms of:

[...] the expression, interpretation, and negotiation of meaning and looks to both psycholinguistic and sociocultural perspectives in second language acquisition (SLA) research to account for its development.

This communicative competence would be the focus of attention on research in subsequent years. Most studies dedicated to the study of a second language and second language teaching, take it as a reference and as the key aspect in the proposal of approaches to teaching, methodologies, materials and assessments.

\subsubsection{The Communicative Approach}

The Communicative Approach has been the mainstream approach in SLA for the past forty years. The main idea supported by this model is that language is essentially and mainly communication, thus implying knowledge beyond the specific particular grammar of the language in question, in order to master it. Communicative language teaching embraces a multidisciplinary perspective including different disciplines: linguistics, philosophy, psychology, sociology, pedagogy, etc. Its focus has been the elaboration and implementation of programs and methodologies able to promote the development of functional language ability through learners' participation in communicative events. 
The Communicative Approach to syllabuses found its basis on Wilkins' Notional Syllabus (1976), which described grammatical-semantic categories (frequency, motion, location), and categories of communicative function, but was quickly criticized and replaced. In this approach, the focus was set on the behavioural organisation related to the reasons why language is learnt, and what types of structures (performances) are necessary to achieve these aims. According to Wilkins (1976:2):

\begin{abstract}
In analytic approaches there is no attempt at this careful linguistic control of the learning environment. Components of language are not seen as building blocks which have to be progressively accumulated. Much greater variety of linguistic structure is permitted from the beginning and the learner's task is to approximate his own linguistic behaviour more and more closely to the global language.
\end{abstract}

However, some of its guiding principles have remained and been used in later approaches. The first is that language learning must be considered a process of development of language-learning systems. The second and most important is that language-learning systems must be learner centred, which implies that the entire teaching system must be needs oriented. In Savignon's words (2002:15):

By definition, CLT puts the focus on the learner. Learners' communicative needs provide a framework for elaborating program goals with regard to functional competence. Functional goals imply global, qualitative evaluation of learner achievement as opposed to quantitative assessment of discrete linguistic features.

The idea of communicative competence was introduced for the learning and speaking of a second language, which then combined with speech and theory. This found application in the functional approach of the 
1970s and 1980s in Europe and focused on the completion of particular communicative functions, such as requesting, complaining, giving opinions, etc. This model has expanded and been reformulated. Nonetheless, it still considers the aim of learning a second language to be able to communicate using it. The implications derived for the design of syllabuses are enormous and have a wide variety of applications.

The discussion between audiolingualism, error treatment, comprehension-based or production-based approaches, and the communicative approach was the starting point which the linguist applied to the problem of language teaching. This, in turn had to be put into practice by the classroom teacher. This led to the debate on whether teachers could be theorists, and whether conclusions could be extracted from daily routines or they could only be taken as experimental data. On the contrary, theories and approaches come to reality when, combined, are practiced. These two aspects find continuous feedback. Quoting Widdowson (1998:138): “[...] practical problems in which language is implicated are referred to theoretical ideas and, reciprocally, theoretical ideas are made relevant to the clarification of these problems". Indeed, recent publications prove the increasing interest paid by researchers in the performance of students, valued in equal terms as the expertise of the theoreticians. Linguists must combine the generalisations formulated by the latest and the particular cases of the former as proposed and explained by their teachers.

As said, the priority of the communicative approach is to meet the communicative needs of the students, which implies the prioritisation of 
the communicative competence over the grammatical competence. This is similar to other postulates: the learners' communicative needs are a basis for the design of curricula (Van Ek, 1975). Canale and Swain (1980) defined communicative competence in terms of four components:

(1) Grammatical competence: words and rules,

(2) Sociolinguistic competence: appropriateness,

(3) Discourse competence: cohesion and coherence, and

(4) Strategic competence: appropriate use of communication strategies.

Some years later, in 1986 Lewandowski redefined these, and proposed five new competences:

(1) Communicative competence, described as entailing the capability of mastering speech acts, using different sub-codes.

(2) Hermeneutic-analytical competence, involving the capability for an appropriate understanding, then,

(3) Linguistic competence, which includes the capability of production and interpreting of signs and combinations of signs,

(4) Social competence, including the knowledge of norms related to social structures and

(5) Tactic-rhetorical competence, the actual realisation of intentions.

The Council of Europe has used (2001) this approach to call for the development of syllabuses for the teaching of a foreign language to European users, in situations in which they might use them, topics they 
might talk about, or language functions they might come upon. Widdowson (1978:67) had justified the need for this type of approach by questioning the traditionally assumed statement that once linguistic skills are acquired, then, the communicative abilities follow automatically:

\begin{abstract}
What evidence we have, however, suggests that this is not the case: the acquisition of linguistic skills does not seem to guarantee the consequent acquisition of communicative abilities in a language. On the contrary, it would seem to be the case that an over emphasis on drills and exercises for the production and reception of sentences tends to inhibit the development of communicative abilities.
\end{abstract}

In 1979, the same author stated with reference to the use of categories promoted by functionalist approaches, and Wilkins' syllabus, (Widdowson, 1979:254) that notional-functional categories were insufficient and focus should be set on discourse to attain effective communication:

\begin{abstract}
[...] only a very partial and imprecise description of certain semantic and pragmatic rules which are used for reference when people interact. They tell us nothing about the procedures people employ in the application of these rules when they are actually engaged in communicative activity. If we are to adopt a communicative approach to teaching which takes as its primary purpose the development of the ability to do things with language, then it is discourse which must be at the centre of our attention.
\end{abstract}

He then moved to propose a different approach to language learning, highlighting that the important aim is to acquire communicative competence, which for him includes the linguistic skills, and other abilities which permit interpreting, rephrasing, solving problems, nonverbal communication, etc. 
In order to do this, learners might use previous knowledge in their own language, that is to say, all language abilities they have in their first language which can be transferred to their second language. Significant in this approach is the disconnection between the mentioned communicative abilities and the (one single) language (Widdowson, 1978:74):

Linking their communicative abilities in their own language to a realization of these abilities in the language they are learning. [...] we need to remove these abilities from a dependence on linguistic skills in the mother tongue and associate them with linguistic skills in the foreign language.

In fact, he proposed the need for integration of skills and abilities in order to acquire the necessary language proficiency, as opposed to the traditional approach which treated them and worked with them separately, as ends in themselves (Widdowson, 1978:144):

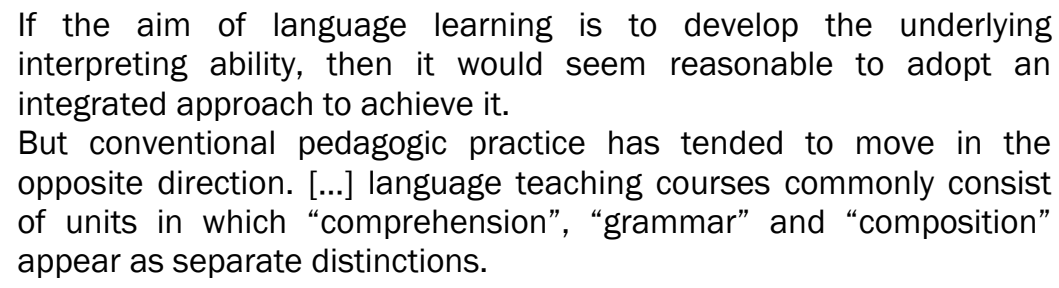

Later on, Firth and Wagner (1997:296) supported this view by criticizing the approach taken by other SLA studies, mainly focused on errors, and the differences between first and second language users, from a sentence-level grammatical perspective, disregarding other significant aspects in language learning and use: 
Researchers working with a reconceptualised SLA will be better able to understand and explicate how language is used as it is being acquired through interaction, and used resourcefully, contingently, and contextually. Language is not only a cognitive phenomenon [...], it is also fundamentally a social phenomenon, acquired and used interactively in a variety of contexts for myriad practical purposes.

The key difference between traditional and learner-centred curriculum development is that in the latter, focused on the learners' needs, the curriculum is necessarily a collaborative effort between teachers and learners, given that learners are closely involved in the decision making process regarding the content of the curriculum and how it is taught.

Often, the different theories proposed for the teaching of an $L 2$ have been established bearing in mind the applications that could be extracted from them. As Ellis (2005) explains, some of these examples are the Monitor Model (Krashen, 1981), the Interaction Hypothesis (Long, 1996), the Skill-learning theory (DeKeyser, 1998) or the Input Processing theory (VanPattern, 1996; 2002).

However, controversy still remains as to whether the traditional methods should still be used, and students be taught mainly grammar, syntax, etc. or whether instruction should focus in communication. Probably the best would be some sort of combination of the two. In any case, Ellis (2005) proposes a set of principles which any kind of teaching should follow, assuming it aims at being rigorous and effective:

(1) The need for instruction to guarantee that learners acquire formulaic expressions and rules,

(2) The need to ensure that learners focus mainly on meaning, 
(3) But that some attention is paid to form,

(4) The conviction that instruction should develop mainly implicit knowledge, although explicit knowledge should also be taken into consideration,

(5) The need for instruction to be based on previous knowledge,

(6) Appropriate input and

(7) Output opportunities, as well as

(8) Opportunities for interaction,

(9) The importance of taking into account the individual particularities, and finally

(10)Instruction needs to examine language in different settings, both free and controlled.

Nunan (1988:26-8) represented the differences between traditional and communicative approaches. The basic differences are the conception of language as communication in the communicative approach, which also determines the areas of interest in the learning course (emphasis on content, meaning, and interest). Then, he adds the idea that learning should be focused on the learner's needs (student-centred) and that this should model the approach to learning. Noteworthy is the fact that the approach to errors is different; the traditional models consider errors as deviances, but the communicative methods see them as opportunities for improvement. The content, rather than the form, is emphasized in the communicative approaches, as can be observed in Table 3: 


\begin{tabular}{|c|c|c|}
\hline & TRADITIONAL APPROACHES & COMMUNICATIVE APPROACHES \\
\hline $\begin{array}{l}\text { Focus in } \\
\text { learning }\end{array}$ & $\begin{array}{l}\text { Language as a structured } \\
\text { system of grammatical } \\
\text { patterns. }\end{array}$ & Language as communication. \\
\hline $\begin{array}{l}\text { How language } \\
\text { items are } \\
\text { selected }\end{array}$ & On linguistic criteria alone. & $\begin{array}{l}\text { On the basis of what language } \\
\text { items the learner needs to know in } \\
\text { order to get things done. }\end{array}$ \\
\hline $\begin{array}{l}\text { How language } \\
\text { items are } \\
\text { sequenced }\end{array}$ & $\begin{array}{l}\text { Determined on linguistic } \\
\text { grounds. }\end{array}$ & $\begin{array}{l}\text { Determined on other grounds, with } \\
\text { the emphasis on content, meaning } \\
\text { and interest. }\end{array}$ \\
\hline $\begin{array}{l}\text { Degree of } \\
\text { coverage }\end{array}$ & $\begin{array}{l}\text { The 'whole picture' of } \\
\text { language structure by } \\
\text { systematic linear progression. }\end{array}$ & $\begin{array}{l}\text { In any particular phase, only what } \\
\text { the learner needs and sees as } \\
\text { important. }\end{array}$ \\
\hline $\begin{array}{l}\text { View of } \\
\text { language }\end{array}$ & $\begin{array}{l}\text { As a unified entity with fixed } \\
\text { grammatical patters and a } \\
\text { core of basic words. }\end{array}$ & $\begin{array}{l}\text { The variety of language is accepted, and } \\
\text { seen as determined by the character of } \\
\text { particular communicative contexts. }\end{array}$ \\
\hline \begin{tabular}{|l} 
Type of \\
language used
\end{tabular} & Formal and bookish. & $\begin{array}{l}\text { Genuine everyday language is } \\
\text { emphasized. }\end{array}$ \\
\hline $\begin{array}{l}\text { What is } \\
\text { regarded as a } \\
\text { criterion of } \\
\text { success }\end{array}$ & $\begin{array}{l}\text { Have students produce } \\
\text { formally correct sentences. }\end{array}$ & $\begin{array}{l}\text { Have students communicate } \\
\text { effectively and in a manner } \\
\text { appropriate to the context they are } \\
\text { working in. }\end{array}$ \\
\hline $\begin{array}{l}\text { Which } \\
\text { language skills } \\
\text { are } \\
\text { emphasized }\end{array}$ & Reading and writing. & $\begin{array}{l}\text { Spoken interactions are regarded } \\
\text { as at least as important as reading } \\
\text { and writing. }\end{array}$ \\
\hline $\begin{array}{l}\text { Teacher/stude } \\
\text { nt roles }\end{array}$ & Teacher-centered. & Student-centered. \\
\hline $\begin{array}{l}\text { Attitude toward } \\
\text { errors }\end{array}$ & $\begin{array}{l}\text { Incorrect utterances are seen } \\
\text { as deviations from the norms } \\
\text { of standard grammar. }\end{array}$ & $\begin{array}{l}\text { Partially correct and incomplete } \\
\text { utterances are seen as such rather } \\
\text { than just "wrong". }\end{array}$ \\
\hline $\begin{array}{l}\text { Similarity/dissi } \\
\text { milarity to } \\
\text { natural } \\
\text { language } \\
\text { learning }\end{array}$ & $\begin{array}{l}\text { Reverses the natural } \\
\text { language learning process by } \\
\text { concentrating on the form of } \\
\text { utterances rather than on } \\
\text { content. }\end{array}$ & $\begin{array}{l}\text { Resembles the natural language } \\
\text { learning process in that the content } \\
\text { of the utterance is emphasized } \\
\text { rather than the form. }\end{array}$ \\
\hline
\end{tabular}

Table 3. Differences between traditional and communicative approach (Nunan, 1988).

As can be seen in Table 3, several items appear to be the focus of the analysis, starting from language focus, which moves from the study of 
grammar in the traditional approach to the study of language as communication. Then, it looks at the way teaching is proposed; the types of items that are considered interesting for the learning process, and how these are sequenced in the process. Traditional methods include only linguistic aspects whereas the communicative approach introduces other aspects considered relevant for the completion of successful language proficiency, such as content or meaning, and what the learner needs and interests are.

The consideration towards what language is and should be (standards and so on), and the type of language chosen for teaching also influence communication. Traditional approaches use only formal, standard language, whereas the communicative approach takes into consideration other forms of the language. The specific abilities required from the students in the different methods are also different: in the traditional method focus is set on receptive activities, whereas the communicative approach is more interested in productive activities.

With regard to the treatment of errors and achievements in the learning process, traditional methods consider error as deviations, whereas in the Communicative Approach interest is set on the point in the learning process students are at. Table 3 also shows the roles of students and teachers, analysing whether the focus is set on the former or the latter. Finally, it seems that the Communicative Approach resembles more the Natural Approach used in the learning of the L1. 
Several definitions exist with reference to the Communicative curriculum, to the way language teaching must be carried out so that a Communicative Approach is obtained, and to the features this type of teaching should include, and conclusively, the types of syllabuses it needs to develop. For instance, Berns (1990:104) provides a useful summary of eight principles for Communicative Language Teaching: it is based on the consideration of language as communication, as a social tool used by speakers to say something with meaning, with a purpose and to someone.

Diversity is seen as positive and accepted as part of language development and use. Indeed, not just one variety of language is accepted as a standard model for teaching and learning. Similarly, there is not only one way of teaching: it is recommended to use more than one methodology in language teaching. The competence of the learner should be seen in relative terms, and no longer in absolute terms; the learner is now expected to use the language in a variety of settings and purposes throughout the learning process.

For this, culture is central to language learning. It is a tool necessary to help the learner obtain a good communicative competence, in his or her own language as well as in one, or many, foreign languages: "Language use is recognized as serving ideational, interpersonal, and textual functions and is related to the development of learners' competence in each" (Berns, 1990:104). 
Again, focus is set on language as communication, and in it is included diversity and variety as parts of language development. Nothing is fixed, or absolute. And the recommendation is that language must be learnt by doing things. The competences the learners must become skilled at are varied, ranging from ideational to interpersonal, and to textual.

Since the Communicative Approach is the foundation of the CEFR, it is considered the way to approach L2 teaching throughout Europe. Thus, the current curricula need to be revised to meet these requirements. In this regard, Savignon (2002:9-11) talks about the items that should be included in the communicative curriculum: the grammatical competence (sentence-level grammatical forms) "the ability to recognize the lexical, morphological, syntactical and phonological features of a language", discourse competence, related to the interconnection of series of utterances to make a whole.

This competence includes concepts as coherence and cohesion. Then, sociocultural competence (Savignon, 2002:18), (based on Canale and Swain's sociolinguistic competence), which "extends well beyond linguistic forms and is an interdisciplinary field of inquiry having to do with the social rules of language use". And finally Savignon (2002:10) points out:

Together these features might be subsumed under the term "cultural flexibility," or "cultural awareness." The "ideal native speaker," someone who knows a language perfectly and uses it appropriately in all social interactions, exists in theory only. 
This author concludes in an interesting approach that in order for a curriculum to be communicative it should include several factors to help students find their place in the new language they are learning. She emphasizes that students must create a new self with which they feel comfortable in the new language they are learning (Savignon, 2002:22). The aspects to be included in a communicative curriculum are:

(1) Language Arts is dedicated to the study of the traditional disciplines, and focuses on forms of the language, including syntax, morphology and phonology.

(2) Language for a Purpose is related to the use of language for real and immediate communicative goals.

(3) My Language Is Me: Personal Second Language Use. This is related to the creation of a new identity in a new language. Everything a learner conveys to the new language would be related to this aspect, including attitude, motivation, etc. In her words (Savignon, 2002:23) "The most successful teaching programs are those which take into account the affective as well as the cognitive aspects of language learning and seek to involve learners psychologically as well as intellectually".

(4) You Be..., I'll Be..., are improvisations allow learners to experiment, to try things out as occasions for language use and role playing.

(5) Theater Arts Beyond the Classroom relates to the reproduction of scripts from the models observed. 


\subsection{COMMON EUROPEAN FRAMEWORK FOR LANGUAGES (CEFR)}

One of the pillars of the European Council has been the promotion of modern language learning ever since its foundation. The actions promoted by the Council of Europe to encourage linguistic diversity and language learning in the field of education fall within the framework of the European Cultural Convention, (1954) ratified by 49 states. There exists the conviction that it is necessary to (Council of Europe, $R(98) 6: 34)$ :

[...] enable all Europeans to communicate with speakers of other mother tongues, thereby developing open-mindedness, facilitating free movement of people and exchange of information and improving international co-operation.

In recent years, this has become a crucial point of interest, as the language community has increased and the number of languages spoken throughout the European Community borders is now greater than ever. The Language Policy Division implements intergovernmental programmes which focus on activities and tools to support policy development. The Council of Europe proclaimed a policy on plurilingualism that involves helping Europeans learn another language, since this is believed to increase and consolidate the feeling of European belonging (Council of Europe, 2001:134):

[...] a linguistic policy choice at an important point in the history of Europe... [...] a matter of helping learners [...] to construct their linguistic and cultural identity through integrating into it a diversified experience of otherness. 
In fact, the linguistic policies of the European Council go far beyond this, and establish several political objectives in language learning throughout Europe. We can find these in the preamble to the Recommendation $\mathrm{R}(98) 6$, adopted by the Committee of Ministers on 17 March 1998 at the 623rd meeting of the Ministers' Deputies, which explains that in order to reach full mobility among the member states it is crucial to cooperate in education, as well as in industry and commerce. Concerned by the increase of racial intolerance, a special call is made in favour of the promotion of mutual understanding and respect to diversity. This diversity is seen as an asset, in need of development and reinforcement, in particular cultural and linguistic diversity, both for minority and majority languages. The preamble also warns of the dangers that might result from the lack of a well-grounded (multi)linguistic knowledge, to communicate in an interactive Europe. To attain this, the consideration (Council of Europe, 1998:33) is that:

[...] the needs of a multilingual and multicultural Europe can be met only by appreciably developing Europeans' ability to communicate with one other across linguistic and cultural boundaries and that this requires a sustained, lifelong effort which must be encouraged, put on an organised footing and financed at all levels of education by the competent bodies.

To work towards this objective, it is recommended also that collaboration between governments and institutions is promoted and that a common method to approach language learning and teaching is found (CE, 1998:34-36) in order to:

[...] encourage institutions to use the [CEFR] to plan or review language teaching in a coherent and transparent manner in the 
interests of better international co-ordination and more diversified language learning. [...] Promote the development of varied forms of assessment and recognition of plurilingual competences which take into account the considerable diversity of needs, paying particular attention to the definition of objectives for partial competences and the assessment of their attainment.

As explained, the Council of Europe agreed to publish in this context, as the result of the project "Language Learning for European Citizenship" developed between 1989 and 1996, the Common European Framework of Reference for Languages (CEFR), which could help professionals work towards this objective.

A European Union Council Resolution (November 2001) recommended the use of this instrument in setting up systems of validation of language competences. In 2008, the Committee of Ministers of the Council of Europe addressed a Recommendation to the member states on the use of the CEFR and the encouragement of plurilingualism.

\subsubsection{The Document}

The CEFR (CE, 2001; 2009) is aimed at helping levelling and assessing language studies throughout Europe, by identifying common levels of aptitude. The document describes language proficiency based on a set of abilities and skills that the speaker needs to master in order to appropriately communicate in a foreign language. The CEFR focuses on communicative and interactive language practice, and the approach chosen in this document is the well-known Communicative Approach. The intention of this approach used for the expression of these abilities 
and skills is threefold: linguistic, sociolinguistic and pragmatic. Each of these consists of knowledge, know-how and skills, following long-lasting learner-centred pragmatic proposals.

As established in the document itself, the purpose of its elaboration are to help teachers and learners apply in their learning processes the principles of the "construction of language-learning systems" (CE, 2001:3). Several specific purposes are described within; this learning process focuses on the "needs, motivations, characteristics and resources" of the students. This is to say that, as explained previously, the method is based on the students, the focus and the measuring point is set on the student, no longer on the aim, the system, or the teacher.

Teaching will therefore need to take into account the actual circumstances and opportunities the learner has when facing the learning process. For this reason, it is written in a way that can be selfapplied and self-assessed, which is established as another secondary purpose by establishing "worthwhile and realistic objectives as explicitly as possible" (CE, 2001:3). Again, the reference point is the learner, who has to understand and work towards realistic objectives. In order to do this, the student needs to know where he or she is going in terms of learning, the steps towards proficiency. To help in this, the third secondary objective is to provide students with sufficient and appropriate materials. This, in some cases, is not easy in the present situation, since the approach to learning and teaching has totally changed and in some cases the materials available were not elaborated bearing those purposes in mind. Finally, the last point which balances 
this description is evaluation. The document aims at helping provide "suitable forms and instruments for the evaluating of learning programmes" (CE, 2001:3).

To achieve these objectives, the CEFR is based on notional and functional aspects of language, and establishes a series of descriptive guidelines to help language professionals in identifying learners' proficiencies in aspects of language use and in planning and leveraging language learning. It establishes a three-stage scale of proficiency: A, B and $C$. These stages are in turn subdivided into levels of language competence (A1, A2, B1, B2, M1 and M2), which are a useful tool in the teaching and learning process, as well as in curriculum and assessment development. The stages relate to the different stages the learners go through in the process of learning a language, and can be seen in the following Figure, (CE, 2001:23):

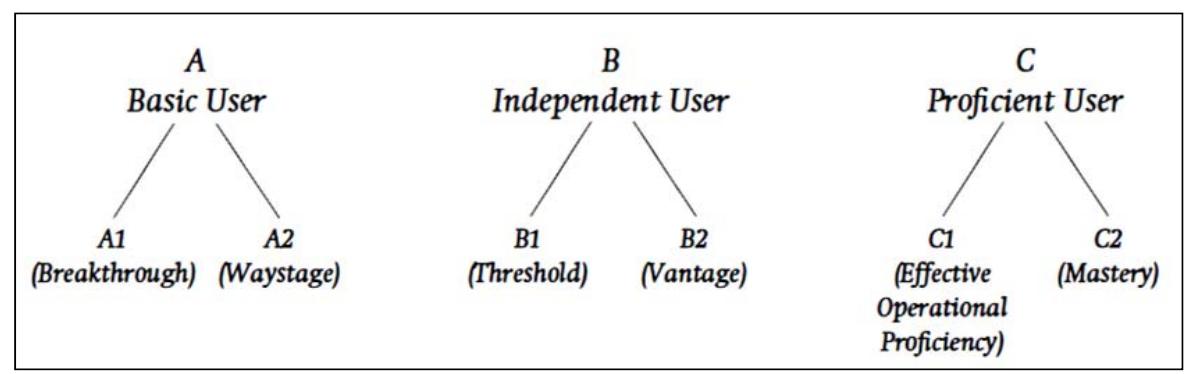

Figure 7. Levels of language proficiency as established in the CEFR.

In addition, evaluation grids are provided in order to help both students and teachers in the learning process. A significant innovation in the document, which appears as a guideline is the inclusion of selfassessment tools for students. The underlying philosophy is that 
students must become independent in their learning process. Learners must acquire autonomy in order to be able to find ways towards selfimprovement. Thus, the teacher is no longer the centre from which knowledge is radiated; learners not only become the focus of attention, they are also the leading force of the learning process. They gain independence from the teacher as they learn. The descriptors provided are written with the intention of helping the students know, not only what they know how to do, but also how well they do it at specific levels of proficiency (CE, 2001:39). Indeed, there is a guideline for self-directed learning, which includes, raising the learner's awareness; selfdetermining feasible objectives; selecting the necessary materials and completing self-evaluation. The student is thus required to take the reins of his or her own learning process.

In the CEFR (CE, 2001:26-27) we find a self-assessment grid for the common reference levels of proficiency. We reproduce only the descriptors offered for the writing skill in all six levels of proficiency, since that is the ability that centres the focus of interest in the present study. In the description can be seen the grading of the difficulty to establish visible progress towards language proficiency (from simple to complex, from short to clear, from connected to detailed, and so on). 


\begin{tabular}{|c|c|c|c|}
\hline W & A1 & $A 2$ & B1 \\
\hline $\begin{array}{l}\mathrm{R} \\
\mathrm{I} \\
\mathrm{T} \\
\mathrm{I} \\
\mathrm{N} \\
\mathrm{G}\end{array}$ & $\begin{array}{l}\text { I can write a short, } \\
\text { simple postcard, for } \\
\text { example, sending } \\
\text { holiday greetings. I can } \\
\text { fill in forms with personal } \\
\text { details, for example } \\
\text { entering my name, } \\
\text { nationality and address } \\
\text { on a hotel registration } \\
\text { form. }\end{array}$ & $\begin{array}{l}\text { I can write short, simple } \\
\text { notes and messages } \\
\text { relating to matters in } \\
\text { areas of immediate } \\
\text { need. I can write a very } \\
\text { simple personal letter, } \\
\text { for example thanking } \\
\text { someone for something. }\end{array}$ & $\begin{array}{l}\text { I can write simple } \\
\text { connected text on topics } \\
\text { which are familiar or of } \\
\text { personal interest. I can } \\
\text { write personal letters } \\
\text { describing experiences } \\
\text { and impressions }\end{array}$ \\
\hline W & B2 & C1 & C2 \\
\hline $\begin{array}{c}\mathrm{I} \\
\mathrm{N} \\
\mathrm{G}\end{array}$ & $\begin{array}{l}\text { I can write clear, detailed } \\
\text { text on a wide range of } \\
\text { subjects related to my } \\
\text { interests. I can write an } \\
\text { essay or report, passing } \\
\text { on information or giving } \\
\text { reasons in support or } \\
\text { against a particular point } \\
\text { of view. I can write } \\
\text { letters highlighting the } \\
\text { personal significance of } \\
\text { events and experiences. }\end{array}$ & $\begin{array}{l}\text { I can express myself in } \\
\text { clear, well-structured } \\
\text { text, expressing points of } \\
\text { view at some length. I } \\
\text { can write about complex } \\
\text { subjects in a letter, an } \\
\text { essay or a report, } \\
\text { underlining what I } \\
\text { consider to be the } \\
\text { salient issues. I can } \\
\text { select style appropriate } \\
\text { to the reader in mind. }\end{array}$ & $\begin{array}{l}\text { I can write clear, } \\
\text { smoothly flowing text in } \\
\text { an appropriate style. I } \\
\text { can write complex } \\
\text { letters, reports or articles } \\
\text { which present a case } \\
\text { with an effective logical } \\
\text { structure which helps } \\
\text { the recipient to notice } \\
\text { and remember } \\
\text { significant points. I can } \\
\text { write summaries and } \\
\text { reviews of professional } \\
\text { literary works. }\end{array}$ \\
\hline
\end{tabular}

Table 4. Self-assessment grid for writing. B2, C1, C2 levels (CE, 2001:26-27).

As can be seen in Table 4, the descriptions are stated using the first person singular, encouraging the students to analyse what type of language command do they have taking into account the sort of things they are able to carry out with them. This is one of the recommendations of the Council of Europe, to promote the learner's autonomy in the learning process.

However, if we analyse the Table in detail, we find that there is quite a significant amount of work required from the students when they 
attempt at evaluating their work. They need to be able to discern whether what they write is clear, short, or simple based on their own criteria and experiences. This, as will be explained later is one of the problems that we encounter when we work with the CEFR; the probable too-lax definition, which leads to ambiguity, of the terminology used. This type of explanation is the sort found for all the categories and every point of view in the document.

\subsubsection{Pragmatics in the CEFR}

The document establishes the philosophy underneath, which explains many of the points of view and understanding of the language learning process presented in it. As a compilation of recommendations and descriptions, the CEFR claims to be comprehensive, transparent, and coherent. Certainly, the document should try to include as much language knowledge, and as many skills and uses as possible, creating different dimensions and steps in the language learning process.

It should also include abilities which are not strictly linguistic but necessary for language learning, “e.g. sociocultural awareness, imaginative experience, affective relations, learning to learn, etc." (CE, 2001:7). In addition, it should be clear and explicit, and free from contradictions. It is even more specific with regard to educational systems, of which a harmonious relation among the parts is expected, in particular in the case of (CE, 2001:7): 
(1) Identification of needs.

(2) Determination of objectives.

(3) Definition of content.

(4) Selection and creation of material.

(5) Establishment of teaching and learning programmes.

(6) Teaching and learning methods employed.

(7) Evaluation, testing and assessment.

As seen, the document aspires to cover all parts of language teaching, and, in addition, be flexible and adaptable to different situations. It claims to be (CE, 2001:7-8):

- Multi-purpose: usable for the full variety of purposes involved in the planning and provision of facilities for language learning.

- Flexible: adaptable for use in different circumstances.

- Open: capable of further extension and refinement.

- Dynamic: in continuous evolution in response to experience in its use.

- User-friendly: presented in a form readily understandable and usable by those to whom it is addressed.

- Non-dogmatic: not irrevocably and exclusively attached to any one of a number of competing linguistic or educational theories or practices.

The CEFR specifies that completing the language learning process implies obtaining certain skills which are concomitant to language communication. These skills guarantee that the language has been learnt, and that the learner is able to improve his or her language expertise by working on these skills to a further degree. The three pillars 
upon which learning communication is based are linguistic competences, sociolinguistic competences and pragmatic skills.

In particular, the present work studies the last, the pragmatic competences as defined in the CEFR. These are linked to the specific functional use of the language; especially language performances (speech acts, language functions production, etc.) and include (CE, 2001:13) "the mastery of discourse, cohesion and coherence, the identification of text types and forms, irony, and parody". In the outset, this competence also includes the need to work the contexts, the environments and the cultures in which the language is produced, also related to the sociolinguistic competence.

The approach to teaching and learning stated on the CEFR (CE, 2001:131) takes this view, insisting on the adoption of a communicative approach, in which focus is set on the learner, and subsequently on the society: "on the tasks, activities and processes that the learners need to carry out in order to satisfy those needs". For this, it is necessary to develop a set of knowledge consisting of information, attitudes and skills combined depending on the specific cases. It is crucial that all learners develop the necessary competences, and the ability to put them into action as well as the ability of developing strategies to make them possible. To do this, the document presents a set of levels and their scales to chart the learners' position in the learning process (A, B, and C proficiency levels). 
In the same line, the document emphasizes the multidimensionality of the learning process, encouraging the introduction of previous linguistic knowledge and the exploitation of many contexts and situations: "Multidimensionality and modularity thus appear as key concepts in developing a sound basis for linguistic diversification in the curriculum and in assessment" (CE, 2001:176).

Language learning should be carried out including a variety of contexts for language use as well as specific projects for language development. The CEFR claims that the categories offered within are useful for this, and to confirm it, Figure 4 (CE, 2001:33) to help situate the learners in one specific context and at a specific point in the learning process, establishing the multidimensionality and modularity of the approach.

To complete this, it is recommended that teachers follow a set of guidelines to establish good practices within the classroom. This idea clarifies up to what point learning is expected to be learner-centred. The assumption is that the teaching methodology proposed takes into account not only learners' backgrounds and previous knowledge, but also their present needs, and the way of assessment that best suits them. In order to understand the sort of specifications and the type of analysis the professor is expected to carry out to offer a multidimensional approach, completely individualised according to the students' needs we reproduce the specifications for multicultural teaching as appear in the document, highlighting the most relevant aspects in Table 5: 
- whether the learners concerned already have some experience of linguistic and cultural plurality, and the nature of this experience;

- whether learners are already able, even if only at a very basic level, to function in several linguistic and/or cultural communities, and how this competence is distributed and differentiated according to the contexts of language use and activities;

- what experience of linguistic and cultural diversity learners may have at the time of their learning (for example parallel to and outside their attendance at a learning institution);

- how this experience might be built on in the learning process;

- what types of objectives appear best suited to learners (see section 1.2) at a particular point in the development of a plurilingual and pluricultural competence, taking account of their characteristics, expectations, interests, plans and needs as well as their previous learning path and their existing resources;

- how to encourage, for the learners concerned, the decompartmentalisation and establishment of an effective relationship between the different components of plurilingual and pluricultural competence in the process of being developed; in particular, how to focus attention on and draw on the learners' existing transferable and transversal knowledge and skills;

- which partial competences (of what kind and for what purposes) might enrich, complexify and differentiate learners' existing competences;

- how to fit learning concerned with a particular language or culture coherently into an overall curriculum in which the experience of several languages and several cultures is developed:

- what options or what forms of differentiation in curriculum scenarios exist for managing the development of a diversified competence for particular learners; what economies of scale can be envisaged and achieved, if appropriate;

- what forms of organisation of learning (a modular approach, for example) are likely to favour management of the learning path in the case of the learners in question;

- what approach to evaluation or assessment will make it possible to take account of, and accord proper recognition to the partial competences and the diversified plurilingual and pluricultural competence of learners.

Figure 8. Linguistic diversification and the curriculum. Summary. (CE, 2001:176).

With regard the type of contexts considered useful for practice and language proficiency, some examples are offered. Four possible domains are established: personal, public, occupational and educational. In each of those categories, seven different groups are 
proposed, which include locations, institutions, persons, objects, events, operations and texts. Since the B1 level of proficiency (i.e. the focus of the present study) is mainly based on the personal domain, we reproduce the part of the Table dedicated to the specifications for it in Table 5. It is expected that the contexts provided by the instructors fall within these categories and offer real situations for work to the students.

\begin{tabular}{|c|c|c|c|c|}
\hline DOMAIN & LOCATIONS & INSTITUTIONS & PERSONS & OBJECTS \\
\hline PERSONAL & $\begin{array}{l}\text { Home: } \\
\text { House, rooms. } \\
\text { Garden: } \\
\text { Own, of family, } \\
\text { of friends, of } \\
\text { strangers. } \\
\text { Own space in } \\
\text { hostel, hotel. } \\
\text { Countryside. } \\
\text { Seaside. }\end{array}$ & $\begin{array}{l}\text { The family. } \\
\text { Social } \\
\text { networks. }\end{array}$ & $\begin{array}{l}\text { (Grand)Parents, } \\
\text { offspring, Siblings, } \\
\text { aunts, uncles, } \\
\text { cousins, in-laws, } \\
\text { spouses. } \\
\text { Intimates, friends. } \\
\text { Acquaintances. }\end{array}$ & $\begin{array}{l}\text { Furnishing and } \\
\text { furniture, Clothing, } \\
\text { Household equipment, } \\
\text { Household goods, } \\
\text { handbags. } \\
\text { Toys, tools, personal } \\
\text { hygiene. } \\
\text { Objets d'art, books, } \\
\text { Leisure/sports } \\
\text { equipment. } \\
\text { Wild/domestic animals, } \\
\text { pets, trees, plants, lawn, } \\
\text { ponds. }\end{array}$ \\
\hline DOMAIN & \multicolumn{2}{|l|}{ EVENTS } & OPERATIONS & TEXTS \\
\hline PERSONAL & \multicolumn{2}{|c|}{$\begin{array}{l}\text { Family occasions, encounters. } \\
\text { Incidents, accidents. } \\
\text { Natural phenomena. } \\
\text { Parties, visits. } \\
\text { Walking, cycling, motoring. } \\
\text { Holidays, excursions. } \\
\text { Sports events. }\end{array}$} & $\begin{array}{l}\text { Living routines: } \\
\text { dressing, } \\
\text { undressing, cooking, } \\
\text { eating, washing, DIY, } \\
\text { gardening. } \\
\text { Reading, radio \& TV, } \\
\text { entertaining. } \\
\text { hobbies, games and } \\
\text { sports. }\end{array}$ & $\begin{array}{l}\text { Teletext, guarantees, } \\
\text { recipes, instructional } \\
\text { material, novels, } \\
\text { magazines, } \\
\text { newspapers. } \\
\text { Junk mail, brochures, } \\
\text { personal letters, } \\
\text { broadcast and recorded, } \\
\text { spoken texts. }\end{array}$ \\
\hline
\end{tabular}

Table 5. External context of use: descriptive categories based on the CEFR (CE, 2001:48-49). 


\subsubsection{Description of competences}

Very early in the document (CE, 2001:9), there is a set of definitions for terms which will be used throughout the document. The ones that concern us discuss the descriptions of competences. The characterisation of competences is very broad, and refers to the sum of information, abilities and features that allow a person to do things, perform actions. These can be linguistic or extralinguistic. Competences that are not specific to language are referred to as general competences, whereas those which "empower a person to act using specifically linguistic means" are called communicative language competences.

For the specification of the particular abilities the CEFR proposes three big groups, which represent the three basic pillars of the communicative competence: linguistic competences, sociolinguistic competences and pragmatic competences. These are, in turn subdivided into smaller abilities which assure language knowledge. For instance, the linguistic competence includes the lexical competence, the grammatical competence, the semantic competence, the phonological competence, the orthographic competence, and the orthoepic competence. The descriptors of the sociolinguistic competence are much more specific, less universal: linguistic markers of social relations; politeness conventions; expressions of folk-wisdom; register differences; and dialect and accent. It needs to be pointed out that, whereas it is generally agreed to analyse politeness from a pragmatic point of view, in 
the document, this aspect appears under the sociolinguistic heading. We find the detailed description for pragmatic competences (CE, 2001:123):

\begin{abstract}
Pragmatic competences are concerned with the functional use of linguistic resources (production of language functions, speech acts), drawing on scenarios or scripts of interactional exchanges. It also concerns the mastery of discourse, cohesion and coherence, the identification of text types and forms, irony, and parody. For this component even more than the linguistic component, it is hardly necessary to stress the major impact of interactions and cultural environments in which such abilities are constructed.
\end{abstract}

Thus, focus is set on a set of items which would represent pragmatic accuracy and correction, of different levels of difficulty and including both textual and extratextual linguistic features such as types of texts, discourse, language functions, cohesion and coherence or irony. These categories characterise all fields and competences internalised by the user; internal representations, mechanisms and capacities, which are expected to evolve as language proficiency does throughout the learning process.

The competences, which fall in the pragmatic perspective considered in the document (CE, 2001:123) are three: discourse competence, functional competence and design competence. The first one relates to the structure and organisation of the text, the second to the execution of communicative functions, and the third to the sequencing of the texts taking into account interaction. Although there is a detailed description of the first two, characterisation for the third is split and included in the discourse competence first and then from the point of view of 
communicative functions. A plain description of the discourse competence is offered; we can read that (CE, 2001:123-130):

Discourse competence is the ability of a user/learner to arrange sentences in sequence so as to produce coherent stretches of language. It includes knowledge of and ability to control the ordering of sentences.

Discourse competence is assessed in terms of (1) topic vs. focus, (2) given vs. new, (3) natural (temporal) sequencing, (4) cause and effect, and (5) structure and manage discourse according to some specific principles, such as rhetorical effectiveness, logical ordering, thematic organisation, style and register, and coherence and cohesion. It is recommended that Grice's cooperative principle ${ }^{7}$ should be observed, by following the maxims of quality, quantity, relevance and manner.

Discourse competence is expected to develop with language proficiency, starting from simple, short sentences, and moving on to longer, more complex utterances at higher levels. Scales are available to measure these pragmatic aspects in tables assessing: flexibility, thematic development, coherence and cohesion and turn-taking (which will be retaken later on in the interaction strategies section). The parts of the tables referred to B1 levels of proficiency are reproduced below. Table 6 refers to flexibility:

\footnotetext{
7 As explained above, Grice's cooperative principle reads: "make your contribution such as is required, at the stage at which it occurs, by the accepted purpose or direction of the talk exchange in which you are engaged, by observing the following maxims: quality (try to make your contribution one that is true, quantity (make your contribution as informative as necessary, but not more); relevance (do not say what is not relevant); manner (be brief and orderly, avoid obscurity and ambiguity)'.
} 


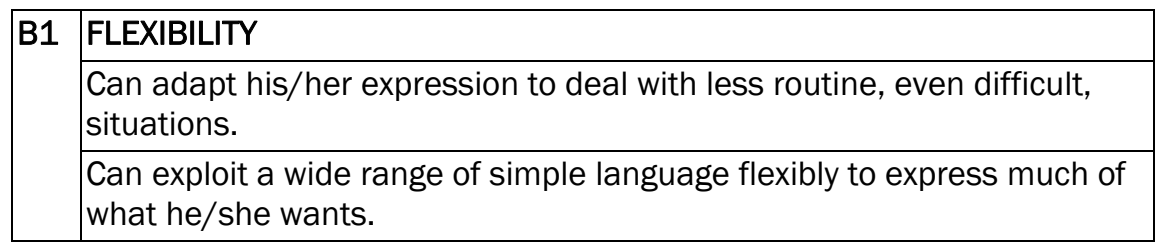

Table 6. Pragmatic competences. Discourse: Flexibility. B1 level (CE, 2001:124).

Flexibility as a pragmatic competence refers to the flexibility of the user to adapt the discourse to the particular situation to a certain point. This includes situations which are slightly out of the ordinary, although not greatly. The user is expected to adapt the expression, although no greater specificity is added as to whether this should be in terms of register, tone, length... or all of these at the same time. The second skill included under this heading refers to the ability to make language adapt to the intentions or the message of the speaker. This is, the ability of a user to find his or her way around the language known to them, and to express whatever is intended with the existing linguistic resources. Table 7 refers to turn taking:

\begin{tabular}{|l|l|}
\hline B1 & TURN TAKING \\
\cline { 2 - 3 } & $\begin{array}{l}\text { Can intervene in a discussion on a familiar topic, using a suitable phrase } \\
\text { to get the floor. }\end{array}$ \\
\cline { 2 - 2 } & $\begin{array}{l}\text { Can initiate, maintain and close simple face-to-face conversation on } \\
\text { topics that are familiar or of personal interest. }\end{array}$ \\
\hline
\end{tabular}

Table 7. Pragmatic competences. Discourse: Turn taking. B1 level (CE, 2001:124).

Turn taking refers mainly to conversations and interaction activities, but only related to familiar topics. This is almost completely linked to aural, and in particular spoken skills, and lies far beyond our field of interest and research. In any case, it refers to the ability of the participant in a 
conversation to know what is convenient to say (which topics are suitable to the conversation in progress), and when should these be said (how to respect the turn in the discussion, and to recognise the moment in which they can intervene and when should they remain silent). This point is strongly related to politeness and multicultural politeness conventions. The next two tables refer not so much to the external conditions to the text, but to intra-textual qualities. First, Table 8 reflects thematic development within the text.

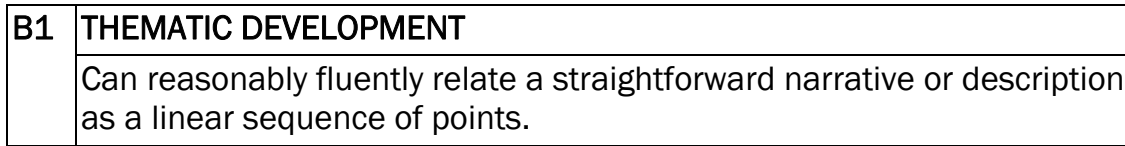

Table 8. Pragmatic competences. Discourse: Thematic development. B1 level. (CE, 2001:125).

In this description we find two elements which are actually very difficult to measure and determine when found in combination: reasonably and fluently. These two are completely subjective adverbs which allegedly explain the type of qualitative competence the user must have. Indeed, these refer to an essential property which reflects the degree of proficiency of the user. However, there is no explanation of what should be understood by reasonably, and the adverb fluently mainly refers to aural utterances. However, this descriptor is set out to be useful for all types of expressions, both oral and written, since it refers to the logical thematic development within the text. We can consult the explanation of competences dedicated to coherence and cohesion, which is the most specific of the group. Information related to this is displayed in Table 9: 
B1 COHERENCE AND COHESION

Can link a series of shorter, discrete simple elements into a connected,

linear sequence of points.

Table 9. Pragmatic competences. Discourse: Coherence \& cohesion. B1 level. (CE, 2001:125).

The approach to coherence and cohesion is far from Halliday and Hasan's 1976 Cohesion in English, in which they identify two categories, collocation and reiteration. These were basically studied from a grammatical and lexical point of view, the categories identified by them refer to in-text references (using a common referent) and frequencies of use (corrected use of words which appear together in different contexts of use). The present definition seems to refer more to the sequencing and temporal logics within the texts. It focuses on the linking of the different parts of the text. It also seems to point to a network structure in which smaller elements fit into greater structures to build discourse. However, with such a short description, it is difficult to clearly value the exact parts of the discourse it refers to, when it talks about linking shorter elements into linear sequences.

Next, we can take a look at the Functional Competence. Although the first approach defines it for the use of spoken discourse and written texts, the actual development in the text is for conversational purposes, (CE, 2001:125):

[As for] Conversational competence [...] Participants are engaged in an interaction, in which each initiative leads to a response and moves the interaction further on, according to its purpose, through a succession of stages from opening exchanges to its final conclusion. Competent speakers have an understanding of the process and skills in operating it. 
In contrast with the short definitions of competences for each level of proficiency, significant amount of detail is given to language functionality (CE, 2001:126). Indeed, microfunctions and macrofunctions are listed quite extensively. Microfunctions are categories for the functional use of single utterances, and include six big groups. Each one of them includes several actions:

(1) Imparting and seeking factual information includes identifying, reporting, correcting, asking and answering.

(2) Expressing and finding out attitudes: factual (agreement/ disagreement), knowledge (knowledge/ignorance, remembering, forgetting, probability, certainty), modality (obligations, necessity, ability, permission), volition (wants, desires, intentions, preference), emotions (pleasure, displeasure, likes/dislikes, satisfaction, interest, surprise, hope, disappointment, fear, worry, gratitude), and moral (apologies, approval, regret, sympathy).

(3) Suasion includes suggestions, requests, warnings, advice, encouragement, asking help, invitations, and offers.

(4) Socialising refers to attracting attention, addressing, greetings, introductions, toasting, and leave-taking.

(5) Structuring discourse, although only three of the twenty-eight microfunctions that belong to this group are listed: opening, turn taking, and closing.

(6) Communication repair, with sixteen microfunctions not specified.

A list of macrofunctions comes next, described as categories for the functional use of spoken or written discourse consisting of a sequence 
of sentences: a more complex sequence of sentences for the functional use of language. These include description, narration, commentary, exposition, exegesis, explanation, demonstration, instruction, argumentation, persuasion, etc. This is very important in the establishment and work with different text types. The list of macrofunctions specifies in detail which elements do students need to master to be able to meet the requirements of the different levels of proficiency. Thus, when we look at the scales provided to check students' proficiency, we see that they are classified depending on the previous functions that had been defined; in the DIALANG ${ }^{8}$ selfassessment scales, students can check whether they can report, pass on information, write personal letters, describe an event, summarise the plot of a book, etc. These descriptions are based on the macrofunctions as established here.

The descriptions related to text design are split between these two sections; the functional competence section, and the interaction competence section. They depend very much on the purpose of the text, and on the interlocutor. Text design needs awareness of the existing conventions in the target community, not only of the appropriate contents, but also how should these be presented and structured (designed) in the target community. For instance this concerns (CE, 2001:123):

8 DIALANG is a programme developed by several European higher education institutions and hosted by the University of Lancaster. It started running on October 2006. This programme helps the user identify the level of proficiency she/he has based on the scales provided by the CEFR. 
How information is structured in [...] macrofunctions (description, narrative, exposition, etc.); how stories, anecdotes, jokes, etc. are told; how a case is built up (in law, debate, etc.); how written texts (essays, formal letters, etc.) are laid out, signposted and sequenced.

This moves on to be more specific throughout the CEFR, as for instance in the interaction activities, in which these functions are described to a great detail, first in pairs (question/answer), and then in triplets, as can be seen in Figure 5, reproduced below:

General Schema for purchase of goods or services

- Moving to place of transaction

- Finding the way to the shop, store, supermarket, restaurant, station, hotel, etc.

- Establishing contact

- Exchanging greetings with the shopkeeper/assistant/waiter/receptionist, etc.

- assistant greets

- Selecting goods/services

- identifying options

- seeking information

- seeking advice

- asking for preference

- identifying particular goods required

- agreeing to purchase

- agreeing prices of items

- receiving/handing over payment

- exchanging thanks

- customer thanks

- leave-taking

- expressing (mutual) satisfaction

- customer expresses satisfaction

- exchanging interpersonal comment (e.g. weather, local gossip)

- exchanging parting greetings

- customer greets
- Finding the way to the counter, department, table, ticket office, reception, etc.

- customer greets

- identifying category of goods/services required

- discussing pros and cons of options (e.g. quality, price, colour, size of goods)

- giving information

- giving advice

- expressing preference, etc.

- examining goods

- exchanging goods for payment

- agreeing addition of total

- receiving/handing over goods (and receipt)

- assistant thanks

- assistant expresses satisfaction - assistant greets

Figure 9. General schema for purchase of goods and services. (CE, 2001:127-128). 
Next, a brief description of two generic qualitative factors, which determine the actual success of the learner from a functional point of view, in the categories of fluency (in spoken language) and propositional precision (described as the ability to formulate thoughts and propositions to express meaning clearly. These general qualities are explained apart from all the remaining activities, and skills. Disregarding now the part which explains fluency, we will pay attention to the account for propositional precision, as usual in the B1 level. This information is displayed in Table 10:

\begin{tabular}{|l|l|}
\hline B1 & PROPOSITIONAL PRECISION \\
\cline { 2 - 3 } & $\begin{array}{l}\text { Can explain the main points in an idea or problem with reasonable } \\
\text { precision. }\end{array}$ \\
\cline { 2 - 2 } & $\begin{array}{l}\text { Can convey simple, straightforward information of immediate relevance, } \\
\text { getting across which point he/she feels is most important. } \\
\text { Can express the main point he/she wants to make comprehensibly. }\end{array}$ \\
\hline
\end{tabular}

Table 10. Functional competence. Qualitative factors: Propositional precision. (CE, 2001:129).

In this definition we find some descriptors aimed at helping identifying and examining a student's progress towards language proficiency. However, the wording used is unclear and vague: the types of utterances described are ideas or problems, and the way in which they should be handled is with reasonable precision. A second issue which is expected from students is related to express the core of their message. This is described as simple, straightforward information, and they are required to be able to identify the most important point in their message and transmit it in an intelligible way. The assessment of all this is considered in the CEFR (CE, 2001:130), where both the student and the teacher are 
invited to state "how qualitative progress in the pragmatic component can be characterised".

A matter of particular interest is the consideration of politeness under the sociolinguistics headline. In the case under study, this approach would be considered even more convenient, for a perspective of study, since it relates to second language learning, in the case of students who are far from the English speaking environment and who have little real input for comparison, except in the classroom. Despite this, we can observe in Figure 6 the descriptors for politeness conventions, trying to follow the indications established in them, moreover since the document itself explains that it is "one of the most important reasons for departing from the straightforward application of the co-operative principle":

Politeness conventions

- 'positive' politeness.

- showing interest in a person's wellbeing;

- sharing experiences and concerns, 'troubles talk';

- expressing admiration, affection, gratitude;

- offering gifts, promising future favours, hospitality;

- 'negative' politeness.

- avoiding face-threatening behaviour (dogmatism, direct orders, etc.);

- expressing regret, apologising for face-threatening behaviour (correction, contradiction, prohibitions, etc.);

- using hedges, etc. (e.g. ' I think', tag questions, etc.);

- appropriate use of 'please', 'thank you', etc.;

- impoliteness (deliberate flouting of politeness conventions).

- bluntness, frankness;

- expressing contempt, dislike;

- strong complaint and reprimand;

- venting anger, impatience;

- asserting superiority.

Figure 10. Politeness conventions. (CE, 2001:119-120). 
As with the description of functional competences, the types of things considered polite in the use of a second language are listed in detail. These are structured in four large groups and range from knowing the things one must do (being interested in somebody's physical condition) and the things one must avoid doing (dogmatism) or know how to correct (apologise), to the recognition and identification of impolite behaviour and formulae in language. However, as expressed in the CEFR, politeness conventions vary with languages, and these expressed are common to a certain group of cultures probably near the Western (European) cultures, but not necessarily universal or good for all languages or all European societies.

Section 9 of the CEFR is entirely dedicated to assessment. However, in spite of specific items considered here, the chapter refers to the descriptors specified throughout the different parts of the document (Chapter 4, in which there is the specification for the Communicative activities, and Chapter 5, which offers the Communicative competences), and not a proposal for assessment.

There is in fact a recommendation to use different types of assessment to evaluate different tasks and functions implemented during the course. The proposal is that certain general ideas are considered when evaluation is carried out depending on the general set of communicative categories used. These are explained in Figure 11: 


\begin{tabular}{|lll|}
\hline Spoken: & $\begin{array}{l}\text { Interaction } \\
\text { (spontaneous, short turns) }\end{array}$ & $\begin{array}{l}\text { Production } \\
\text { (Prepared, long turns) } \\
\text { Conversation } \\
\text { Informal discussion } \\
\text { Goal-oriented co-operation }\end{array}$ \\
Written: & & $\begin{array}{l}\text { Description of his/her academic } \\
\text { field }\end{array}$ \\
& & $\begin{array}{l}\text { Report/Description of his } / \mathrm{her} \\
\text { academic field }\end{array}$ \\
\hline
\end{tabular}

Figure 11. Communicative categories. (CE, 2001:179).

The recommendations given as for the real assessment are, as most of the points in the document, not very specific. For instance, the descriptors found in Chapter 4 for the communicative activities can be used to check whether objectives have been attained during the learning process, by means of (1) Construction (scales used to specify the design of assessment tasks), (2) Reporting (very useful scales for reporting results), and the final one, which is most likely to be helpful to the actual assessment of the level of proficiency: (3) Self- or teacher-assessment, in the form of grids or checklists. In fact these are the three systems recommended for use (CE, 2001: 181): scales, checklists and grids.

Scales, in turn can be of two sorts:

(1) Proficiency Scale. This type offers a definition of the relevant levels for certain categories.

(2) Examination Rating Scale. This is the scale used to select descriptors for each relevant category which describes the desired pass standard (rating from 1 to 5 ).

Next, there is a description of ways to testing results by comparing them with others taken as a reference or as a starting point (CE, 2001:182): 
(1) Equating (producing alternative versions of a test).

(2) Calibrating (linking the results from different tests to a common scale).

(3) Statistical moderation (correcting for the difficulty of test papers or the severity of examiners).

(4) Benchmarking (comparison of work samples in relation to standardised definitions and examples).

(5) Social moderation (building up a common understanding through discussion).

Table 11 offers a long list of types of assessment we might use or want to know when evaluating our language level, in terms of functions, texts or utterances:

\begin{tabular}{|l|l|l|}
\hline \multicolumn{4}{|l|}{ TYPES OF ASSESSMENT } \\
\hline 1 & Achievement assessment & Proficiency assessment \\
\hline 2 & Norm-referencing (NR) & Criterion-referencing (CR) \\
\hline 3 & Mastery learning CR & Continuum CR \\
\hline 4 & Continuous assessment & Fixed assessment points \\
\hline 5 & Formative assessment & Summative assessment \\
\hline 6 & Direct assessment & Indirect assessment \\
\hline 7 & Performance assessment & Knowledge assessment \\
\hline 8 & Subjective assessment & Objective assessment \\
\hline 9 & Checklist rating & Performance rating \\
\hline 10 & Impression & Guided judgement \\
\hline 11 & Holistic assessment & Analytic assessment \\
\hline 12 & Series assessment & Category assessment \\
\hline 13 & Assessment by others & Self-assessment \\
\hline
\end{tabular}

Table 11. Types of assessment (CE, 2001:183). 
Although there is a wide explanation of the differences between these types of assessment, there are no specific recommendations as to how those descriptors offered as a basis for the assessment must be used. However, in relation to this, a useful table is obtainable (CE, 2001:206), dedicated to the development of proficiency descriptors for assessment. It offers very general positive and negative criteria that should be used to assess language proficiency and language progress to proficiency. It has been reproduced in Table 12. As can be seen, the descriptors are very general and refer to other documents of reference. The CEFR offers a general idea of what should be evaluated by the teacher, in which way should proficiency be looked at, how can student proficiency be assessed, and how it has been implemented in several implementations of the principles stated in it (Eurocentres, Finland, Netherlands, etc.). 


\begin{tabular}{|c|c|}
\hline POSITIVE & NEGATIVE \\
\hline $\begin{array}{l}\text { - has a repertoire of basic } \\
\text { language and strategies which } \\
\text { enables him or her to deal with } \\
\text { predictable everyday } \\
\text { situations. (Eurocentres, Level } \\
\text { 3: certificate). } \\
\text { - basic repertoire of language } \\
\text { and strategies sufficient for } \\
\text { most everyday needs, but } \\
\text { generally requiring compromise } \\
\text { of the message and searching } \\
\text { for words. (Eurocentres, Level } \\
\text { 3: assessor grid). }\end{array}$ & $\begin{array}{l}\text { - has a narrow language } \\
\text { repertoire, demanding constant } \\
\text { rephrasing and searching for } \\
\text { words. (ESU, Level 3). } \\
\text { - limited language proficiency } \\
\text { causes frequent breakdowns } \\
\text { and misunderstandings in non- } \\
\text { routine situations. (Finnish, Level } \\
\text { 2). } \\
\text { - communication breaks down as } \\
\text { language constraints interfere } \\
\text { with message. (ESU, Level 3). }\end{array}$ \\
\hline $\begin{array}{l}\text { - vocabulary centres on areas } \\
\text { such as basic objects, places, } \\
\text { and most common kinship } \\
\text { terms. (ACTFL, Novice). }\end{array}$ & $\begin{array}{l}\text { - has only a limited vocabulary. } \\
\text { (Dutch, Level 1). } \\
\text { - limited range of words and } \\
\text { expressions hinders } \\
\text { communication of thoughts and } \\
\text { ideas. (Gothenburg, U). }\end{array}$ \\
\hline $\begin{array}{l}\text { - produces and recognises a set } \\
\text { of words and short phrases } \\
\text { learnt by heart. (Trim, } 1978 \\
\text { Level 1). }\end{array}$ & $\begin{array}{l}\text { - can produce only formulaic } \\
\text { utterances lists and } \\
\text { enumerations. (ACTFL, Novice). }\end{array}$ \\
\hline $\begin{array}{l}\text { - can produce brief everyday } \\
\text { expressions in order to satisfy } \\
\text { simple needs of a concrete } \\
\text { type (in the area of salutation, } \\
\text { functional information, etc.). } \\
\text { (Elviri; Milan, Level } 1 \text { 1986). }\end{array}$ & $\begin{array}{l}\text { - has only the most basic } \\
\text { language repertoire, with little or } \\
\text { no evidence of a functional } \\
\text { command of the language (ESU, } \\
\text { Level 1). }\end{array}$ \\
\hline
\end{tabular}

Table 12. Assessment: positive and negative criteria. (CEFR. Appendix A).

Based on this, the document invites to a concretisation of the general standards established within. Indeed, the general direction which should lead these evaluation signposts (descriptors) must be ruled by definiteness ("describe concrete tasks and/or concrete degrees of skill”), clarity (be transparent, not jargon-ridden), brevity, and 
independence (from one another), in a way that it is contemplated that a student can evolve and be proficient in an activity, a competence or a skill and not in another.

\subsubsection{Communicative activities: Written communication}

Within the group of communicative activities, the CEFR describes two types of interactive activities (conversing, and letter writing) and two types of productive activities (monologuing and describing). The document also points at aesthetic activities which may be productive, receptive, interactive or mediating. Again, these can exist in the oral or the written domain. In the present dissertation we will be looking at written production carried out by first year university students and, in particular, at texts produced during the academic course.

As far as Pragmatics is concerned, the interest of the dissertation is set on the students' ability of recognising types of texts and using the appropriate type of language depending on the situation, the interlocutor, and the context, which in the CEFR is graded and assessed as written production. Errors in different aspects of these will be studied and analysed.

In this dissertation, to start, we will just consider the descriptors proposed in the document. The appropriate level of proficiency to focus on for university students in their first year could be established as B1. In the self-assessment grid provided to this aim, as mentioned above, 
the specifications for this group of learners are that they must be able to "write simple connected text on topics which are familiar or of personal interest", as well as "write personal letters describing experiences and impressions". This would be the general aim of this level of proficiency, by means of the operation of planning, execution, evaluation and repair strategies, also explained in general terms in the document. Activities considered useful for developing written skills are explained in the form of different types of texts a student should be able to recognise and produce, in general for all levels, and not specific for each (that is, a student should be able to write a newspaper article whether he or she has a B1 or an A1 level of proficiency). These include diverse domains, from the personal to the professional, and from the direct and formulaic to the creative and personal. They are summarised in Table 13, (CE, 2001:61):

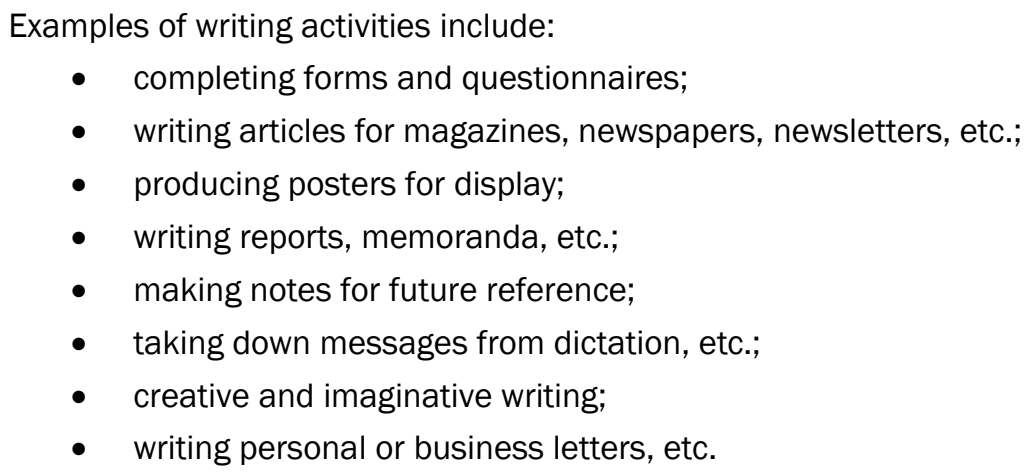

Scales are provided in the text for three types of activities, the general, overall written production, creative writing, and reports and essays. Unlike in this, in the specific tables, there are specifications for each 
level of proficiency. Nevertheless, the document specifies that the descriptors for these three scales have been created by recombining elements of descriptors from other scales. Any B1 proficient student should be able to write connected texts on familiar subjects and subjects of interest, and in the case of creative writing should also have the ability to describe feelings and reactions. Students should be able to describe, narrate, summarise, report and justify in quite simple texts and contexts. These scales are shown in Tables 14, 15 and 16 (CEFR: 2001, 61-62):

\begin{tabular}{|l|l|}
\hline B1 & OVERALL WRITTEN PRODUCTION \\
\cline { 2 - 2 } & $\begin{array}{l}\text { Can write straightforward connected texts on a range of familiar subjects } \\
\text { within his field of interest, by linking a series of shorter discrete } \\
\text { elements into a linear sequence. }\end{array}$ \\
\hline
\end{tabular}

Table 14. Overall written production activities (CE, 2001:61).

\begin{tabular}{|l|l|}
\hline B1 & CREATIVE WRITING \\
\cline { 2 - 3 } & $\begin{array}{l}\text { Can write straightforward, detailed descriptions on a range of familiar } \\
\text { subjects within his/her field of interest. } \\
\text { Can write accounts of experiences, describing, feelings and reactions in simple } \\
\text { connected text. } \\
\text { Can write a description of an event, a recent trip - real or imagined } \\
\text { Can narrate a story }\end{array}$ \\
\hline
\end{tabular}

Table 15. Creative writing activities. (CE, 2001:62).

\begin{tabular}{|l|l|}
\hline B1 & REPORTS AND ESSAYS \\
\cline { 2 - 3 } & $\begin{array}{l}\text { Can write short, simple essays on topics of interest. } \\
\text { Can summarise, report and give his/her opinion about accumulated } \\
\text { factual information on familiar routine and non-routine matters within } \\
\text { his/her field with some confidence. }\end{array}$ \\
\cline { 2 - 2 } & $\begin{array}{l}\text { Can write very brief reports to a standard conventionalised format, which } \\
\text { pass on routine, factual information and state reasons for actions. }\end{array}$ \\
\hline
\end{tabular}

Table 16. Overall written production activities. (CE, 2001:62). 
As can be seen, the explanations included in these tables are closely related to the listing of types of texts included (CE, 2001:92), to help identify sorts of texts that can be used in the classroom to provide for real-context literature. Indeed, a long description is dedicated to the role written texts should play in the learning process. Students are expected to learn from written copies in one of the following forms (CE, 2001:145146):

a) by simple exposure;

b) by simple exposure, but ensuring that new material is intelligible by inferencing from verbal context, visual support, etc.;

c) by exposure, with comprehension monitored and ensured by L2 question and answer, multiple choice, picture matching, etc.;

d) as c), but with one or more of the following: comprehension tests in L1; explanations in L1; explanations (including [...] translation), in L2; systematic pupil/student translation of text into L1; pre-listening and/or group listening activities, prereading activities, etc.

In addition, the texts presented to the students must be authentic, untreated, produced for communicative purposes without the language teaching filtering, or specially composed for use in the language classroom, but always trying to resemble the real thing, based on authentic texts. 
In the same line, students are expected not only to know but also to produce dictated passages, written exercises, essays, translations, written reports, project works, letters to pen-friends, faxes and e-mails.

The document also offers a general descriptions of types of texts, which can be very helpful to analyse the students' work from a pragmatic perspective, since this is basically the main focus of interest in the entire written section, what types of texts can professors use, what types of texts should students recognise, what types of texts should they be able to reproduce. The list of text types recommended is reproduced in Figure 8, (CE, 2001:95):

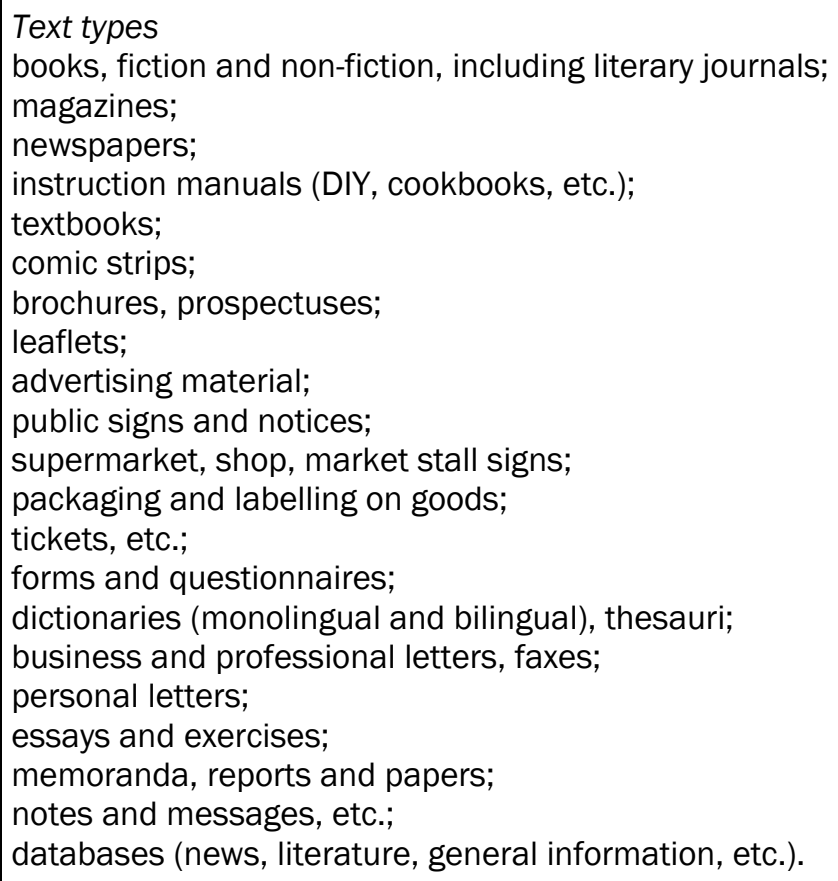

Figure 12. Text types in CEFR (CE, 2001:95). 
All these tables and scales aim at helping the student increase her/his proficiency in second language written production, which is a considerably difficult domain to master, since "writing is more institutionalised than talk and less contextualised too" (Grundy, 2002:2). Indeed, this author insists that writing is more difficult than speaking, recalling that norms are more enduring in written than in speaking. Additionally, the globalisation of English and the multiplying of models do not help in the founding of standards. Although there is a general trend which supports the relativity of strict norms in favour of communication and intelligibility, sometimes these problems that arise impede real, fluent communication.

Indeed, learning to write in an L2 is difficult. In some cases problems occur in the use of the language because the listener's expectations have not been met, or L2 inferences are not necessarily the same as in the MT. It is essential to review all that is taken for granted in language production, in order to find out the key aspects of communication which might be difficult to confer from one language to another.

To support the assessment section of the CEFR document, reference is made to the DIALANG9 ${ }^{9}$ programme. Skills included in this programme are reading, writing, listening, grammar and vocabulary, and DIALANG's languages are Danish, Dutch, English, Finnish, French, German, Greek, Icelandic, Irish-Gaelic, Italian, Norwegian, Portuguese, Spanish and Swedish. Appendix C (CE, 2001:233) gives us an example of what this

9 Although the general website of DIALANG is no longer available, the programme can be consulted at http://www.lancs.ac.uk/researchenterprise/dialang/about. 
programme offers for the evaluation of B1 students. It is reproduced in Table 17:

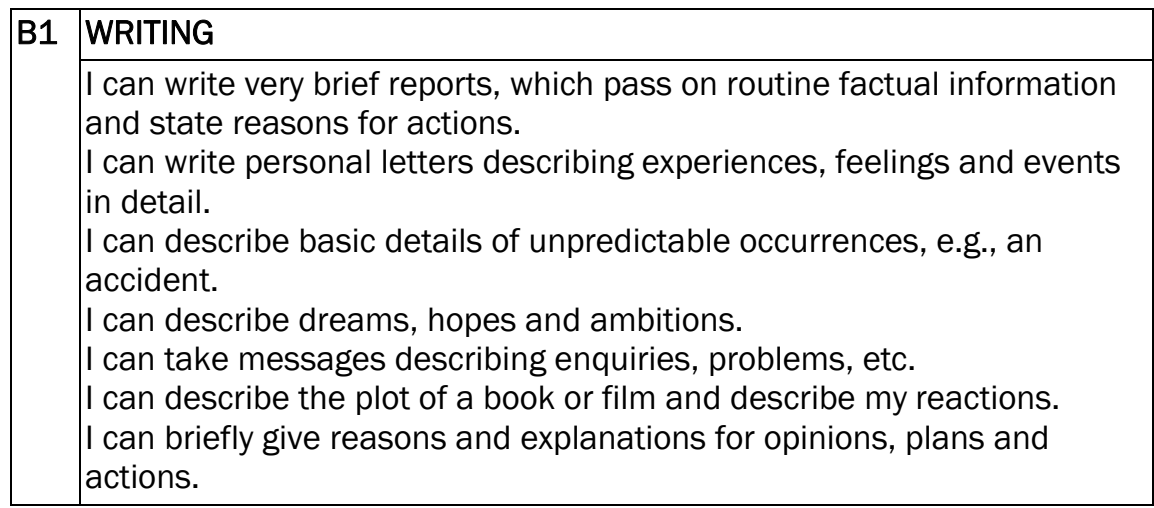

Table 17. The DIALANG scale for B1 level of proficiency (CE, 2001:233).

As can be seen, the DIALANG scales reproduce almost literally those offered by the CEFR, but display a greater level of detail. However, the terminology used is very similar to that of the CEFR, when it comes to analyse how this ability can be measured. The way we determine if we can write personal letters to an acceptable degree of difficulty is not specified in the document, nor in these scales provided as examples, although the recommendation is that they are objectively determined (CE, 2001:21).

\subsubsection{Errors in the CEFR}

The approach given in the CEFR to error treatment is based on the distinction between errors and mistakes. The first are described as typical of language learners, in the sense that they are considered 
deviations from the standard use that an L1 speaker would have. Errors, in the approach explained at the CEFR, can only be incurred into by L2 learners, since they fall, by definition, within the realm of the interlanguage. Also, it is completely seen as an individual problem, one centred and caused by the user. The literal quotation is (CE, 2001:155):

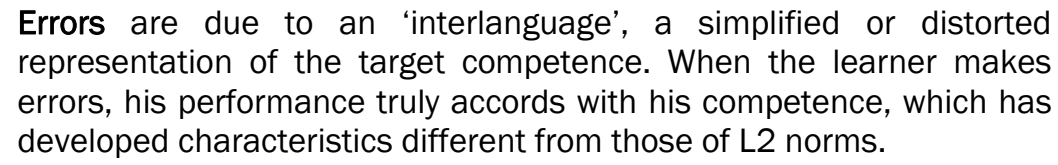

Conversely, both learners and users can make mistakes. They are not seen as individual deviations from the standard, but as faulty use (or misuse) of competences. This implies that the user, or the learner, know the rules, and are able to express themselves correctly, but somehow fail to do so in a particular utterance: "Mistakes, on the other hand, occur in performance when a user/learner (as might be the case with a native speaker) does not bring his competences properly into action" (CE, 2001:156).

A very general inventory is offered (CE, 2001:155) as to what are the different approaches to errors, although not expressed in detail. Errors range from the traditional consideration of errors as something wrong which should be avoided, to their characterization of steps in the learning process, and thus, necessary moves towards language proficiency. Furthermore, they can also be a reflection of the teacher's or of the learner's inability. The list also collects the approaches which consider the focus set on the teacher, and those set on the learner: 
(1) Errors and mistakes are evidence of failure to learn;

(2) Errors and mistakes are evidence of inefficient teaching;

(3) Errors and mistakes are evidence of the learner's willingness to communicate despite risks;

(4) Errors are an inevitable, transient product of the learner's developing interlanguage.

(5) Mistakes are inevitable in all language use, including that of native speakers.

Although an ample variety of possible actions offered to respond to those errors is given in the CEFR, none of the possible approaches is proposed as optimal or recommended to use by L2 teachers. As in the previous case, possibilities range from teacher correction to peer correction to correction and explanation of errors, to overlooking of mistakes but not errors, to neglecting of errors if they interfere with communication, to complete ignorance of both errors and mistakes (CE, 2001:155-156):

1) All errors and mistakes should be immediately corrected by the teacher.

2) Immediate peer-correction should be systematically encouraged to eradicate errors.

3) All errors should be noted and corrected at a time when doing so does not interfere with communication (e.g. by separating the development of accuracy from the development of fluency).

4) Errors should not be simply corrected, but also analysed and explained at an appropriate time.

5) Mistakes which are mere slips should be passed over, but systematic errors should be eradicated.

6) Errors should be corrected only when they interfere with communication.

7) Errors should be accepted as 'transitional interlanguage' and ignored. 
With regard the use that errors and error analysis can be given, there is also an extensive list of possibilities. These stretch from course planning, either individual-based or group-based, to materials development, or even evaluation and assessment.

Three questions arise in this regard: are students assessed primarily in terms of their errors and mistakes in performing the tasks set? If not, what other criteria of linguistic achievement are employed?, are errors and mistakes weighted and if so according to what criteria?

The primary concern in this view is not so much how errors are seen when they are assessed (a crucial part in the learning process, a flaw, etc.), but what consideration will teachers give to those errors they encounter in the students' productions. That is, whether they will be the core of assessment, whether they are weighted with successful bits or in any other way, whether they will be ignored and only successful parts be considered for evaluation.

Our position is that errors help us know in which situation learners are in the learning process. They are not so useful in telling us about how poorly the learner performs, as in offering some light about useful and useless approaches in the classrooms, and, most importantly, about the level of proficiency and the possibilities for further work and further development. In particular, the CEFR proposes to focus on the different errors in pronunciation, spelling, vocabulary, morphology, syntax, usage as well as in sociocultural issues. 
Additionally, the recommendation reads (CE, 2001:156) that users should "consider and where appropriate state their attitude to and action in response to learner errors and mistakes". Furthermore, it should be judged whether these criteria apply to the items in Figure 13:

- phonetic errors and mistakes;

- orthographic errors and mistakes;

- vocabulary errors and mistakes;

- morphological errors and mistakes;

- $\quad$ syntactic errors and mistakes;

- sociolinguistic and sociocultural errors and mistakes;

- $\quad$ pragmatic errors and mistakes.

Figure 13. Errors and mistakes (CE, 2001:145-146).

As can be seen, although the document claims to support a communicative approach, and propose communicative strategies and activities, the table dedicated to explain error has a completely different approach. Indeed, the errors that are listed are mainly grammatical and lexical: phonetic, orthographic, vocabulary, morphological and syntactic. Cultural aspects are considered in this section with the sociolinguistic issues, and there is a final generic section named pragmatic errors, without mention for discourse errors or some other specific types of errors. 


\subsubsection{Proposals for error analysis based on the CEFR}

When faced with the task of analysing errors based on the CEFR, the first need is to localise and categorise the descriptions offered within. As we have seen throughout the analysis, it is sometimes difficult to identify and concretise the particular skill, proficiency and assignment that users should be able to complete successfully if they want to be considered as proficient in one level.

We have grouped all those descriptions found in the CEFR for three different aspects of language knowledge: general, in which there are general guidelines which affect features such as linguistic, or lexical, or even orthographic competence, written, those offered to assess written texts, and the particular guidelines given for the pragmatic approach to teaching.

\subsubsection{General errors}

\section{Linguistic range}

Included as general features, the first to be mentioned is the linguistic. In order for users to obtain a specific level of proficiency, they must be able to master the language to a certain extent. Recommendations for a B1 level of proficiency (CE, 2001:110) read that learners must "have range of language to describe unpredictable situations, explain main points, be precise, have sufficient vocabulary and avoid repetition due to lexical limitations". 
Errors that could be derived from these descriptions would be:

- Deficiency of infrequent vocabulary

- Impossibility to focus on central aspects

- Vagueness

- Insufficient vocabulary

- Repetition

The vocabulary range given as reference for a B1 level of proficiency (CE, $2001: 112$ ) is that the user "has a sufficient vocabulary to express him/herself with some circumlocutions on most topics pertinent to his/her everyday life such as family, hobbies and interests, work, travel, and current events".

For this reason, vocabulary related to unfamiliar situations or events is considered a problem in this level of proficiency, and a source for error. Indeed, this idea is expressed again for vocabulary control, where the text (CE, 2001:112) explains that the B1 user "shows good control of elementary vocabulary but major errors still occur when expressing more complex thoughts or handling unfamiliar topics and situations."

\section{Lexical competence}

Under the heading Lexical Competence in the CEFR (CE, 2001:110) we can find a list of lexical elements that account for the lexical competence of the student. These include: 
- Fixed expressions:

o Sentential formulae: exponents of language functions (greetings.), proverbs, archaisms, etc.

o Phrasal idioms, intensifiers and fixed frames, e.g.: "Please may I have", phrasal verbs, compound prepositions, e.g. "in front of".

o Fixed collocations, consisting of words regularly used together, e.g. "to make a speech/mistake".

- Single word forms (polysemy).

\section{Grammatical competence}

The CEFR then lists a set of word classes, to help us identify the grammatical elements used in a particular utterance, the mastery of which help us identify a proficient use of the language. In these competences, the listings are precise, although short, and include a series of grammatical issues which can account for a higher or lower level of language proficiency. These are ranged from the simplest to the most complex. For instance, first on the list come articles, (a, the), quantifiers (some, all, many, etc.) or demonstratives (this, that, these, those). Then it includes personal pronouns, question words and relatives, possessives, prepositions, auxiliary verbs, conjunctions and particles. This could be useful to analyse the different use of these elements in specific texts produced by students, or, in our case, errors in the use of these elements in texts produced by students. 
The same occurs with the grammatical competence, which requires the specification of elements, categories, classes, structures, or processes and relations. The list dedicated to the specification of grammatical elements is included here in Figure 14. As above, any error which might appear in any of the mentioned categories could be useful to identify levels of proficiency and specific learners' needs.

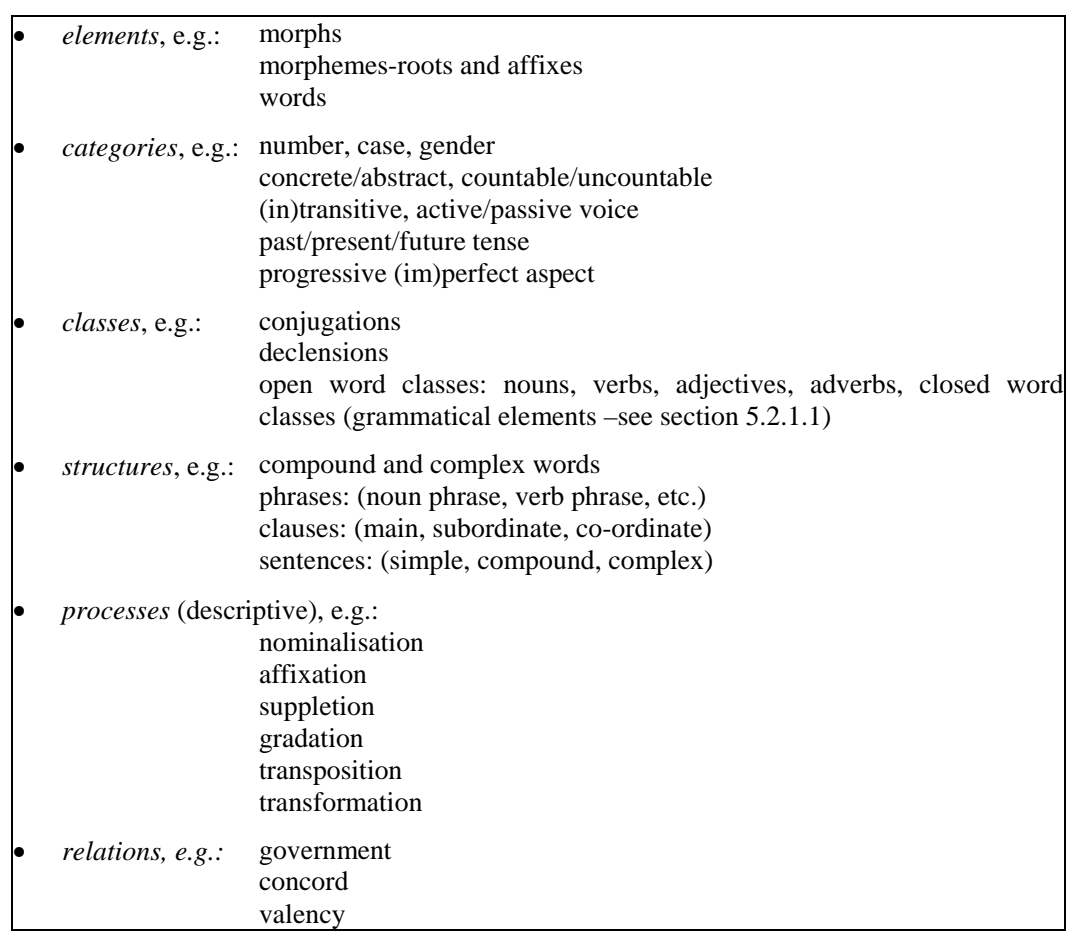

Figure 14. Grammatical elements for analysis. (CE, 2001:113).

Next in the text are found the specifications for the different proficiency levels once more expressed in general and abstract terms, using quite indeterminate terminology to describe for instance grammatical accuracy: reasonable accuracy, generally good control, noticeable 
influence or reasonably accurately. As can be seen in Table 18, there is not correspondence between the grammatical elements proposed for analysis and the evaluation or control grids offered for the levels of proficiency:

B1 Communicates with reasonable accuracy in familiar contexts; generally good control though with noticeable mother tongue influence. Errors occur, but it is clear what he/she is trying to express.

Uses reasonably accurately a repertoire of frequently used routines and patterns associated with more predictable situations.

Table 18. Grammatical accuracy for B1 level of proficiency (CE, 2001:114).

There is also a grid for spelling and orthographic matters. According to the grid, the only requirement for a B1 level of proficiency is to be generally intelligible, with expectations of problems in spelling, punctuation and layout. According to this, certain awareness with regard spelling and layout is expected, although with errors in them. It is interesting to point out that MT interference is expected and tolerated at this level of proficiency. Another aspect that must be pointed out is that in all the grids that have appeared throughout the document of reference, the $\mathrm{B} 1$ level of proficiency corresponds to the familiar: $a$ familiar environment, a familiar routine, a familiar situation.

Examples of errors which could be derived from these specifications are lack of precision (ambiguity), lack of control in communicating what is intended, clear MT influence or failure to make him/herself understood, and limited vocabulary to express everyday actions (Table 19). 
B1 Can produce continuous writing which is generally intelligible throughout spelling, punctuation and layout are accurate enough to be followed most of the time.

Table 19. Orthographic competence for B1 level of proficiency (CE, 2001:114).

As has been seen, apart from a couple of lists offering examples of grammatical elements and word classes, the descriptions with relation to the competences (grammatical, lexical, orthographic) only offer a general approach, without clear specifications as to which should be expected to be accurate or appropriate to the specific levels. Expected errors in these sections would obviously be related to James' collection of surface errors: omissions, additions, misformations, or misorderings.

The next section is dedicated to the revision of descriptors and guidelines for B1 written texts. Only the parts of the tables dedicated to this level of proficiency have been selected for analysis. It should be expected that clearer descriptors are offered in these grids and tables, since, as seen above, written texts on the document are mainly analysed from a text-type point of view, thus referring to the intention or layout of the document.

\subsubsection{Written production}

The first grid that seems helpful in our revision is dedicated to selfassessment. We can find hints as to help students identify the level of proficiency and work the particular issues that need adjustment or further study. For this reasons, specifications are offered in the first 
person singular, and refer to the general skills, distributed in three components: understanding, speaking and writing. The first is in turn subdivided into listening and reading then appear spoken interaction, spoken production and finally writing as cited in Table 20.

B1 I can write simple connected text on topics which are familiar or of personal interest. I can write personal letters describing experiences and impressions.

Table 20.

Self-assessment grid for B1 level of overall writing (CE, 2001:26).

Reference is given to the connexion of themes in the utterance. Indeed, the key word in this description of competence is connected. Although the texts are expected to be simple and not related to new or unexpected events, but to the personal milieu, students need to be able to offer an intelligible and logically ordered discourse. Errors related to this would be linked to wrong use or lack of connectors. Descriptors dedicated to writing are, as mentioned above, closely related to the type of text that is being written by the learners. The CEFR offers specifications for different types of writings, and different types of purposes, forms, etc. Table 21 is dedicated to creative writing, the most open possibility for students, in which the specifications are expected to be broader and more general. 
B1 Can write straightforward, detailed descriptions on a range of familiar subjects within his/her field of interest.

Can write accounts of experiences, describing feelings and reactions in simple connected text.

Can write a description of an event, a recent trip - real or imagined.

Can narrate a story.

Table 21. Writing. Creative writing. B1 level (CE, 2001:62).

According to this, possible learner errors would be related to coherence and cohesion, since the descriptor refers to the logical linearity of the text and its connectors, although with a low degree of complexity. Errors could also be related to register and text type, since a reference to differences in accounting, describing and narrating is made. Next, we will examine the specifications for reports and essays. These are inscribed within the category of formal writing, with the linguistic features applicable to them: greater complexity, use of third person pronouns, verb tense, specific structure and layout, etc. Descriptors in this category are reproduced in Table 22:

B1 Can write short, simple essays on topics of interest.

Can summarise, report and give his/her opinion about accumulated factual information on familiar routine and non-routine matters within his field with some confidence.

Can write very brief, reports to a standard conventionalised format, which pass on routine factual information and state reasons for actions.

Table 22. Writing. Reports and essays. B1 level (CE, 2001:62).

In this case, interest is set on text types and formal text conventions. This could be the source of errors under this category. Apart from these rubrics, the CEFR also refers to a set of strategies that can help the 
students improve their skills: planning, compensating, monitoring and repair.

Planning (Table 23) relates to the possibility of applying new concepts or using new words. It also refers to the possibility of exploiting all resources available. Compensating (Table 24), in turn, refers to the ability to rephrase, use synonyms or invent a word in order to convey a message. Monitoring and repair (Table 25) refer to the capacity to mend an error. Each item is described in terms of abilities:

B1 Can rehearse and try out new combinations and expressions inviting feedback. Can work out how to communicate the main point/s he/she wants to get across, exploiting any resources available and limiting the message to what he/she can recall or find the means to express.

Table 23. Written production strategies. Planning (CE, 2001:64).

B1 Can define the features of something concrete for which he/she can't remember the word.

Can convey meaning by qualifying a word meaning something similar (e.g. a truck for people - bus).

Can use a simple word meaning something similar to the concept he/she wants to convey and invites "correction".

Can foreignise a mother tongue word and ask for confirmation.

Table 24. Written production strategies. Compensating (CE, 2001:64).

B1 Can correct mix-ups with tenses or expressions that lead to misunderstandings provided the interlocutor indicates there is a problem. Can ask for confirmation that a form used is correct Can start again using a different tactic when communication breaks down.

Table 25. Written production strategies. Monitoring and repair (CE, 2001:65). 
Errors related to these categories would imply inability to communicate, to be flexible or able to work the way around words in order to express a message.

With regard communicative language processes, the CEFR specifies that to write, the learner must be able to either write or type the text and to organise and to formulate the message (referring to cognitive and linguistic skills). These apply to note taking and text processing. Descriptors for this have been gathered in Table 26 and Table 27.

B1 Can take notes during a lecture which are precise enough for his/her own use at a later date, provided the topic is within his/her field of interest and the talk is clear and well-structured.

Can take notes as a list of key points during a straightforward lecture, provided the topic is familiar, and the talk is both formulated in simple language and delivered in clearly articulated standard speech.

Table 26.

Written Production. Note-taking. (CE, 2001:96).

B1 Can collate short pieces of information from several sources and summarise them for somebody else.

Can paraphrase short written passages in a simple fashion, using the original text wording and ordering.

Table 27. Written Production. Processing text. (CE, 2001:96).

These categories refer to the ability to transform information into different formats, layouts or even genres as well as to the ability to edit and paraphrase texts obtained in a variety of ways, respecting the original formats. 


\subsubsection{Pragmatic errors}

According to the CEFR (CE, 2001:123), and as mentioned repeatedly, three different aspects are considered Pragmatic competences: discourse competence, functional competence and design competence. Each one of these refers to specific aspects of communication, for instance discourse competence deals with the organisation, structure and arrangement of the text, functional competence is related to communicative functions, and design competence refers to the sequencing of messages according to interactional and transactional schemata.

Focusing on Discourse, errors in this category would be related to the failure of a learner to arrange sentences in sequence so as to produce coherent stretches of language. Thus, errors would be related to the misidentification or lack of identification of topic/focus, or given/new items. Additionally, failure to take into account a natural sequencing (for instance a temporal sequencing), or a cause and effect relation would be considered errors.

Furthermore, other items are considered crucial in the organisation of information to be conveyed, if the aim is to communicate, these could be errors related to discourse structure: unclear thematic organisation, lack of coherence or cohesion in structure, or illogical or unreasoned ordering. The recognition and reproduction of the style and register required for the type of text written are essential in its appropriateness or lack of it. Moreover, rhetorical effectiveness is required. The explicit 
inclusion of Grice's cooperative principles as the pragmatic reference in the document is a tool to help us identify errors in the implementation of pragmatic awareness. According to the text, inefficient communication can be caused for lack of consideration of these principles (CE, 2001:123):

[...] the 'co-operative principle' (Grice 1975): 'make your contribution such as is required, at the stage at which it occurs, by the accepted purpose or direction of the talk exchange in which you are engaged, by observing the following maxims:

- quality (try to make your contribution one that is true);

- quantity (make your contribution as informative as necessary, but not more);

- relevance (do not say what is not relevant);

- manner (be brief and orderly, avoid obscurity and ambiguity)'.

With regard design competence in the document, it basically considers text design, and requires the ability to know the design conventions of every specific text and genre, regarding a wide variety of possibilities, from the realisation of macrofunctions (description, narrative, etc.), to the recognition and ability to reproduce ways in which specific utterances are produced, such as anecdotes, stories, cases, essays, formal letters, etc. Emphasis is set on possible differences between MT and L2 designs. Any shortage in this sense would be considered an error and a hinder to communication.

The following tables (28 to 31 ) display the abilities which identify these aspects in written texts. These descriptors are crucial in the understanding of the particular abilities required at a given level of proficiency (B1), since, as seen, the explanations associated to them are 
quite extensive and general, and it is not required of the learner to master them, but to be able to take them into account at a certain level.

B1 Can adapt his/her expression to deal with less routine, even difficult, situations

Can exploit a wide range of simple language flexibly to express much of what he/she wants.

Table 28. Pragmatic competences. Flexibility (CE, 2001:124).

For instance, an error related to flexibility would refer to impossibility or a failure to adapt either a message or the particular vocabulary the learner is able to use. Although at a simple level, a significant amount of vocabulary is required.

\begin{tabular}{|l|l|}
\hline B1 & Can intervene in a discussion on a familiar topic, using a suitable phrase
\end{tabular} to get the floor.

Can initiate, maintain and close simple face-to-face conversation on topics that are familiar or of personal interest.

Table 29. Pragmatic competences. Turn taking (CE, 2001:124).

Turn taking is associated to the ability to recognise the structure of a conversation and certain cultural and social conventions. However, as is only related to oral communication, it is not considered in the present study.

B1 Can reasonably fluently relate a straightforward narrative or description as a linear sequence of points.

Table 30. Pragmatic competences. Thematic development. (CE, 2001:125). 
Errors in a thematic development of an utterance would be related to inability to narrate or describe following a linear structure, or to be clear in the report.

B1 Can link a series of shorter, discrete simple elements into a connected, linear, sequence of points.

Table 31. Pragmatic competences. Coherence and cohesion. (CE, 2001:125).

Coherence and cohesion are crucial in communication, also at this given level of proficiency, and are very much linked to the previous item, since they are the elements which pinpoint the structure and the sequencing of the narration. Errors in this matter could be related to lack of knowledge or misuse.

Additionally, the text includes as pragmatic competence issues related to sociolinguistic aspects of communication, for instance markers of social relations, register differences, politeness conventions, and L2 cultural knowledge. Table 32 accounts for the necessary abilities related to this significant issue in communication and appropriateness:

\begin{tabular}{|l|l|}
\hline B1 & $\begin{array}{l}\text { Can perform and respond to a wide range of language functions, using } \\
\text { their most common exponents in a neutral register. } \\
\text { Is aware of the salient politeness conventions and acts appropriately. } \\
\text { Is aware of, and looks out for signs of, the most significant differences } \\
\text { between the customs, usages, attitudes, values and beliefs prevalent in } \\
\text { the community concerned and those of his or her own. }\end{array}$
\end{tabular}

Table 32. Sociolinguistic appropriateness (CE, 2001:122).

As can be seen, it emphasizes the need for appreciation and use of social conventions in L2, as well as the comparison between elements which might be different, in order to avoid both confrontation and 
misunderstanding. At this stage of proficiency, the use of a neutral register is required, but the recognition of several registers is expected. A certain degree of politeness is likely in the learner of an L2, which should consider not L1 conventions, but conventions in the foreign language studied. Any shortage in these issues would be considered an error. 

OBJECTIVES 



\section{OBJECTIVES}

A considerable amount of literature has been devoted to the study of Pragmatics in relation to SLA. The approaches have been varied, as are their main points. Earlier studies focused on the relationship between Grammar and Pragmatics. Mindful of this, the works of Ellis (1992; 1997), or Kasper (1999) are crucial, in addition to those of Canale and Swain (1980). The latter proposed a framework of reference for SLA, establishing three components: grammatical, sociolinguistic, and strategic competences. For these, the pragmatic competence was included within the sociolinguistic competence and thus, included within the confines of sociolinguistics.

Throughout literature, it has been accepted that error can be a useful tool both for teachers and students to establish a clear rationale of the point in the learning process where they stand. This, in turn, can help in the demarcation of the particular aspects in need of improvement to progress and achieve a greater level of proficiency and fluency. Additionally, it can also help examine the teaching method itself, and clarify whether the proposals offered are useful for the learner. This shifts the focus of interest from the teacher or the 
method to the actual users, and the possible results obtainable throughout their learning process.

The intention of the present work is to contribute to this type of analysis, by examining written text production in English at university level from a pragmatic perspective and, in particular the texts of students in their first year at university. By this stage, according to the CEFR, students should have acquired a B1 level of proficiency. Some errors are specific to this particular stage of proficiency. Two interpretations can be extracted from this. The first involves the type of errors that can be assigned to a certain level of proficiency, whereas the second refers to the ways in which errors can be used to identify, clarify or define the level of proficiency students have at a certain point in their learning process.

\subsection{General objectives}

The general objective of this research relates to the role of error in language learning. In the case of analysing the production of linguistic error in languages foreign to the user, the different approaches have been highly developed throughout the literature. Some authors have focused on the reasons behind error production, in an attempt to explain why users produce linguistic errors in languages different from their own (Corder, 1967; 1974; 1981; Bueno González, Carini Martínez \& Linde López, 1992; Carrió, 2004; 2005b; Hamid, 2007). Indeed, they have been interested in clarifying whether this is a matter of defective teaching, or a result of poor presentation by teachers of the subject - 
second language - to their students. Some authors have also considered whether it is intrinsic to learnt (as opposed to native) language, focusing on the differences between first and second language acquisition (French, 1949; Haugen, 1950; Richards, 1971; 1974; Friedlander, 1990).

The main aim of this study is to detect and analyse the types of errors made by students when writing in English as a foreign language. Three elements have been included in the analysis: The first area of concern was error detection and analysis. Here, pragmatic errors in written production in English are examined in order to clarify the error type. Additionally, a classification, which looks at how errors can influence -or hinder-communication is outlined.

Secondly, the learning of English as a second language, and the point in the learning process where students stand is considered and examined, taking the items in which errors are incurred as a measuring unit. The intention is to identify the most common errors students make at a given point in their learning process. This helps in the identification of the CEFR level of proficiency.

Finally, the approach aims to study production at university level, which should comply with the current provision, or at least follow the recommendations proposed in this particular environment. In the case of the university, the CEFR is used as a reference for analysis. In addition, this can also have implications for the evaluation of existing assessment guidelines and their possible future improvement, and the enhancement of University syllabuses capable of pursuing the specific items which have proven problematic for students. 


\subsection{Specific objectives}

This particular investigation is interested in exploring error and its relation to language learning. Several research questions justify these objectives:

\section{Can Error Analysis assist in language teaching?}

The first specific objective of this dissertation is to establish the way in which error analysis can assist in language teaching. To do this, it is necessary to analyse the types of errors students make, and use these as proposals for improving the learning process. For some time now, indeed since the end of the last century, we have been immersed in a changing conception of what language teaching should be (Canale \& Swain, 1980; Carrió, 2008). This change involves the idea that a language is not only a set of different items which needs to be mastered (vocabulary, grammar, etc.), but also, and foremost, is a tool for communication. Indeed, many authors (Widdowson, 1978; Canale \& Swain, 1980; Ellis, 1985; 1994; 2005) have argued that language teaching (and consequently language learning) must be directed at teaching those skills which enable the student to communicate. This is commonly referred to as the Communicative Approach, as extensively explained in previous chapters.

Among other implications, the Communicative Approach proposes shifting the focus throughout the learning process from the teaching or the method to the student. This contrasts with other teaching methodologies. Over the past decades, the Communicative Approach 
has been introduced at different levels of education, and is central to the proposals reinforced by the European Community in its latest legislation relating to languages and language learning.

The Communicative Approach includes the linguistic, sociolinguistic and pragmatic aspects of language. Thus, in order to study errors, and possible proposals for improvement, the document concentrates firstly on completing a pragmatic analysis of several texts produced by students. As is widely acknowledged, some pragmatic aspects can be transferred from L1 to $L 2$. This can be useful to analyse whether students are conscious of this in addition to examining the use they make of their L1 or L2 pragmatic knowledge.

2. Can an Error Analysis grid be elaborated to determine the types of errors students make and relate them to their proficiency levels and pragmatic awareness?

The second specific objective is to elaborate a quantifiable and reliable analysis grid, in order to investigate the proficiency level of students, in addition to their pragmatic awareness. Focusing on the learner, the Communicative Approach confers on Pragmatics a significant role in the learning process. Certainly, if the CEFR no longer focuses on traditional approaches or grammar, it is necessary to consider whether the CEFR offers the necessary means to approach, assess and calibrate error from a perspective in the Communicative Approach; Pragmatics. Teachers are invited to use the CEFR, as extensively explained above. However, applying the recommendations contained within this to error assessment and correction in the classroom environment is not 
straightforward. Indeed, the document is set out in very broad terms, the application of which should be made available to teachers in a simpler and more understandable manner.

3. Are the CEFR guidelines and descriptors useful for error analysis?

The third specific objective of the dissertation is related to the Common European Framework for Languages (CE, 2001). This objective aims to detect if the sort of descriptions, guidelines and assessment contained within the CEFR are useful for error analysis, or if they need to be actualised. The CEFR is intended to facilitate work with the Communicative Approach in the European classrooms. Based on the perception of language as communication, this framework document establishes guidelines which can help teachers and students in the learning process. For this, the proposals related to the Communicative Approach in the CEFR are examined to see how they can be used to help teachers and students approach learning, (self) assessment and (self) correction.

4. Can errors be classified from a Pragmatic point of view using the CEFR?

Accordingly, the fourth specific objective of the dissertation is to propose a classification and rate errors from a pragmatic point of view following the guidelines proposed by the CEFR. As explained earlier, the results obtained from the study can help address the issue of whether the CEFR 
levels offer the appropriate means to analyse and correct the errors incurred by students from a pragmatic perspective.

5. Can language teaching be improved by combining the CEFR, the Communicative Approach, and Error Analysis?

The fifth and last objective aims to establish if a combination of the CEFR, the Communicative Approach, and error classification can help improve language teaching and learning. It specifically attempts to elucidate whether we can improve the level of proficiency of students by focusing on the errors they make. Traditionally, students within the Spanish Academic System have been rated very poorly with regard to second language proficiency. For this reason, it is crucial to analyse methods for improving both the ways in which we learn language and the ways in which we teach it.

Indeed, universities throughout Europe are now experiencing a time of change after the Bologna Process was agreed by the member states, including Spain. In addition to the different principles and contents that need to be added by all European universities to their syllabuses, in some areas levelling is necessary in order to guarantee suitable mobility and equality in the obtainment of a university degree. Such is the case for the English language. Universities are now requested to provide the opportunity for their students to obtain a minimum B2 level of English and/or another foreign language.

As for the applications of these objectives, the levels of proficiency of students can be established depending on the type of errors they make. 
This can help determine the actual levels of proficiency in the language classroom for each language competence, and specifically for the pragmatic competence.

Indeed, by studying errors, it is possible to establish the ways in which issues in Pragmatics could be addressed in the language classroom and other ways of promoting student's self-improvement and selfassessment may also be determined.

The CEFR document can be used to establish useful and objective assessment tools, based on the analysis of its descriptors and approaches to communication.

Based on actual results, these objectives can also help harmonise the existing perceptions of language knowledge and communicative efficacy in the English classroom. If proven necessary, it would be possible to use the results obtained in the modification of University syllabus, to include the particular issues in which students prove to have more difficulties. 
METHODOLOGY 



\section{METHODOLOGY}

In this chapter, the material used in this doctoral dissertation is presented. A series of written texts produced by students of English as a second language at university level is analysed from a pragmatic perspective in this research. The methodology employed is described hereafter.

The first section presents an overview of the process of data collection. First, it introduces the students who produced the texts. Next are described the texts analysed together with their background (for example, text types, level of proficiency, etc.). Subsequently, in the third subsection, the corpus chosen for analysis, and the particular specifications (amount of texts, specific features) derived from these are explained.

A second section is dedicated to providing a detailed explanation of the idiosyncrasy of the error-tagging and correction system used in the texts. The first subsection details the correction process; the second, the markers who carried out the correction and tagging. This involves taking into account the CEFR as a framework of reference, and the specific items related to pragmatic awareness and proficiency chosen to analyse 
the texts. Then, the third section introduces the pilot study used as the foundation of the present research. Finally, the fourth section presents the analysis grid elaborated to spot and tag error.

The methodological approach chosen is a mixed research method. In Applied Linguistics, the distinction between quantitative and qualitative research methods is well known and broadly accepted. Quantitative research includes the collection of data intended to obtain numerical results, whereas qualitative research usually refers to non-numerical data, analysed by means other than statistical analysis. However, Richards (2005, in Dörnyei, 2006:25) wisely emphasises that "qualitative and quantitative data do not inhabit different worlds. They are different ways of recording observations of the same world". Indeed, Sandelowski (2003) broadens this notion and explains that qualitative and quantitative investigations are not plainly distinguishable, arguing that a comparison between these two cannot be made.

Due to the idiosyncrasies of the features analysed in this doctoral dissertation, it was difficult to consider the text merely from a quantitative viewpoint. A mixed method was thought to be much more appropriate for the purposes of the analysis, coinciding with the recommendations expressed by Miles and Huberman (1994, in Dörnyei 2006:42):

Entertain mixed models. [...] Quantitative and qualitative inquiry can support and inform each other. Narratives and variable-driven analyses need to interpenetrate and inform each other. [...] think of it as hybrid vigour. 
And also with the Grounded Theory by Strauss and Corbin (1990:34):

Qualitative and quantitative forms of research both have roles to play in theorising. The issue is not whether to use one form or another but rather how these might work together to foster the development of theory.

The corpus analysed consists of a collection of texts studied from a pragmatic perspective. The examination centres on a set of items, some broad and others specific, intended to evaluate different aspects of the written texts. The revisions were carried out by different markers in order to offer a wider perspective of the results obtained. Since part of the analysis always depends on the criterion of the markers, which introduces open aspects to the analysis, a mere quantitative analysis was considered insufficient. Indeed, some of the items analysed were easy to identify and leave little room for interpretation, however, others were much more open to the judgment of the marker. Apart from a quantitative statistical analysis, a qualitative analysis of the results is also presented for some of the items.

If we reproduced Larsen-Freeman \& Long's explanation (1991) about research methodologies in SLA, in which they compare cross-linguistic (quantitative) and longitudinal (qualitative) approaches, establishing a continuum for them, the present study could focus on the participant observation, since the teacher who instructed the students also participated in the research. However, the post-analysis of results takes a more external view, and uses a quantitative approach, as we can observe in Figure 15. 
Introspection

\section{(1)} observation

\begin{tabular}{c|c|c}
$\begin{array}{c}\text { Nonparticipant } \\
\text { observation } \\
\text { tht }\end{array}$ & Pre- \\
Focused \\
description
\end{tabular}

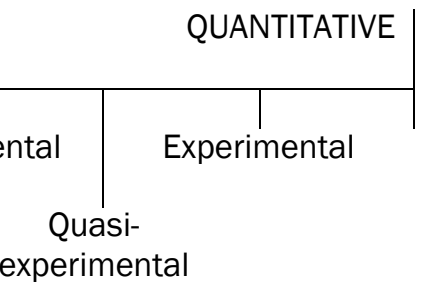

Figure 15. Qualitative-Quantitative Continuum of Research Methodologies. LarsenFreeman \& Long (1991:15).

The texts analysed were collected over three different academic years: 2008-2009, 2009-2010 and 2010-2011. However, the system chosen to study them is not a longitudinal investigation, since although collected data referred to the different time periods, the study did not aim to compare the differences between the years of production of the texts, but rather chose to focus on the particular text types and specific items proposed for the analysis. Nevertheless, this still cannot be considered a cross-sectional analysis, since it does not establish comparisons between the different groups analysed, but rather considers all the texts as one single corpus, and disregards the group of origin.

In this manner, it can be said that the outset of the analysis could be considered qualitative, including participant observation, since the texts were written as a result of the teacher's instructions, and were not produced freely by students in an open context. Moreover, the texts were selected to match those proposed in the CEFR document. Additionally, the study incorporates quantitative analyses to focus on and study the results obtained, including statistical resources, required to deal with 
different variables such as texts, pragmatic issues, and markers, as well as a qualitative analysis.

This particular methodology was firstly chosen to help illustrate what exactly are considered errors in ESL, from the viewpoint of Pragmatics. Secondly, it may also prove useful to reflect upon its particular implementation; how errors are spotted and annotated. This can lead to the analysis of the degrees of convergence and divergence expected and those identified in the actual corrections. Additionally, it reveals the extent of agreement in the application of the correction and subsequent tagging of errors. Thirdly, it is helpful in assessing the items used for the correction. The correction of the texts gives some insight into the actual items themselves. Indeed, the results provide information about the usefulness and reliability of the items selected. Finally, the particular errors encountered can help in the classification of the types of errors expected at a B1 level of proficiency.

\subsection{Data collection}

Two different chapters are dedicated to data. The first refers to data collection and includes the setting for the analysis and the different processes leading to the obtainment of data, prior to being treated for use in the analysis. All aspects related to the treatment and processing of these data are included in the next section: data processing. 
In the following subsections all the features related to the type of data analysed and their collection and preparation for the analysis are described. General explanations are offered for each particularity of the corpus of the texts gathered. The process of data collection is presented first, and consists of three different sections. The initial subsection is dedicated to the description of the students who wrote the texts, referring to sources of the texts and the levels of proficiency in the texts. Next, the second subsection is devoted to the actual texts, explaining the contexts which occasioned them, the justification of the texts chosen and their relationship to the CEFR as a reference point, both with regard to the proposal of the texts to the students by the instructor and in the subsequent analytic procedure. Finally, an extensive third subsection details the construction of the corpus for analysis, with the variables included to offer significant information from different viewpoints.

\subsubsection{The students: origin of texts and level of proficiency}

On the subject of the particular data related to students, only a general overview can be offered. Most of these students were aged between 18 and 20 and were enrolled in the first academic year of a degree at the Universitat Politècnica de València. Students of different origins and educational backgrounds attended the classes, but all the texts selected had been produced by students with a Spanish academic background. 
While the degrees of fluency and levels of proficiency varied considerably in that first year of education at university, all students had received similar instruction in their previous schooling. They had been studying English for an average of ten years ${ }^{10}$. Some of the students may have taken English courses privately, or attended the Escola Oficial d'Idiomes, or even spent some time in an English-speaking country, as a summer activity.

Prior to being enrolled at university, each student had passed the University Entrance Examination, although there are no data as to whether they passed or failed the English exam ${ }^{11}$, or just averaged their mark $^{12}$. Some students may not have passed the English exam, but they had definitely passed the examination, obtaining an overall mark.

The students registered for the Degree in Tourism at the Escola Politècnica Superior de Gandia, of the Universitat Politècnica de València (UPV). This can suggest a particular leaning towards languages, and in particular, towards English, the first foreign language taught in Spain, followed by French and German.

English is a compulsory subject throughout the Degree in Tourism Management (over three academic years, resulting in 27 ECTs, at the

10 In the Spanish education system, English is an obligatory subject in primary and secondary compulsory education. It is also obligatory in the optional secondary education curriculum, prior to entrance to University.

11 The University Entrance Examination consists of a set of exams, six in total, which students have to sit. These exams include three core subjects for the type of secondary school studies (Batxillerat/Baccalaureate) chosen, and three specific to their area of specialisation; ScientificTechnical, Health Sciences, Humanities, Social Sciences or Arts.

12 The final mark is calculated as the mean obtained from the exams sat (the minimum mark to be considered for the global calculation being 4/10), representing $40 \%$ of the mark, and the mean of the academic record of secondary education, which represents $60 \%$ of the final mark. 
Universitat Politècnica de València, as was the case for the previous B.A. in Tourism (also over three years, for a total of 18 UPV credits $^{13}$ ). In view of the fact that the texts were produced during their first year at university, this change in the number of credits and the number of hours dedicated to the learning of the language is not significant, since the students arrived with a similar level of proficiency, which had been obtained through their previous education at Primary and Secondary School, and at Sixth Form college (in Spain 16 to 17 year olds).

\subsubsection{The texts}

A short description now follows of the general characteristics of the texts analysed. This is necessary in order to explain the explicit instructions motivating these, although the particular specifications of each text included in the set are explained in the section dedicated to the description of the corpus. The entire corpus of texts produced by the students is available in Annex 2. This initial introduction only aims to present the context in which the texts were instructed and produced.

\subsubsection{General description of the texts}

The collection of texts analysed was produced from written tasks set as homework for the classes of English I and English for International Tourism over the academic years 2008-2009, 2009-2010 and 2010-

\footnotetext{
13 In 2009 the new Bachelor Degree Programme in Tourism Management (in compliance with EHEA) was introduced at the Escola Politècnica Superior de Gandia., and subsequently, the former Bachelor Degree in Tourism was discontinued.
} 
2011. The tasks aimed at helping these learners to improve their writing skills, as well as to achieve specific competences such as text recognition, register awareness or introduction of specific vocabulary. In the CEFR (CE, 2001:165), it is recommended that:

In evaluating a text for use with a particular learner or group of learners, factors such as linguistic complexity, text type, discourse structure, physical presentation, length of the text and its relevance for the learner(s), need to be considered.

The students were given specific instructions regarding the production of texts and expected length. In the case of specific written pieces, explanations and classroom work preceded the individual tasks. In cases where specific vocabulary was required, preparatory work had already been carried out in the classroom.

The electronic learning platform existing at the Universitat Politècnica de València (PoliformaT) was used as the communication tool between the teacher and students. The tasks assigned were uploaded electronically by the teacher and the students consequently uploaded the tasks produced in the time established for them, without any other contact. There was no interference in the reception, or the correction of the texts. Examples of the assignments given to the students are ${ }^{14}$ :

- GIVE YOUR OPINION. What do you know about the International Women's Day? Find attached a document on the history of March 8 and the link to the UN charter. Give your personal opinion on the situation of women in the world today. (150-200 words).

14 The entire list of assignments can be found in Annex 1. 
- GIVE YOUR OPINION. What does it mean to be a student today? Write a short dissertation expressing your opinion about what a university student's life is and should be. (150-200 words).

- WRITE A FORMAL E-MAIL. Reply to an e-mail enquiry ${ }^{15}$. Pay attention to the language used (100-150 words).

- WRITE A LETTER OF APOLOGY in response to the one reproduced below ${ }^{16}$. Use the expressions and vocabulary learnt in class. Pay attention to the layout. (100-150 words).

- WRITE THE COVERING LETTER you would send with your CV to apply for this job. Use the appropriate expressions and layout. (150-200 words).

- SUMMARISE A FILM. What is the last film you have seen and liked? Can you summarise the plot? What happened? (Max.: 200 words).

As explained, the texts selected for analysis had been produced in a digital format by the students. This simplified the correction of the set in two ways; first of all, all previous corrections and ratings, which had been used in class as part of class homework and marking, were eliminated from the texts. Secondly, the possibility that the student's handwriting could obstruct the correction or interpretation of the texts was eliminated. The topics chosen were related to the specific subject matters students had been learning and practising in class -topic, vocabulary - and the format, layout and structure required for each of these had also been explained and practised during class. The texts, however, were produced by the students as individual tasks without guidance from the tutor.

15 The e-mail is reproduced in Annex 1.

16 The letter is reproduced in Annex 1. 


\subsubsection{Text types in the CEFR}

The Common European Framework of Reference for Languages establishes (CE, 2001:13) the identification of text types and forms as one of the Pragmatic competences that students should master. The document also offers a list of text characteristics, specifying which aspects would be useful in helping students to reach proficiency in their L2 (CE, 2001:164-5):

[...] familiarity with the genre and domain (and with assumed background and sociocultural knowledge) helps the learner in anticipating and comprehending text structure and content; the concrete or abstract nature of the text is also likely to play a role; for example, concrete description, instructions or narratives (particularly with adequate visual supports), for example, are likely to be less demanding than abstract argumentation or explanation [...].

Additionally, short texts are highlighted as preferable to long texts, thus helping avoid distraction or fatigue. Special significance is placed on whether the text produced is relevant to the learner or not. This is related to the actual motivation of the writer, and is crucial in the student's involvement in achieving proficiency, (CE, 2001:166):

Encouraging learners to express their personal knowledge, ideas and opinions within a comprehension task may increase motivation and confidence, and activate linguistic competence related to the text. Embedding a comprehension task within another task may also help to make it inherently purposeful and increase learner involvement.

The texts chosen for analysis were selected from those proposed by the CEFR (hereby reproduced in Figure 12). The text types listed under the category of written texts and proposed for study and schoolwork in the 
CEFR (CE, 2001:95) are, to mention a few: books; magazines; newspapers; instruction manuals (DIY, cookbooks, etc.); textbooks; comic strips; brochures, advertising material; public signs and notices; market stall signs; packaging and labelling on goods; forms and questionnaires; dictionaries (monolingual and bilingual), thesauri; business and professional letters, faxes; personal letters; essays and exercises; reports and papers; notes and messages.

Since level B1 falls almost entirely under the familiar and personal domain within the CEFR ${ }^{17}$, four sets of text are based on the students' opinions regarding the different subjects proposed. In Table 1 of the Common Reference Levels (CE, 2001:24), when dealing with the global scale ${ }^{18}$, focus is centred on the linguistic field (setting, or, as referred to in the document, domain), which should be familiar, or standard in the case of students possessing certain linguistic skills, but who have not yet reached a sufficient level of fluency to deal with more complex situations. The Table also gives us instructions as to the type of texts the learners should be able to produce at this particular level of proficiency (CE, 2001:24):

Can understand the main points of clear standard input on familiar matters regularly encountered in work, school, leisure, etc.

Can deal with most situations likely to arise whilst travelling in an area where the language is spoken.

\footnotetext{
17 In the CEFR, Domain refers to "the broad sectors of social life in which social agents operate. A higher order categorisation has been adopted here limiting these two major categories relevant to language learning/teaching and use: the educational, occupational, public and personal domains".(CEFR, 2001:10)

18 Global scale is described in the CEFR (CE, 2001:24) as "single holistic paragraphs, [...] a simple 'global' representation will make it easier to communicate the system to non-specialist users and will also provide teachers and curriculum planners with orientation points.
} 
Can produce simple connected text on topics which are familiar or of personal interest.

Can describe experiences and events, dreams, hopes and ambitions and briefly give reasons and explanations for opinions and plans.

The types of texts chosen for analysis in this particular investigation are connected with the activities proposed in the CEFR as written production activities (CE, 2001:61). Indeed, the text not only recommends a particular environment, but also specifies the variety of texts that a B1 user is expected to be able to write, according to the skills required and the level of difficulty this can introduce.

Descriptors are offered for creative writing, directly related to the fields of interest, personal life events or experiences, or stories which somehow fall within their range of knowledge. In this section, the learner is not expected to have any specific knowledge, since all descriptors relate to familiar environment, standard setting, and to personal interest, without any type of specialisation, as can be seen:

\footnotetext{
Can write straightforward, detailed descriptions on a range of familiar subjects within his/her field of interest.

Can write accounts of experiences, describing feelings and reactions in simple connected text.

Can write a description of an event, a recent trip - real or imagined.

Can narrate a story.
}

Similarly, for reports and essays, the descriptions given for a B1 level consider the personal interest of the writer, focusing on the individual approach to the explicit subjects proposed, thereby establishing a personal relationship between the specific types of texts recommended and the authors behind them. Indeed, the CEFR refers to confidence as 
a feeling which can support a text, as well as to the possibility of establishing reasons for actions and consequences (CE, 2001:62), as observed in:

Can write short, simple essays on topics of interest.

Can summarise, report and give his/her opinion about accumulated factual information on familiar routine and non-routine matters within his/her field with some confidence.

Can write very brief reports to a standard conventionalised format, which pass on routine factual information and state reasons for actions.

However, there is an explanatory note to these descriptors, specifying the lack of a general scale by which to analyse them. This leaves us with the need to find an appropriate scale to measure these activities (CE, 2001:61):

The descriptors on this scale and on the two sub-scales which follow (Creative Writing; Reports and Essays) have not been empirically calibrated with the measurement model. The descriptors for these three scales have therefore been created by recombining elements of descriptors from other scales.

This relates to what Weir $(2005: 281)$ refers to as the limitations of the CEFR, explaining that in some cases, the document falls short of specifications, and other means are necessary to be able to test or even assess the production of the learners:

Though also containing much valuable information on language proficiency and advice for practitioners, in its present form the CEFR is not sufficiently comprehensive, coherent or transparent for uncritical use in language testing.

In the process of text selection, macrofunctions, as described in the CEFR (CE, 2001:126) were taken into account: “Macrofunctions are 
categories for the functional use of spoken discourse or written text consisting of a (sometimes extended) sequence of sentences". Among the examples offered the following can be mentioned: commentary, description, narration, exposition, exegesis, explanation, demonstration, instruction, argumentation or persuasion.

In addition, the set selected for analysis also includes several texts related to the self-expression of daily situations, while others are related to formal writing, which was learnt by the students as part of their training in Tourism Management. These were included to analyse some aspects connected to the specificity of the language, since they were produced at university level.

\subsubsection{The error corpus}

Even before the use of computer software, the study of language has often been conducted based on the analysis of linguistic corpora, capable of offering the required variations in contexts, items and uses as proposed by Palacios and Alonso (2005:749):

\footnotetext{
Corpus-based approaches to the study of language have been proven to be particularly suitable for the analysis of lexical features of a language (meaning and senses of words, frequency of words and word-counting concordances, word combinations, vocabulary patterns, collocations and fixed expressions).
}

With regard to the appropriate methodology, which could help in analysing and reflecting upon the possibilities offered by the CEFR to work with the students' written production from a Pragmatic perspective, 
several options were examined. Hence, the overriding theme was to find the most appropriate method to analyse written texts produced by students, flexible enough to permit a different approach from those proposed by Palacios and Alonso, and to support a Pragmatic perspective.

The first issue to address was the need to create an adequate error corpus to work with. To facilitate this, the approach proposed by McEnery (1996:21) was considered and followed:

\begin{abstract}
In principle, any collection of more than one text can be called a corpus, [...]. But the term "corpus" when used in the context of modern linguistics tends most frequently to have more specific connotations than this simple definition provides for. These may be considered under four main headings: sampling and representativeness, finite size, machine-readable form, a standard reference.
\end{abstract}

The third of these characteristics was disregarded. Indeed, the treatment of the error corpus was not executed in a digital form. Although all the texts analysed had been produced in an electronic format, the marking was carried out manually. The reasons being the complexity surrounding the interpretation of the items that had to be marked in the texts, and the preferences of the markers when facing the texts, as will be explained later. Indeed, the type of correction applied to the texts made it preferable to complete the marking of errors manually, since it was not necessary to correct the errors encountered, but to mark them and annotate them from the list proposed, as errors of a particular type. 
The remaining three features (sampling and representativeness, finite size, and standard reference) were taken as the starting points from which to create the corpus. Regarding sampling and representativeness, it was impossible to analyse all written texts produced by students at university. Thus, although aware of the fact that some aspects could be omitted due to the size of the corpus or the type of texts, we have chosen a sufficiently large corpus to average out the total and offer "a reasonably accurate picture of the entire language population in which we are interested" (McEnery, 2001). Specifically regarding sampling, in accordance with Sinclair (2004:31) some considerations were regarded:

There are three considerations that we must attend to in deciding a sampling policy:

1. The orientation to the language or variety to be sampled.

2. The criteria on which we will choose samples.

3. The nature and dimensions of the samples.

As mentioned previously, all texts were produced by first year University students between 2008 and 2011 over three different school years; in 2008-2009 by students of English I in the existing B.A. in Tourism, and 2009-2010 and 2010-2011 by students of English for International Tourism in the relatively new degree of Tourism Management.

For the purposes of this investigation, a finite size corpus was created, composed of 206 texts, which add up 38,829 words and 1,760 paragraphs. The ten sets of texts were selected from those written by students as belonging to different categories and layouts which appropriately matched the text types proposed by the CEFR. As explained above, the criterion chosen to select the texts was based 
solely on the educational background of the students, and no other filter was applied to the set. Table 33 represents the type of texts and the amount of utterances produced in each case can be seen below:

\begin{tabular}{|l|r|}
\hline TEXT & N. TEXTS \\
\hline 08-09 SUMMARISE A FILM & 21 \\
\hline 08-09 OPINION & 20 \\
\hline 08-09 COVER LETTER & 28 \\
\hline 09-10 APOLOGY & 17 \\
\hline 09-10 OPINION 1 & 18 \\
\hline 09-10 OPINION 2 & 16 \\
\hline 09-10 SHORT SUMMARY & 21 \\
\hline 10-11 NARRATE A TRIP & 26 \\
\hline 10-11 OPINION & 20 \\
\hline 10-11 E-MAIL & 19 \\
\hline \multicolumn{2}{|c|}{ Number of texts per text type. }
\end{tabular}

Thus, all students attended class with the same tutor, and were given identical instructions. They produced the texts as homework assignments. All texts included in the corpus were written by the group of students who met two particular specifications. Firstly, student background - which referred, as explained above, to students who had completed their secondary education in Spain - and secondly, the text type chosen for analysis, among the many written by the students. In short, although the text type and origin of student were taken into account when deciding on the texts which would integrate the corpus, no further selection of the texts was carried out. This is congruent with the 
specifications given by Dörnyei (2007:98) as to which sampling strategy can be most convenient for the analysis:

The most common sample type in L2 research is the 'convenience' or 'opportunity sample', where an important criterion of sample selection is the convenience of the researcher [...] Captive audiences such as students in the researcher's own institution are prime examples of convenience samples.

The texts have been classified according to the year of production (08, 09 or 10) and given a code to ensure these are easily identifiable. As can be observed in Table 34, the different text types considered for evaluation are Narration/Summary $(\mathrm{N})$, Opinion (O), and Formal writing (L):

\begin{tabular}{|l|r|c|}
\hline TEXT & TEXTS & CODE \\
\hline 08-09 SUMMARISE A FILM & 21 & 08-S1 \\
\hline 08-09 OPINION & 20 & $08-01$ \\
\hline 08-09 COVER LETTER & 28 & $08-$ L1 \\
\hline 09-10 APOLOGY & 17 & $09-$ L2 \\
\hline 09-10 OPINION 1 & 18 & $09-02$ \\
\hline 09-10 OPINION 2 & 16 & $09-03$ \\
\hline 09-10 SHORT SUMMARY & 21 & $09-S 2$ \\
\hline 10-11 NARRATE A TRIP & 26 & $10-S 3$ \\
\hline 10-11 OPINION & 20 & $10-04$ \\
\hline $10-11$ E-MAIL & 19 & $10-L 3$ \\
\hline & 206 & \\
\hline
\end{tabular}

Table 34. Number of texts and codification.

Under the category of narration/summary, two different types of production were included: narrations and summaries. These fall within the narrative text type and also belong to the informal writing group. These are 08-S1, with 19 texts, 09-S2, with 21 texts, and 10-S3, with 26 
texts. Regarding the texts included under the category of Opinion, it should be highlighted that the same task was proposed over the various years to the three different groups of students (texts 08-01, 09-02 and 10-04 -these add up a total of 60 texts), although it was not of interest to this investigation to compare the results for the different years analysed, as previously explained. An additional set belonging to this category is 09-03, with 16 opinions. The last group includes all texts relating to formal writing; 08-L1 (28 texts), 09-L2 (15 texts), 10-L3 (19 texts). Table 35 represents the number of texts under each of the broad categories, as well as the total number of texts included in each group:

\begin{tabular}{|c|c|c|c|c|}
\hline GROUP & CODE & TEXT & TEXTS & TOTAL \\
\hline \multirow{3}{*}{$\begin{array}{l}\text { NARRATION / } \\
\text { SUMMARY }\end{array}$} & 08-S1 & 08-09 SUMMARISE A FILM & 21 & \multirow{3}{*}{68} \\
\hline & 09-S2 & 09-10 SHORT SUMMARY & 21 & \\
\hline & $10-53$ & 10-11 NARRATE A TRIP & 26 & \\
\hline \multirow{4}{*}{ OPINION } & $08-01$ & 08-09 OPINION & 20 & \multirow{4}{*}{74} \\
\hline & $09-02$ & 09-10 OPINION 1 & 18 & \\
\hline & $09-03$ & 09-10 OPINION 2 & 16 & \\
\hline & $10-04$ & 10-11 OPINION & 20 & \\
\hline \multirow{3}{*}{$\begin{array}{l}\text { FORMAL } \\
\text { WRITING }\end{array}$} & 08-L1 & 08-09 COVER LETTER & 28 & \multirow{3}{*}{64} \\
\hline & 09-L2 & 09-10 APOLOGY & 17 & \\
\hline & $10-\mathrm{L} 3$ & 10-11 E-MAIL & 19 & \\
\hline
\end{tabular}

Table $35 . \quad$ Number of texts per group.

Since the texts were produced as class assignments, the authorship of some of these is coincidental. However, there is no possibility of one student writing the same text twice. The relationship between the number of texts written and the different authors is shown in Table 36. 


\begin{tabular}{|l|r|r|r|r|r|}
\hline YEAR & 1TEXT & 2TEXTS & 3TEXTS & 4TEXTS & STUDENTS \\
\hline 2008 & 11 & 11 & 10 & & 32 \\
\hline 2009 & 5 & 5 & 10 & 7 & 27 \\
\hline 2010 & 7 & 14 & 10 & & 31 \\
\hline
\end{tabular}

Table 36. Relationship between authorship and texts.

As a result, the texts obtained for the first year of the analysis (2008-09) include the works of 32 students, those obtained for 2009-10 were produced by 27 students, and 31 students wrote the texts examined for the 2010-11 course. Ninety students produced a total of 206 texts, each responsible for an average of 2.28 texts.

Needless to say, even if the texts had been obtained as a result of class assignments, the copies analysed had been cleaned of any previous annotation or tagging. This was easily attained since the corpus had been collected in digital format.

Although the types of texts chosen for analysis were not random, as outlined above, the language gained from the texts was unprocessed. As suggested by McEnery (1996), who insists that language needs to be obtained from such texts, and cannot be pre-determined according to the language used in them. Thereby helping to ensure that the sampling was as varied and unbound as possible, which was one of the main requirements to develop and work with language corpora (McEnery, 1996: 37): 
We are therefore interested in creating a corpus which is maximally representative of the variety under examination, that is, which provides us with an as accurate a picture as possible of the tendencies of that variety, as well as their proportions.

The texts chosen for analysis are consistent both with the descriptions offered by the CEFR regarding the type of texts, written activities and (macro)functions a B1 language user is expected to master and the particular learner specifications of university students registered for the Degree in Tourism Management. Consideration was given to the longestablished debate concerning what actually constitutes a valuable and feasible corpus (Carter \& McCarthy, 1995; Sinclair, 1992), and, in line with Hunston (2001:26), it was deemed important to really consider what is available, ensuring that the volume of the corpus meets the minimum size requirements. Hunston also insists upon the need to create a moderately balanced corpus, in which representativeness is considered not in the simplest form (equal number of words per category, for instance), but from a more complex perspective, while always being aware of the complicated issues which can arise from this, (Hunston, 2001:30): "The real question as regards representativeness is how the balance of a corpus should be taken into account when interpreting data from that corpus". As can be seen in the data processing and results sections, the findings take into account the size of the corpus as well as the variables considered in the analysis. 


\subsection{Data processing}

The experimental study carried out consists of two clearly differentiated parts. The first is related to the creation of the corpus, which includes the gathering and compilation of the texts. The second part concerns the actual processing of these data in order to offer specific results related to those initial raw texts. This is followed by a chapter dedicated to scrutinising the results obtained. The following section describes the treatment and preparation of the texts for analysis. This includes a description of the particular correction procedure used, the markers and their approach to correction, and the items chosen for tagging in the texts.

\subsubsection{Correction process}

In order to analyse the texts from a pragmatic perspective based on the CEFR, it was necessary to approach correction taking into account the specifications given in the document, in addition to the concrete aspects of interest in the texts. Undeniably, there is an increasing acceptance among teachers of the need to present a more communicative approach in all language courses, by incorporating the practice of new skills, functions and perspectives useful in the mastery of language. However, teachers frequently lack guidance as to how to approach the correction or grading of these new aspects introduced in the classroom. This problem is widely explained by Weir (2005:282), who insists on the 
inefficacy of the CEFR to test, whereas it is able to guide and to establish contexts for language development:

- The scales are premised on an incomplete and unevenly applied range of contextual variables/performance conditions (context validity);

- Little account is taken of the nature of cognitive processing at different levels of ability (theory-based validity);

- Activities are seldom related to the quality of actual performance expected to complete them (scoring validity);

- The wording for some of the descriptors is not consistent or transparent enough in places for the development of tests.

It is common for more importance to be given to the traditional methods of correcting and testing than to the actual training of these items. That is to say, although less time and instruction is dedicated to the study of grammar, this is still a crucial aspect in the correction of all production assigned to students. The correction carried out for this study differs slightly from this perspective, as is explained later. It is available in Annex 4.

\subsubsection{Markers}

There are many factors influencing error assessment, to guarantee validity and reliability 19 of the correction in process, which depend on the particular individuals responsible for completing the task of marking and correcting the texts. These have been studied in literature from different perspectives (Bachman \& Palmer, 1996; McNamara, 1996; Hillocks, 2002; Weir, 2005; Shaw \& Weir 2007). Indeed, these authors insist that

19 Although the validity of the texts analysed and the reliability of the corrections and ratings realised have usually been related to language testing (Fulcher \& Davidson, 2007; Hughes, 1989; Bachman \& Palmer, 1996), they are obviously important aspects of language correction when carried out by different professionals. 
the reliability issue is generally more complicated when tests involve human raters because human judgments involve subjective interpretation on the part of the rater and, as such, may lead to disagreement.

Therefore, a significant variable affecting text correction is, in fact, the individual marker ${ }^{20}$. Other variables can include the time allocated for completing each task, or location during task production (at home or in the classroom). Whereas validity usually refers to the texts, reliability in the correction and assessment stages is broadly related to the markers. In this sense, ensuring that the markers have specific instructions with regard to the method to employ when tackling the corrections is crucial for this research. According to Jones (1979), reliability depends on two variables: (1) the simulation of the test tasks, and (2) the consistency of the ratings. Regarding this second aspect, several types of reliability have been established: (1) inter-examiner reliability, (2) intra-examiner reliability, (3) inter-rater reliability, and (4) intra-rater reliability (Jones, 1979). In our case, attention should be given to (3) and (4).

In this study, we are very conscious that the fact that the correction was carried out by three different markers lends a degree of variability to the study. Indeed, when rating, different causes have been reported to result in inconsistency on the part of the markers. This depends on the

20 The term marker has been chosen following the Manual for Language Test Development and Examining to complement the CEFR in assessment issues. The document explains that (2011:38) marking, "covers all activities by which marks are assigned to test RESPONSES". However, a distinction is made between markers and raters. "Clerical markers do not need to be testing experts - having a high level of proficiency in the language tested is a sufficient qualification [...]. Training for such a marker would involve familiarisation with the procedures to follow." 
background of the markers regarding errors (James, 1998) and the way in which they approach the particular corrections. One way of dealing with this in order to obtain greater consistency between the corrections was to provide markers with a list of criteria to help them in the evaluation of the texts. Nevertheless, Eckes (2008) insists on the facets of rater variability. He points out that, despite the experience of raters, a certain degree of variability is involved, and is associated with characteristics of the raters (severity or leniency) and not with the actual performance of examinees. Hence, a component of unwanted variability is introduced. However, Eckes (2008) stresses that rater training does not significantly reduce variability.

Consequently, raters may differ with regard to the understanding of the construct being measured, the interpretation and use of scoring criteria, the overall degree of severity or leniency, the degree of compliance with the scoring rubric, or the understanding and use of rating scale categories to name but a few. However, a possible comparison of the results from the texts obtained by all three markers was considered to be of interest.

Three different markers (M1, M2 and M3) completed the correction and assessment of the 206 texts written by the 90 students. All three markers have a similar educational and professional background. They are currently employed as English language instructors at the Universitat Politècnica de València. The three markers have completed their university education obtaining a BA in English Philology. They have also completed $\mathrm{PhD}$ courses under different Doctorate programmes. Markers 
M2 and M3 have gained their Diploma d'Estudis Avançats (DEA) ${ }^{21}$. All three markers have considerable experience in Second Language Teaching (over 6 years). Of the three, markers M1 and M2 are also experienced in teaching at secondary school levels or in professional settings. The skills and experience of the markers are consistent with Salamoura's (2008:6) recommendation:

The CEFR level of the designed task(s) may be further validated by obtaining ratings from expert CEFR raters. Expert CEFR raters can also be recruited to rate the resulting learner written performances after data collection. These raters could be professional writing examiners, item writers, teachers, researchers or other independent markers trained in using the relevant CEFR scales.

Needless to say, the results from these three markers are expected to vary considerably. Two factors contribute to this: the variability conferred to the markers themselves, as described above, since they can interpret their particular correction according to their own personal criteria, and the open nature of some of the issues to be analysed. Thus, in the analysis there are errors of a different nature, some of which concern the entire text, others, one single word. Greater variability is expected among items which are more open to interpretation than, for instance, spelling errors. As such, in the subsequent analysis, errors examined by one, two or all three markers are considered separately, and these divergences are consequently analysed in the Results chapter.

21 This is equivalent to the English MAS or the former French DEA/DESS diplomas. It confers a higher qualification credential than a Master of Philosophy or Master of Studies but lower than Doctorate. 
Special attention was paid to the tagging of the texts, since this had to be completed following the pattern established specifically for the present study and particularly for the texts analysed, as explained later. Once the markers gained a clear understanding of what was expected, and the type of errors they had been asked to identify and annotate, there was no further interference with their work.

\subsubsection{Correction according to the CEFR}

In order to achieve the maximum degree of standardisation possible in the correction of the texts, the list of items for analysis was created in accordance with the CEFR (CE, 2001). Although the CEFR does not offer specific items for language correction for some of the specific aspects considered in the analysis, the markers were still able to consult the Written Assessment Criteria Grid found in the manual for Relating Language Examinations to the Common European Framework of Reference (2003). The markers were familiar with the CEFR due to their extensive teaching experience, and were well acquainted with the Pragmatics principles, which could be assessed as part of the communicative approach used during the English courses. Nevertheless, it was considered appropriate to give the markers thorough instruction as to how to approach the particular correction of the texts. Thus, in line with Salamoura (2008:6):

The CEFR scales for written production (Council of Europe 2001, 615) and the Manual's Table 5.8 Written Assessment Criteria Grid (Council of Europe 2003, 82) can be a useful starting point at this stage. [...] As it has probably become evident by now, linking data to the CEFR can be a highly judgemental process. The quality of 
judgements is, therefore, a decisive factor in this process. In order to ensure the quality of judgements a thorough training of the raters is required.

Following this, the markers were instructed in the specific aspects considered to be of interest in the texts. As specified below, a grid was also created to help them in the correction process. This was based on the descriptors offered at the CEFR relating to different aspects: writing, pragmatics and levels of proficiency.

\subsubsection{Descriptors and text types}

When working with the CEFR as a framework for reference, it soon becomes obvious that it is more suited to measuring and interpreting student learning and proficiency levels than a tool for assessment and evaluation. Hence, North (in Weir, 2005) advocates lighter use of the document:

\footnotetext{
A key idea always present in the development of the CEFR was to use the descriptor scales ... to profile the content of courses, assessments and examinations. These can then be related to each other through their CEFR profile without making direct comparisons between them or claiming that one is an exact equivalent of the other.
}

Some authors question the global usefulness of the document to evaluate and assess results. To give but one example, we can point to the widely endorsed opinion as expressed by Weir when warning of the limitations of the document as a tool for evaluation, based on the lack of situational an interactional authenticity (Weir, 2005:283): 
A framework is required that helps identify the elements of both context and processing and the relationships between these at varying levels of proficiency, i.e., one that addresses both situational and interactional authenticity (see Bachman and Palmer, 1996). Since the CEFR is deficient in both, it is not surprising that a number of studies have experienced difficulty in attempting to use the CEFR for test development or comparability purposes (see Huhta et al., 2002; Jones, 2002; Little et al., 2002; Alderson et al., 2004; Morrow, 2004).

However, since it is our aim to assess and evaluate errors in the learning of a second language at university level, where the CEFR is the recommended legal framework for reference, we have used it as a starting point in our analysis. Indeed, it is not our aim to test -evaluatestudents, but to observe what types of errors are encountered when reaching a B1 level of proficiency, in our case, when students enter their first year at university.

In order to establish the arrangement for the searching and placing of errors of different types, it was necessary to look at the descriptors referred to in the CEFR. These offer information about the different skills, competences, abilities and fluency levels required at our particular level of interest. However, the levels of proficiency do not necessarily correspond in different competences; in some cases, there can be intermingling of levels, resulting in good proficiency in flexibility, to mention one example, but poor results for coherence and cohesion.

Consequently, the descriptors in the CEFR have been used to establish the parameters in our analysis. In particular, the pragmatic competences established therein; discourse competence, text competence, and functional competence were all used as the starting point for this analysis. 
As has been largely explained in the section dedicated to the CEFR and its thirty-nine descriptors, in terms of methodology only the way in which these descriptors were used needs to be clarified. This can be done using the grids related to Pragmatics (flexibility, turntaking, thematic cohesion, coherence and cohesion, etc.), and to writing (creative writing, report writing), etc. Furthermore, Grice's maxims, referred to and recommended in the document, have also been included in the analysis grid.

Additionally, particular attention was paid to the approach assigned to several aspects of communication, such as discourse competence topic and focus, sequencing, cause and effect, functional competence in the texts; different uses of language, or text design reproduction and recognition-. Attention was also paid to knowledge of the different macrofunctions (narrate, inform) and their particularities, as well as to genres, which are treated in the CEFR in 5.2.3 Pragmatic Competences. Indeed, text types and genres are included within this learner competence.

In addition, lexical and grammatical elements appear in the CEFR as an intrinsic part of the competence to write adequate texts at a particular level of proficiency. Specifications for each level are also offered extensively in the document of reference. 


\subsubsection{Tagging}

The present work involved the ability to acquire a synthetic tool which, from a standpoint, would be useful in the analysis of errors. Undeniably, although recommendations existed with regard to what ought to be expected in the texts written by students, these had to be categorised, incorporated into types and hierarchies, and integrated, in order to ensure these would be as clear and objective as possible.

Several references exist regarding which principles to follow when tagging a corpus (Leech, 1997; Garside \& Smith, 1997; Hunston, 2002). Tagging in the present study consists of the manual application of a given set of abbreviations previously developed to take into account the pragmatic aspects of the written discourse. Error tagging, which is the only method acceptable in CL, cannot be completed automatically. (Hunston, 2002:82):

Corpus tagging needs to be done automatically, that is, by a computer programmed to recognise part of speech [...] Programs that assign tags (taggers) tend to work on a mixture of two principles: rules governing word-classes and probability.

As can be seen in the following sections, not all the items had the same degree of difficulty, neither for students, nor for the markers. Indeed, in some cases, the interpretation of the possible cause of errors was not univocal, and was left to the marker. For instance, this is the case for interpretation where MT influence occurs, which in some cases could prevail over other sources of error, such as lack of vocabulary, whereas in other cases these must remain unnoticed, if a grammatical error is 
present, or the interference is not clear. In other cases, for students, who failed to recognise the type of texts or the macrofunction that they were expected to write. A detailed explanation of this is given below.

As for the tagging system itself, this was devised using different abbreviations to identify the various groups. The classification was simple: thirteen large groups were created to establish a framework for the errors. To give some examples, these included text purpose, style and register, domain, or content knowledge required. The analysis was based upon these, and also the entire tagging system, for the types of error analysed. The tags reflected these general groups ( $L$ for lexical, D for discourse, G for grammar, etc.). Next, the particular error expected under that specific category was classified, for instance the tags CKG and CKS refer to the content knowledge required. CKG refers to the general knowledge. CKS refers to the specific knowledge. A thorough explanation of the items analysed follows.

Errors were manually annotated in the margins of the texts produced by the students, and the cause or the interpretation of the error considered by each marker, while always following the specifications given in the analysis grid. Some errors were tagged with more than one label, since different interpretations could coexist, whereas one single utterance could include different error types.

Naturally, depending on the type of error spotted, the tags used refer not only to words, but also to larger units; collocations, phrases, sentences, etc. Indeed, since the analysis was conducted taking into account 
pragmatic issues, some of the errors analysed exceeded the word limit. The tags used in the texts are reproduced in Table 37:

\begin{tabular}{|l|l|l|l|}
\hline TAG & ERROR & TAG & ERROR \\
\hline TT & Text Type & PRVWW & Errors in complex topics \\
\hline TP & Text Purpose & DVM & Extrapolate meaning \\
\hline RI & Too informal register & DSS & Sequencing \\
\hline RF & Too formal register & DSV & Verb tense \\
\hline RAU & Consideration of audience & DSWO & Word order \\
\hline RP & Paraphrasing & DSC & Connectors/transitions \\
\hline RS & Using own words & DSTH & Summarising (text types) \\
\hline CKG & General knowledge required & DSFOCUS & Main points \\
\hline CKS & Specific knowledge required & DCC & Coherence and cohesion \\
\hline GP & Wrong patterns & OS & Spelling \\
\hline GMT & MT influence & OL & Layout \\
\hline GSE & Grammatical errors in simple & OP & Punctuation \\
\hline sentencing & SOP & Politeness \\
\hline LF & Fixed expressions & SOC & Cultural differences \\
\hline LI & Intensifiers & RHQ & Rhetorical effectiveness \\
\hline LPV & Phrasal verbs & RHP & Precision \\
\hline LC & Collocations & Accuracy \\
\hline LPOL & Polysemy & Focus \\
\hline PRVN & Insufficient vocabulary & Requacy to own limitations \\
\hline PRVC & Errors in common vocabulary & Adaptation to text complexity \\
\hline
\end{tabular}

Table 37. Analysis grid. Tags used in the correction of the texts.

As can be seen in the Table, all possible errors were identified by a tag which offered information about the level of language and about the category to which it belonged. 


\subsubsection{Items}

Forty items were selected for evaluation. The items analysed range from spelling errors to the rhetorical effectiveness of the texts. It is certainly a wide spectrum of aspects which relate to the pragmatic accuracy of the written work. Including both the analysis at a word level and at a text level makes it possible to provide a thorough analysis of the pragmatic competences acquired by the students with the second language. Additionally, the shortages and non-transferable aspects which may be of relevance to future approaches to language teaching and learning can be identified.

Although the CEFR offers no specific guidance relating to concrete issues which could be used directly in the present study, the descriptors of the aspects which are the object of our study were listed. Using these, the type of error which could be described under that particular aspect was deducted. For instance, with regards to the text types in the CEFR, the descriptors refer to the recognition, production and reproduction of macrofunctions: describing, narrating, expositing, to give a few examples. The possible errors connected to this descriptor would consist of the students' failure to recognise the type of text they were expected to produce. 


\subsubsection{Foundation. A pilot study}

When faced with the need to analyse the texts produced by the students in order to identify the types of errors incurred, an analysis grid was devised taking into account both the CEFR, as a general framework of reference, and the Pragmatic competences established within this in relation to a B1 level of competence. Additionally, competences and skills relating to writing in the CEFR were included in the grid. Finally, special attention was paid to Grice's maxims, which although mentioned in the document of reference, are not assigned an in-depth treatment in the text.

In particular, the grid includes information about text types and macrofunctions as explained above. In it can be found, text purposes, register, and domain, but it also advises on the grammatical and lexical competences. These were incorporated in the section dedicated to the writing, as well as the cognitive processes and the sociolinguistic aspects described in the CEFR. With regards to the sociolinguistics aspects, and following Bachman's proposal (1990), it was considered interesting to analyse how politeness conventions affect the writing at this level, although the subject was not strictly related to the pragmatics of the texts. The inclusion of the Gricean maxim of rhetorical effectiveness, also mentioned in the CEFR, was an attempt at analysing whether this represents a significant drawback in language learning, since it is unlikely that the linguistic choices made will take this into account, due to insufficient language mastery, at least at the B1 level of proficiency. The mere use of this item to study the texts was 
complicated, since it differs considerably from the aspects usually analysed in texts produced by students. A final item was introduced to include Sperber and Wilson's Relevance theory in the research, described as the "relevance of an input to an individual at a time". It was marked as Rel and, by synthesising, expected to provide an answer to the question: Was this the simplest way of saying this?

Thus, to create the grid, two significant Pragmatic theories were taken into account, as well as the CEFR. From the CEFR were chosen, in particular, the guidelines related to general proficiency, writing (creative and formal), and sociolinguistic and pragmatic competences.

The analysis completed here is based on several pilot studies designed to establish the most beneficial way of approaching the research. First of all a study was planned in order to establish a corresponding relationship between the descriptors in the CEFR and the expected competences expressed in them. These would later be used to establish possible causes for error in a given text. An example of this can be seen below, since the grid dedicated to processing text, the CEFR (CE, 2001:96) states that a B1 user of L2:

Can collate short pieces of information from several sources and summarise them for somebody else.

Can paraphrase short written passages in a simple fashion, using the original text wording and ordering.

Although the levels of proficiency cannot be inferred from these descriptors or guidelines, there are some competences which can be 
conjectured from these. It is therefore implied that a B1 learner should be able to

- Summarise short pieces of information

- Paraphrase short written passages in a simple fashion

- Respect text wording and ordering when rephrasing

This type of study was carried out for each of the grids used in the present analysis. At a second stage, the results were collected into several groups, depending on the type of competence they described and the category implied within this, and was not so reliant on the function established by the CEFR (written text, creative text, etc.). In this manner, the following groups were obtained:

Discourse

- Connectors

- Cohesion

- Sequencing

- Register

Grammar

- Paraphrasing

- Vocabulary

- Lexical elements

- Repetition

- Spelling

- Word order

- Punctuation

- MT influence

- (Verbs)

Text Type (genre)

- Layout

External Factors (sociological, cultural... conventions)

- Social conventions

- Precision 
In this second phase of the preliminary studies, a pilot study was completed once a list of items had been obtained, in order to test the elements, and identify their productivity in the study of texts. This helped establish their level of usefulness for the analysis on a greater scale. It was important to discern if the items chosen for investigation based on the framework document could result in useful tools for text examination. Several texts from the corpus (the set grouped under the heading 09-L2) were analysed to consider just this. The result being that some of the items proposed were useful for these specific cases, and some were not.

To identify their usefulness for the present study, the items were classified according to a scale ranging from very productive, productive, to unproductive. Below can be found items regarded as unproductive, without any reference to problems or errors in the texts analysed:

- Sequencing

- Layout: closing and post

- Lexical reiteration

In a different category can be found items which presented few problematic cases, and were labelled as productive. :

- Word order

- MT influence

- Intensifiers

- Fixed frames

- Punctuation

- Precision
- Layout:

o Heading,

o Address,

o Salutation,

o Purpose of first paragraph

o Name 
Finally, and always in the same context, several items presented a considerable amount of occurrences and were rated as very productive for the analysis undertaken. These were:

- Improper use of connectors

- Lexical collocations

- Cohesion: reference

- Inappropriate use of vocabulary

- Sentential formulae, idioms, collocations

In order to set up this first study, it had been deemed necessary to select the texts which would represent the entire set. Three different categories were established; poor, average and good. Accordingly, one text was selected from each category. The results grouped in terms of errors were studied to discard the possibility that all similar errors had been produced by the same author. The results of this analysis show that some items were only incurred in one specific text:

Text 1 (poor)

- Conjunctions

- Fixed frames

- Punctuation

- Layout

Text 2 (average)

- Repetition

- Precision

Text 3 (good)

- Word order

- Politeness

At the final stage of this pilot study, a comparison between coincidences among the texts was made and some correlations were established. Interestingly, errors of the same categories were found in texts 1 and 2 
and 1 and 3 , but no coincidences were found for texts 2 and 3 . This is probably due to the small size of the sample. The coincidences found are reproduced below:

- Texts 1 and 2

o Not enough connectors

o Register (formality)

- Texts 1 and 3

o Connectors not properly used

o Layout: date

Seven items were particularly productive in terms of errors. Not only were there errors in all texts, but they were also many errors related to these items. These could be organised under the following categories:

- Paraphrasing

- Vocabulary

- Lexical collocation

- Cohesion: Reference
- Verbs

- Body: first line: reference

- Sentential formulae, phrasal idioms

Taking all these aspects into account, it was considered that the analysis grid, proposed to analyse the different aspects which could lead to error in the particular case of B1 students of English, was fruitful and could help analyse a much larger corpus of texts. 


\section{Expectations}

Although a numerical analysis is included in the Results chapter, aimed at clarifying the most common errors students with a B1 level of proficiency make, there is also a section dedicated to the analysis of the idiosyncrasies of the results, since not all errors can be scrutinised in the same manner.

From the previous pilot study, it was believed that the analysis of the corpus could be conducted at different levels. Hence, comparisons were established taking into account the different variables, in order to clarify the most productive type of analysis. It was important to determine comparisons between types of texts, between markers and also between types of items. Variation in all these three categories was expected to help in understanding the problems related to competence acquisition as well as the possibilities of establishing them as central points in future teaching projects.

Additionally, and also based on this previous study, after having been tested as useful for the analysis, some items should prove to be much more productive than others (in terms of errors produced in that category). This is not only due to the fact that some errors are general while others are specific, but also due to the coincidence in the type of error produced at a given level of proficiency. More specifically, it is expected that students with a B1 level of proficiency coincide in the types of errors made. 
From the pilot study, it can be assumed that the amount of errors related to items referring to the entire text (text type or text purpose) is expected to be less numerous than those related to phrasal structures (collocation, phrasal verbs). These, in turn are even more likely to be less numerous than those pertaining to words (spelling). However, the quantitative analysis of errors in the texts can help focus on the specific shortcomings students display at this particular point in their learning process, which could be of great use to teachers and testers.

A complementary look at the study involved considering the importance of errors which appeared most frequently in the texts in relation to the entire set of error types. This implied the possibility of establishing a categorisation and a hierarchy among the errors found, in an attempt to derive which are more problematic for communication. Finally, the study is also expected to shed light on the difficulty sometimes encountered in pragmatic analysis when considering objective items for any type of analysis, or items as detached as possible from the teacher, marker or investigator.

The stipulation that three different markers were used to analyse the same texts was decided upon in order to help identify items in which total coincidence occurs (the most objective issues), which could be used to profile, or scale or leverage the students, and those where the markers show great divergences, (and as such, more related to the marker's own criteria), thereby showing that the correctness or incorrectness of the item greatly depends on the severity, or even the interpretation of the marker. 


\subsection{Analysis grid}

As explained above, the error analysis grid 22 includes thirty nine different items, obtained from the CEFR, Grice's maxims and Sperber's Relevance Theory. As shown below, the items are grouped under different categories. As such, although the initial grouping took into account the different sources listed in order to ensure the inclusion of all approaches and all items in the analysis, these were later regrouped depending on the type of error they identified (whether these were errors related to discourse, rhetoric, lexical features, etc.).

First, the initial grid, including all items and categories, is represented in Table 38, with the examples offered in the different documents of reference. Next, the grid as used for the analysis is presented and explained. The first column shows the item included for the analysis. A second column presents the descriptors and rubrics offered for the different documents. Next, a third column identifies the possible errors derived from the listed categories. The final column provides the tag used for the identification of the errors in the different documents analysed.

22 For reasons of simplicity, the Item grid has been split into sections. Each part includes all the elements which have been obtained from the same source. 


\begin{tabular}{|c|c|c|c|c|c|c|}
\hline \multicolumn{7}{|c|}{ RHETORICAL FUNCTIONS. TEXTS (CEFR) } \\
\hline ITEM & \multicolumn{4}{|c|}{ DESCRIPTORS/RUBRIC/ELEMENTS } & ERROR & TAG \\
\hline \multirow{8}{*}{$\begin{array}{l}\text { RHETORICAL } \\
\text { FUNCTION(S) } \\
\text { EXPECTED }\end{array}$} & \multicolumn{2}{|c|}{ describing (events) } & \multicolumn{2}{|c|}{ describing (processes) } & \multirow{8}{*}{$\begin{array}{l}\text { Text type } \\
\text { - Problems in recognising } \\
\text { or reproducing the type } \\
\text { of text required } \\
\text { - Problems meeting the } \\
\text { requirements of the } \\
\text { task assigned } \\
\text { - Does s/he respect the } \\
\text { structure required in the } \\
\text { different text forms? }\end{array}$} & \multirow[t]{8}{*}{$T T$} \\
\hline & \multicolumn{2}{|l|}{ narrating } & \multicolumn{2}{|c|}{ commentating } & & \\
\hline & \multicolumn{2}{|l|}{ expositing } & \multicolumn{2}{|l|}{ explaining } & & \\
\hline & \multicolumn{2}{|l|}{ demonstrating } & \multicolumn{2}{|c|}{ instructing } & & \\
\hline & \multicolumn{2}{|l|}{ arguing } & \multicolumn{2}{|c|}{ persuading } & & \\
\hline & \multicolumn{2}{|c|}{ reporting events } & \multicolumn{2}{|c|}{ giving opinions } & & \\
\hline & \multicolumn{2}{|c|}{ making complaints } & \multicolumn{2}{|c|}{ comparing/contrasting } & & \\
\hline & \multicolumn{2}{|l|}{ suggesting } & \multicolumn{2}{|c|}{ exemplifying } & & \\
\hline \multirow{2}{*}{$\begin{array}{l}\text { TEXT } \\
\text { PURPOSE }\end{array}$} & \multicolumn{2}{|l|}{ referential } & \multicolumn{2}{|l|}{ emotive } & \multirow{2}{*}{$\begin{array}{l}\text { Text purpose } \\
\text { - Does s/he recognise } \\
\text { the purpose of the text? } \\
\text { - Does s/he express the } \\
\text { purpose expected? }\end{array}$} & \multirow[t]{2}{*}{ TP } \\
\hline & \multicolumn{2}{|l|}{ conative } & \multicolumn{2}{|l|}{ phatic } & & \\
\hline \multirow[t]{3}{*}{ REGISTER } & \multicolumn{2}{|l|}{ informal } & \multicolumn{2}{|c|}{$\begin{array}{l}\text { unmarked to } \\
\text { informal }\end{array}$} & $\begin{array}{l}\text { - Does s/he recognise the } \\
\text { level of formality of the text? } \\
\text { - Doess/he reproduce it? }\end{array}$ & \\
\hline & \multicolumn{2}{|l|}{ unmarked } & \multicolumn{2}{|c|}{ unmarked to formal } & Too informal & RI \\
\hline & \multicolumn{2}{|l|}{ formal } & & & Too formal & RF \\
\hline $\begin{array}{l}\text { STYLE AND } \\
\text { REGISTER; }\end{array}$ & $\begin{array}{l}\text { Considers } \\
\text { Audience }\end{array}$ & the & $\begin{array}{r}\text { Considers } \\
\text { - Does tr } \\
\text { audien }\end{array}$ & $\begin{array}{l}\text { audience } \\
\text { ne text sho } \\
\text { ce it is add }\end{array}$ & $\begin{array}{l}\text { W any consideration of the } \\
\text { tressed at? }\end{array}$ & RAU \\
\hline & $\begin{array}{l}\text { Paraphrase sh } \\
\text { written passa } \\
\text { a simple fashi }\end{array}$ & $\begin{array}{l}\text { ort } \\
\text { Ses in } \\
\text { on }\end{array}$ & $\begin{array}{r}\text { Paraphras } \\
\text { - Is the s } \\
\text { him/he }\end{array}$ & $\begin{array}{l}\text { ing } \\
\text { tudent abl } \\
\text { irself unde }\end{array}$ & $\begin{array}{l}\text { le to paraphrase to make } \\
\text { rstood? }\end{array}$ & RP \\
\hline & $\begin{array}{l}\text { Adapt to sligh } \\
\text { difficult situat }\end{array}$ & ly & $\begin{array}{l}\text { - Is s/he } \\
\text { the mo }\end{array}$ & $\begin{array}{l}\text { able to ex } \\
\text { st commor }\end{array}$ & $\begin{array}{l}\text { press him/herself outside } \\
\text { n and useful situations? }\end{array}$ & \\
\hline & $\begin{array}{l}\text { Exploit langua } \\
\text { own purposes }\end{array}$ & ge to & $\begin{array}{l}\text { Using own } \\
\text { Problems in }\end{array}$ & $\begin{array}{l}\text { words } \\
\text { findingways }\end{array}$ & around difficult language situations & RS \\
\hline DOMAIN & personal & publi & & Does $\mathrm{s} / \mathrm{h}$ & e recognise and use the & \\
\hline & occupational & $\begin{array}{l}\text { educ } \\
\text { acad }\end{array}$ & $\begin{array}{l}\text { cational/ } \\
\text { demic }\end{array}$ & $\begin{array}{l}\text { language } \\
\text { domain? }\end{array}$ & required in the specific & \\
\hline $\begin{array}{l}\text { CONTENT } \\
\text { KNOWLEDGE }\end{array}$ & $\begin{array}{l}\text { general/non- } \\
\text { specialised }\end{array}$ & $\begin{array}{l}\text { spec } \\
\text { knou }\end{array}$ & $\begin{array}{l}\text { cialised } \\
\text { wledge }\end{array}$ & $\begin{array}{l}\text { Does s/h } \\
\text { knowledg }\end{array}$ & $\begin{array}{l}\text { e have the general } \\
\text { se required? }\end{array}$ & CKG \\
\hline |REQUIRED & $\begin{array}{l}\text { very specialisec } \\
\text { knowledge }\end{array}$ & $\begin{array}{lr}a \\
\text { arnou }\end{array}$ & $\begin{array}{ll}\text { range of } \\
\text { wledge }\end{array}$ & $\begin{array}{l}\text { Does } \mathrm{s} / \mathrm{h} \\
\text { knowledg }\end{array}$ & $\begin{array}{l}\text { e have the specific } \\
\text { se required? }\end{array}$ & CKS \\
\hline
\end{tabular}

Table 38. Items for analysis based on CEFR. Texts. Rhetorical functions. 
The core of Table 38 displays the tools related to different approaches to rhetoric issues, ranging from the functions expected in a given document to the content knowledge required in a text. As can be observed, the descriptors are varied and do not always coincide in the identification of the speech functions. These first items include text organisation and content related issues, together with style and genre issues, as well as purpose and rhetorical functions. Some descriptors are very broad, whereas others are very detailed. It can be seen that while there is an extensive list of possible rhetorical functions in the CEFR, (narrating, suggesting, reporting events, etc.), the descriptors related, for instance, to the identification of register are simply too informal or too formal.

This is then complemented by a second entry which includes not only register but also style, and in which two aspects are considered for analysis: the ability of the language user to paraphrase using his or her own words, and a consideration of the audience as part of the communication act. Apart from structural considerations, the grid also includes knowledge of vocabulary and of context. As such, there is specification regarding the domain to which the specific texts belong, but this only considers those four broad domains included in the CEFR as recommended in the classroom for work and language development.

As can be easily observed, most items in this part of Table 39 refer to the text as a unit. In this sense, errors belonging to these categories were expected to appear just once in the texts analysed. Thus, except for the possibility of expressing something in the user's own words, which could be considered at a sentence scale, all other items refer to the text. 
The next part of the framework used to analyse the texts, in Table 39, relates to the linguistic competences proven in the texts. It includes four distinct parts; grammatical competence, lexical competence, orthographic competence and proof of cognitive processing. It includes the most traditional approach to the analysis of language and is representative of the view of the CEFR on the importance of grammar, spelling and lexical issues.

\begin{tabular}{|c|c|c|c|}
\hline \multicolumn{4}{|c|}{ LINGUISTIC COMPETENCES (CEFR) } \\
\hline ITEM & DESCRIPTORS/RUBRIC/ELEMENTS & ERROR & TAG \\
\hline \multirow{3}{*}{$\begin{array}{l}\text { GRAMMATICAL } \\
\text { COMPETENCE } \\
\text { EXPECTED }\end{array}$} & $\begin{array}{l}\text { Grammatical accuracy in familiar } \\
\text { contexts }\end{array}$ & $\begin{array}{l}\text { Grammatical errors in } \\
\text { simple sentencing }\end{array}$ & GSE \\
\hline & Mother tongue influence & MT influence & GMT \\
\hline & $\begin{array}{l}\text { Repertoire of routines and } \\
\text { patterns associated with more } \\
\text { predictable situations }\end{array}$ & $\begin{array}{l}\text { Wrong patterns } \\
\text { (infelicities in copying } \\
\text { the example given) }\end{array}$ & GP \\
\hline \multirow[t]{5}{*}{$\begin{array}{l}\text { LEXICAL } \\
\text { COMPETENCE } \\
\text { EXPECTED }\end{array}$} & $\begin{array}{l}\text { Fixed expressions: Sentential } \\
\text { formulae: exponents of language } \\
\text { functions greetings, proverbs, } \\
\text { archaisms, } \\
\text { Phrasal idioms, }\end{array}$ & $\begin{array}{l}\text { Fixed expressions: } \\
\text { - Sentential } \\
\text { formulae } \\
\text { - Idioms }\end{array}$ & LF \\
\hline & Intensifiers & Intensifiers & LI \\
\hline & $\begin{array}{l}\text { Fixed frames, e.g.: 'Please may I } \\
\text { have', phrasal verbs, compound } \\
\text { prepositions, e.g. in front of. }\end{array}$ & Phrasal verbs & LPV \\
\hline & $\begin{array}{l}\text { Fixed collocations, consisting of } \\
\text { words regularly used together, } \\
\text { e.g. to make a speech/mistake. }\end{array}$ & Collocations & LC \\
\hline & Single word forms (polysemy). & Polysemy & LPOL \\
\hline \multirow{3}{*}{$\begin{array}{l}\text { ORTHOGRAPHIC } \\
\text { COMPETENCE }\end{array}$} & Intelligible writing & Spelling & OS \\
\hline & \multirow{2}{*}{$\begin{array}{l}\text { Spelling, punctuation and layout } \\
\text { are accurate enough to be } \\
\text { followed most of the time }\end{array}$} & Layout & OL \\
\hline & & Punctuation & OP \\
\hline \multirow[t]{2}{*}{$\begin{array}{l}\text { COGNITIVE } \\
\text { PROCESSING }\end{array}$} & $\begin{array}{l}\text { Reproduction of } \\
\text { known/established ideas }\end{array}$ & & \\
\hline & Knowledge transformation & & \\
\hline
\end{tabular}

Table 39. Items for analysis based on the CEFR. Linguistic competences. 
Table 39 introduces grammatical and lexical errors listed in detail, but only refers to some types. Thus, generally speaking, items in which there can be a conflict at either the syntactic or semantic relations level are included in the list (phrasal verbs, identifiers, or collocations, for instance). This reflects an in-depth analysis of grammar, taking into account the phrase or the sentence as a unit for analysis.

Additionally, items which reflect different degrees of infelicity in the reproduction of the correct language appear in the list. These refer to situations in which the students are not creating but reproducing something learnt in the language, and fail to do so correctly. It also includes problems with orthography and punctuation.

Finally, the section dedicated to cognitive processing refers to the exploitation of previously acquired knowledge, not necessarily in the new language being learnt, but perhaps in a previous L1 with regard to new situations, and the reproduction of personal ideas in the target language. As can be seen from the grid, no tag was assigned to cognitive processing, since it was deemed that this very aspect, although very abstract, was already included in other items which appeared in detail in the document. An example of this can be paraphrasing or using one's own words, in addition to being sufficiently flexible to circumvent difficult situations and other obstacles.

The next part of the general grid encompasses items listed specifically as pragmatic for analysis within the CEFR. Also, the few items incorporated under the umbrella of sociolinguistic issues have been included for analysis, taking into account the items chosen as examples 
of sociolinguistic competence in the CEFR and their importance in communication. This can be seen in Table 40.

\begin{tabular}{|c|c|c|c|c|c|c|}
\hline \multicolumn{7}{|c|}{ CEFR PRAGMATIC AND SOCIOLINGUISTIC COMPETENCES } \\
\hline ITEM & \multicolumn{4}{|c|}{ DESCRIPTORS/RUBRIC/ELEMENTS } & ERROR & TAG \\
\hline \multirow[t]{4}{*}{ FLEXIBILITY } & \multicolumn{4}{|c|}{ Sufficient. } & $\begin{array}{l}\text { Insufficient } \\
\text { vocabulary }\end{array}$ & PrVN \\
\hline & \multirow{3}{*}{\multicolumn{2}{|c|}{ Vocabulary }} & \multicolumn{2}{|c|}{ Circumlocutions / paraphrasing. } & & \\
\hline & & & \multicolumn{2}{|c|}{ Everyday life. } & \begin{tabular}{|l} 
Errors in \\
common \\
vocabulary
\end{tabular} & PrVC \\
\hline & & & \multicolumn{2}{|c|}{$\begin{array}{l}\text { Good control of elementary but } \\
\text { errors with more complex topics. }\end{array}$} & $\begin{array}{l}\text { Errors in } \\
\text { complex topics }\end{array}$ & PrWWW \\
\hline \multirow{16}{*}{$\begin{array}{l}\text { DISCOURSE } \\
\text { COMPETENCE }\end{array}$} & \multirow{2}{*}{$\begin{array}{l}\text { topic/focus } \\
\text { given/new; }\end{array}$} & \multicolumn{3}{|c|}{ Identify unfamiliar words. } & \multirow{2}{*}{$\begin{array}{l}\text { Extrapolate } \\
\text { meaning }\end{array}$} & DVM \\
\hline & & \multicolumn{3}{|c|}{ Extrapolate meaning } & & \\
\hline & \multirow{3}{*}{\multicolumn{3}{|c|}{$\begin{array}{l}\text { Natural } \\
\text { sequencing: } \\
\text { temporal }\end{array}$}} & Sequencing. & Sequencing & DSS \\
\hline & & & & Verb tenses. & Verb tense & DSV \\
\hline & & & & Word order. & Word order & DSWO \\
\hline & \multirow[t]{3}{*}{ structure } & & use /effect & Linking. & $\begin{array}{l}\text { Connectors / } \\
\text { transitions }\end{array}$ & DSC \\
\hline & & \multirow{2}{*}{\multicolumn{2}{|c|}{$\begin{array}{l}\text { Thematic } \\
\text { organisation }\end{array}$}} & $\begin{array}{l}\text { Summarise short } \\
\text { pieces of } \\
\text { information. }\end{array}$ & $\begin{array}{l}\text { Summarising } \\
\text { (text types) }\end{array}$ & DSTH \\
\hline & & & & $\begin{array}{l}\text { link simple } \\
\text { elements. }\end{array}$ & Main points & DSFoas \\
\hline & \multirow{8}{*}{\multicolumn{3}{|c|}{ coherence and cohesion; }} & Repetition. & \multirow{8}{*}{$\begin{array}{l}\text { Coherence and } \\
\text { cohesion }\end{array}$} & \multirow[t]{8}{*}{ DCC } \\
\hline & & & & Synonymy & & \\
\hline & & & & Antonymy. & & \\
\hline & & & & Pro-forms. & & \\
\hline & & & & Collocation. & & \\
\hline & & & & Enumeration. & & \\
\hline & & & & Parallelism. & & \\
\hline & & & & Transitions & & \\
\hline \multirow{4}{*}{$\begin{array}{l}\text { SOCIOLING. } \\
\text { APPROPR. }\end{array}$} & \multicolumn{4}{|c|}{ Perform and respond to language functions } & & \\
\hline & \multicolumn{4}{|c|}{ Common exponents in neutral register } & & \\
\hline & \multicolumn{4}{|c|}{ Politeness conventions } & Politeness & SoP \\
\hline & \multicolumn{4}{|c|}{ Aware of cultural differences } & $\begin{array}{l}\text { Cultural } \\
\text { differences }\end{array}$ & SoC \\
\hline
\end{tabular}

Table 40. Items for analysis based on the CEFR. Pragmatic and Sociolinguistic competences. 
In Table 40, issues of different natures are included. On the one hand, there are pragmatic issues, such as flexibility in language use and discourse analysis and interpretation, and on the other, issues related to sociolinguistic appropriateness.

The first issue refers to flexibility in the use of language, and focuses on the amount of vocabulary used and available to the user. It includes both vocabulary errors and misuses and lack of language knowledge. This is the largest and most extensively explained issue in the document. It is dedicated to the discourse competence and includes all traditional issues bestowed on this competence.

First of all, Table 40 includes the traditional discourse devices for the management of meaning (topic and focus, given and new knowledge), including both meaning identification and the extrapolation of new meaning from context.

Next, it refers to structure, mentioning issues related to coherence within the text, such as sequencing, verb tense or word order, as well as the transitions between parts of the text, which would include the different linking of elements and cause-effect relationships to name a few. Coherence and cohesion are explained in detail, with the inclusion of synonymy and antonymy relations, pro-forms, collocations, enumerations or parallelisms. As can be observed, some of the issues presented previously reappear in this grid. Here, the unit for analysis centres on text sections as well as phrases, and in some cases (synonymy and antonymy) words. 
Finally, the last section of the grid refers to all issues related to sociolinguistics. These have been included in the grid due to the fact that they are considered crucial in communication and form part of the required pragmatic skills. Indeed, the conventions of culture and politeness often play a crucial role in the correct use of language and are necessary for an efficient pragmatic approach to language learning. Moreover, they include awareness about register and language functions, which have been included previously.

In this part of the grid we can pinpoint some aspects which are very simple to spot and identify (problems with collocations or phrasal verbs), and some which are subtle implying a complex analysis (cultural awareness). These final are open to interpretation and, in some cases, depend on the subjective opinion of the marker. Whereas it is expected that in the former item a certain degree of coincidence among teachers is found, the latter can be very variable depending on the person responsible for the corrections.

The next section of the grid (Table 41) includes some specific aspects of different Pragmatic approaches, such as those proposed by Grice and also those proposed by Sperber and Wilson. Only the aspects of these theories mentioned in the CEFR have been included, with an extra mention given to the Relevance principle, to test the relationship between effort and benefit obtained at this level of proficiency. 


\begin{tabular}{|c|c|c|c|c|}
\hline \multicolumn{5}{|c|}{ GRICE'S MAXIMS. SPERBER'S PRINCIPLES. } \\
\hline ITEM & \multicolumn{2}{|c|}{ DESCRIPTORS/RUBRIC/ELEMENTS } & ERROR & TAG \\
\hline \multirow[t]{10}{*}{$\begin{array}{l}\text { RHETORICAL } \\
\text { EFFECTIVENESS }\end{array}$} & \multirow[t]{4}{*}{$\begin{array}{l}\text { Quality (try to } \\
\text { make your } \\
\text { contribution one } \\
\text { that is true); }\end{array}$} & $\begin{array}{l}\text { Tries new } \\
\text { combinations to get } \\
\text { message through }\end{array}$ & $\begin{array}{l}\text { - Rhetorical } \\
\text { effectiveness: } \\
\text { - Get message } \\
\text { through }\end{array}$ & RHQ \\
\hline & & Explains main points & - Main points & DSFOOS \\
\hline & & Be precise & Precision & RHP \\
\hline & & Sufficient vocabulary & & \\
\hline & \multirow{2}{*}{$\begin{array}{l}\text { Quantity (make } \\
\text { your contribution } \\
\text { as informative as } \\
\text { necessary, but } \\
\text { not more); }\end{array}$} & $\begin{array}{l}\text { Circumlocution and } \\
\text { paraphrases }\end{array}$ & Accuracy & \multirow[t]{2}{*}{ RHAC } \\
\hline & & Explain in own words & & \\
\hline & $\begin{array}{l}\text { Relevance (do } \\
\text { not say what is } \\
\text { not relevant); }\end{array}$ & & Focus & RHF \\
\hline & \multirow{3}{*}{$\begin{array}{l}\text { Manner (be brief } \\
\text { and orderly, avoid } \\
\text { obscurity and } \\
\text { ambiguity)'. }\end{array}$} & $\begin{array}{l}\text { Confine message to } \\
\text { what s/he can say }\end{array}$ & $\begin{array}{l}\text { Adequacy to } \\
\text { own limitations }\end{array}$ & RHA \\
\hline & & $\begin{array}{l}\text { Correct own } \\
\text { discourse }\end{array}$ & & \\
\hline & & $\begin{array}{l}\text { Feedback: ask for } \\
\text { confirmation }\end{array}$ & & \\
\hline RELEVANCE & \multicolumn{2}{|c|}{$\begin{array}{l}\text { (17) Relevance of an input to an } \\
\text { individual } \\
\text { Other things being equal, the greater } \\
\text { the positive cognitive effects } \\
\text { achieved by processing an input, the } \\
\text { greater the relevance of the input to } \\
\text { the individual at that time. }\end{array}$} & \begin{tabular}{|l|} 
Relationship \\
amount \\
effort/benefit \\
(adaptation text \\
complexity)
\end{tabular} & REL \\
\hline
\end{tabular}

The structure of this last section of the grid is straightforward. There is an initial section in which the four Gricean principles have been listed, including the issues which could be identified as sources for errors for each of these. First of all, there is Quality, relating to the ability to 
transfer a true message, thus the ability of getting the message through, as well as to identifying and transmitting the main points of a message. Next in the analysis grid, this is followed by the item connected to the maxim of Quantity, which is identified in terms of accuracy of the utterance. The third aspect considered for analysis is the relevance of the message transmitted and the ability to focus on the core of the subject. The last Gricean principle refers to the avoidance of opacity when transmitting a message. The descriptors established in the CEFR included several aspects which are more readily identified with oral communication and, as such, have been omitted.

The final item, as mentioned above, refers to the principle of Relevance and the ability to restrict the message to the actual possibilities of the communicator. It aims to analyse the ability of the speakers to recognise and adapt to their own limitations regarding message complexity.

The items were simplified and grouped for reasons of convenience, eliminating all possible repetitions and focusing the actual points of interest on the identification of errors made by the students. Thus, regardless of their source, they have been grouped in terms of similarity or correspondence in the analysis carried out. Tables 42 and 43 compile the items used in the analysis of the texts, as used by the markers. 


\begin{tabular}{|c|c|c|}
\hline ITEM & ERROR & TAG \\
\hline \multirow{3}{*}{$\begin{array}{l}\text { Rhetorical } \\
\text { function(s) } \\
\text { Text purpose }\end{array}$} & Text type & $\pi$ \\
\hline & Problems in recognising/reproducing the type of text required & \\
\hline & $\begin{array}{l}\text { Purpose } \\
\text { Does } \mathrm{s} / \text { he recognise/express the purpose of the text? }\end{array}$ & TP \\
\hline \multirow{5}{*}{$\begin{array}{l}\text { Register } \\
\text { Style and } \\
\text { register }\end{array}$} & Too informal & RI \\
\hline & Too formal & RF \\
\hline & $\begin{array}{l}\text { Considers audience. } \\
\text { Consideration of the audience it is addressed to? }\end{array}$ & RAU \\
\hline & $\begin{array}{l}\text { Paraphrasing. } \\
\text { Able to paraphrase to make him/herself understood? }\end{array}$ & RP \\
\hline & $\begin{array}{l}\text { Using own words. } \\
\text { Finding ways around difficult language situations }\end{array}$ & RS \\
\hline \multirow{2}{*}{$\begin{array}{l}\text { Content } \\
\text { knowledge } \\
\text { required }\end{array}$} & Does $s /$ he have the general knowledge required? & CKG \\
\hline & Does $\mathrm{s} /$ he have the specific knowledge required? & CKS \\
\hline \multirow{3}{*}{$\begin{array}{l}\text { Grammatical } \\
\text { competence } \\
\text { expected }\end{array}$} & Grammatical errors in simple sentencing & GSE \\
\hline & MT influence & GMT \\
\hline & Wrong patterns (infelicities in copying the example given) & GP \\
\hline \multirow{5}{*}{$\begin{array}{l}\text { Lexical } \\
\text { competence }\end{array}$} & Fixed expressions: Sentential formulae, idioms & LF \\
\hline & Intensifiers & $\mathrm{LI}$ \\
\hline & Phrasal verbs & LPV \\
\hline & Collocations & LC \\
\hline & Polysemy & LPOL \\
\hline
\end{tabular}

Table 42. $\quad$ Analysis grid. Items grouped and arranged for analysis (1).

Table 42 displays the items after the elaboration of the grids, and their grouping to help the identification and tagging of errors: rhetorical functions and text purpose, style and register, content knowledge required, grammatical competence and lexical competence. As can be seen, all explanations have been eliminated from the table, and only the general descriptors for identification remain. 


\begin{tabular}{|c|c|c|}
\hline ITEM & ERROR & TAG \\
\hline \multirow{3}{*}{$\begin{array}{l}\text { Orthographic } \\
\text { competence }\end{array}$} & Spelling & OS \\
\hline & Layout & $\mathrm{OL}$ \\
\hline & Punctuation & OP \\
\hline \multirow{5}{*}{ Flexibility } & Insufficient vocabulary & PRVN \\
\hline & Errors in common vocabulary & PRVC \\
\hline & Errors in complex topics & PRVWW \\
\hline & Extrapolate meaning & DVM \\
\hline & Sequencing & DSS \\
\hline \multirow{5}{*}{$\begin{array}{l}\text { Discourse } \\
\text { competence }\end{array}$} & Verb tense & DSV \\
\hline & Word order & DSWO \\
\hline & Connectors/transitions & DSC \\
\hline & Summarising (text types) & DSTH \\
\hline & Coherence and cohesion & DCC \\
\hline \multirow{2}{*}{$\begin{array}{l}\text { Sociolinguistic } \\
\text { appropriateness }\end{array}$} & Politeness & SOP \\
\hline & Cultural differences & SOC \\
\hline \multirow{6}{*}{$\begin{array}{l}\text { Rhetorical } \\
\text { effectiveness }\end{array}$} & Rhetorical effectiveness: Get message through? & RHQ \\
\hline & Main points & DSFOCUS \\
\hline & Precision & RHP \\
\hline & Accuracy & RHAC \\
\hline & Focus & RHF \\
\hline & Adequacy to own limitations & RHA \\
\hline Relevance & $\begin{array}{l}\text { Relationship amount effort/benefit } \\
\text { (adaptation text complexity) }\end{array}$ & REL \\
\hline
\end{tabular}

Table 43 includes the remaining groups of items, related to orthographic competence, flexibility, discourse competence, rhetorical effectiveness, sociolinguistic appropriateness, and relevance. Any possible conflicts have been removed from the table, as for instance the inclusion of the item main points, related in the CEFR both to discourse competence and 
to rhetorical effectiveness. These same items and groups are later studied and analysed in the data processing and data presentation sections. In some cases, some of these have been -in turn- regrouped.

Table 44 shows all the variables included in the research to present the global analysis carried out: first, the 3 markers, then, the 39 items in the analysis grid, and finally, all 10 text types. 


\begin{tabular}{|l|}
\hline MARKERS \\
\hline M1 \\
\hline M2 \\
\hline M3 \\
\hline
\end{tabular}

\begin{tabular}{|l|l|}
\hline ITEMS \\
\hline TT & Text type \\
\hline TP & Text purpose \\
\hline RI & Informal Register \\
\hline RF & Formal Register \\
\hline RAu & Considers Audience \\
\hline RP & Paraphrases \\
\hline RS & Use of own words \\
\hline CKG & General Content Knowledge \\
\hline CKS & Specific Content Knowledge \\
\hline GSE & Grammatical errors simple sentencing \\
\hline
\end{tabular}

TEXTS

08-09 SUMMARISE A FILM 08-S1

\begin{tabular}{|l|l|}
\hline 08-09 OPINION & 09-S2 \\
\hline
\end{tabular}

\begin{tabular}{|l|l|}
\hline 08-09 COVER LETTER & 10-S3 \\
\hline
\end{tabular}

\begin{tabular}{l|l}
\hline $09-10$ APOLOGY & $08-01$ \\
\hline
\end{tabular}

\begin{tabular}{ll}
\hline $09-10$ OPINION 1 & $09-02$ \\
\hline
\end{tabular}

09-10 OPINION 2 09-03

\begin{tabular}{|l|l|}
\hline $09-10$ SHORT SUMMARY & $10-04$ \\
\hline
\end{tabular}

\begin{tabular}{|l|l|}
\hline 10-11 NARRATE A TRIP & 08-L1 \\
\hline
\end{tabular}

GMT Mother Tongue influence

10-11 OPINION $09-\mathrm{L} 2$

\begin{tabular}{|l|l|}
\hline $10-11$ OPINION & $09-L 2$ \\
\hline $10-11$ E-MAIL & $10-L 3$ \\
\hline
\end{tabular}

\begin{tabular}{|l|l|}
\hline GP & Wrong patterns \\
\hline
\end{tabular}

\begin{tabular}{l|l|}
\hline LF & Fixed expressions \\
\hline LI
\end{tabular}

\begin{tabular}{l|l}
\hline LI & Intensifiers \\
\hline
\end{tabular}

\begin{tabular}{|l|l}
\hline LPV & Phrasal verbs \\
\hline LC & Collocations \\
\hline
\end{tabular}

\begin{tabular}{l|l}
\hline LC & Collocations \\
\hline LPOI & Polysemy \\
\hline
\end{tabular}

LPol Polysemy

\begin{tabular}{l|l}
\hline PWN & Insufficient vocabulary \\
\hline PrVC & Errors in common vocabu
\end{tabular}

PrVC Errors in common vocabulary

PWWW Errors in complex topics

DVM Extrapolate meaning

DSS Sequencing

DSV Verb tense

DSWO Word order

DSC Connectors/transitions

DSTH Summarising (text types)

DSFocus Main points

\begin{tabular}{l|l}
\hline DCC & Coherence and cohesion \\
\hline
\end{tabular}

OS $\quad$ Spelling

\begin{tabular}{ll}
\hline $\mathrm{OL}$ & Layout \\
\hline
\end{tabular}

\begin{tabular}{|l|l}
\hline OP & Punctuation \\
\hline
\end{tabular}

\begin{tabular}{l|l}
\hline SoP & Politeness \\
\hline
\end{tabular}

SoC Cultural differences

RHQ $\quad$ Rhetorical effectiveness

RHP Precision

RHAC Accuracy

\begin{tabular}{l|l}
\hline RHF & Focus \\
\hline
\end{tabular}

RHA Adequacy to own limitations

\begin{tabular}{|l|l|}
\hline Rel & Relationship amount effort/benefit \\
\hline
\end{tabular}

Table 44. Elements included in the analysis. 

RESULTS 



\section{RESULTS}

This chapter presents the results obtained from the analysis of the texts. As explained above, it incorporates information relating to the three variables included in the present research; the markers, the errors encountered and the text typologies. Herein the results are presented and detailed. All the data used is available in Annex 5. Further interpretation and analysis is provided in the Conclusions chapter.

Due to the nature of the analysis carried out, it has been deemed appropriate to present in the first section the specific procedure employed to assess the data obtained. This has been carried out through a process of combining items for each given category. This initial introductory section helps us to obtain a global view of the subsequent presentation of the results.

Next, specific explanations are proffered for each series considered in the study. Hence, the first subsection shows the partial results, which take into account each category of the analysis. First of all, the results obtained for the markers are presented. This part includes the results for the markers giving the total amount of occurrences, and their individual contributions to each error category. 
Later, the second subsection sets out the core of the research, and is dedicated to the items that identify the errors themselves. In addition, several charts are included which illustrate the errors encountered in the global analysis of the texts, the error categories which appear to be more productive and also those which seem to be less productive, and the distribution of errors within the error categories. This part also shows the distribution of texts within the entire set, explaining the nature of good and bad texts.

Finally, a third subsection is assigned to the presentation of the results obtained for the different text types. Here, several charts illustrate the distribution of error categories depending on the text type analysed, thereby allowing a comparison of the differences between genres.

\subsection{Setting of the study}

As previously explained, the study has been set out with the inclusion of different variables, in order to find data capable of apprising the many issues that have arisen during the development of the study. The variables forming the basis of the analysis are markers, texts and items. Thus, the variable markers will help to clarify some aspects related to correction as a process: differences in correction, objectivity of the items used for correction, and the usability of the Table, for instance. The variable text will facilitate the study of the written productions both from an individual (text-by-text) point of view, and from a group perspective (depending on the text type). Finally, the different items will be self- 
explanatory and demonstrate whether they are productive or not in the texts, whether they are clear and straightforward, or whether great divergences exist in their correction. As was the case for the texts, the items have been analysed both individually and in groups, depending on the category to which they belong. Table 45 gives a clearer view of the elements and the perspective used in the analysis. Additionally, the abbreviations used in the analysis are also included, in order to assist with the subsequent presentation of data.

\begin{tabular}{|l|l|l|}
\hline CORRECTION & TEXT & ITEM \\
\hline Marker (M) & Text (T) & Item (I) \\
\hline & Text Type (TT) & Group of items (GI) \\
\hline \multicolumn{2}{|l}{ Table 45. } & Variables used in the analysis: Marker, Text, Item.
\end{tabular}

By analysing these aspects, the aim is to obtain information about the errors produced by students. This will enable us understand both the major and minor difficulties related to writing encountered by students during the learning process. It will also assist in examining whether the grid, designed with the CEFR specifications and descriptors in mind, is useful for analysis or not. Additionally, it helps us focus on the types of errors and error taxonomies that may be related to the texts.

It is generally assumed that there are considerable differences among markers. This is due to several factors, as explained in detail in the Methodology chapter. However, special attention has been given to the differences in deviations between the markers depending on the type of error examined. The analysis shows dissimilar degrees of coincidence 
depending on the type of item evaluated. This can suggest a varying degree of difficulty in the identification and tagging of some specific types of errors.

Finally, the texts have been analysed focusing on the particularities of each text type, as part of the pragmatic awareness that students need to have acquired. As explained above, several general items for description were included (text type, text purpose) to establish whether students experience a greater degree of difficulty with a particular type of text, or whether the errors incurred differ depending on the type of text produced by all the students in the same set.

The general purpose of the study is to account for a B1 level of proficiency in students. From the errors found in the texts, it is possible to identify a certain set as being prototypical of a B1 level of proficiency. All things considered, while always being cautious when making these types of deductions, the study interprets whether a specific group of items can be identified as the most productive within all errors, and if one type of text can be identified as producing a significantly greater amount of errors in comparison with the others.

Thus, to the three initial elements for analysis considered in the investigation, can be added a fourth, that is, the deduction and analysis of the level of proficiency revealed by the texts. This can be included in the general setting. Hence, the four elements embraced in this section:

(1) Variances between markers

(2) Analysis of items 
(3) Particularities of each text type

(4) Account of B1 level of proficiency

In order to establish a reliable framework for the analysis of the data, and thus extract the results, the research has centred on the following working hypotheses:

H1: The three markers are able to identify the errors in a text derived from the listed items.

H2: Each element included in the analysis categories: marker, item, text type, is independent of the rest of elements.

$\mathrm{H}$ 2(a): Errors cannot be classified as zero items. This implies that all errors identified belong to the categories proposed in the analysis grid.

$\mathrm{H}$ 2(b): The error estimation of each marker is considered independent of the rest of the elements.

$\mathrm{H}$ 2(c): The items are defined univocally, and treated as independent, although these are subsequently grouped into categories.

H3: Error estimation is based on a quantitative criterion, independent of the text, the marker and the item under consideration.

H3(a): Error estimation does not consider repetition (coincidence) due to the different markers. The results are considered as though they were the results obtained from different texts and markers.

H3(b): Error estimation is independent of the item. Errors are significant for the study regardless of the number of occurrences on 
the global scale. All items described in the analysis grid are considered to be equivalent in the results.

H3(c): Error estimation is independent of the text analysed. All errors in a text will be taken into account for the study, regardless of either the length, or the text type or any other text consideration.

H4: A qualitative criterion is applied for items of which the quantitative results offer no valuable data and therefore no valid interpretation is possible.

Of all the combinations that could result from these variables, Marker (M); Text (T); Item (I); Text Type (TT); Group of items (GI), the following Table shows those considered to be of interest for analysis: apart from the items selected at the outset, TE represents the total number of errors including all texts and all markers.

Table 46 shows the possible combinations of items, which could have been used for the analysis, and those used in the present study, marked with a $(\sqrt{ })$. 


\begin{tabular}{|l|l|l|l|l|l|l|l|}
\hline M-I-TT & & M-T & & M & $\sqrt{ }$ & TE & V \\
\hline M-GI-TT & & M-TT & & I & $\sqrt{ }$ & & \\
\hline M-GI-T & & M-I & $\sqrt{ }$ & GI & $\sqrt{ }$ & & \\
\hline & & M-GI & & T & $\sqrt{ }$ & & \\
\hline & & T-I & & TT & $\sqrt{ }$ & & \\
\hline & & T-GI & $\sqrt{ }$ & & & & \\
\hline & & TT-I & & & & & \\
\hline & & TT-GI & $\sqrt{ }$ & & & & \\
\hline
\end{tabular}

Table 46. Descriptors used in the analysis.

After having analysed the global results for markers, items and texts, a set of two-item combinations was established. For instance, a look at the correction and item combination (C-I) can present the possibility of a biased correction by one of the markers. The objective is to find deviations not in the global set, which will obviously happen, but within the rest of the correction. This implies that there could be a tendency to tag or avoid tagging one particular item. It can help identify item overrating and underrating per marker. Then, the grouping of texts and error categories (T-Gl) is aimed at helping to explain whether a group of items occurs more frequently in a given text. This can help in the identification of the most common errors in particularly wrongly performed or particularly well performed texts. In our case, interest is focused on the identification of the most common groups of errors within the majority of texts, those that can be located either in the mean, or near the mean for all text types. Finally, in this second-degree type of grouping, we have considered the combination of Error categories and text types (GI-TT). This will shed light on the proportion of error 
occurrences related to the type of text in which they are found. In this sense, the results will show whether a particular type of text has been proven to have more or less errors belonging to one category when compared to another.

Next, another type of study has been considered, including the combination of more than two items. This can be observed in Table 47. This Table consists of all the types, combinations and issues used in the final analysis of referential parameters carried out on the texts.

\begin{tabular}{|l|l|l|}
\hline 1 & $\mathrm{M} / \mathrm{TE}$ & Comparison of markers \\
\hline 2 & $\mathrm{M}-\mathrm{Gl} / \mathrm{Gl}$ & Number of errors in an error category per marker \\
\hline 3 & $\mathrm{Gl} / \mathrm{TE}$ & Comparison of groups of items within the total of errors \\
\hline 4 & $\mathrm{VGI}$ & Most common item within a group of items \\
\hline 5 & $\mathrm{I} / \mathrm{TE}$ & Ranking of items with the greatest amount of errors \\
\hline 6 & $\mathrm{TT} / \mathrm{TE}$ & Presence of errors in one text type \\
\hline 7 & $\mathrm{~T} / \mathrm{TT}$ & $\begin{array}{l}\text { Particularly good/poor texts. Establishment of the mean. } \\
\text { Are there different levels of proficiency in the same group? }\end{array}$ \\
\hline 8 & $\mathrm{TT}-\mathrm{Gl} / \mathrm{TT}$ & Most common groups of items within a text type \\
\hline 9 & $\mathrm{TT}-\mathrm{Gl} / \mathrm{Gl}$ & Distribution of errors depending on text type \\
\hline 10 & $\mathrm{~T}-\mathrm{Gl} / \mathrm{T}$ & $\begin{array}{l}\text { Most common error types in average texts. } \\
\text { Can this help establish the level of proficiency? }\end{array}$ \\
\hline
\end{tabular}

Table 47. Analysis parameters.

The first descriptor, which combines markers and the total of errors $(\mathrm{M} / \mathrm{TE})$, shows a general comparison of the markers with the total of errors encountered in the texts. This can help establish whether the correction has been similar in broad terms or whether one or more markers were biased in one or several aspects of the correction.

Then, the second parameter includes the relationship between the markers and the groups of errors (C-Gl/GI), and explains any particular 
tendency of a marker towards one type of item. It has been considered interesting to interpret one particular item, and not the group of items corrected, in order to avoid compensations within a group of items. This will be calculated by relating the results of one marker for a particular item to the total results obtained by all markers for that item.

Thirdly, the combination that includes the groups of errors and compares them with the total of errors found in the texts (Gl/TE) establishes a comparison of groups of items within the total number of errors. The types of errors included in this result will help us identify the needs of the students during their learning process. It can also help teachers focus on certain specific areas of work in order to correct the most common types of errors. In this manner, the most common group of items also assists in the identification of the general level of proficiency. In particular, it can help set the focus on one specific type of errors that appear in the majority of the texts included, as being identifiable with a proficiency level.

Next, by relating the type of item and the group to which it belongs (I/GI), the most common error type within a given taxonomy can be found. This is a powerful tool when identifying the level of proficiency of a given student. By correlating the types of errors within one group with the level of proficiency, clear specifications as to what teachers should expect and focus on in their teaching, can be provided. This can result in a reelaboration of syllabuses and a reconsideration of materials for use in the classroom. 
At a later stage, the assessment of the total amount of errors, (I/TE) provides a ranking of items with the greatest amount of errors. From this, several actions could develop. Firstly, the elimination of errors with insignificant results, since these are of no interest to the research. This implies that some of the items considered in the correction of the texts and the subsequent analysis of data proved unproductive, and added no significant new information to the data offered by other items or groups of items. This can help in the identification of errors in general, without pertaining to one particular group, which correspond to a B1 level of proficiency.

The following cluster combines the type of text with the total of errors (TT/TE) and accounts for a given presence of errors within one type of text. This helps in studying the type of text whereby students produce the greatest amount of errors, thereby permitting the types of errors produced in comparison with other text types to form the focal point. It is interesting to focus on this aspect, since one of the issues in which the CEFR is particularly insistent upon, is the ability of students to recognise and reproduce genres. Indeed, it has been widely demonstrated that the CEFR offers extensive accounts with regards to the types of texts that it would be appropriate to work with in class, and the types of texts students should have to confront. As explained above, the genres chosen for analysis were selected from the list proposed by the CEFR.

This is concluded by the following two combinations, which relate the text type with the groups of items found within, from two different perspectives. First, there is the combination (TT-Gl/TT) explaining which 
groups of items are most common within one text type, thereby helping in the identification of the areas where more work would be useful for one particular genre. Next, the combination (TT-GI/GI), which explains the distribution within groups of errors, assembled by the type of text in which these is found. In this way, a clear comparison of the distribution of errors within the text types can be seen.

As explained above, by contrasting one particular text with the total number of texts (T/TT), we can gather information about particularly well performed or particularly wrongly performed texts, allowing a comparison of levels of proficiency for all the text types obtained. In the Methodology chapter, it was explained that the research had not focused on a longitudinal study of errors, and therefore, the possibility of comparing different outcomes for the different years analysed has not been included in the analysis, since the aim is not to find out whether the level of proficiency has improved or worsened throughout the years.

Finally, the combination that includes one particular text and the groups of items found within this ( $\mathrm{T}-\mathrm{Gl} / \mathrm{T}$ ) helps to establish the groups of errors that can be expected at a given level of proficiency. This helps to identify the most common errors. Furthermore, by analysing errors at a text level, and therefore analysing the particular texts and not the global results, the idea is to provide ways in which to relate errors with levels of proficiency (A1, A2, B1, B2, etc. from the CEFR).

Table 48 provides a graphic explanation of all the combinations that have been considered for the particular analysis conducted. These combinations offer information about the types of items that help limit 
and explain the level of proficiency of students; the items within the total amount of errors and the particularities of the texts chosen to represent the level of proficiency under examination, B1.

\begin{tabular}{|l|l|l|l|l|l|l|}
\hline & PARAMEIER & LEVEL & MARKER & GENRE & TEXT & $\begin{array}{l}\text { ERROR } \\
\text { TYPE }\end{array}$ \\
\hline 1 & C/TE & & & & & \\
\hline 2 & C-I/I & & & & & \\
\hline 3 & GI/TE & & & & & \\
\hline 4 & I/GI & & & & & \\
\hline 5 & $\mathrm{I} / \mathrm{TE}$ & & & & & \\
\hline 6 & T/TE & & & & & \\
\hline 7 & TT-Gl/TT & & & & & \\
\hline 8 & TT-Gl/Gl & & & & & \\
\hline 9 & T/TT & & & & & \\
\hline 10 & T-Gl/T & & & & & \\
\hline
\end{tabular}

As can be observed from the Table, information about the level of proficiency of the group used for the analysis as well as of the majority of students, can be acquired using several combinations. In particular, we have highlighted the most common error categories and the total amount of errors, the text type and error categories encountered within one particular text as opposed to the total amount of texts, and the error categories found in one particular text and in most texts.

The information obtained about the markers necessarily includes results in these being included as a variable, firstly in order to identify their partial results within the total, and secondly, to focus on the particular error categories. Subsequently, information about the total number of 
analysed text types is provided by combining the errors found in them, as well as the groups to which these errors belong, and their genre.

Information about one particular text is given by contrasting that piece with the total number of texts. This can, in turn, reveal the most common errors found within a text, grouped according to the language level at which the error is produced. Finally, most combinations help in understanding the type of error; markers, groups of items -level of errors-, total amount of errors, text type, etc.

In the following sections, explanations are offered for the results obtained in each of the analysed categories. The results are presented in numbers and percentages according to the different results obtained for each group. Extensive examples of the types of errors mentioned are included in Annex 3.

\subsection{Data obtained per markers}

The results show that 11,544 errors were found in all the texts. The first issue analysed are the results for the markers who participated in the research. As previously explained, three different markers, with a similar educational background (a degree in English Philology and Postgraduate education) and teaching experience (over six years, and currently working at Universitat Politècnica de València), corrected all the texts. In order to account for any possible bias in the correction of the texts, the 
percentage of the total number of errors for each marker is presented in Chart 1.

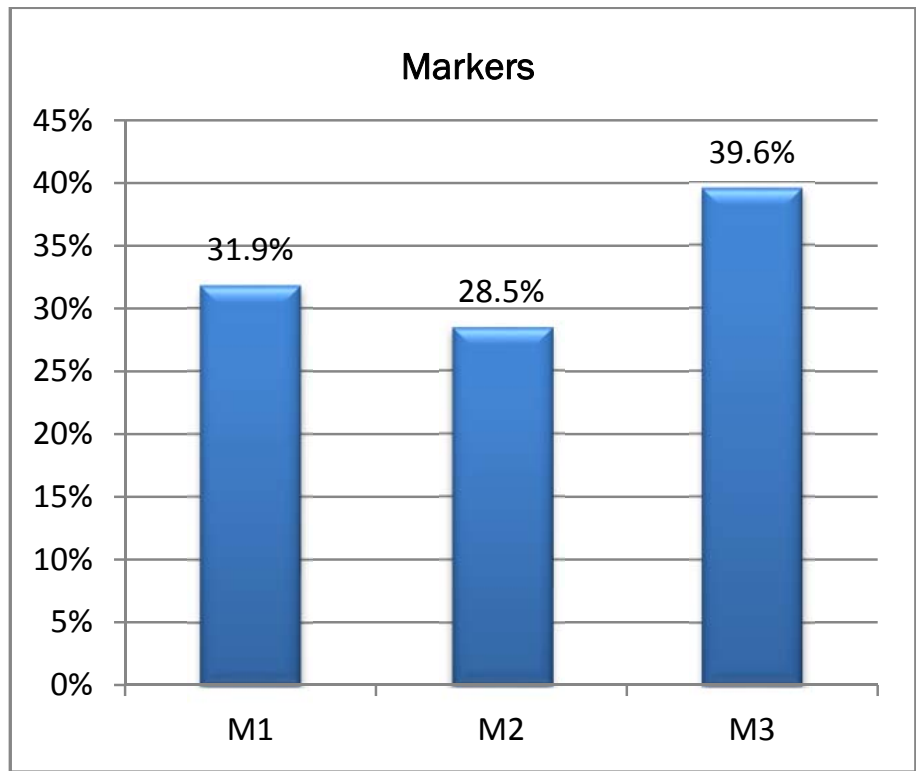

Chart 1. Results per marker in the total of errors.

As can be witnessed in the Figure, marker 1 (M1) identified $31.89 \%$ of the total number of errors occurring, that is 3,681 errors including all categories and text types. The results for marker 2 (M2) were 3,292 errors, which accounted for $28.52 \%$ of the total obtained. Finally, marker 3 (M3) accounts for $39.60 \%$ of errors, adding up 4,571 incidences.

It can be observed that some differences exist in the way each marker contributed to the total identification of errors. However, although marker 3 contributed by identifying almost 10\% more errors, it can be said that the correction level was quite similar for all three markers. This descriptor can only account for the degree of severity used by the 
markers when confronting the actual texts, since no information is included as to the type of error corrected.

This information is set out below, in separate charts depending on the type of error analysed. From these, crucial information can be extracted with regards to how markers have understood and interpreted the grid used for the analysis, and the type of errors spotted.

As explained previously, the charts can also help us to establish a classification regarding the levels of coincidence in the different texts for the types of errors encountered. An analysis of this will follow in the section dedicated to the items. To facilitate this, the errors have been grouped accordingly.

\subsubsection{Coincidence in error detection}

First of all, we look at the groups of errors in which there is a considerable amount of coincidence surrounding the outcome offered by the three markers. This implies that there was either a greater amount of coincidence in the interpretation of the items or that the items corrected were more obvious or more impartial than those belonging to other groups, in which greater significance is allocated to the particularities of each individual, thus resulting in a greater degree of divergence between them.

The charts presented are those referring to grammatical competence; errors in simple grammar, MT influence, wrong pattern reproduction, etc. 
Errors relating to flexibility (inappropriate or insufficient vocabulary, errors in complex topics) would also be included under this heading. Next, we have lexical competence errors: fixed expressions, sentential formulae, idioms, intensifiers, phrasal verbs, etc. Finally, discourse competence, that is, errors in extrapolating meaning, sequencing, verb tense, word order, connectors and transitions, simple connectors, and identifying the main points in a document, also fall into this category.

Of the total 3,444 errors identified as being related to grammatical competence in Chart 2, M3 was responsible for 1,414 (41,06\%). Then, M1 identified $37.20 \%$ (1,281 errors), and finally M2 accounting for $21.75 \%$ (749 errors). In the case of flexibility errors (Chart 3 ), there is a slight change in the trend; M2 was the marker with greater amount of incidences (427), with 40.90\%, whereas M3 only accounted for 296 (28.30\%) of the cases. Finally, M2 identified $30.75 \%$ of errors (321).

M2 was, once again, placed first in the identification of orthographical errors (Chart 4), with more than 41\%, (666 errors) then, M1 representing just over 35\% (567 errors) of the total errors found and finally M3, accounting for only 24\% (374 errors) of the total. Once again, the balance is inverted for Chart 5 included in this category; M3 identified more than 41\% (1203) of all discourse errors, but was followed closely by M1, who identified more than 37\% (1071). Finally, M2 tagged 20\% (600) of errors. 


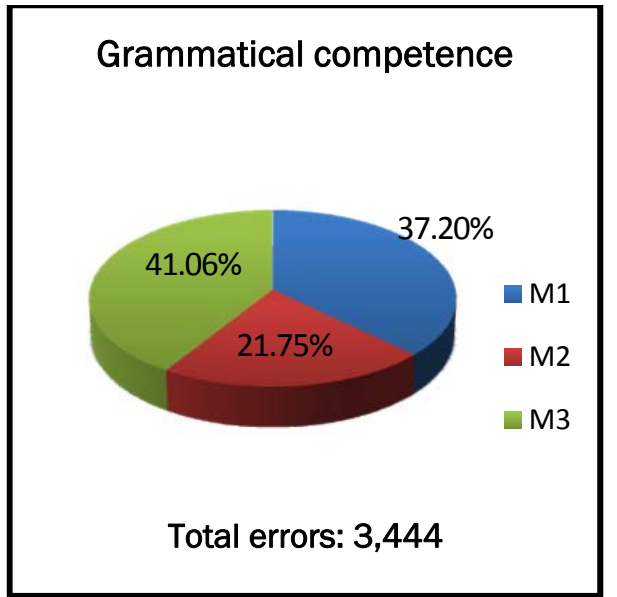

Chart 2. Grammatical competence per marker.

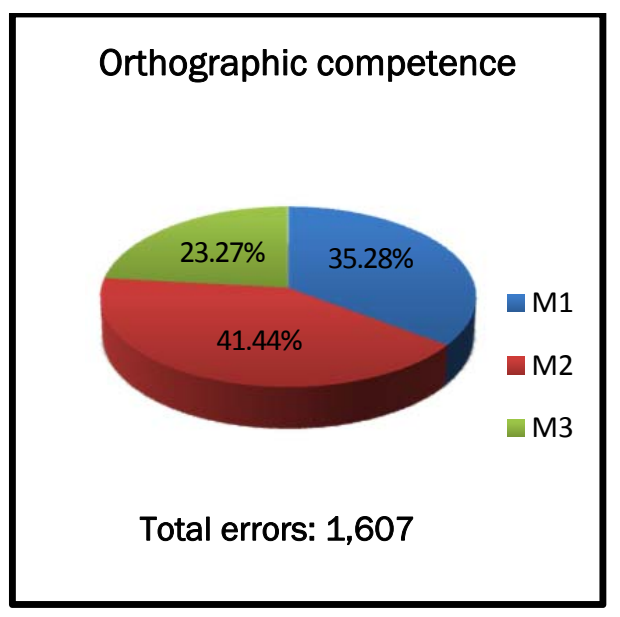

Chart 4. Orthographic competence per marker.

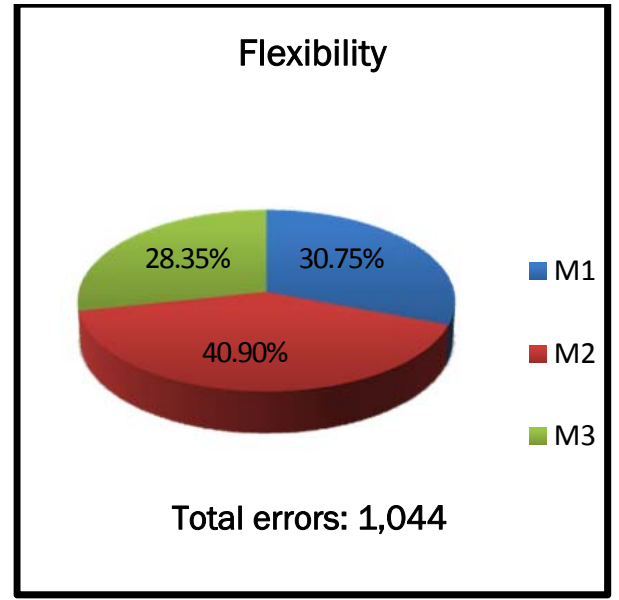

Chart 3. Flexibility per marker.

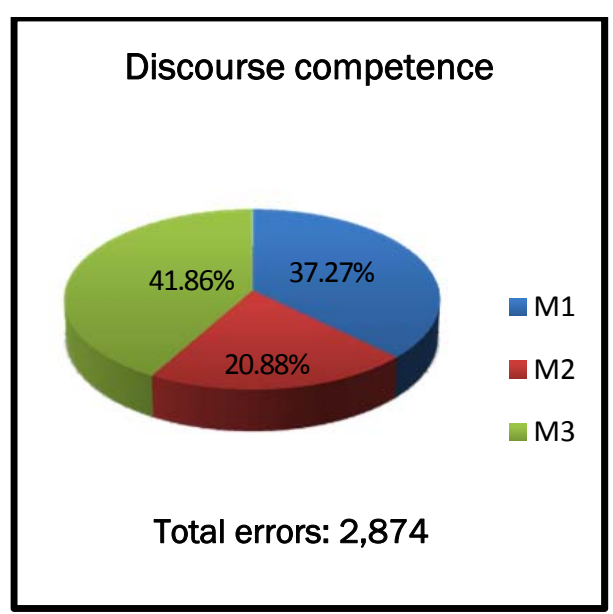

Chart 5. Discourse competence per marker.

In all these cases of error categories, it can be seen that, although there are some differences in the results obtained by the three markers, in the cases where one marker was responsible for a greater proportion of errors than the others, this represented approximately $40 \%$ of the 
results, and the remaining errors were more or less equally distributed. Furthermore, something similar occurs at the other end of the scale, whereby none of the markers offered a result below $25 \%$ of the errors.

It can also be said that although no excessive differences are observed, the greater amount of variability was offered by markers 2 and 3 , who proved to be stricter than the other markers for some error categories, whereas M1 stayed within the mean for all the cases analysed.

\subsubsection{Divergence in error detection}

The following charts show the cases in which there was a slight difference in the individual results, showing that a single marker had particular significance for the global results, since she was responsible for most of the errors encountered in that specific category. This can also highlight a tendency for one marker to identify or focus on one type of error, thus rating these differently from the other markers.

This is the case for the items related to rhetorical functions and effectiveness, and lexical competence. rhetorical functions refer to errors in the identification of the text genre, both text type and text purpose. Additionally, rhetorical effectiveness refers to all items relating to the ability of the learners to communicate their message. Finally, lexical competence errors are connected to language use, as explained before: sentential formulae, idioms, phrasal verbs, etc. 
When viewing the Charts (6 to 8 ), a slight bias with reference to M3 can be noted. She seems to have been more severe when correcting errors related to rhetorical functions and lexical competence. Regarding Chart 6 , it is important that we look at the total amount of errors in this section, since there are 96 errors relating to rhetorical functions. This low amount of errors is barely representative from a quantitative viewpoint, and few conclusions can be extracted from this. However, this cannot be offered as an explanation for lexical errors (Chart 8), of which there are more than 400, representing an average size of error category, or for rhetorical effectiveness errors (Chart 7), with over 1,000. In this group, M2 is responsible for almost $50 \%$ of all errors encountered.

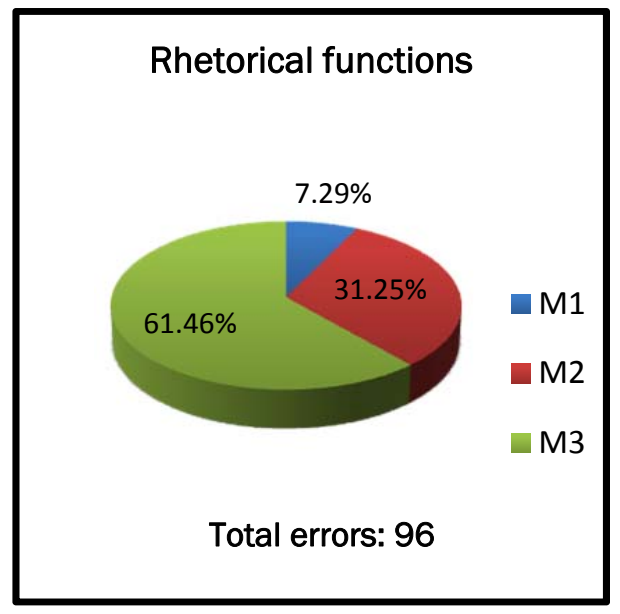

Chart 6. Rhetorical functions per marker.

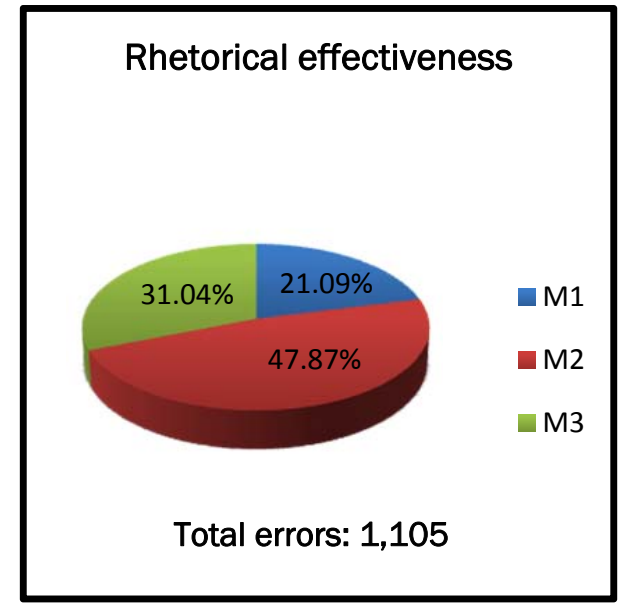

Chart 7. Rhetorical effectiveness per marker. 


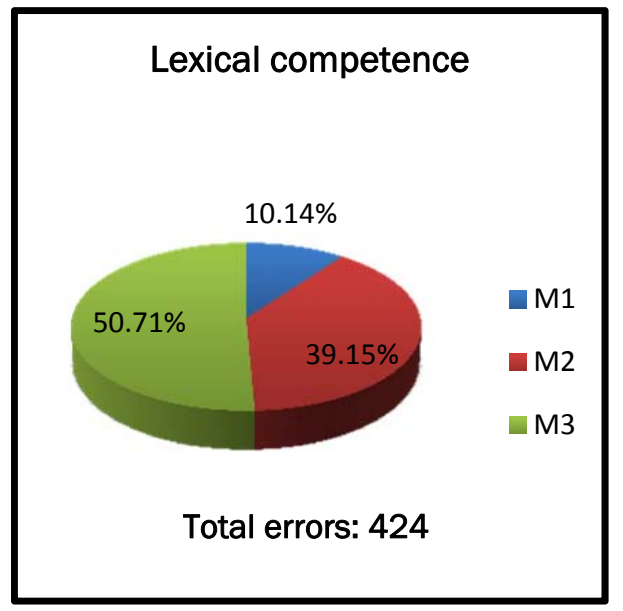

Chart 8. Lexical competence per marker.

At this point, it should be highlighted that the first two items, in which there is a given tendency for overcorrection by some markers, as opposed to others, are rhetorical issues. This could be due to a greater degree of subjectivity permitted in the interpretation of these issues, or to a broader interpretation of the elements in this category: accuracy, precision, etc.

Despite the difference in the interpretation of some texts, these tables also show that there is substantial agreement over the identification of errors. Although there are variations in the final numbers, the three Charts illustrate that the categories are distributed in a relatively even manner. 


\subsubsection{Exceptionality in error detection}

In some cases, errors belonging to one category were exclusively identified by one marker, or by one marker who spotted more than $70 \%$ of all occurrences, whereas the other marker did not mark them as errors. This can be due to the significance that the markers assigned to these errors with regard to communication, or to the fact that some markers overlooked some specific types of errors for whatever reason. It may also be due to the possibility that one error had different causes or could belong to different categories and, as such, was labelled in different ways.

This applies to style and register errors, sociolinguistic errors, content knowledge and relevance (Pragmatic) errors (Charts 9 to 12). Except for style and register errors (Chart 9), with more than 700 errors, in which M3 is responsible for more than $70 \%$ of the incidences tagged, and the other $30 \%$ is distributed between the other two markers, only two markers appear in Chart 10 and Chart 11. Indeed, these show allocations of error categories with very few occurrences in the total of texts (there are 29 sociolinguistic errors, 89 errors related to content and 76 errors relating to the pragmatic relevance principle). This can account for the enormous difference in the approach to these errors by the markers, since there is not enough available data to offer reliable results, which would facilitate extrapolation.

Only M1 and M3 spotted and tagged sociolinguistic competence errors, as can be seen in Chart 10, as well as content knowledge errors (Chart 
12), and only M2 and M3 marked relevance errors (Chart 11). This also indicates some type of variation in the interpretation of error, thus greater subjectivity, or a broader margin for interpretation of error categories in all these cases.

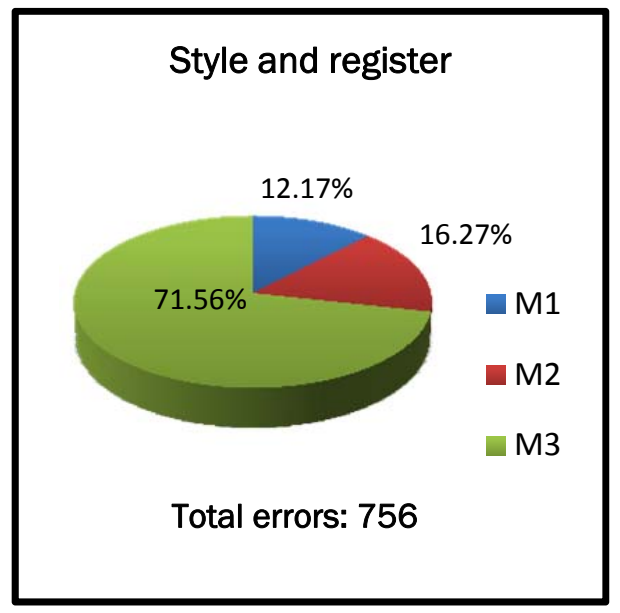

Chart 9. Style and register per marker.

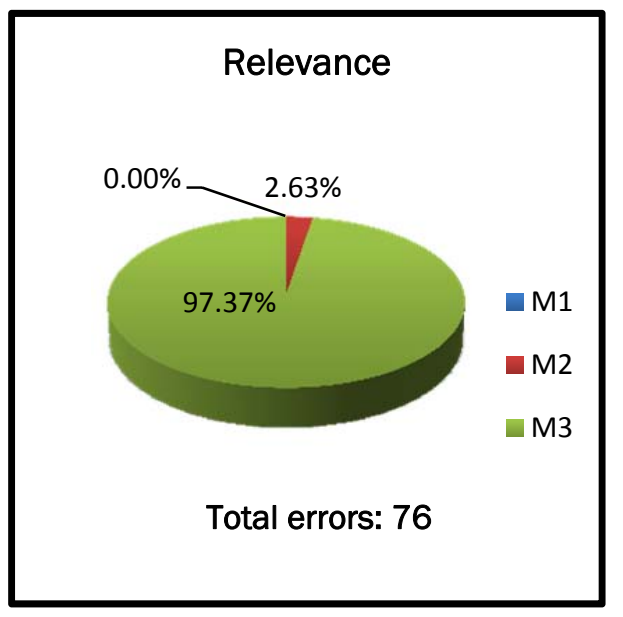

Chart 11. Relevance per marker.

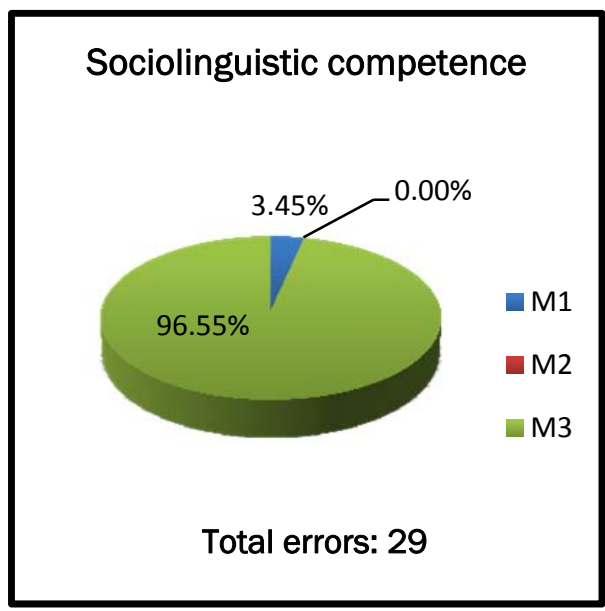

Chart 10. Sociolinguistic competence per marker.

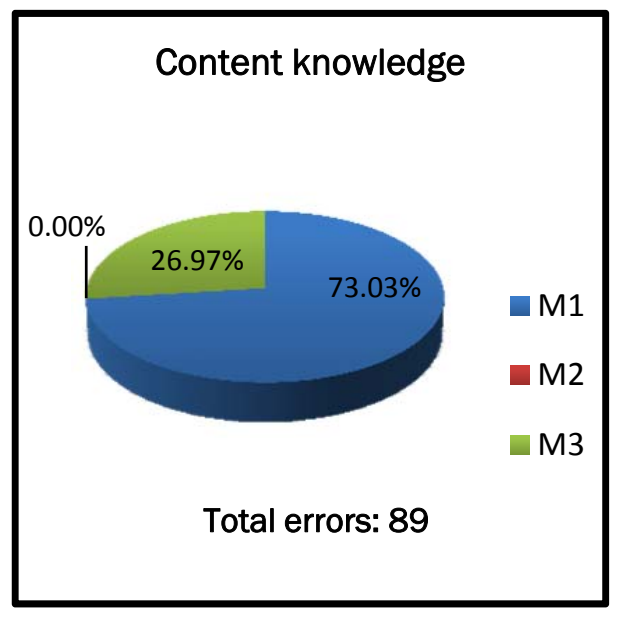

Chart 12. Content knowledge per marker. 
Since all the errors spotted by the markers have been considered, these data are useful to illustrate the different criteria shown by the markers when facing the specific texts under study. Differences in the approach or interpretation of texts could also be regarded as the causes for these divergences.

Other causes of divergence should also be considered, such as difficulty in the identification of error type, or degree of subjectivity in the assessment. A broader analysis of these results is offered in the section dedicated to the qualitative analysis of error categories with particularities that cannot be accounted for just by taking into account the numerical data.

\subsection{Analysis of items}

This point introduces the core of the analysis, offering a general view of all the errors encountered, and then dividing these into separate items in order to facilitate the presentation of the data. Different approaches are offered in the display of these results, since several interpretations and views could be extracted from them.

As explained in the Objectives chapter, the interest of the current research is to examine the types of errors made by students when they begin university. At this point, they hold a B1 level of proficiency, in accordance with the University Entrance Examination. Since the approach recommended for use at this level is that offered by the CEFR, 
based on the Communicative Approach, errors related to pragmatic issues have been studied in the current research, as previously explained.

The analysis presented here includes all the errors spotted by the markers, regardless of their level of convergence or discrepancy, since the interest is fixed on the types of errors made by students with a B1 proficiency level when writing and in identifying which of these are more easily spotted and quantified by their tutors. Also of interest is the evaluation of the distribution of error and error categories, in order to extract conclusions, which can help correlate them with the given level of proficiency, thus offering a tool for leveraging students, which is currently absent.

Another area of interest for this approach is the assessment of the practicality of the guidelines offered to teachers in the CEFR. This can be carried out by evaluating the degree of productivity of the given items, which have been obtained from the European document.

The subsection is structured as follows: an initial section in which the total number of errors found in the texts analysed is displayed. Next, a second part introduces the totals obtained for the particular errors, and a third section displays the data found for these errors grouped into the different error categories. This helps in identifying both the error category in which more errors are found, and also those, which are most problematic for students. On the one hand, all these data will provide information about the students and their level of proficiency, while, on the other hand, it will help in the identification of errors, and error 
categories, in terms of efficiency and usefulness for any subsequent analysis or teaching strategy. The conclusions obtained from these results will be expounded in the next section.

\subsubsection{General outcome}

The results obtained from the total number of corrections show a significant amount of errors, in particular 11,544 occurrences, which account for all three markers and the entire set of 39 items, which belong to 11 item groups. They have been obtained from 206 texts belonging to three different genres.

Although there is a short separate explanation of the items, most of the study has been conducted taking into account the error categories. As such, the outcome is quite clear when it comes to identifying the main causes for error, although some observations must be made as to the global application of the study.

First of all, some of the items described in the CEFR refer to issues that apply to the text or the text type perceived as a unit. For instance, this is the case for errors related to text type or text purpose identification, or errors related to style and register. Customarily, when these occur, there is only one example per text. The approach to this type of error necessarily implies an identification of the texts in which these errors appear and not a global totalling of numbers. 
Secondly, some error categories include several items for identification (up to five in the case of style and register or rhetorical effectiveness), whereas others comprise of only one or two items. This is not only due to the nature of the error itself, but also to the descriptors offered by the CEFR for the identification and learning of strategies, abilities and skills. In other words, there is some sort of correlation between the categories, which include a greater amount of items within these, and the CEFR descriptors dedicated to the treatment and explanation of a particular item. Within this an implicit focus or interest can be identified.

This section consists of a global view, which focuses on the items themselves, and then data are presented in the error categories. After this, subsequent pie and bar charts have been produced to show all the partial results obtained in the analysis. The charts include an explanation of two different types of errors, and offer quantitative and qualitative analyses of the errors in each category identified. In addition, they also include an examination of the specific items belonging to the same error category, in order to look at their productivity as error spotting tools capable of helping towards the improvement of the students' level of proficiency.

When the results obtained are considered as a number of occurrences, prior to their classification into groups and their identification as errors at a given language level, there is a clear recognition of the main errors encountered in the texts. These errors appear repeatedly in the texts produced by the students, and, hence, specific attention should be given to them, as will be explained in the Conclusions chapter. 
Since the number of items selected for consideration in the analysis grid was very large (39 items in total) ${ }^{23}$, a selection of the most frequent ones is reproduced in Table 49.

\begin{tabular}{|c|c|c|}
\hline POSITION & TAG & OCCURRENCES \\
\hline 1 & GSE & 1784 \\
\hline 2 & GMT & 1361 \\
\hline 3 & DCC & 1051 \\
\hline 4 & DSV & 1035 \\
\hline 5 & OP & 857 \\
\hline 6 & PrVC & 774 \\
\hline 7 & OS & 693 \\
\hline 8 & DSWO & 501 \\
\hline 9 & RHAC & 478 \\
\hline 10 & RP & 387 \\
\hline 11 & GP & 299 \\
\hline 12 & RI & 256 \\
\hline 13 & DSC & 225 \\
\hline 14 & RHQ & 205 \\
\hline 15 & PrVN & 194 \\
\hline
\end{tabular}

Table 49. Most common errors in the corpus.

Table 49 presents the outcome obtained for the first fifteen items in the ranking of errors. It shows their position and the number of errors encountered in the texts with these tags. The very same results shown in Table 49 are displayed in the Chart 13, which offers a graphic picture of the results, making it easier to put them into perspective. The largest item shown in the Table (GSE) represents 1,784 errors. The smallest

${ }^{23}$ See Annex 6 for the ranking of all items 
(PrVN), contains 194 errors, still a considerable amount of them, since they refer to errors due to insufficient vocabulary.

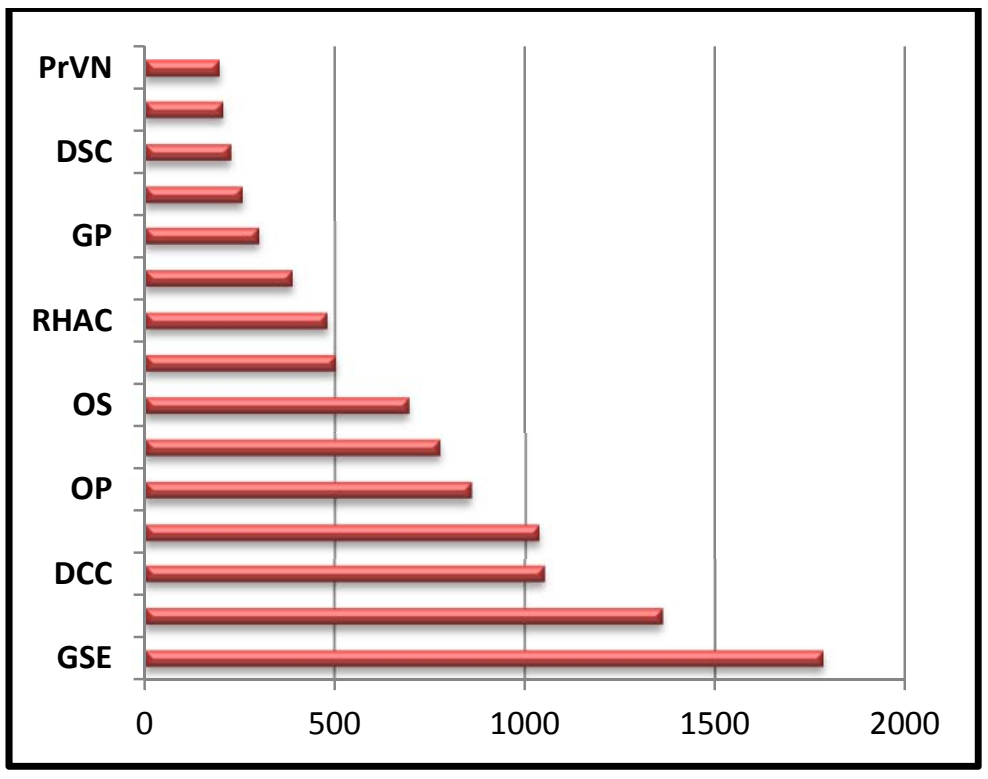

Chart 13. Ranking of errors in the corpus.

The fact that there are great differences in the number of errors found is evident. The two most common errors belong to the same error category: grammatical competence. They are, in order, grammatical errors in simple sentencing and MT influence. The third and last item included in the analysis grid as grammatical error is wrong pattern reproduction, which appears in position 11.

These are followed by two items connected to discourse competence, and refer to verb tense and coherence and cohesion errors. Orthography errors are listed with a significant amount of occurrences: punctuation is fifth, with 857 occurrences, and spelling is seventh, with 693 . 
Only in the sixth position does the first item considered in the CEFR as connected to Pragmatic competence and to flexibility in the use of language, in particular vocabulary, appear. Noteworthy in Chart 13 are several issues relating to rhetorical effectiveness, specifically accuracy, with 478 incidences and failure to communicate (205).

The following section explains error distribution taking into account the categories to which errors belong. Most errors belong to the same categories, although not all of them have the same degree of incidence in the results.

Furthermore, the treatment of errors according to specific categories can possibly help the work of teachers and researchers at a much deeper level, as opposed to just one individual focusing on one set of errors.

\subsubsection{Error categories}

Chart 14 provides a general view of all the errors encountered in the texts by the markers. It offers the global numbers prior to any discrimination or partial analysis. To facilitate its interpretation, errors are displayed by being grouped into categories. 


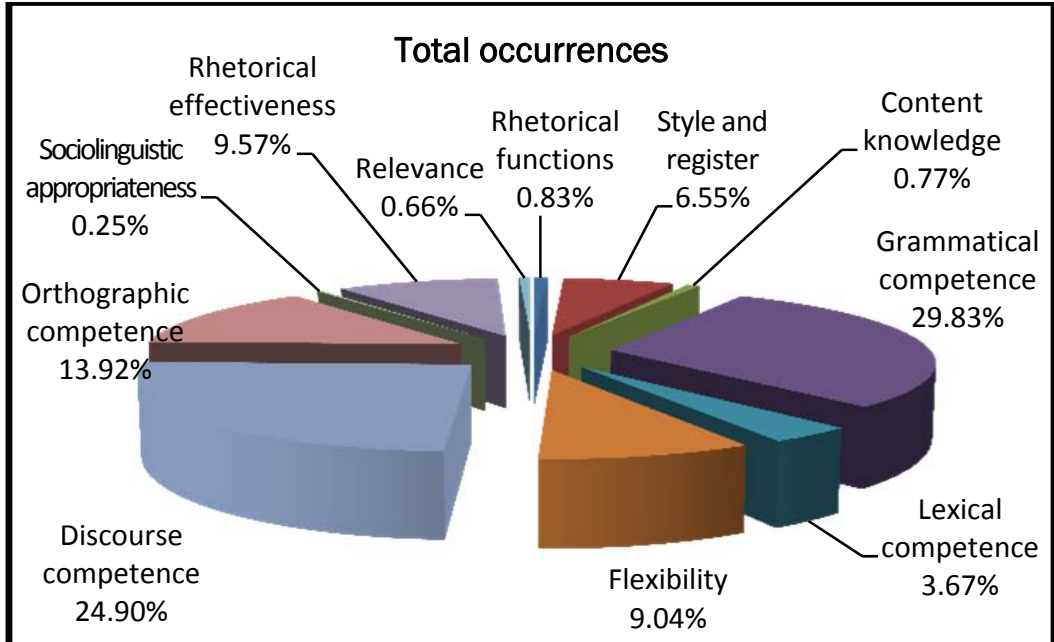

Total errors: 11,544

Chart 14. Distribution of error categories in the corpus.

As can be observed, the greatest amounts of errors correspond to the grammatical competence, which accounts for nearly a third of all errors. Next in Chart 14 can be seen discourse competence errors, with 2,874 errors, almost $25 \%$ of the set analysed. Orthographic competence errors are next representing around $14 \%$ of all errors found. Noticeable is the fact that these errors are easily identified with traditional errors connected to grammar and orthography.

Responsible for the least amount of errors are sociolinguistic appropriateness, rhetorical functions and relevance, as well as content knowledge errors, all of which account for less than one per cent of the errors. As explained above, a different approach is employed to deal with these types of errors, since they are different in essence from the others. 
Responsible for approximately $10 \%$ or less of all the errors found in the 11 categories considered (that is, in the clearest mean point) are rhetorical effectiveness, flexibility, lexical competence and style and register. Some errors occur in these categories, but these are not the categories responsible for the majority of errors.

This can be seen in Chart 15, which displays a ranking of error categories, ranging from those with the greater amount of occurrences, i.e. grammar, with 3,444 to those with a lower amount of incidences, i.e. sociolinguistic, 29.

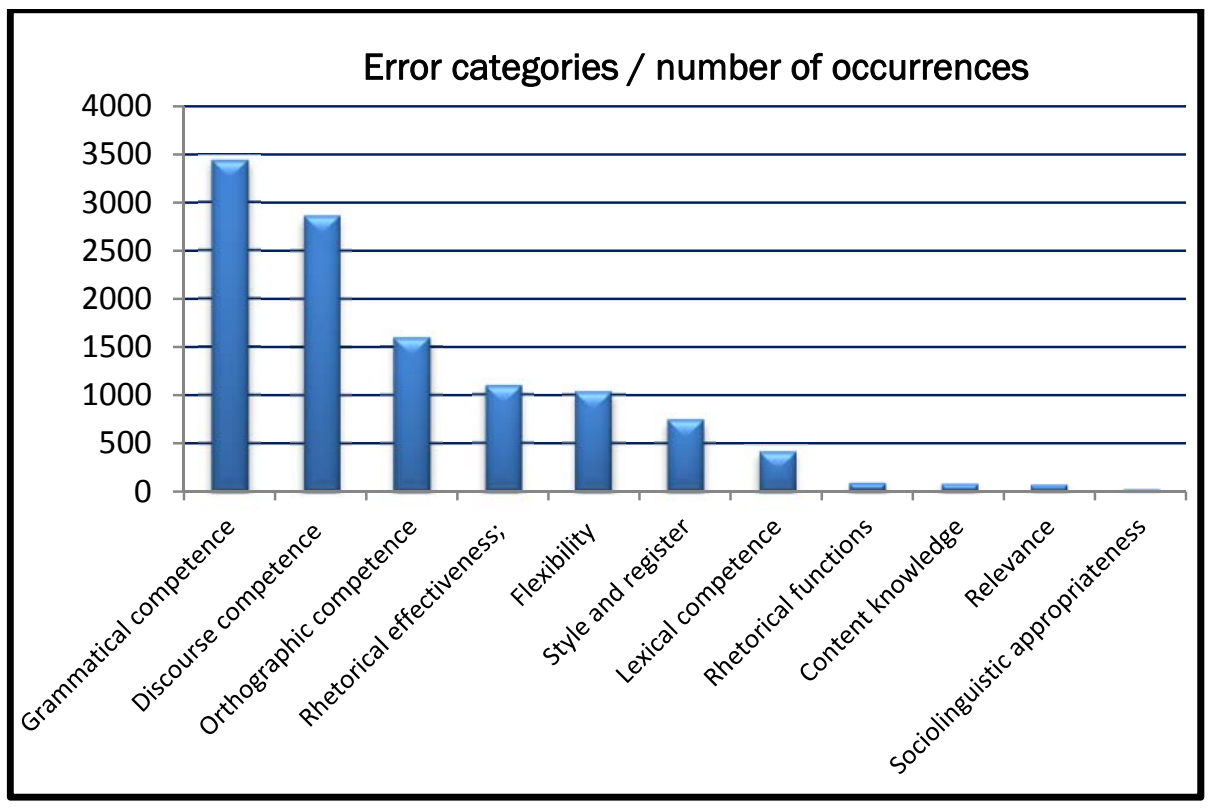

Chart 15. Ranking of error categories in the corpus.

Although Chart 15 does not display the specific percentages for each item analysed, it offers a clear view of the errors that proved most numerous. This Chart ranges from the greatest amount of errors 
(grammatical, with 3,444 occurrences) to the smallest amount of errors (sociolinguistic, with only 29 occurrences).

\subsubsection{Items within error category}

Data is now given for error distribution. Charts 16, 17 and 18 represent error categories to depict the contribution of each item to the total volume. This can help identify the issues, which present the greatest amount of difficulty for students, as well as the items, which offered no results, being unproductive, or almost unproductive in the entire set.

It also helps in the visualisation of those categories having many items for consideration, and those having few or none. Regarding this, it should be noted that there is no chart representing relevance, since it is a one-item category.

The first set analysed is integrated by the three categories that represent the greatest amount of errors: grammar, shown in Chart 16, discourse, shown in Chart 17, and orthography, shown in Chart 18. 


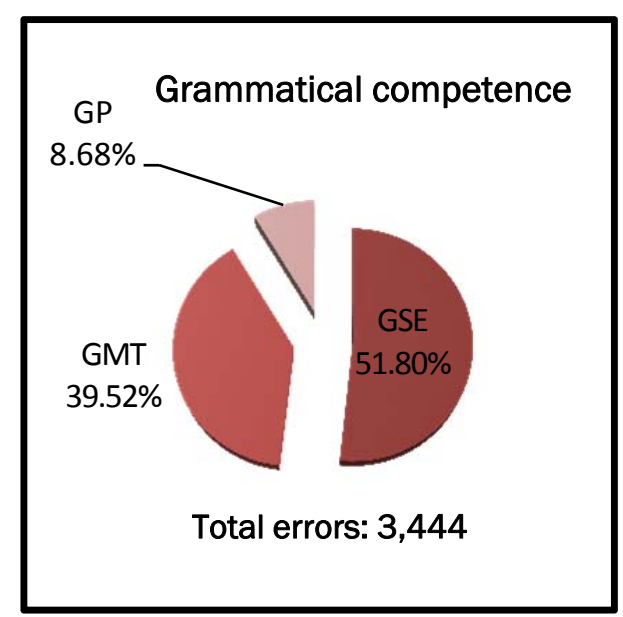

Chart 16. Occurrences in grammatical competence items.

\section{Discourse competence}

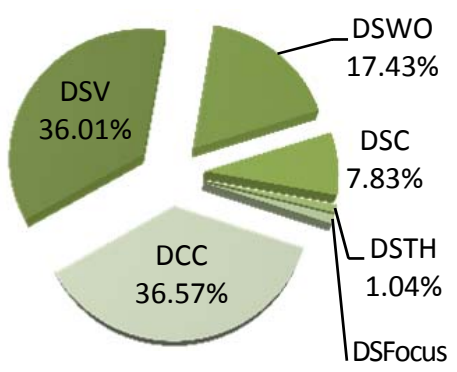

Total errors: 2,874
Chart 17. Occurrences in discourse competence items.

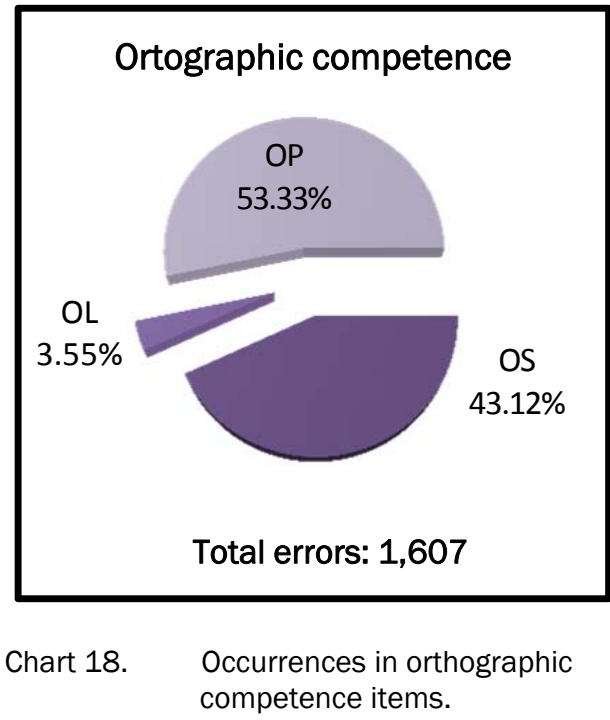

As can be seen in Chart 16, the majority of errors correspond to grammatical problems in simple sentencing, followed by errors that arise due to MT interference. Very few errors correspond to the infelicities in the reproduction of patterns given to the student. 
Chart 17 offers a view of all the items related to rhetoric competence. In this case, five different items are introduced for the comparison. The majority of errors correspond either regarding problems with verb tenses or with coherence and cohesion issues. These two items combined account for over $70 \%$ of the errors analysed. Quite significant were the results for word order errors. However, the other three items, i.e. transitions and connectors, summarising an idea and identification and reproduction of main points, display a very low number of occurrences, and should be considered of little significance.

Chart 18 represents errors related to orthography. As can be seen, only those errors related to spelling and punctuation, and in particular, the latter, are of significance for the researcher or teacher. The remaining $4 \%$, that is, 67 errors have been marked as layout errors.

Charts 19, 20, 21 and 22 display errors in the categories that reveal an average rate of errors. Interestingly, most of these categories are also directly related to pragmatic awareness or issues of pragmatic abilities. 


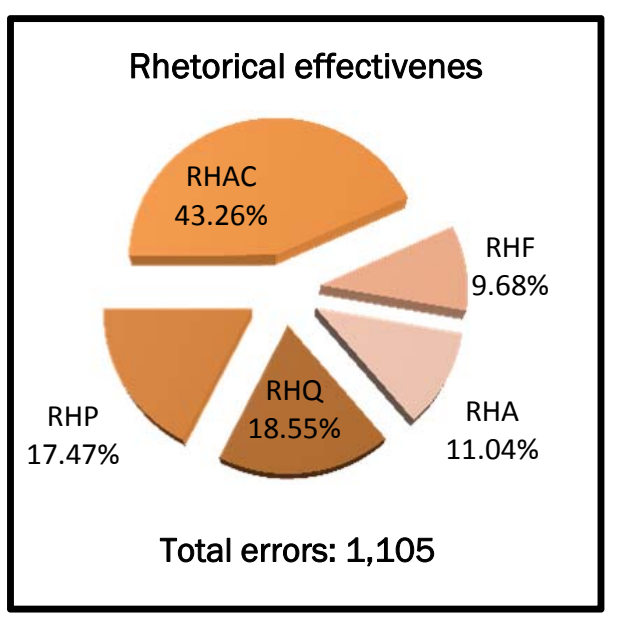

Chart 19. Occurrences in rhetorical effectiveness items.

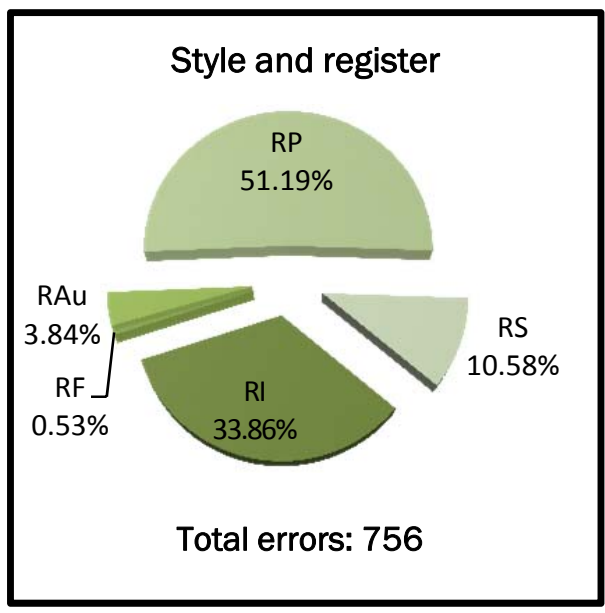

Chart 21. Occurrences in style and register items.

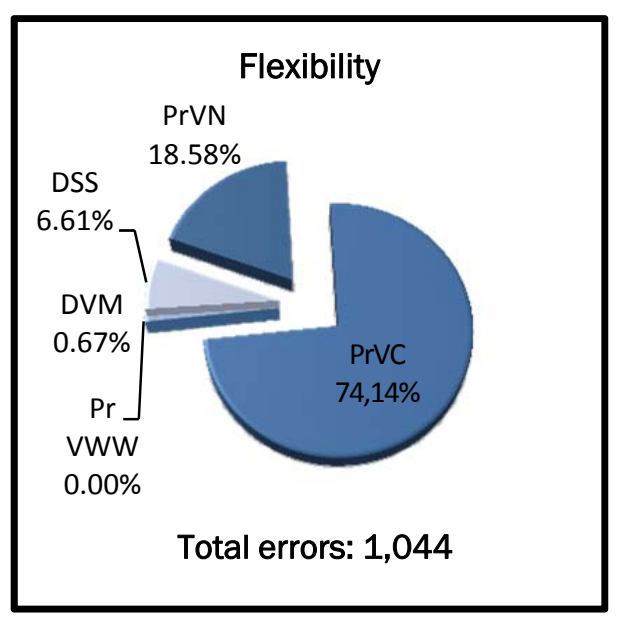

Chart 20. Occurrences in flexibility items.

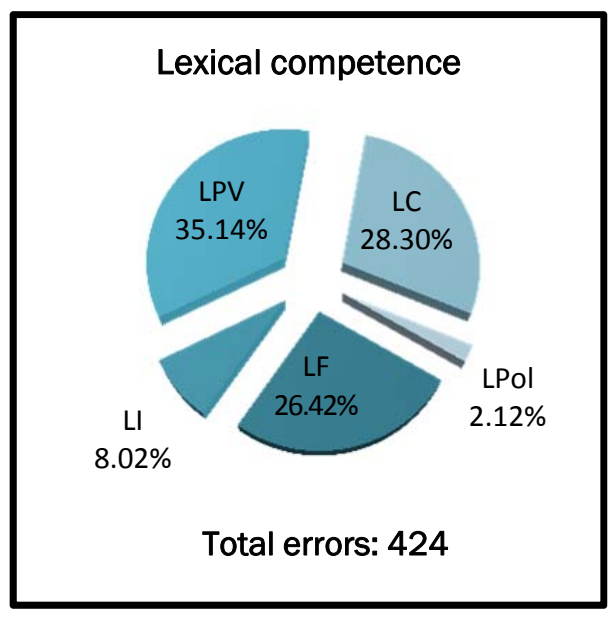

Chart 22. Occurrences in lexical competence items.

As can be seen, most errors in the group for rhetorical effectiveness are errors of accuracy, followed by errors in precision and the student inability to convey the intended message. 
Although Chart 20 also includes five different items, mostly related to semantic issues, only one seems productive, that which spots errors in common vocabulary, PrVC, which accounts for almost $75 \%$ of all errors. This is the most common cause of errors in flexibility. Also worth mentioning is the use of the tag for insufficient vocabulary for this range of errors. It should be acknowledged that the only item in the analysis grid that produced no results in the entire analysis is grouped in this category: PrVWW, i.e. errors in complex topics. This will be analysed at a later point and is related to the fact that very few complex topics are present at this level of proficiency.

Most style and register errors concern register (Chart 21). Students employed either too formal (almost 52\%) or too informal (around 34\%) register in their writings. These two items alone account for around 85\% of the total. There is only one area related to style, in particular to the use of the student's own words to express ideas or opinions, or simply to narrate a story.

Finally, lexical issues are quite evenly distributed in Chart 22 between LPV (phrasal verbs), which accounts for 35\% of occurrences, LC (collocations), having $28.30 \%$ of incidences, and LF (fixed expressions), with $26.42 \%$. The rest of the items, related to polysemy (LPol) and the use of intensifiers (LI), assemble a very small amount of errors.

Charts 23, 24 and 25 represent the error categories with fewer items. 


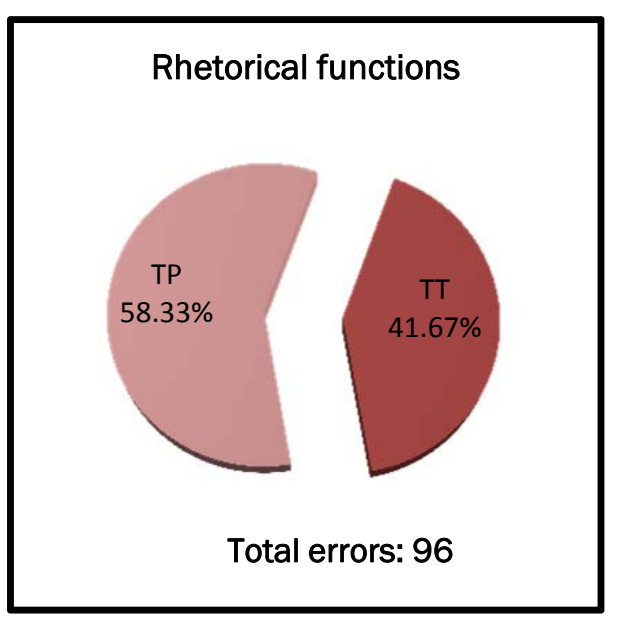

Chart 23. Occurrences in rhetorical functions items.

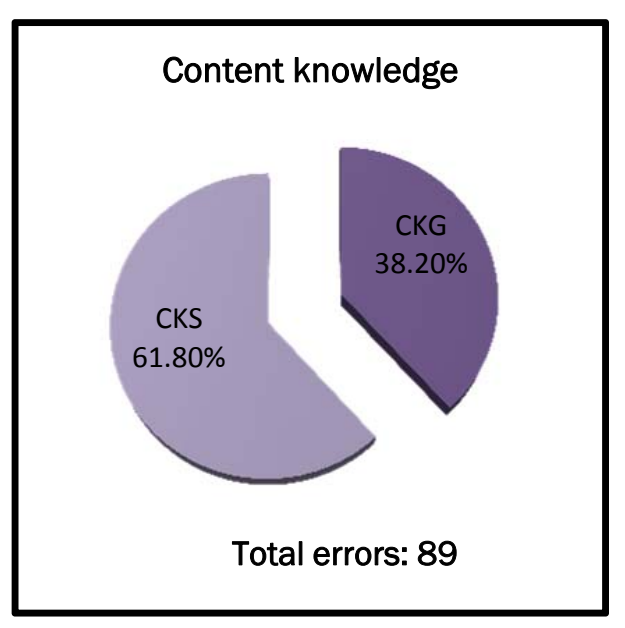

Chart 24. Occurrences in content knowledge items.

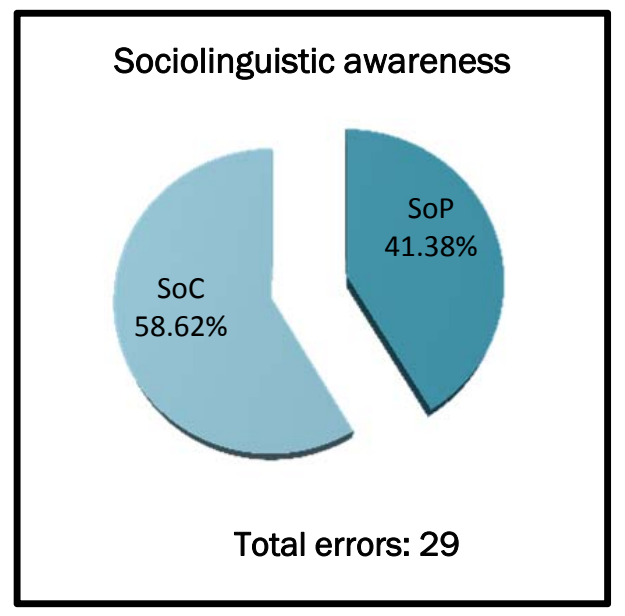

Chart 25. Occurrences in sociolinguistic awareness items.

These are integrated by only two items. In first position, with regards to the number of errors, are the rhetorical functions: recognition and reproduction of text type and text purpose, with 96, a slightly greater amount of which are related to the latter error type. 
Next, errors related to content are displayed, looking at whether students have the general or specific content knowledge required. These account for 89 occurrences. Students show a lower level of specific knowledge than of general knowledge.

Finally, sociolinguistic errors are represented in Chart 25. There is a slight difference in the results, with almost $60 \%$ being due to cultural issues, whereas more than $40 \%$ are the result of politeness problems. Only 29 errors were identified as falling into this category.

\subsection{Particularities of each genre}

This section analyses the data obtained for the different types of texts. We have used the term genre to refer to these issues, simply reproducing the terminology and synonymy used in the CEFR. As explained previously, the research has been based on three text types: opinions, summaries, and formal letters.

In the first subsection, a series of pie charts shows the distribution of the different error categories depending on the text type. Then, all errors specific to one individual text type are analysed. Next, an overview of the averages of results for all errors is given, and information obtained with reference to the levels of proficiency is displayed. Finally, the errors analysed using a qualitative method i.e. mainly pragmatic errors, are presented. 


\subsubsection{Impact of genre on error category}

In global terms, enormous differences in the outcome obtained for the different types of texts do not exist. Although some differences are present, errors are quite evenly distributed throughout all the genres. This can be observed in Table 50, which displays the total number of errors for each type of text: summary, opinion, and letter.

From Table 50, it is apparent that the trends for every error category are quite similar across genres; more errors appear in the categories of grammatical competence, discourse competence and orthographic competence. However, the distribution of items in the spectrum of errors is not exactly the same, as will be explained later.

\begin{tabular}{|l|r|r|r|}
\hline ITEM & SUMMARY & OPINIONLETTER \\
\hline RHETORICAL FUNCTIONS & 29 & 32 & 35 \\
\hline STYLE AND REGISTER & 181 & 236 & 339 \\
\hline CONTENT KNOWLEDGE & 61 & 12 & 16 \\
\hline GRAMMATICAL COMPETENCE & 1246 & 1207 & 991 \\
\hline LEXICAL COMPETENCE & 153 & 147 & 124 \\
\hline FLEXIBILITY & 465 & 348 & 231 \\
\hline DISCOURSE COMPETENCE & 1299 & 954 & 621 \\
\hline ORTHOGRAPHIC COMPETENCE & 613 & 416 & 578 \\
\hline SOCIOLINGUISTIC AP. & 3 & 1 & 25 \\
\hline RHETORICAL EFFECTIVENESS & 406 & 447 & 252 \\
\hline RELEVANCE & 19 & 32 & 25 \\
\hline \multicolumn{4}{|l}{ Table 50. Number of errors in each text type. } \\
\end{tabular}


The categories that represent the smallest group of errors are slightly different in the three groups, as highlighted in bold in Table 50. Here, in the case of summary and opinion, it is sociolinguistic appropriateness, whereas in the formal letters, content knowledge has the lowest number of incidences.

The distribution of errors per category according to the type of text is given in Charts 26, 27, 28 and 29. First of all, those cases in which there was almost complete parity in the distribution of errors in all three text types are displayed. That is the case for two error categories which contain a large amount of errors, i.e. grammar and orthography, and two in which the number of error is non-significant, i.e. rhetorical functions or average, i.e. lexical competence.

Students demonstrated a similar command of language in these four competences, as can be seen in Charts 26, 27, 28 and 29.

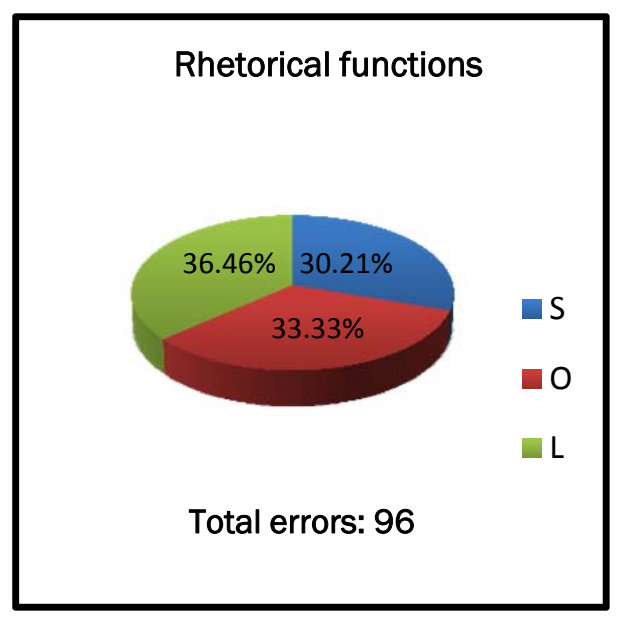

Chart 26. Rhetorical functions in genres.

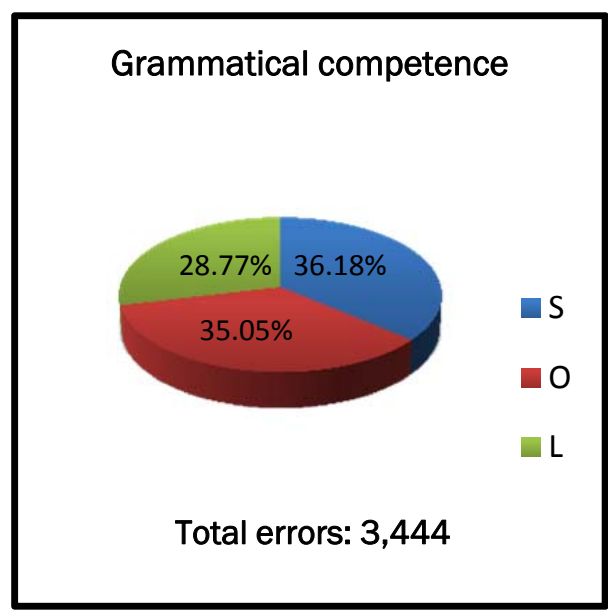

Chart 27. Grammatical competence in genres. 


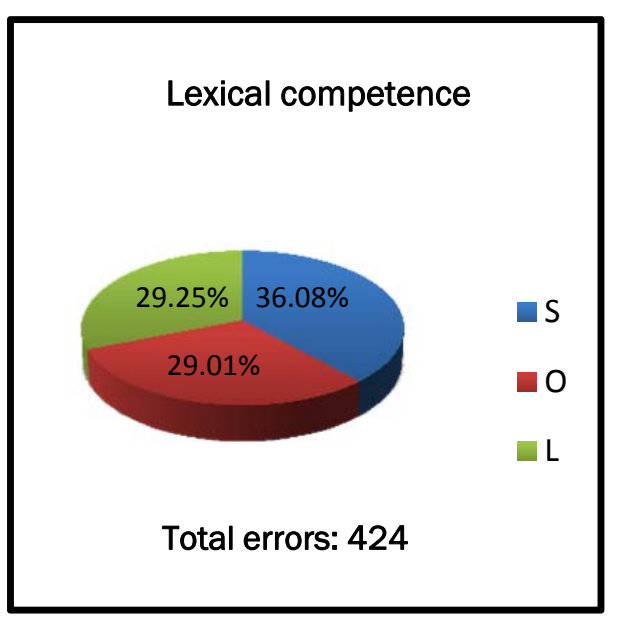

Chart 28. Lexical competence in genres.

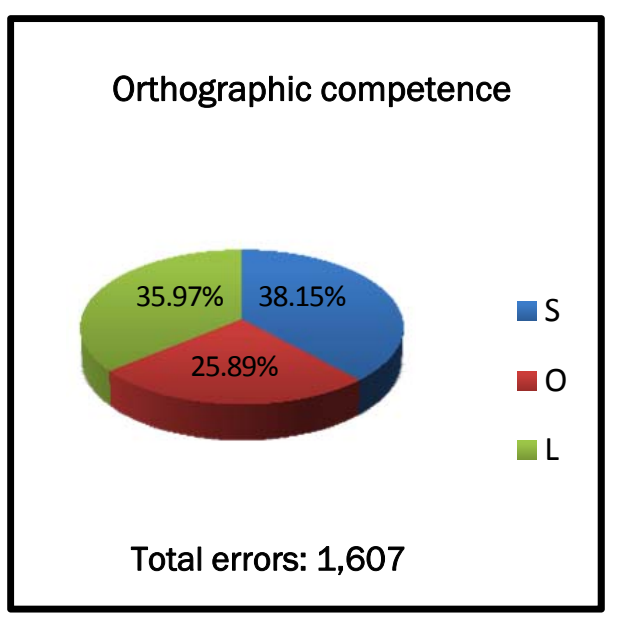

Chart 29. Orthographic competence in genres.

Although there seem to be fewer errors with regard to rhetorical functions in summaries (almost 30\%), in general, summaries display the greatest amount of errors (grammar, lexical and orthographic). This may be due to the combination of skills required in order to produce this type of text. This involves, on the one hand, the ability to summarise, and, on the other, the ability to explain something using one's own words, thus bringing a certain degree of freedom to writing. In Chart 27, we also find a smaller amount of grammatical errors in letters (almost 29\%), probably due to the reproduction of patterns in this type of text. Opinion texts show fewer errors both in lexical and orthographic competences.

Charts $30,31,32$ and 33 exhibit cases in which a group of texts displayed a slightly greater amount of errors for a certain category. This refers to two large categories: flexibility and rhetoric effectiveness, an average-size category: register and style, and a small category: relevance. 


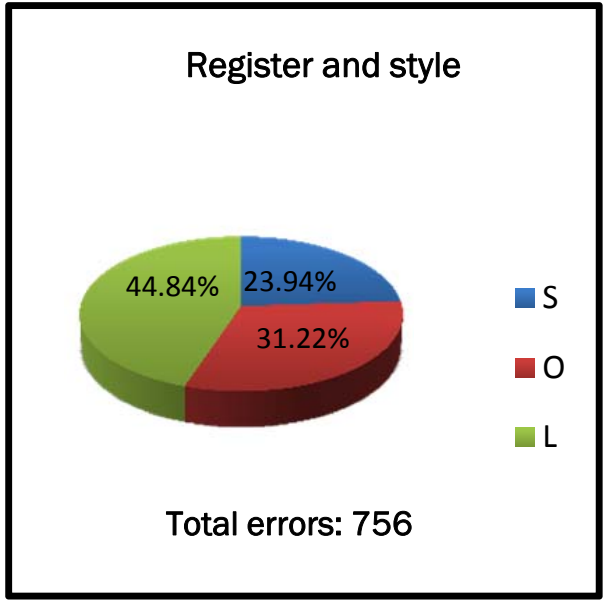

Chart 30. Register and style in genres.

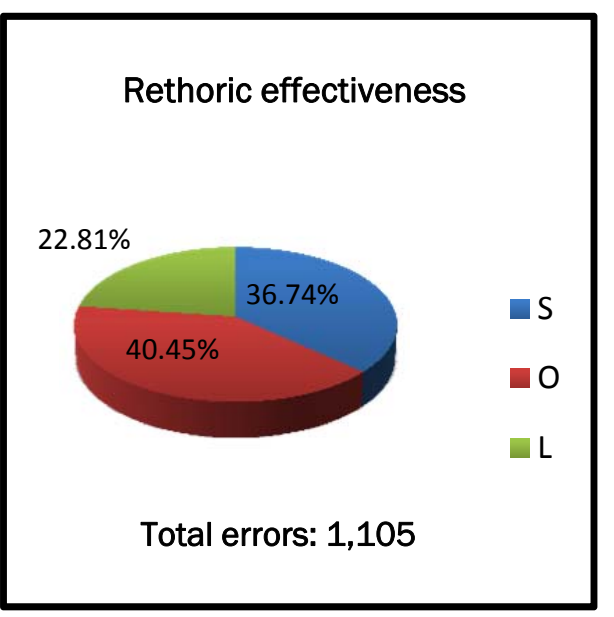

Chart 32. Rhetoric effectiveness in genres.

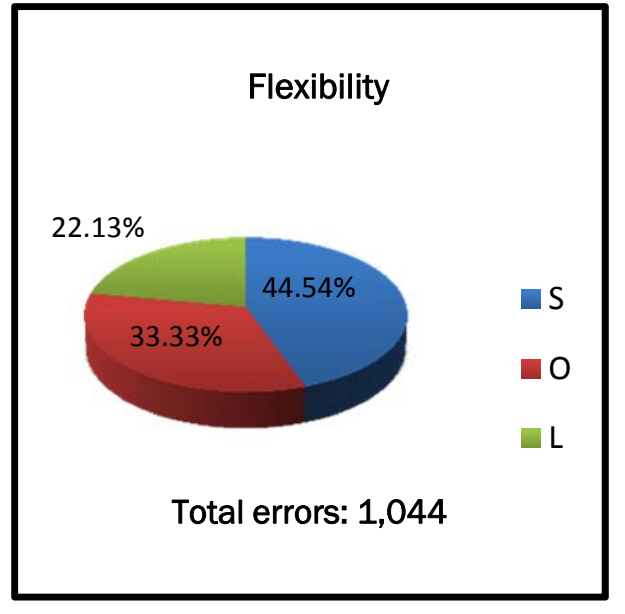

Chart 31. Flexibility in genres.

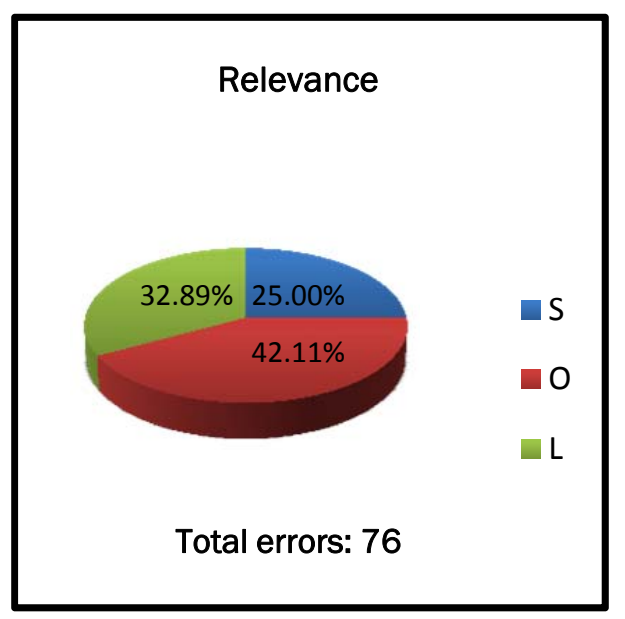

Chart 33. Relevance in genres.

In Chart 30, i.e. register and style, most errors are produced in letters (almost $45 \%$ of all errors), where there is probably a misinterpretation of the degree of formality required. More flexibility (Chart 31 ) is required in summaries, where almost $45 \%$ of errors stem from this text type. 
The other categories reveal a significantly higher number of occurrences in the case of opinions. These two items are related to the ability to transmit a message, and the restraint of adapting to complexity, in terms of effectiveness in communication. It could be alleged that these relate more to texts that require students to express themselves without any prior arrangement or established format.

Next, a series of Charts 34,35 and 36 are displayed in which one text type was responsible for most errors belonging to one category. In this set, all pie charts representing proportions above $45 \%$ for one particular genre have been included. This applies to discourse competence errors, represented in Chart 35, content knowledge errors, represented in Chart 34, and sociolinguistic competence errors, represented in Chart 36.

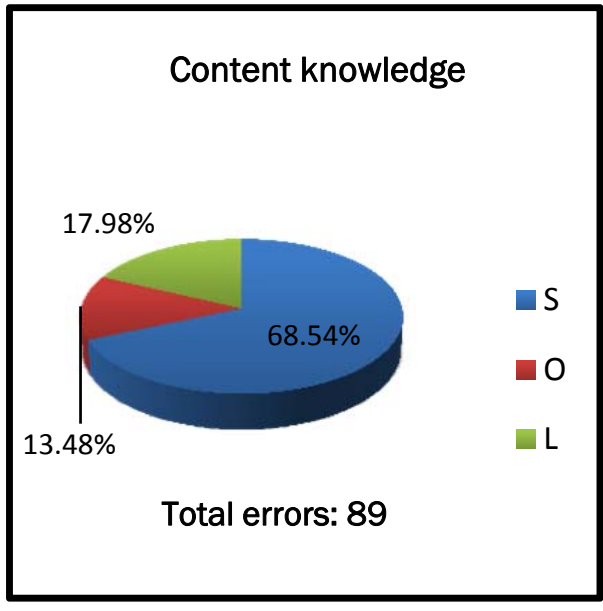

Chart 34. Content knowledge in genres.

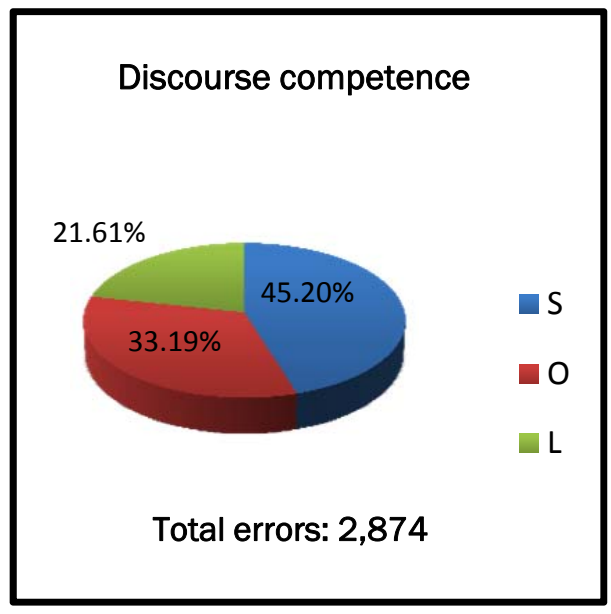

Chart 35. Discourse competence in genres. 
Sociolinguistic competence

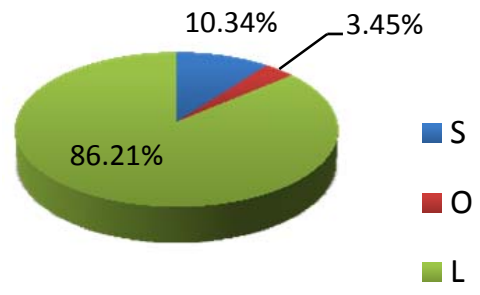

Total errors: 29

Chart 36. Sociolinguistic competence in genres.

It should to be pointed out that most of these categories display a very low number of errors, thus offering results that must be carefully considered, since the data offered may not be consistent. As explained, a different analysis method will be applied to these settings. This is the case for sociolinguistic and content knowledge errors, the results for which can be found in Charts 34 and 36. In Chart 36, most errors (around $86 \%$ ) are linked to letter writing, probably due to an ignorance surrounding cultural issues. In Chart 34, almost $69 \%$ of errors were tagged in summaries. This seems to suggest that students lack the necessary content knowledge with regards to the topics proposed for summary. Most errors relating to the discourse competence were detected in opinions, representing more than $45 \%$ of all the errors found in this category for all three text types. 


\subsubsection{Distribution of errors within the text type}

We now analyse each text type in order to pinpoint the distribution of errors in each genre analysed, and to establish whether the results are comparable in terms of type of error. To begin with, we will look at the individual errors, to identify all possible differences in the texts analysed. Following this, the results are analysed in error categories in order to facilitate reading and further study. The ten most frequent types can be observed in Tables 52, 53 and 54, classified according to the type of text.

\begin{tabular}{|c|c|c|}
\hline \multicolumn{3}{|c|}{ SUMMARY } \\
\hline 1 & GSE & 646 \\
\hline 2 & DSV & 587 \\
\hline 3 & GMT & 545 \\
\hline 4 & DCC & 382 \\
\hline 5 & PRVC & 348 \\
\hline 6 & OP & 322 \\
\hline 7 & OS & 285 \\
\hline 8 & DSWO & 209 \\
\hline 9 & RHAC & 191 \\
\hline 10 & RP & 127 \\
\hline
\end{tabular}

Table 51. Specific errors in summaries (1-10)

\begin{tabular}{|c|c|c|}
\hline \multicolumn{3}{|c|}{ OPINION } \\
\hline 1 & GSE & 656 \\
\hline 2 & GMT & 506 \\
\hline 3 & DCC & 408 \\
\hline 4 & DSV & 271 \\
\hline 5 & PRVC & 255 \\
\hline 6 & OS & 212 \\
\hline 7 & OP & 202 \\
\hline 8 & RP & 173 \\
\hline 9 & DSWO & 173 \\
\hline 10 & RHAC & 172 \\
\hline
\end{tabular}

Table 52. Specific errors in opinions (1-10).

\begin{tabular}{|c|c|c|}
\hline \multicolumn{3}{|c|}{ LETTER } \\
\hline 1 & GSE & 482 \\
\hline 2 & OP & 333 \\
\hline 3 & GMT & 310 \\
\hline 4 & DCC & 261 \\
\hline 5 & RI & 202 \\
\hline 6 & GP & 199 \\
\hline 7 & OS & 196 \\
\hline 8 & DSV & 177 \\
\hline 9 & PRVC & 171 \\
\hline 10 & DSWO & 119 \\
\hline
\end{tabular}

Table 53. Specific errors in letters (1-10).

It can be observed in tables 51 to 53 that there are differences in the errors tagged in the texts. The texts coincide in the first cause of error, i.e. grammar, but not in the second, which is verb tense for summaries, 
MT influence for opinions and punctuation for letters. This is an interesting discovery, since it points to the need for specialised training if we are to look for specificity in the use of language.

Verb tense could be a problem in summaries if students are asked to reproduce a past event, whereas the problem with regard to Letters is that students do not know how to punctuate properly, which becomes increasingly apparent within a formal setting. mother tongue is a problem when students express themselves freely and not so much attention is paid to structure or layout.

If we examine the categories that present the lowest rate of incidence, thus representing items that were not tagged in the texts, we find similar results; a certain coincidence within the items observed, although not distributed exactly in the same manner for the different genres. Tables 54 to 56 display the items with the lowest rate of occurrences in the texts. 


\begin{tabular}{|l|l|r|}
\hline \multicolumn{3}{|c|}{ SUMMARY } \\
\hline 1 & DSFOCUS & 11 \\
\hline 2 & $\pi$ & 7 \\
\hline 3 & OL & 6 \\
\hline 4 & DVM & 5 \\
\hline 5 & SOC & 3 \\
\hline 6 & RF & 2 \\
\hline 7 & RAU & 1 \\
\hline 8 & LPOL & 0 \\
\hline 9 & SOP & 0 \\
\hline 10 & PR VWW & 0 \\
\hline
\end{tabular}

Table 54. Specific errors in summaries (29-39).

\begin{tabular}{|l|l|r|}
\hline \multicolumn{3}{|c|}{ OPINION } \\
\hline 1 & CKG & 5 \\
\hline 2 & DSTH & 5 \\
\hline 3 & RF & 2 \\
\hline 4 & DVM & 2 \\
\hline 5 & OL & 2 \\
\hline 6 & LPOL & 1 \\
\hline 7 & SOP & 1 \\
\hline 8 & RAU & 0 \\
\hline 9 & SOC & 0 \\
\hline 10 & PR VWW & 0 \\
\hline
\end{tabular}

Table 55. Specific errors in opinions (29-39).

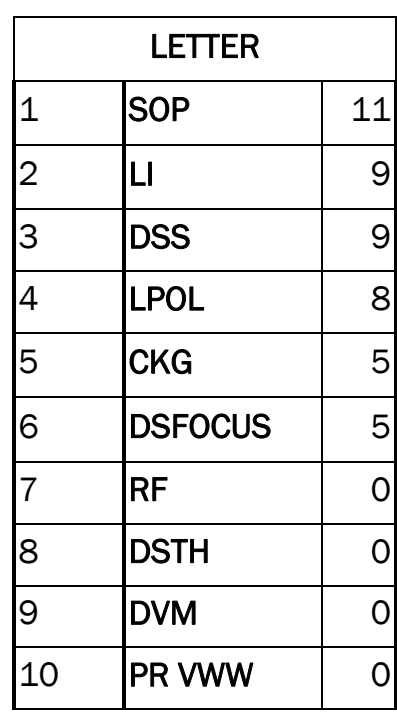

Table 56. Specific errors in letters (29-39).

As has been repeatedly stated, for cases in which data is so scarce, we must be very careful when interpreting the results. However, since we are dealing with global numbers, some appreciations are obvious.

As observed in Tables 54 to 56, no errors in complex topics were identified in the texts, since all were found to deal with simple themes. As for sociolinguistic issues, there were no errors relating to politeness in summaries, and no errors relating to culture in opinions. Considerable variations can be seen, for instance, in the case of polysemy, which appears in fourth position in letters (Table 56), in sixth position, with only one case, in opinions (Table 55), and fails to occur in summaries (Table $54)$. 
Some items are only applicable to one type of text, as can be seen in the case of OL, which represents layout issues. It appears in the summary and opinion Tables, but does not appear in Table 56. In contrast to this, $\mathrm{RAU}$, which reflects a lack of consideration of the audience, does not appear in the letter ranking (Table 56), but does occur in Tables 54 and 55 , reflecting a greater awareness towards the recipient of the message in that specific circumstance.

In addition, items such as DVM, or SOP appear in all three Tables, but in different positions. DVM, which reflects an inability to extrapolate meaning, is fourth in summaries and opinions, and ninth in letters (Table 56). SOP relates to politeness issues, appears in ninth, seventh, and first position, respectively in the three Tables.

Next follows a detailed analysis of the errors found, taking into account the variables of error category and genre. First of all, Chart 37 includes all incidences for all genres, then, these incidences are analysed separately. 


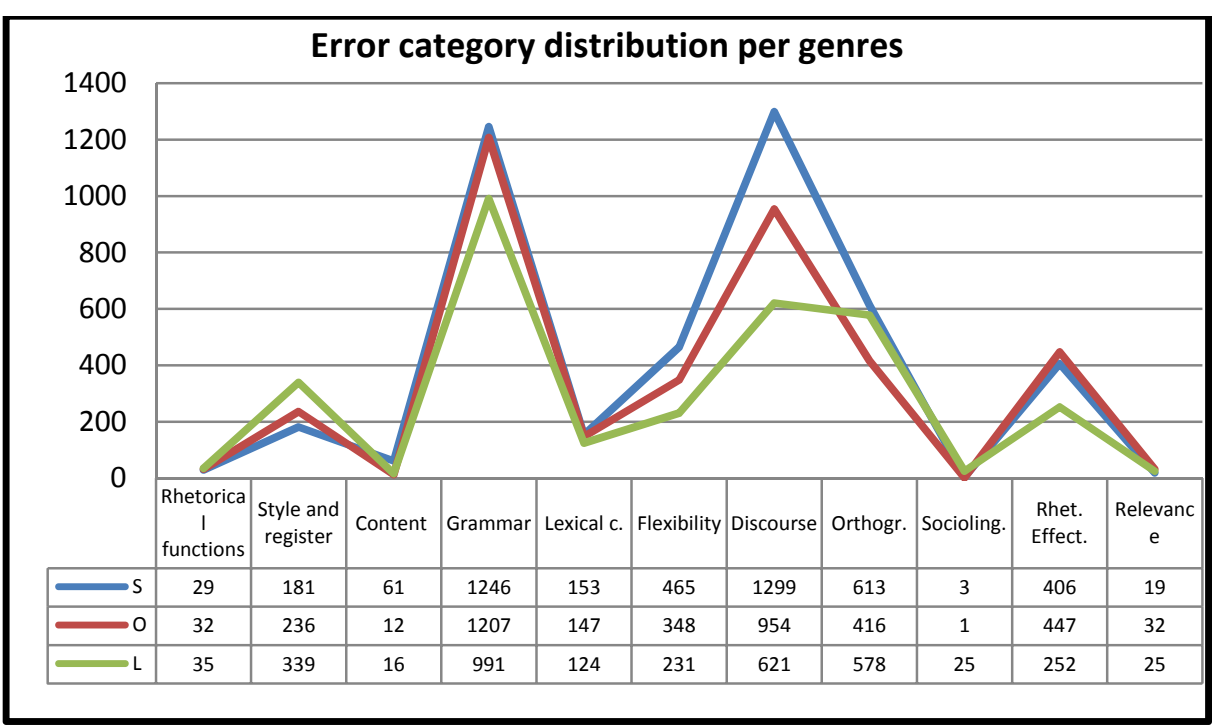

Chart 37. Error category distribution per genres in the corpus.

As can be seen in Chart 37, although the peaks in the error categories with the greatest amount of occurrences are analogous, some differences can be observed in the total results. In general, letters display a lower amount of errors with a total of 3,237 errors, compared to 3,832 for opinions and 4,475 for summaries. This is clearly noticeable with regard to those referring to discourse competence, which accounts for less than half the number of errors found in summaries (Chart 37). Once again, this could be due to the type of text. For example, those texts that leave students with a freer structure to work with require a greater knowledge of connectors, linkers, and other coherence issues. In the case of rhetoric effectiveness, a similar outcome is observed. Students find it easier to communicate their message when presented with texts with a more confined layout. 
On the contrary, letters reveal a high rate of incidences in the case of style and register, i.e. letters account for 339 errors, which almost doubles the amount obtained in summaries. As previously explained, this is linked to register recognition and reproduction in formal writing. Summaries have the highest peak in number of errors, in particular errors relating to flexibility (465 occurrences), discourse competence (1,299 occurrences) and orthographic competence (613 occurrences).

As for the remainder of the error categories, the number of grammar errors seems quite similar for all three genres, as is the case for content knowledge, lexical competence or sociolinguistic errors. Most of these present a very low number of occurrences, as can be seen in Chart 37. An in-depth examination of the type of error found in each genre, grouped into categories is presented in Chart 38 below. This is interesting as it allows us to see the errors that are specific -or at least, most common- within a text type. Again, some similarities and certain dissimilarities can be found in the comparison of the three types of texts. These are shown in Charts 38 to 40. 


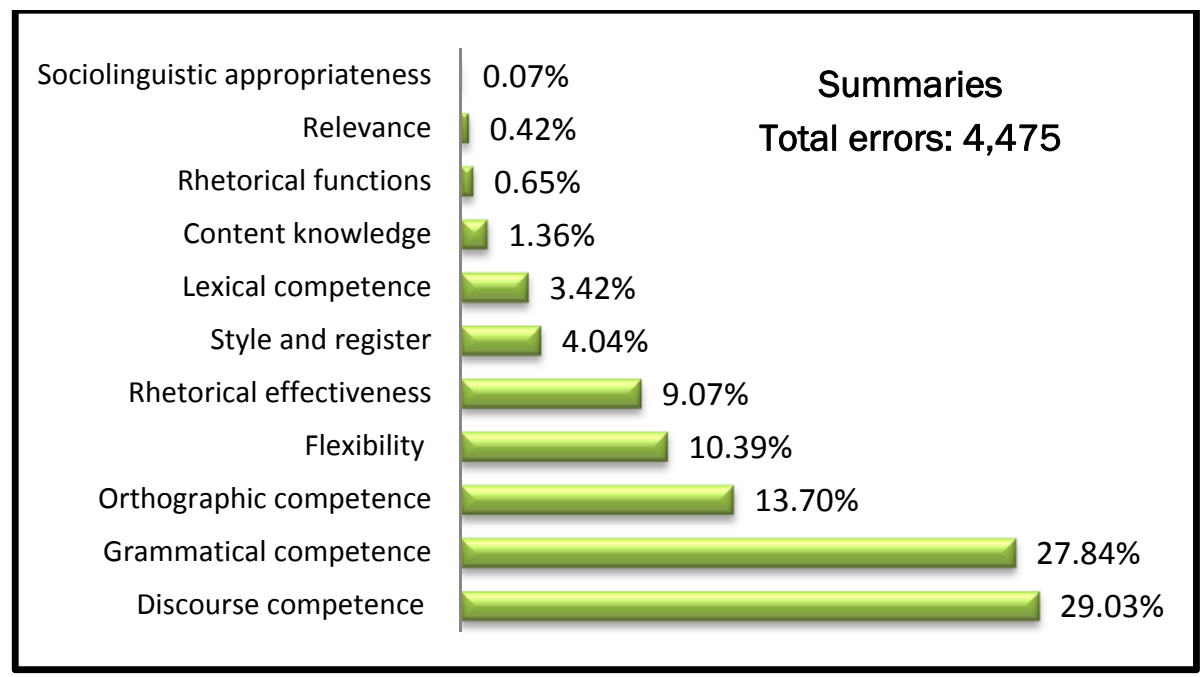

Chart 38. Error distribution in summaries in the corpus.

As can be seen in Chart 38, in the case of summaries, discourse competence errors account for almost 30\%, followed by errors in grammar, with almost $28 \%$ of occurrences. Lagging far behind are those errors found in orthography and vocabulary (10\% and 9\% respectively). The least common errors in this type of text are sociolinguistic and relevance errors, and errors relating to the recognition of text types and purposes (returning non-significant results, below 1\%). 
Sociolinguistic appropriateness

Content knowledge

Rhetorical functions

Relevance

Lexical competence

Style and register

Flexibility

Orthographic competence

Rhetorical effectiveness

Discourse competence

Grammatical competence
$0.03 \%$

$0.31 \%$

$0.84 \%$

$0.84 \%$

$3.21 \%$

$6.16 \%$

$9.08 \%$

$10.86 \%$

$11.66 \%$

Opinions

Total errors: 3,832

Chart 39. Error distribution in opinions in the corpus.

As can be seen in Chart 39, in the case of opinion texts, there is a slight switch in the number of errors. Grammar errors represent 31\% of the total number of occurrences, whereas discourse competence errors signify $25 \%$.

Three categories characterise approximately $10 \%$ of errors; flexibility, orthographic competence and rhetorical effectiveness, and four account for just $1 \%$ of the results obtained: sociolinguistic problems, content knowledge, text recognition and relevance.

In the case of errors, grammar is the main cause of incorrect utterances in more than $30 \%$ of the texts, followed by discourse competence $(20 \%)$ and orthographic competence (almost 18\%). 


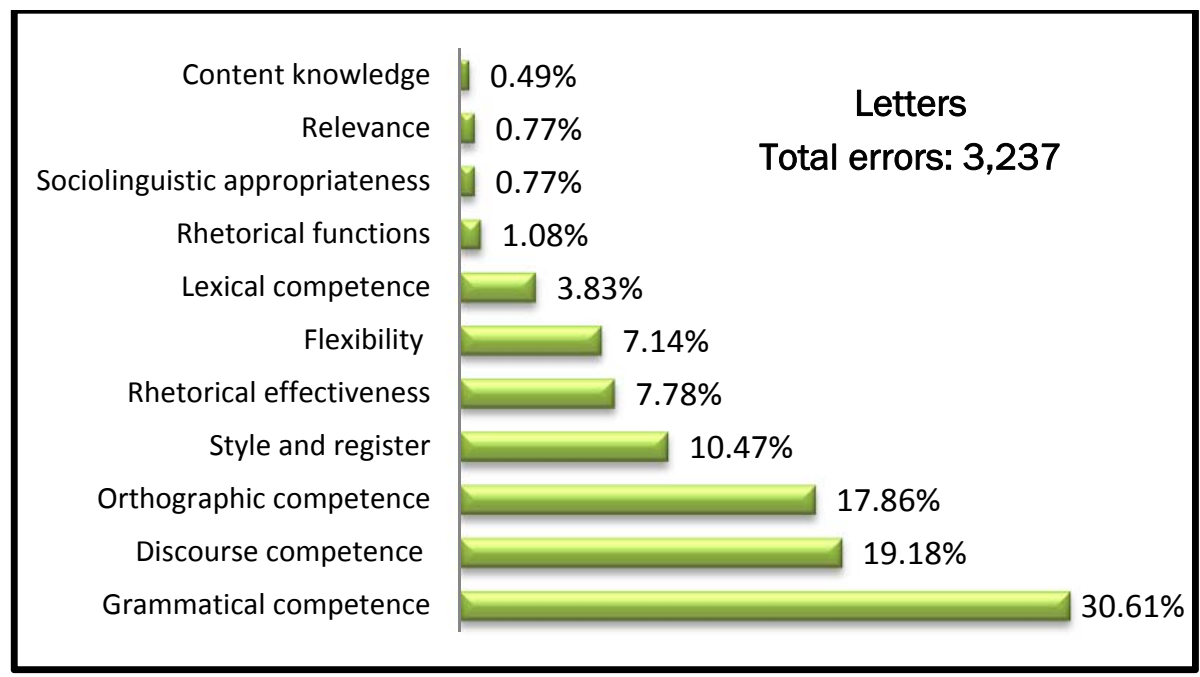

Chart 40. Error distribution in letters in the corpus.

This Chart shows that the average categories are below or above $10 \%$, (style and register, rhetorical effectiveness and flexibility), and that those categories with the lowest number of occurrences, as in the previous boxes, represent less than $1 \%$ of errors in letters.

Summing up, despite the differences in the rates, lexical competence is approximately $3 \%$ for all cases, and grammatical competence approximately $30 \%$.

\subsection{Account of B1 level of proficiency}

This section of the Results chapter is dedicated to giving an account of the level of proficiency observed in the texts as it affects error analysis. 
This section displays the results for the calculation of what can be considered to be average texts in these settings.

The first part is concentrated on explaining the statistical analysis of means in Table 57, which displays the general numbers for all the types of texts, markers, and items. Then, an analysis of the results obtained is clarified, averaging the texts in order to find those with a clearer B1 level of proficiency. In the final part, the specific errors found in those texts are summarised in the final passage.

A statistical calculation has been carried out in order to identify those texts with an average number of errors in all the categories studied. Texts with extremely good and extremely bad results, as well as texts belonging to the majority of productions analysed have been considered, based upon the number of errors encountered in them. In Table 57, the displayed results are separated into three columns representing the three genres.

\begin{tabular}{|l|r|r|r|}
\hline STATISTIC & SUMMARY & OPINION & LETTER \\
\hline MAX & 191 & 138 & 152 \\
\hline THIRD QUARTILE & 89 & 67 & 60 \\
\hline MEDIAN & 62 & 50 & 47 \\
\hline FIRST QUARTILE & 27 & 32 & 33 \\
\hline MIN & 6 & 11 & 10 \\
\hline
\end{tabular}


The term MAX accounts for texts with an extraordinarily high number of errors, that is, particularly poor productions. In the case of summaries, we have found more than 191 occurrences, in the case of opinions, more than 138 errors, and in the case of letters, more than 152 errors.

The term THIRD QUARTILE incorporates productions included within $75 \%$ of texts, that is, all those productions where the number of errors is below 89 errors, as in the case of summaries, with 67 occurrences in the case of opinions and 60 occurrences with regards to letters. Here, a difference in errors can be easily identified. Most summaries have a significantly higher amount of errors than the rest of the productions.

The term FIRST QUARTILE represents texts that are comprised in 25\% of all writings, and includes the well-performed texts in all the production of errors. This applies to texts with less than 27 errors for summaries, 32 errors for opinions, and 33 errors for letters. Interestingly, if generally speaking, summaries have more errors than the rest of the texts, they also have fewer errors in $25 \%$ of the texts, revealing a greater discrepancy between well performed and poor texts.

Finally, good texts are identified in the term MIN row. Texts that were extremely well written, of which there are less than 25\% for each genre. In the case of summaries, the best produced text has six errors; there are eleven errors in the most successful opinion text, whereas the most proficient letter written by a student has 10 errors. 
This can be seen in the following boxplot (Chart 41), which offers a clear picture of the results obtained, facilitating interpretation. The boxes show all texts that fall within the average (range between $25 \%$ and $75 \%$ ), and leave out texts below or above this level of proficiency. In green can be seen texts above average, in red, texts below average.

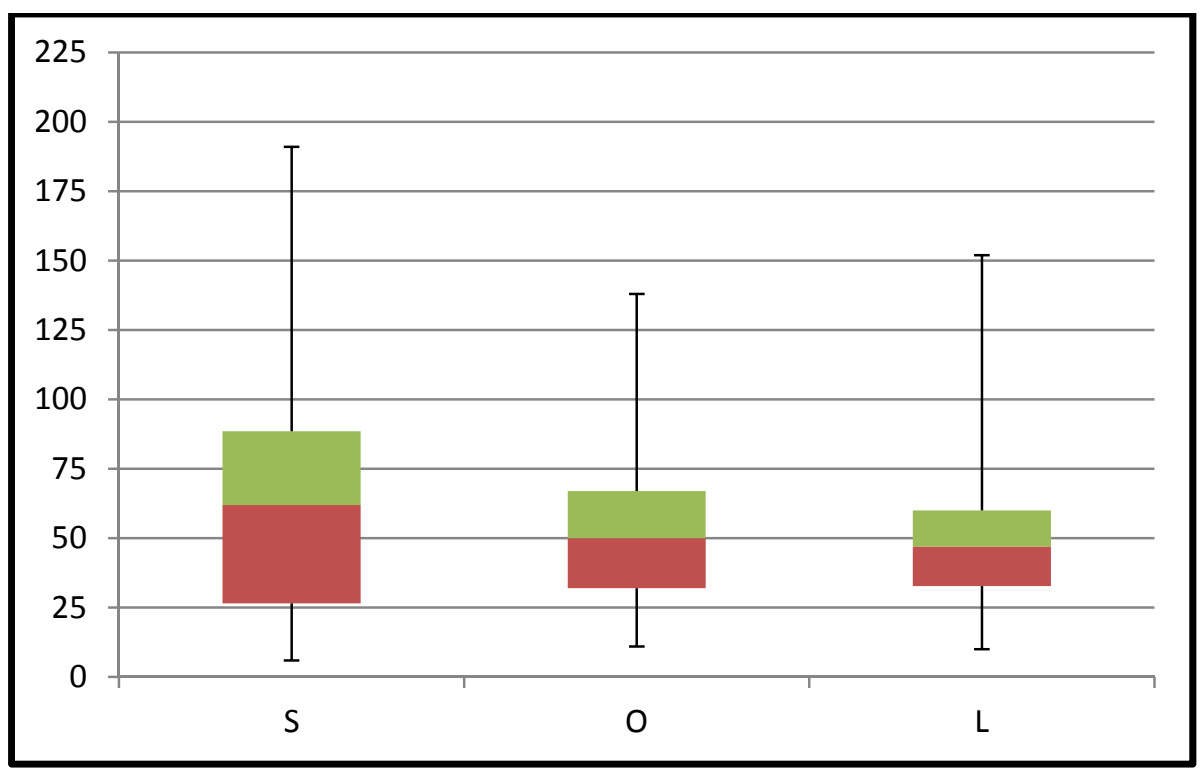

Chart 41. Boxplot for texts and errors in the corpus.

As can be seen in Chart 41, opinions and letters show a greater degree of homogeneity than summaries, in which there is a greater degree of dispersion, since the results considered in the majority of the class range from 27 to 89 errors. In the case of opinions, these texts range between 32 and 67 occurrences, whereas letters range from 33 to 60 errors. This means that students' performances are markedly more similar when writing letters or stating opinions than when they having to summarise a text or an experience. 
In the case of summaries, a considerable amount of texts is significantly above the average number of errors, as is the case for letters. Cases of particularly well written texts are much rarer.

Table 58 shows the number of texts for each genre that fall within these parameters (summaries with 27 to 89 errors, opinions with 32 to 67 errors, and letters with 33 to 60 errors). Here, it can be observed that this applies to approximately half the texts.

\begin{tabular}{|l|l|l|l|}
\hline GROUP & N. TEXTS & TOTAL & \\
\hline SUMMARY & 28 & 66 & $42.42 \%$ \\
\hline OPINION & 36 & 76 & $47.37 \%$ \\
\hline FORMAL WRITING & 33 & 62 & $53.23 \%$ \\
\hline
\end{tabular}

Table 58. Total of number of texts with a range of errors within the average.

Additionally Charts 42, 43 and 44 illustrate the results obtained for each text type. It can be seen that the partial results are consistent with the results for the entire set, as becomes apparent when comparing these with Charts 38, 39 and 40, where Rh $F$ stands for rhetorical functions, $S \& R$ for style and register, and $R h$ eff. for rhetoric effectiveness. Possible variances are explained at a later stage in these charts. 


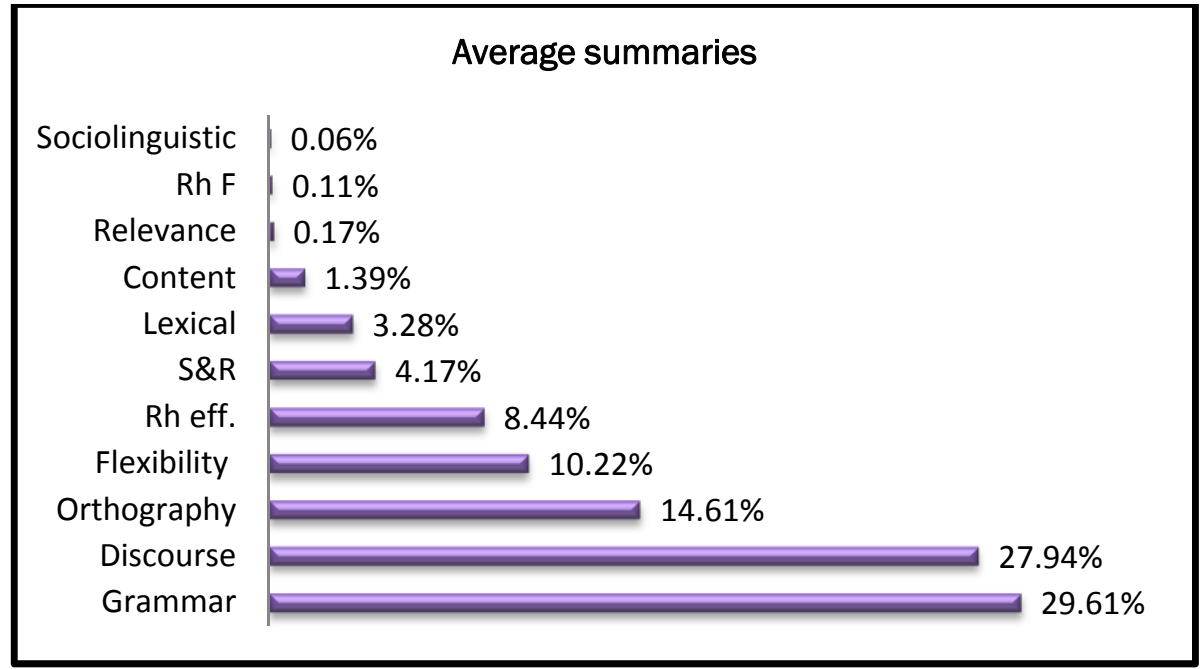

Chart 42. Errors in average summaries in the corpus.

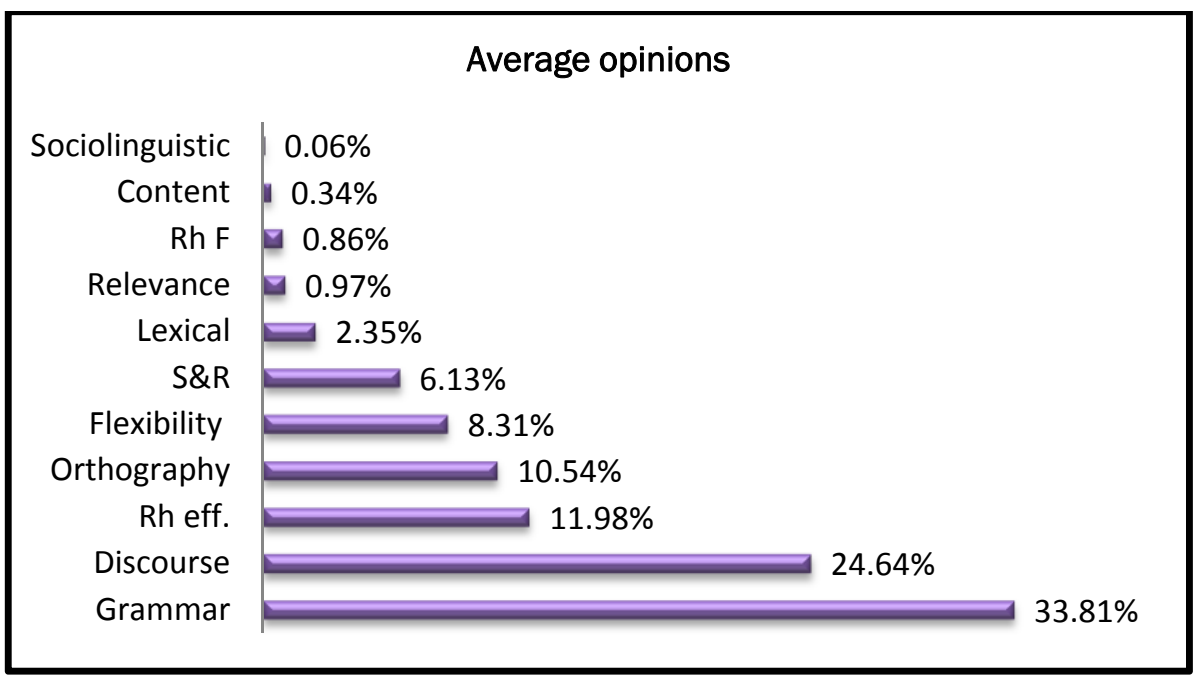

Chart 43. Errors in average opinions in the corpus. 


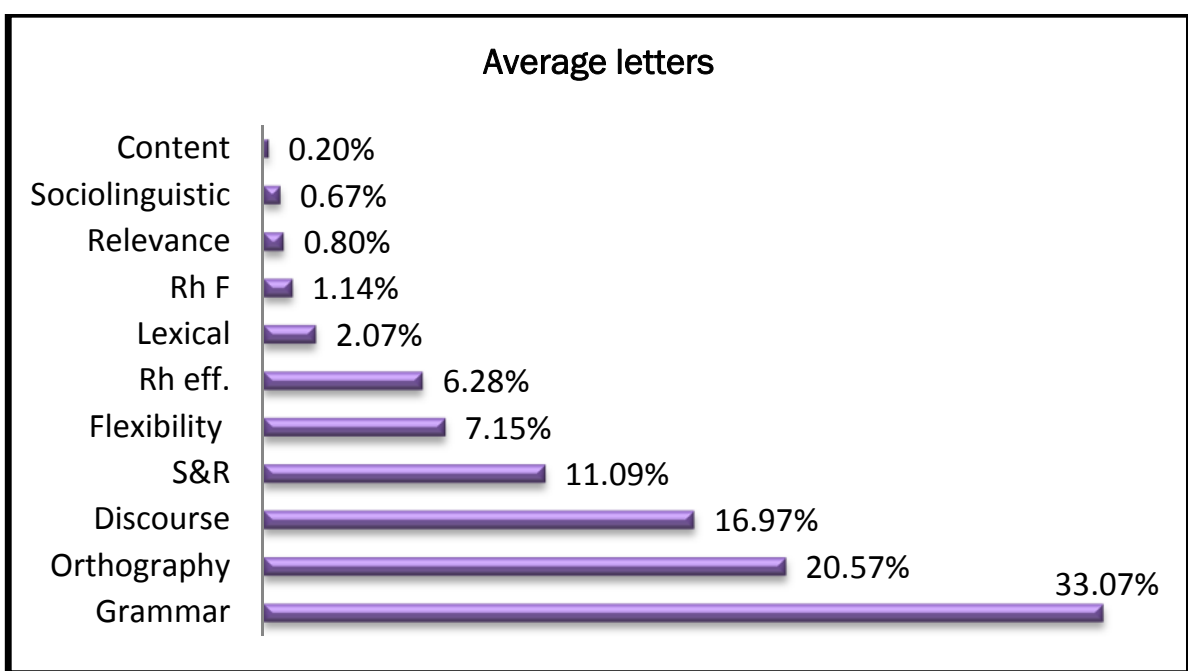

Chart 44. Errors in average letters in the corpus.

As can be seen in Charts 43 and 44, slight differences in the order of importance of errors depending on the type of text exist, as is the case for the total occurrences. Here, once again, the most important errors found are grammar, orthography and discourse. Sociolinguistic, relevance and content errors bear little significance in all cases.

Charts 45 to 47 illustrate the comparison of results for average and total texts. Although there are slight differences, it is clear that error distribution and the relevance of error categories in the production are similar. 


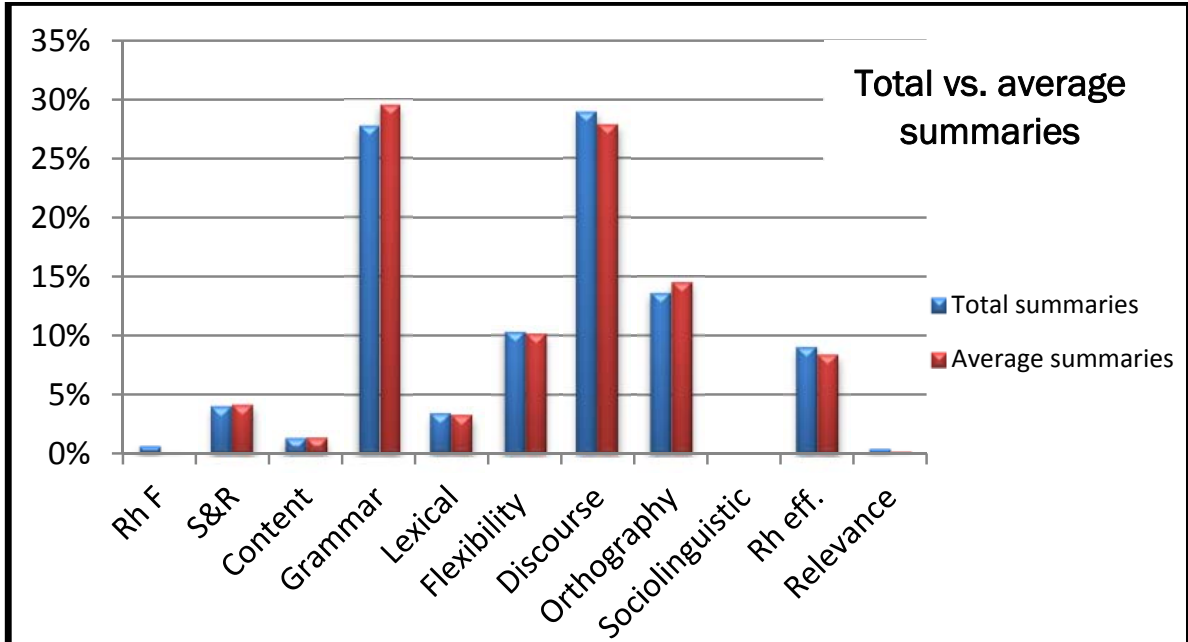

Chart $45 . \quad$ Summaries. Total vs. average.

As can be seen in Chart 45, the results for average summaries show a slightly higher number of grammatical and orthography errors than those of the total set of texts. In contrast, they show fewer occurrences for discourse errors and errors related to rhetoric effectiveness.

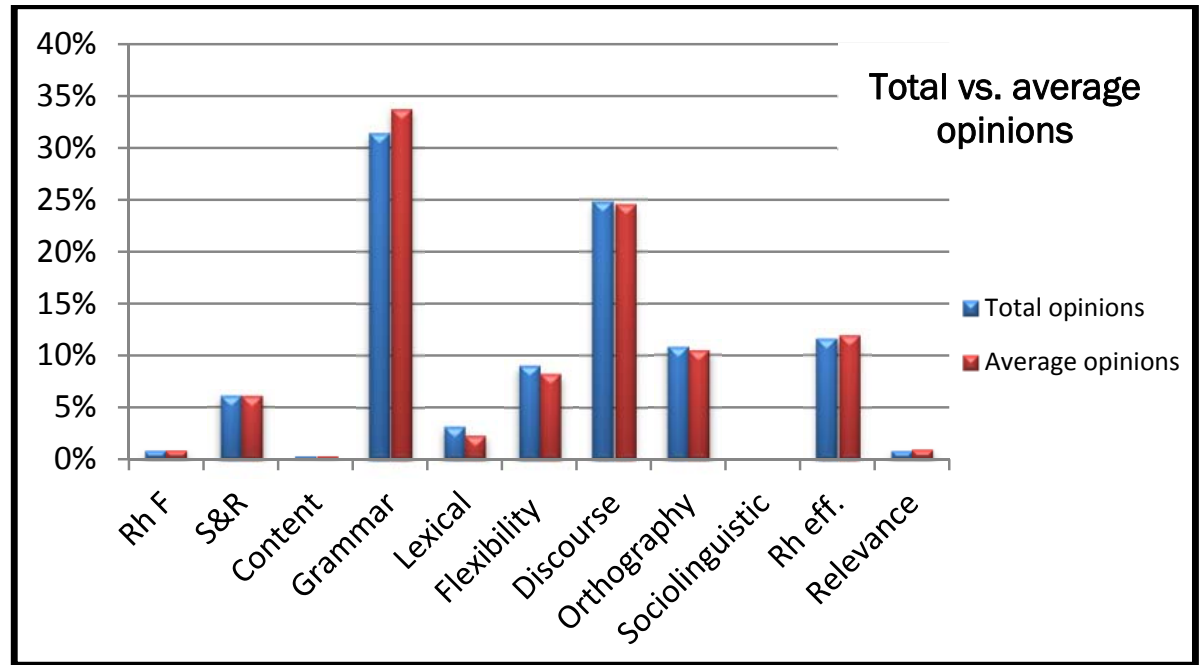

Chart 46. Opinions. Total vs. average. 
It can be seen in Chart 46 that average opinions present greater number of occurrences for grammatical errors and rhetoric effectiveness errors. The remaining categories show quite similar results.

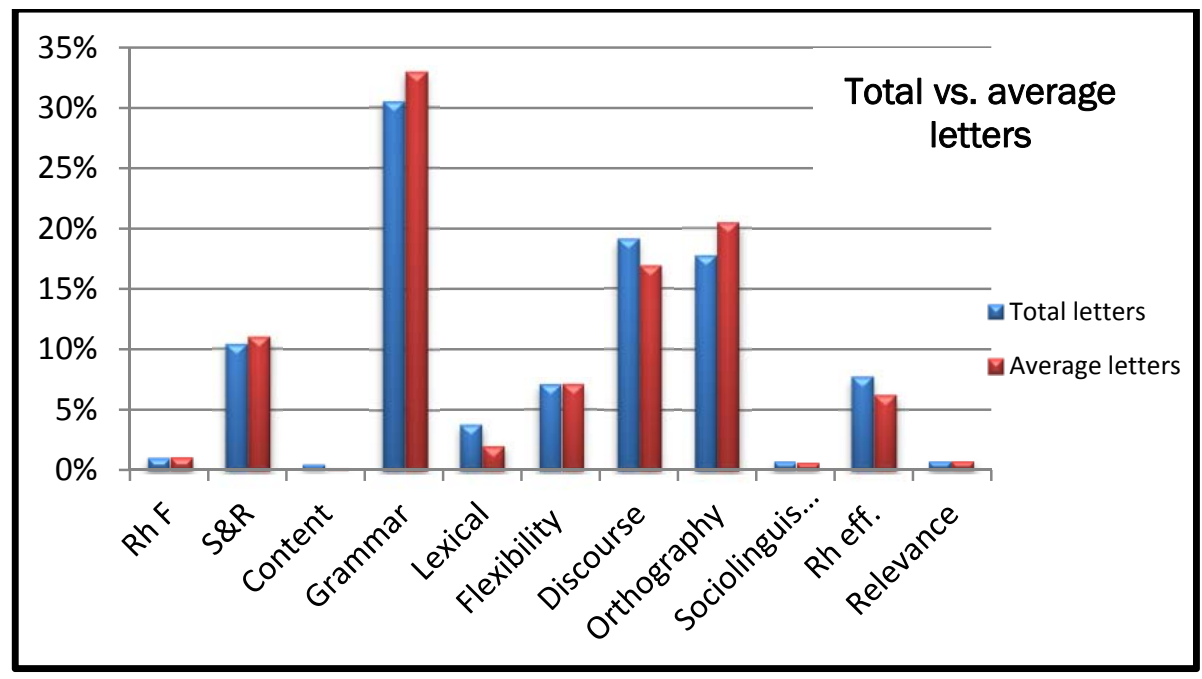

Chart $47 . \quad$ Letters. Total vs. average.

In Chart 47 can be seen that a greater number of grammatical and orthography errors are displayed for average texts, whereas they show less occurrences for discourse and rhetoric effectiveness errors.

Summing up, in this section, an analysis of the disposition of the markers who analysed the texts, the types of individual errors and error categories found in the texts, and the nature of each genre in the outcome of errors has been presented. 


\subsection{Qualitative analysis of Pragmatic error categories}

This section looks at the items that returned a significantly low level of results. In this case, the approach chosen for analysis is qualitative, as a method for counteracting the quantitative analysis carried out and complementing it. As previously mentioned, due to the nature of the items analysed, it was deemed that not all items would be equally productive. Indeed, in some cases, the items analysed related to very specific issues connected to either content or to purpose. Examples of all error categories analysed can be found in Annex 3.

For instance, the group of items intended to detect rhetorical functions aimed to study whether students were able to identify the purpose and type of the text they were asked to reproduce. Obviously, in such settings, errors could only be produced once (either they recognised the text purpose or not), twice at the most; if we consider cases in which texts, for some reason, revealed different types of errors of this type, or texts that showed dissimilar types of errors throughout their structure.

However, in other cases, the problem could relate to the small number of items integrating this error category. Since the categories used for the analysis were based strictly upon the descriptors displayed in the CEFR, some of them display a greater number of items than others.

This was interpreted as evidence of greater importance being allocated to some issues than to others in the CEFR. Strategies to balance these divergences were not present in the present dissertation. For instance, two items account for sociolinguistic appropriateness: SoP (politeness), 
and SoC (cultural differences), whereas six items account for discourse competence: DSV (verb tense), DSWO (word order), DSC (connectors and transitions), DSTH (summarising -text types), DSFocus (main points), DCC (coherence and cohesion), as can be seen in the item abbreviation list on page 21 . The outcome obtained for each category is unlikely to be compared by simply reviewing the numerical results.

Finally, another situation appears in which the number of results obtained is particularly low, due to the difficulty experienced in assessing the item under consideration. This refers to the case of relevance. As defined in the CEFR, this ascribes the maxim of relevance (Wilson \& Sperber, 2004:252), i.e., the significance of an input to an individual at a given time which ensures that "Other things being equal, the greater the positive cognitive effects achieved in an individual by processing an input at a given time, the greater the relevance of the input to that individual at that time".

Thus, four error categories, mainly related to the discipline of Pragmatics, are analysed in this section ${ }^{24}$ considering the additional information they can offer in the analysis; rhetorical functions, content knowledge, relevance, sociolinguistic appropriateness. As can be seen in Table 59, in all items the number of total occurrences obtained for all 206 texts was below 100 .

${ }^{24}$ All the data used is available in Annex 7. 


\begin{tabular}{|l|r|r|r|r|}
\hline & M1 & M2 & M3 & TOTAL \\
\hline RHETORICAL FUNCTIONS & 7 & 30 & 59 & 96 \\
\hline CONTENT KNOWLEDGE & 65 & 0 & 24 & 89 \\
\hline SOCIOLINGUISTIC APPROPRIATENESS & 1 & 0 & 28 & 29 \\
\hline RELEVANCE & 0 & 2 & 74 & 76 \\
\hline & 73 & 32 & 185 & 290 \\
\hline
\end{tabular}

Table 59. Error categories with less than 100 errors. Markers.

Three issues are of interest in this particular part of the discussions of the results, which can be observed in Table 59. Firstly, the degree of coincidence or divergence among markers; secondly, the differences and similarities encountered in the texts depending on the genre; and, thirdly the level of correctness of the texts in which these error categories appear, that is, whether they are found in texts with particularly few or particularly abundant errors, or whether their presence is random in all text types.

As mentioned in the section dedicated to the analysis of results per marker, significant divergences were discovered in these four categories. Chart 48 shows the total number of errors identified by the different markers. 


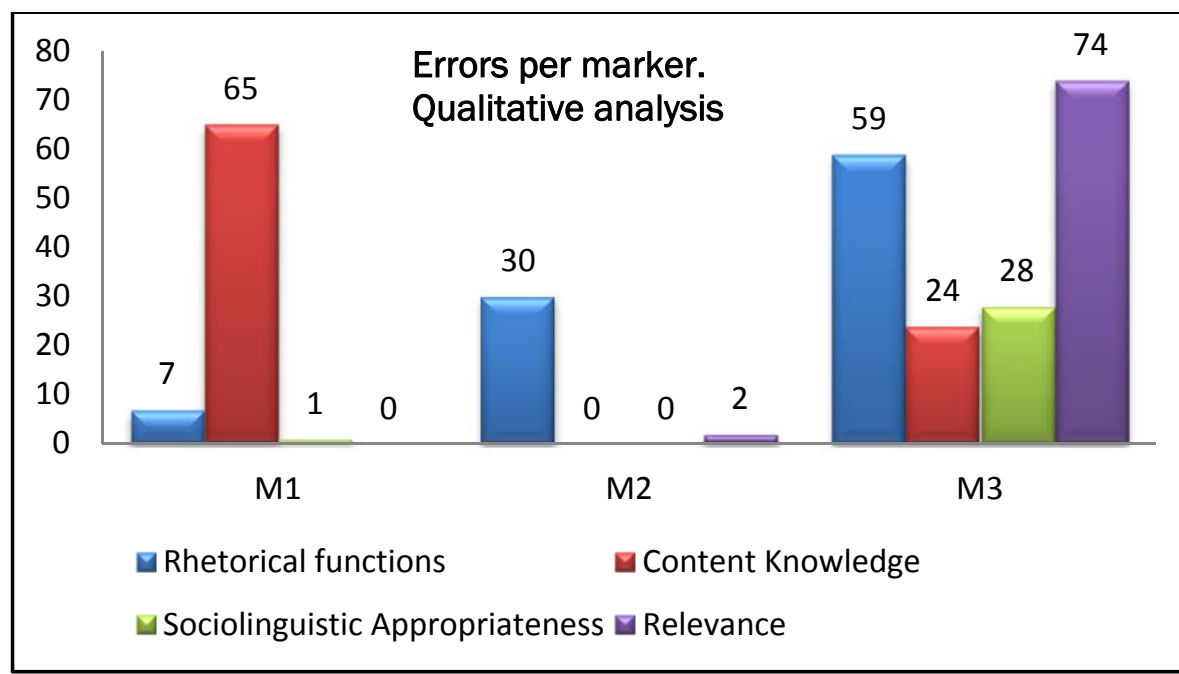

Chart 48. Total errors per markers in the corpus. Qualitative analysis.

If we incorporate all these results into one single figure, it can be seen that, with the exception of errors within the category of rhetorical functions, in which all markers identified errors, although the total numbers did not coincide, the remaining categories reveal great differences in the results. Indeed, in all three cases, one single marker accounts for the majority of errors spotted. This can be attributed to the individuality of the marker, since it is not repeated in all the figures, it can be seen just in three of the four figures nor can it be credited to just one of the markers (for instance, M2 is responsible for most content knowledge error identification).

It is also worth noting that out of 290 errors found in this category, M3 is responsible for 185 . This implies that she identified almost $64 \%$ of these errors, a considerable amount in comparison with the other markers. Mindful of this, if we look at the total numbers, M3 identified all errors 
relating to sociolinguistic awareness except one, and all errors related to relevance except two.

From this, it can be derived that partial exception could apply to Hypothesis $\mathrm{H} 1$, since not all markers confront all errors with the same approach. These results show that there is a substantial margin for interpretation in relation to pragmatic issues as defined in the CEFR. Furthermore, in order to clearly identify and approach these items in the classroom, teachers or evaluators could benefit from specific training.

The results obtained in the different genres analysed will be shown. In Table 60 , it is possible to observe differences in the number of errors found for the different text types. Most errors belonging to the four categories analysed were detected in summaries. In fact, summaries account for almost 39\% of all errors found. Within this, the greatest group belongs to errors relating to content, since $69 \%$ of errors fall within this category and group.

Opinions are responsible for the least number of errors, $27 \%$ of the total per genres as can be observed in Table 60. Particularly noteworthy is the fact that there is only one error in this text type relating to sociolinguistic appropriateness. Although opinion texts show a similar amount of errors as letters in items such as content knowledge, rhetorical functions, or relevance, there are few errors in them relating to sociolinguistic issues due to the particular features of the type of text analysed. 
Contrary to this, most errors linked to sociolinguistic appropriateness are found in letters, i.e. $86 \%$. These are probably also related to problems with register, and to the inability of students to use the appropriate forms of address and a suitable degree of familiarity when writing letters in a language other than their own.

\begin{tabular}{|c|c|c|c|c|}
\hline ITEM & SUMMARY & OPINION & LETTER & TOTAL \\
\hline RHETORICAL FUNCTIONS & 29 & 32 & 35 & 96 \\
\hline CONTENT KNOWLEDGE & 61 & 12 & 16 & 89 \\
\hline \begin{tabular}{|l|} 
SOCIOLINGUISTIC \\
APPROPRIATENESS
\end{tabular} & 3 & 1 & 25 & 29 \\
\hline RELEVANCE & 19 & 32 & 25 & 76 \\
\hline TOTAL & 112 & 77 & 101 & 290 \\
\hline
\end{tabular}

If we finally analyse in Table 60 the quality of the texts in which these errors are found,deduced from the number of errors found in each text as opposed to the total obtained for texts in the same text group, it is interesting to observe the uneven distribution of these items.

As can be seen in Table 61, although all four error categories show quite high results for errors in average texts, they account for almost half of the total number of errors encountered for these categories. If we only take the results for average texts in Table 61, it can be seen that almost half of the texts showed problems with text type and text purpose recognition, but very few had any sociolinguistic appropriateness problems; only $16 \%$ of all texts considered as average had problems of this type. 


\begin{tabular}{|l|c|c|c|c|c|c|c|}
\hline \multicolumn{1}{|c|}{ ITEM } & \multicolumn{3}{c|}{$\begin{array}{c}\text { AVERAGE } \\
\text { (97 TEXTS) }\end{array}$} & \multicolumn{3}{c|}{$\begin{array}{c}\text { ABOVE AVERAGE } \\
\text { (44 TEXTS) }\end{array}$} & $\begin{array}{c}\text { TOTAL } \\
\text { (206 TEXTS) }\end{array}$ \\
\hline & Errors & Total & Average & Errors & Total & Average & Errors \\
\hline $\begin{array}{l}\text { RHETORICAL } \\
\text { FUNCTIONS }\end{array}$ & 47 & $49.0 \%$ & $48.5 \%$ & 27 & $28.1 \%$ & $61.4 \%$ & 96 \\
\hline $\begin{array}{l}\text { CONTENT } \\
\text { KNOWLEDGE }\end{array}$ & 36 & $40.4 \%$ & $37.1 \%$ & 0 & $0.0 \%$ & $0.0 \%$ & 89 \\
\hline $\begin{array}{l}\text { SOCIOLINGUISTIC } \\
\text { APPROPRIATENESS }\end{array}$ & 16 & $55.2 \%$ & $16.5 \%$ & 1 & $3.4 \%$ & $2.3 \%$ & 29 \\
\hline RELEVANCE & 38 & $50.0 \%$ & $39.2 \%$ & 5 & $6.6 \%$ & $11.4 \%$ & 76 \\
\hline
\end{tabular}

Table 61.

Errors in average and in above average texts.

Focusing now on the 44 texts which proved above average, with results of less than 27 errors in summaries, less than 32 errors in opinions and less than 33 errors in letters, it can be observed that none of these had any content knowledge inaccuracies, and only text had a problem relating to sociolinguistic appropriateness. Only $6.6 \%$ of errors linked to relevance could be identified as belonging to this group. Again, for well written texts, rhetorical functions was the most productive error category, since $61 \%$ of good texts displayed an error of some kind derived from this type.

\subsection{Limitations in the results of the present study}

Some findings of interest have been presented in the present study with regards the student's levels of competence when they enter the university with a B1 level of proficiency. A thorough analysis of the types of text they produce (with given specifications as to the genre) and their knowledge of certain aspects related to language proficiency (such as 
flexibility in the use of language, style, or rhetorical functions recognition and reproduction) has been completed.

Nevertheless, some limitations need to be considered when approaching these results. The first is related to the fact that the research was carried out with students of Tourism degrees at the Universitat Politècnica de València. Thus, although an exhaustive study was completed with students from three different courses (2008-2009, 2009-2010 and 2010-2011), the results obtained can only be generalised for students included in the study.

Secondly, the texts were corrected manually. This confers the study an even greater degree of particularity, in that it is entirely based on the performance of the participants, both students and teachers and their own peculiarities. Indeed, although teachers were given instructions as to how to face the correction, significant differences can be seen in the results, which can be related to the interpretation of these specifications.

Likewise, although the texts analysed were written as belonging to very specific text types in order to comply with the recommendations of the CEFR, none of them included specific language. This implies that the genres included in the analysis were specific, but not so the vocabulary and expressions used within, with the possible exception of formal letters, in which a certain degree of specific content knowledge was required. In this sense, although the research was set at a University level, students were not required to have specific language knowledge. 
Additionally, the research carried out was based on the proposals of Error Analysis, and its recommendations for study. This implies that only errors were considered in the analysis, aiming at establishing error categories and types, as well as most common causes of error. It also intended to identify differences in the perception of errors on the side of the markers. For this reason, no consideration was given to the issues in which students performed well.

The items identified as errors were strictly derived from the CEFR document. However, in some cases overlapping between items could exist, or else different interpretation of error categories or error definitions. This would obviously result in a different outcome.

Finally, with regard the methodology used for the processing of texts, it must be recalled that the data was treated in bulk numbers. That is, all errors found in all texts by all markers were treated equally, and no selection was made in the texts regarding coincidences in the correction, or text length, for instance. This, although explained in the methodology section, represents limitations in the global interpretation of results, since any change in the variables would result in a different outcome. Also, the statistical analysis of the outcome obtained was very basic as it only treated the data obtained in the results in order to obtain percentages and distribution of use, and mean averages for best and worst texts. 


\section{CONCLUSIONS}





\section{CONCLUSIONS}

In this dissertation, we set out to study the theoretical background related to the learning and teaching of English as a second language and the improvements to be carried out in certain aspects. The field of study chosen was Pragmatics, examining the ways in which students used language in real life situations, and the focus was set on the types of errors students make in a second language (English in our case) when entering university. This point is essential if we wish to analyse the proficiency level of students and the inadequacies they need to overcome in order to improve their fluency, based on actual data.

The conclusions offered in the present study are structured according to the objectives which were established for its setting and justification. They respond to the questions proposed as the bases for the investigation.

\section{General objective}

In reference to the general objective, formulated as the clarification of the role of error in language learning and teaching, several conclusions can be reached. 
Firstly, that error analysis can play a crucial role in language learning and teaching as a marker of proficiency levels. Indeed, by analysing the types of errors students make, it is possible to reveal the problems they encounter at different language levels.

Secondly, regarding the type of errors analysed in the present study, all error types described in the CEFR for written production and for pragmatic competences were included in the analysis. The combination of these two error types resulted in a set of categories which formed the base of the grid used for detecting and marking the errors. In particular, with regard to Pragmatic competences the analysis is centred on errors linked to Rhetorical Functions, Linguistic Competences (Grammar, Orthography, Flexibility), Discourse elements, Sociolinguistic Competences, and Pragmatic competences based on specific Pragmatic Theories Rhetoric Effectiveness (Grice) and Relevance (Sperber \& Wilson).

Thirdly, it can be concluded that EA is a useful and practical tool for the implementation of the CEFR guidelines. Indeed, by analysing errors based on the guidelines proposed, and focusing on specific aspects of interest for study, the CEFR document is made functional for teachers and learners and useful to apply from the point of view of the Communicative Approach.

Finally, by analysing the types of errors associated with the levels of proficiency proposed by the CEFR, it could be concluded that errors belong to different language levels. This implies that they do not necessarily coincide in terms of proficiency; students display greater 
levels of proficiency in some language competences than in others, and these differences are not so much related to the proficiency levels established in the CEFR as to the individual.

As ramifications of this general objective, other issues were considered for study. They refer to the research questions and the specific objectives established, the conclusions obtained are explained below.

1. Can Error Analysis assist in language teaching?

2. Can an Error Analysis Grid be elaborated to determine the types of errors students make and relate them to their proficiency levels and pragmatic awareness?

3. Are the CEFR guidelines and descriptors useful for error analysis?

4. Can errors be classified from a Pragmatic point of view using the CEFR?

5. Can language teaching be improved by combining the CEFR, the Communicative Approach, and Error Analysis?

\section{Specific objectives}

1. Can Error Analysis assist in language teaching?

By studying the types of errors students make when writing in an $L 2$, the intention was to clarify the point in the learning process where they stand, thus drawing conclusions as to the ways in which improvements could be made with regards to this. 
Although the CEFR offers guidelines for the application of the Communicative Approach in the classroom, and the ways in which the proficiency levels of students can be identified, by means of competences: "Can understand the main points of clear standard input on familiar matters regularly encountered in work, school, leisure, etc." (CE, 2001:24).

However, these descriptors are sometimes based on perceptions and are difficult to quantify. Error Analysis can be a valuable tool to assist teachers in the application of these recommendations, based on the actual needs of students. This will be explained with reference to specific objective 4 .

However, the relationship between EA and language teaching proves to be fruitful in yet another field. The items analysed in the present dissertation as sources for error were strictly based on the CEFR. Also the types of texts used in the analysis were extracted from the ones proposed by the CEFR as useful in the language classroom. The subsequent analysis of results helps identify fields in which further work is necessary, as well as those areas in which the CEFR would require a further degree of specification.

We will focus on errors with particularly few occurrences, which may be a result of deficiencies in the setting of the analysis, due to either the CEFR descriptors or the analysis grid used to spot errors.

Indeed, the results reveal that some of the items included in the analysis grid for analysis were either totally or virtually unproductive. This is the 
case for problems with politeness issues, polysemy, extrapolating meaning, the use of formal register and complex vocabulary.

This indicates several possibilities, either they are not likely to occur in any type of texts, such as polysemy, or they cannot be evaluated in the type of texts chosen for analysis, such as extrapolating meaning, which is much more likely to be related to oral contexts or even reading situations, and not so much to writing. A third possible instance is the inadequacy of the item for the level of proficiency. This can apply to the use of complex vocabulary. At the language level that we are studying, situations in which the student uses complex vocabulary are highly unlikely. This analysis item could probably be more appropriate for higher levels of proficiency.

Some items established to identify errors produced very few results. This applies to those errors related to content (both specific and general), to audience consideration, or to expressing main points or summarising. Obviously, these errors are of very different natures, and it is difficult to represent them even in the greater picture. For instance, errors related to content. From the analysis, it can be said that students are generally able to identify the topic they are writing about, and show little problems in relation to both general and specific topics.

Thus, EA can help in the identification of problematic areas regarding both the students themselves and the teaching method used in the classroom, based on the CEFR descriptors. It can offer an objective perspective for quantifying the utility of classroom work, materials and approach. 
2. Can an Error Analysis grid be elaborated to determine the proficiency level of students and their pragmatic awareness?

One of the objectives of the present work was to analyse the operational ability of the CEFR as a guiding tool for teachers and researchers in a language teaching and learning process based on the Communicative Approach.

In the development of the present work we have been able to devise an analysis grid based on the items considered of interest for study; the CEFR tables related to pragmatics and writing competence were selected and integrated. This grid proved useful for teachers in their assessment of the students' production.

Pragmatics formed the focus of the analysis, since this is a core issue in the Communicative Approach and the understanding of language as communication. As explained, the error analysis grid includes thirty nine different items, obtained from the CEFR, taking into account Grice's maxims and Sperber's Relevance Theory. These have been grouped into eleven different error categories, following the specifications offered by the CEFR; Rhetorical functions, Style and register, Content knowledge, Grammatical competence, Lexical competence, Flexibility, Discourse competence, Orthographic competence, Sociolinguistic appropriateness, Rhetorical effectiveness, and Relevance.

Specifically thirty-nine items were identified as possible sources of error: text type; text purpose; informal register; formal register; considers audience; paraphrasing; using own words; general content knowledge; 
specific content knowledge; errors simple sentencing; mother tongue influence; wrong patterns; fixed expressions; intensifiers; phrasal verbs; collocations; polysemy; insufficient vocabulary; errors in common vocabulary; errors in complex vocabulary; extrapolating meaning; sequencing; verb tense; word order; connectors/transitions; summarising; identification of main points; coherence and cohesion; spelling; layout; punctuation; politeness; cultural awareness; ability to get message through; precision; accuracy; focus; adequacy to own limitations; relevance.

From the analysis of the 206 texts by the three markers, there were some items in which the results were dissimilar for all three corrections. By focusing on results which show a certain degree of disparity, we can refer to problems with text type identification, paraphrasing, or wrong pattern choice, as well as difficulties in getting the intended message across and MT transfer. MT has traditionally been identified as one of the main causes of error. If the degree of divergence in the identification of MT as a cause of error is significant, as it seems to be in the present study, this could mean that, as pointed out by many authors, the identification of the intentions and misuses of the learner is not always straightforward

Additionally, there was complete disparity in the three corrections studied in a set of errors. In some cases, only one marker spotted all the errors, or two thirds of these. For instance, this is the case for style and register errors, or errors related to sociolinguistic competence or relevance. Interestingly, if we look at the individual errors, the greatest 
degree of inequality was mostly found in errors related to Rhetorical Effectiveness; in expressing main points, and focus in the text, and in showing precision and accuracy. Also in this category are included all the items classified as Sociolinguistic (cultural appropriateness and politeness), as well as Relevance.

This is probably due to variations in the teachers' own awareness towards these issues, pointing to a possible disregard for these problems in the correction by some of the markers. Also, this could be interpreted as a lack of definition in some aspects and a need for greater consistency in subsequent studies. Another possible cause for this may involve the different interpretations of the importance given to these issues regarding communication. This could suggest a need for further preparation on the part of the teachers in issues related to sociolinguistics and pragmatics.

3. Are the CEFR guidelines and descriptions useful for error analysis?

With regards to the CEFR, it can be stated that, although the general guidelines offered can be useful for establishing an initial, broad framework to work with these types of issues, more specificity would be needed to make it really useful in the classroom and for schoolwork based on the Communicative Approach. Hence, it accounts for traditional issues of concern to teachers, but overlooks specifications as to how to include issues such as sociolinguistics or relevant pragmatic matters in the curriculum. 
It would also be helpful for future study to expand the document, and introduce ways in which these issues could be analysed and rated, and to assess the importance that should be given to them at the specific points in the learning process. Undeniably, a similar degree of pragmatic awareness, to give an example, cannot be expected from a learner with A1 or B2 levels of proficiency. Clearer recommendations for teachers could be introduced in this regard.

This is consistent with the proposals and conclusions of the research carried out within the English Profile Project with regards to CEFR levels and descriptors, as established by Saville N. \& Hawkey R. (2010), Green (2010) or Hawkins J.A \& Buttery P. (2010).

Thus, it can be concluded from the study that most CEFR descriptors are formulated in a very general form, which does not facilitate correction or assessment. Hence, the majority of errors found in texts were related to those aspects considered in traditional teaching methods, such as grammatical or orthographic errors.

This also indicates that, although the focus of the CEFR is the Communicative Approach to language teaching, not all issues related to language use are given the same degree of detail. Hence, some categories used in this study, such as Rhetorical Effectiveness, were integrated by a large number of items, whereas others were formed by just one or two. For instance, Relevance is one of the items for analysis considered in the pragmatic issues section. However, no descriptors as to how to measure or tackle it are offered. This variation in treatment 
obviously produces different results in terms of numbers, which imply differences in the way teachers spot and identify errors.

The study revealed that in broad terms, and albeit with some differences, an analogous number of errors were found by the markers in the texts. Each marker identified around one third of errors, although the results show different degrees of severity among them. In this, the research coincides with previous studies which point to a certain degree of variance in the role of the teacher in teaching and assessing processes.

Errors that could be considered objective or common had the greatest degree of agreement between markers (with quite even distributions in the identification). This was the case for errors related to grammar, orthography, vocabulary or discourse. In particular, if we consider the items separately, the greatest degree of coincidence was found in grammatical errors in simple sentencing, errors in text sequencing, use of wrong verb tense, and problems with spelling.

4. Can errors be classified from a Pragmatic point of view using the CEFR?

The CEFR includes three competences in the pragmatic perspective: discourse competence, functional competence and design competence. In our analysis, discourse competence errors were ranked as the second most common. The implications derived from this are twofold; on the one hand, a need for greater work towards pragmatic awareness and competence is needed, since students were rated low on this 
competence. On the other, the analysis grid, produced from the descriptors related to pragmatic issues, was a useful tool for teachers to spot and identify discourse errors.

Other error categories included in the analysis grid, such as Style and Register or Flexibility, are close to traditional teaching views including genre and vocabulary, but also include the new perspective linked to the Communicative Approach as presented in CEFR. These produced sufficient amounts of errors as to be considered appropriate.

Conversely, errors related to Rhetorical Functions, Content Knowledge, Relevance, or Sociolinguistic Appropriateness did not produce sufficient amounts of errors as to permit conclusive remarks. Indeed, a second, qualitative analysis of results was necessary to obtain sufficient data for a reliable analysis. A more thorough and detailed description of these types of items would prove useful for teachers and students.

As for the case of the consideration of the interlocutor in their writings, this issue is very difficult to contemplate, since there are no variables that can help us identify whether this has occurred in the mind of the writer previously. Additionally, it appears that this issue is also taken care of by other items more easily identified by markers; items related to register. Finally, there is an item that is particularly interesting: summarising. Indeed, substantial effort is dedicated to the description of this skill; in the CEFR there is a special descriptor dedicated to this. Particular importance is given to the type of texts that should be used in class, and the types of expertise expected on the part of the students. In identifying the main points, summarising is considered a crucial ability in 
the construction of texts, and not only with regard to this particular text type. This probably accounts for such a low number of errors found in this category, since it is difficult to apply to some of the texts used in the analysis.

If we continue to look at the individual errors, the items which have been proven to cause the greatest amount of errors are grammatical errors in simple sentencing, errors caused by mother tongue transfer, coherence and cohesion errors and errors related to verb tense. All these items are formulated in very broad terms, and include a great variety of problems which can occur in language writing. Although there is great disparity in character, they relate to sentence structure and text organisation.

Even more interesting conclusions can be obtained if we look at the items grouped in error categories, as analysed in the results chapter. Some error categories were integrated by one, two or three items, whereas others contained up to five or six. This was not directly related to the outcomes obtained. Indeed, three items accounted for grammar errors in the texts; grammatical errors in simple sentencing, Mother Tongue Influence and wrong patterns. However, more errors were encountered as belonging to this group than to rhetorical effectiveness, integrated by problems with transferring the message, establishing and reproducing the main points within a text, precision and accuracy, focusing or adequacy to one's own limitations. In this sense, as there is no direct relationship between the number of items within a category and number of errors in it, the results can be considered a useful tool to identify the greatest causes of errors in the texts. 
There was a coincidence of markers in the identification of grammatical errors, discourse competence errors, and orthographic errors. With the exception of discourse competence errors, these categories are not integrated by a great number of issues. However, in the case of grammar, it includes all possible simple grammatical problems, which presents a very broad field for error. Orthographic errors are also quite easily identified, including spelling, punctuation and layout. These are also traditional errors usually corrected by teachers in written production. They are commonly identified and teachers are accustomed to spotting and correction of errors. However, they differ from the conceptions and principles of the Communicative Approach proclaimed in the CEFR.

Lexical Competence or Style and Register are error categories that range in the intermediate section of the outcome list. In the case of lexical competence errors, this may be due to the fact that, unlike all other categories (in which there are general descriptions and room for interpretation), there is a great degree of specification in the CEFR as to what constitutes lexical errors. Indeed, as possible causes of error in this category, the reference document specifies inaccuracies in the use of fixed expressions, intensifiers, phrasal verbs, collocations or polysemes. Apart from the possible low rate of use in texts, these issues are, as was the case with the use of complex vocabulary, beyond the knowledge of a B1 user of an L2.

With regards to Style and Register, a significant amount of occurrences can be found in the use of informal register in formal settings. However, 
the opposite, that is, the use of formal register in informal situations, has not occurred in the texts. This can be connected to the fact that the B1 level of proficiency is mainly dedicated to the study and knowledge of familiar topics, and students find it difficult to correctly identify and reproduce other degrees of formality.

At this point, it should be recalled that the analysis completed and presented here considered the quantitative results for errors. For this reason, not all errors were expected to produce a similar outcome. This was also analysed, and special attention was fixed on the groups of items (error categories) which resulted in very few errors.

Interestingly, most categories presenting these specifications are related to Pragmatics. These are Rhetorical Functions, Content Knowledge, Relevance, and Sociolinguistic Appropriateness, in descending order of results. In all cases, the results obtained were small in comparison with the rest of the categories.

As mentioned above, significant divergences were found in the examination of each particular marker, and, in this regard, a greater awareness of these is probably required, since most errors were spotted by one marker (M3), and only that marker offered results for all error categories. For instance all errors related to Relevance were spotted by $M 3$, showing that it is difficult to identify this item in the texts without previous training and a clear view of what is to be expected.

These four categories are obviously closely related to genres, and the identification of text types. The results show that most errors are found 
in summaries, and mostly relate to content knowledge. Summaries, in general, have a significant amount of errors pertaining to the fact that students often fail to identify the functions related to summarising. Almost the entire set of errors related to sociolinguistic appropriateness can be found in letters. It is easy to relate this to a lack of knowledge regarding the specific cultural conventions associated with letters, or differences in the degree of politeness and register.

Also of interest are the results establishing the quality of the texts in which these items were found, (by establishing quality through relating the amount of errors in the particular texts and the amount of errors in the total set), those with low amounts of errors, and the identification of whether they are found in the best or the worst texts, or whether no conclusion can be extracted. For instance half of the texts within the average range show problems related to rhetorical functions, but this incidence increases for texts above the average range. This could be related to an increased ability to spot this type of error in texts that show greater coherence and a smaller number of grammatical errors, thus offering greatest readability.

If it has been said that most errors related to summaries refer to content knowledge, then no content knowledge errors are found in those texts above average. A similar circumstance can be observed for errors related to sociolinguistic appropriateness; only one error of this type is found in texts above the average. With regards to Relevance, average and good texts account for $60 \%$ of all errors spotted, assigning the remaining $40 \%$ to texts below average. 
Finally, looking at the particularities of each genre and their possible incidence in the results obtained, there is an even distribution of most error categories, with the exception of Rhetoric Effectiveness inaccuracies, which were mainly found in opinions, and Content knowledge and Discourse competence errors, which were spotted in the summaries. Letters are responsible for most errors related to register and style and sociolinguistic competence, due to the possible intercultural differences, as explained above.

Looking at the items in relation to the type of text in which they were encountered, there are also differences in the greatest causes of errors. Grammar is the main cause of error for all students and texts, but noteworthy divergences appear in the second category of error; Mother Tongue influence for Opinions, Verb Tense for Summaries, and Punctuation for Letters. This points to the need for specialised training when the aim is specificity in the use of language.

Whereas for opinions, texts in which students have a greater degree of freedom in the interpretation of their ideas, MT influence is the second most important cause of error, it rates third in the other two text types. In summaries, the greatest problem concerns discourse competence, as students are asked to reproduce a past event, or to summarise something they have seen or read. In these cases, the proper use of verb tenses can be problematic. The difficulty with regard to Letters is Punctuation. Errors with this particular issue become more apparent in a formal setting where layout and form are essential. 
There were no errors relating to politeness in summaries, and no cultural adequacy errors in opinions. Considerable variations can be seen, in the case of Polysemes, which appear in fourth position in letters, in sixth position in opinions (with only one case), and fails to occur in the summaries group.

Although the peaks in the error categories with the greatest amount of occurrences are analogous, some differences can be observed in the total results. In general, Letters display a lower amount of errors, noticeable with regard to those referring to discourse competence, with less than half the number of the errors found in summaries. Once again, this could be due to the type of text; those texts that leave students with a freer structure to work with require a greater knowledge of connectors, linkers, and other coherence issues. In the case of rhetoric effectiveness, a similar outcome is observed. Students find it easier to communicate their message when presented with texts with a more restricted layout.

However, there were significant differences in some other aspects analysed in the texts. Due to their nature and rationale in the analysis grid used, these items analysed allowed for different degrees of subjectivity in their correction. A significant amount of divergence was found in errors related to Rhetorical Functions, Rhetorical Effectiveness, and Lexical Competence. In these error categories, although all three markers identified errors, differences in the results point to different interpretations of the items analysed on the part of the markers. 
5. Can language teaching be improved by combining the CEFR, the Communicative Approach and Error Analysis?

The errors encountered in the different texts have been analysed and classified. Possible causes for errors have been inferred and several deliberations are made regarding the results obtained, taking into account the different variables considered.

In order to look into the results derived from the analysis, it must be recalled that the error analysis was conducted in order to establish a clear rationale of the point in the learning process where students stand in their first year at University. These points in the learning process are identified in this dissertation using the proficiency levels described in CEFR, the focus of attention being the B1 level. Hence, our conclusions establish a relationship between the point in the learning process (B1) and the errors students make at this point. Additionally, this needs to be related to the particular application of these results in the language classroom.

By doing this, we have been able to establish considerations in three spheres, which constitute the structure of the present section; first, to clarify and classify the types of errors encountered. Then, to relate those types of errors to the specific level of proficiency (B1) students have at this point in the learning process and to extrapolate from this the particular aspects in need of improvement. Finally, to establish whether an in-depth analysis of the results obtained for the Pragmatic features points to some specific requirements that need to be included in classroom practice. 
It has been assumed that the B1 level of proficiency can be identified with those texts which fall within the average, excluding both extremely good and extremely bad texts, which could be considered as belonging to the next or previous level of proficiency.

In order to apply these findings in the classroom, it may be useful to identify the issues which require a greater degree of analysis and work. It would also be helpful to study the ways in which these could be incorporated in the particular application of the communicative approach in the classroom, and intensify work requiring improvement in specific competences.

With this in mind, it can be said that the greatest cause of error at this level of proficiency, according to the results obtained in the analysis, is grammar, followed by discourse competence and orthography. At this point in their learning process, students still have difficulty with simple grammar and orthography. From this we could determine that pragmatic awareness issues should probably be introduced at a later stage, or at least, introduced while grammar and orthography are still an issue in class. Problems with sentence and text structure are also crucial at this point.

The following groups in importance per percentage of errors in average texts are Flexibility (in summaries), Rhetorical Effectiveness (in opinions) and Style and Register (in letters). Consequently, this indicates deficiencies in vocabulary and meaning, as well as in ways to express oneself when this vocabulary is lacking. Also, it indicates the need for greater accuracy and precision in the use of that lexis, pointing towards 
more specialised terminology. Issues related to differences in genre and degrees of formality are also essential when working at this level of proficiency.

Generally speaking, students show few problems in identifying either the type of text they are required to write or the purpose of that writing. Here, in such cases, problems are more related to adequacy when producing the texts. With regards to sociolinguistics awareness, or pragmatic relevance very few texts within the average displayed this kind of problem, as most errors are presented at linguistic level. Issues associated with these are more likely to be effectively treated at higher levels of proficiency.

Thus, it can be concluded that by relating EA, the CEFR and the Communicative Approach some issues are easily spotted and assessed using the CEFR as a reference document, whereas other issues need further clarification to help teachers focus on the particular aspects in need of assessment. The guidelines are helpful in the most traditional aspects of error correction, but seem to be lacking with regard to communicative issues. Furthermore, the fact that some of the issues proposed in the CEFR offer a greater degree of subjectivity than others, and a clearer identification with the level of proficiency analysed could render these useful in their interpretation. This is particularly necessary in the case of the pragmatic issues studied. Additionally, the Communicative Approach focuses on the communicative competences of students, and EA can help in the development of the communicative skills required for effective communication. Indeed, by analysing the 
specific shortcomings students have at a specific point in their learning process, help can be given to overcome these in order to achieve the required competences.

\section{Proposals for further work}

Several investigations can be derived from the results obtained in the present dissertation. Below some thoughts on possible lines of research are reproduced, although there could obviously be others.

First of all, a similar analysis could be carried out with students from disciplines other than Tourism Management, for instance, students enrolled in Engineering or other technical degrees. Fruitful research would result from this in two different ways. On the one hand, it would permit a comparison of the differences and similarities of the errors students make, requiring from them a greater or a lower degree of language specificity. On the other hand, it could help verify or refute the description of errors and their ratings found at this level of proficiency and education obtained in the present study.

In addition, this could result in a clearer identification of the real proficiency level of students, establishing a linguistic tool for the analysis and assessment of levels, thus avoiding having to rely on external specifications, such as the legal descriptors established in High School syllabuses or the University Entrance level specification.

Moreover, the analysis concluded could be expanded to look at other levels of proficiency. This could be used in the Universities which now need to 
certify a minimum B2 level of English or another foreign language for their students. Indeed, research similar to this could be completed in order to establish common errors at higher levels of proficiency (B2), taking into account other available resources, such as the English Profile Project.

Based on the types of errors students make, the present dissertation could also be the basis for establishing the language approach and the specific linguistic contents that should be included in University syllabuses to ensure the accomplishment of the appropriate level of proficiency for their students in subsequent years.

This could also be expanded to incorporate specific training for teachers, as well as existing materials in some of the subjects included in the present research, such as the pragmatic issues encountered. Indeed, although teachers are aware of and are able to work with specific pragmatic issues, they often lack the resources to do so in class. Moreover, ways to approach, assess and evaluate these issues in the classroom would be of great use to them.

Finally, the research has also shown that, although the CEFR descriptors are useful and appropriate for some error types, in other cases these could be improved to help in the learning and teaching process. Further work could be dedicated to studying these particular items and providing complementary descriptors and guidelines for use. 


\section{REFERENCES}





\section{REFERENCES}

AL-JARF, R. (2000). "Grammatical agreement errors in L1/L2 translations". IRAL, 38:1-15.

AlCARAZ, E. (1990). Tres paradigmas de la investigación lingüística. Alcoy: Marfil.

AlCARAZ, E. (2000). El inglés profesional y académico. Madrid: Alianza.

Alcón, E. \& SAfONT M.P. (2008). "Pragmatic Awareness in Second Language Acquisition" Encyclopedia of Language and Education: 1948-1959.

ALEXANDER, L.G. (1994). Right word, wrong word: words and structures confused and misused by learners of English. London: Longman.

ANSCOMBRE, J.C. (1989). "Théorie de l'argumentation, topoï, et structuration discursive". Revue québécoise de linguistique, 18-1: 13-55.

ANSCOMBRE, J.C. \& DUCROT, O. (1983). L'argumentation dans la langue. Bruxelles: Mardaga.

ARCHIBALD, A. (1994). The acquisition of discourse proficiency: A study of the ability of German school students to produce written texts in English as a foreign language. Frankfurt: Peter Lang.

ARCHIBALD, A. \& JefFerY, G.C. (2000). "Second language acquisition and writing: a multi-disciplinary approach". Learning and Instruction, 10: 1-11. 
AsHer, N. \& LASCARIDES, A. (2001). “Indirect Speech Acts”. Synthese, 128.

ATKINSON, D. (2004). "Contrasting rhetorics/contrasting cultures: why contrastive rhetoric needs a better conceptualization of culture" Journal of English for Academic Purposes, 3: 277-289.

Austin, J.L. (1962). How to do things with words. Oxford: Oxford University Press.

BACHMAN, L. (1990). Fundamental Considerations in Language Testing. Oxford: Oxford University Press.

BACHMAN, L.F. \& PalmeR, A.S. (1996). Language testing in practice. Oxford: Oxford University Press.

BAKER, W. \& HANSEN BRICKER, R. (2010). "The effects of direct and indirect speech acts on native English and ESL speakers' perception of teacher written feedback". System, 38-1: 75-84.

BANATHY, B.H. \& Madarasz P.H. (1969). "Contrastive Analysis and Error Analysis”. Journal of English as a Second Language, 4-2: 72-92.

BARDOVI-HARLIG, K. (1996). "Pragmatics and Language Teaching: Bringing Pragmatics and Pedagogy together" in Bouton, L.F. (Ed.). Pragmatics and Language Learning, 7: 21-39.

BASSANO D. (1991). "Opérateurs et connecteurs argumentatifs: une approche psycholinguistique". Intellectica, 1-11: 149-191.

BenvenISTE, E. (1971). Problems in General Linguistics. Florida: University of Miami Press.

Berns, M. (1990). Contexts of Competence: Sociocultural Considerations in Communicative Language Teaching. New York: Plenum.

BhatiA, V. K. (1993). Analysing Genre: Language Use in Professional Settings. London: Longman.

BIALYSTOK, E. (1993). "Symbolic representation and attentional control in pragmatic competence" in G. Kasper \& S. Blum-Kulka (Eds.). Interlanguage Pragmatics. New York: Oxford University Press: 43-57. 
Bloomfield, L. (1933). Language. New York: Henry Holt and Co.

Blum-Kulka, A. House J. \& KASPER. G. (Eds.). (1989). Cross-cultural Pragmatics: Requests and apologies. Norwood: Abblex.

BonDI, M. (1999). English across genres: Language variation in the discourse of economics. Modena: Edizione II Fiorino.

Brown, G. \& Yule G. (1983). Discourse Analysis. Cambridge: Cambridge University Press.

BUCKINGHAM, T. \& ESKEY D.E. (1980). "Toward a definition of applied linguistics" in R. Kaplan (Ed.). On the Scope of Applied linguistics. Rowley, MA: Newbury House: 1-3.

Bueno González, A., Carini Martínez, J.A. \& Linde López A. (1992). Análisis de errores en inglés: tres casos prácticos. Granada: Universidad de Granada.

BURT, M. \& KIPARSKY, C. (1972). The Gooficon: A repair manual for English. Rowley: Newbury House.

Butler, C., Gomez-Gonzalez, M.A. \& Doval Suarez S.M. (Eds.). (2005). The dynamics of language use. Functional and contrastive perspectives. Amsterdam-Philadelphia: John Benjamins.

Butler, C., Mairal Usón, R. Martín Arista J. \& Ruiz de Mendoza, F. (1999). Nuevas Perspectivas en Gramática Funcional. Barcelona: Ariel.

Byram, M. (1988). Cultural Studies in Foreign Language Education. Clevedon: Multilingual Matters.

CANALE, M. (1983). "From communicative competence to communicative language pedagogy" in J.C. Richards \& R.W. Schmidt (Eds.). Language and Communication. London: Longman: 2-27.

Canale, M. \& Swain M. (1980). "Theoretical bases of communicative approaches to second language teaching and testing". Applied Linguistics, 1: 1-47. 
Candlin, C.N. (1997). "General Editor's Preface" in B.L. Gunnarsson, P. Linell, \& B. Nordberg (Eds.). The Construction of Professional Discourse. London: Longman.

CarRió, M.L. (2004). “Las implicaciones de los errores léxicos en los artículos en ingles científico-técnico". RAEL: Revista Electrónica de Lingüística Aplicada, 3: 21-40.

CARRIó, M.L. (2005a). Contrastive analysis of scientific-technical discourse: Common writing errors and variations in the use of English as a non-native language. Ann Arbour: UMI.

CARRIÓ M.L. (2005b). “Errores verbales en la escritura científica”, in M. L. Carrió (Coord.) Perspectivas interdisciplinares de la lingüística aplicada. Valencia: Asociación Española de Lingüística Aplicada.

CARRIó, M.L. (2006). “Definición y características del aprendizaje colaborativo asistido por ordenador" in M.L. Carrió (Ed.). Aprendizaje colaborativo asistido por ordenador. Valencia: Blauverd Impressors: 9-35.

CARRIó, M.L. (2007). "Internet as a tool to learn a second language in a technical environment". European Journal of Engineering Education, 32-5: 599-612.

CARRIó, M.L. (2008). Innovaciones docentes en la lingüística y las lenguas aplicadas. Valencia: Editorial de la Universidad Politécnica de Valencia.

CARRIó, M.L. (2009a). "Contrasting specific English corpora: Language variation". International Journal of English Studies, 9-1: 221-234.

CARRIó, M.L. (2009b)."Sharing CLIL in Europe” in M.L. Carrió, (Ed.). Content And Language Integrated Learning: Leveraging Cultural Diversity. Bern: Peter Lang.

CARRIó, M.L. \& MeSTRE, E.M. (2010). “Implications of a corpus of lexical errors in second language learning". Proceedings of the II International Congress. AELINCO. A Coruña: Servicio de Publicaciones de la Universidad de A Coruña. 
CARRIÓ, M.L. \& SEIZ, R. (2000). "La expresión escrita en inglés técnico. Sus errores". Actes del III Congrés Internacional sobre Llengües per a Finalitats Específiques. Barcelona: Universitat de Barcelona: 69-73.

Carroll, J.B. (1955). The study of Language. Cambridge: Harvard University Press.

CARTER, R. \& McCARThy M. (1995). "Grammar and the spoken language". Applied linguistics, 16-2: 141:158.

CHARLES, M. (2007). "Argument or evidence? Disciplinary variation in the use of the noun that pattern in stance construction". English for Specific Purposes, 26: 203-218.

Chesterman, A. (1998). Contrastive Functional Analysis. Amsterdam: John Benjamins.

CHICK, J. (1996). "Intercultural communication" in S. McKay \& $\mathrm{N}$. Hornberger (Eds.). Sociolinguistics and language teaching. New York: Cambridge University Press: 329-348.

CHomsky, N. (1966). Linguistic Theory. Reprinted in J.P.B. Allen \& P. Van Buren (Eds.). Chomsky: Selected Readings. London: Oxford University Press: 152-159.

CHomsky, N. (1980). Rules and Representations. Oxford: Basil Blackwell.

CHomsky, N. (1986). Knowledge of Language: Its Nature, Origin and Use. New York: Praeger.

CLARKE, M.A. (1994). "The dysfunctions of the theory/practice discourse". TESOL Quarterly, 28: 9-26.

CONFEDERATION OF EU RECTORS' CONFERENCES AND THE ASSOCIATION OF EUROPEAN UNIVERSITIES (CRE) (2000). The Bologna Declaration on the European space for higher education: an explanation. Retrieved [5/10/2010] from http://ec.europa.eu/education/policies/ educ/bologna/bologna.pdf 
CONNOR, U. (1996). Contrastive rhetoric: Cross-cultural aspects of second-language writing. Cambridge: Cambridge University Press.

CONNOR, U. (2003). "Changing currents in contrastive rhetoric: implications for teaching and research" in B. Kroll, Exploring the dynamics of second language writing. Cambridge: Cambridge University Press: 218-241.

CONNOR, U. (2004). "Intercultural rhetoric research: Beyond texts". Journal of English for Academic Purposes, 3-4: 291-304.

Cook, V.J. \& Newson, M. (1996). Chomsky's Universal Grammar. Cambridge: Blackwell Publishers.

CORDER, S.P. (1967). “The significance of learners' errors”. International Review of Applied Linguistics, 5: 160-170.

CORDER, S.P. (1973). Introducing Applied Linguistics. Hardsmondsworth: Pelican Books.

CORDER, S.P. (1974). "Error analysis" in J. Allen \& S.P. Corder (Eds.). The Edinburgh Course in Applied Linguistics, 3. Oxford: Oxford University Press.

CORDER, S.P. (1981). Error analysis and interlanguage. Oxford: Oxford University Press.

Coulmas, F. (2001). "Sociolinguistics" in Aronoff, A. \& J. Rees-Miller (Eds.). The Handbook of Linguistics. Oxford: Blackwell Publishers: 563-582.

COUNCIL OF EUROPE. (1998). Recommendation N. R(98)6 of the Committee of ministers to member estates concerning modern languages. (Adopted by the Committee of Ministers on 17 March 1998 at the $623^{\text {rd }}$ meeting of the Ministers' Deputies). Retrieved [29/10/10] from https://wcd.coe.int/com.instranet.Instra Servlet?command=cominstranet.CmdBlobGet\&InstranetImage $=530647 \&$ SecMode $=1 \&$ Docld $=459522 \&$ Usage $=2$ 
COUNCIL OF EUROPE. (2001). Common European Framework of Reference for Languages: Learning, Teaching, Assessment. Cambridge: Cambridge University Press.

Crandall, E. \& Basturkmen, H. (2004). "Evaluating Pragmatics-focused materials”. ELT Journal, 58-1: 38-49.

CROOKES, G. \& SCHMIDT, R. (1991). "Motivation: Reopening the research agenda". Language Learning, 41-4: 469-512.

CRYSTAL, D. (1997). The Cambridge encyclopaedia of language. Cambridge: Cambridge University Press.

CUENCA M.J. (2003). "Two ways to reformulate: a contrastive analysis of reformulation markers". Journal of Pragmatics, 35: 10691093.

DA SILVA, A.J.B. (2003). "The effects of instruction on pragmatic development: teaching polite refusals in English". Second Language Studies, 22-1: 55-106.

DEKEYSER, R. (1998). "Beyond focus on form: cognitive perspectives on learning and practicing second language grammar" in Doughty, C. \& J. Williams, (Eds.). Focus on Form in Classroom Second Language Acquisition. Cambridge: Cambridge University Press: 42-63.

Díaz-Negrillo, A. \& Fernández-Domínguez, J. (2006). "Error tagging systems for learner corpora". RESLA, 19: 83-102.

Dık, S.C. (1978). Functional Grammar. Amsterdam: North-Holland.

DIK, S.C. (1989). The Theory of Functional Grammar, 1. Dordrecht: Foris.

DöRNYEl, Z. (2007) Research Methods in Applied Linguistics. Oxford: Oxford University Press.

DudLEY-EVANS, A. (1994). "Genre analysis: an approach to text analysis for ESP" in M. Coulthard (Ed.). Advances in Written Text Analysis. New York: Routledge. 
DudLEY-Evans T. \& SAINT John M.J. (1998). Developments in English for Specific Purposes: A Multidisciplinary Approach. New York: Cambridge University Press.

Dulay, H., Burt, M. \& Krashen, S. (1982). Language Two. Rowley: Newbury House.

DULAY, H.C. \& BuRT M.K. (1974). "You can't learn without goofing. An analysis of children's second language "errors" in J.C. Richards (Ed.). Error analysis. Perspectives on second language acquisition. London: Longman: 95-123.

DURRANT, P. (2009). "Investigating the viability of a collocation list for students of English for academic purposes". English for Specific Purposes, 28: 157-169.

ECKES, T. (2005) "Identifying Rater Types in TestDaF Writing Performance Assessments". $2^{\text {nd }}$ Annual Conference of EALTA. Voss, Norway: 2-5.

EL-DALY, H.M. (2010). "On the philosophy of language: searching for common grounds for pragmatics". International Journal of Academic research, 2-6: 244-262.

ELLIS, R. (1985). Understanding Second Language Acquisition, Oxford: Oxford University Press.

ElLIS, R. (1994). The Study of Second Language Acquisition. Oxford: Oxford University Press.

ELLIS, R. (1997). "Second language acquisition" in Oxford Introduction to Linguistics. Oxford: Oxford University Press.

ELLIS, R. (2005). “Principles of Instructed Language Learning”. Asian EFL Journal, 7-3: 9-24.

ELLIS, R. (2006). “Modelling Learning Difficulty and Second Language Proficiency: The differential contributions of implicit and explicit knowledge". Applied Linguistics, 27-3: 431-463. 
ERISKSON, F. (1979). "Talking down: Some cultural sources of miscommunication in interracial interviews" in A. Wolfgang (Ed.). Nonverbal behavior: Applications and cultural implications. New York: Academic Press: 99-126.

ERLAM, R. (2006). "Elicited Imitation as a Measure of L2 Implicit Knowledge: An Empirical Validation Study". Applied Linguistics, 27-3: 464-491.

ESCANDELL, M.V. (1996). "Towards a cognitive approach to politeness". Language Sciences, 18-3/4: 629-650.

Escandell, M.V. (2004). "Norms and principles. Putting social and cognitive Pragmatics together" in R. Márquez Reiter \& M.E. Placencia, (Coords.). Current trends in the Pragmatics of Spanish. Amsterdam-Philadelphia: John Benjamins.

ESCANDELL, M.V. (2006). Introducción a la pragmática. (2ª Ed). Barcelona: Ariel.

ESLAMI-RASEKH, Z. (2005). "Raising the pragmatic awareness of language learners”. ELT Journal, 59-3: 199-208.

FEHRINGER, C. \& FRY, C. (2007). "Hesitation phenomena in the language production of bilingual speakers: The role of working memory". Folia Linguistica, 41-1/2: 37-72.

FERNÁNDEZ GonZÁlEZ, J. (1995). El análisis contrastivo: historia y crítica. Valencia: Publicacions de la Universitat de València.

FERNÁNDEZ, S. (1995). Interlengua y análisis de errores en el aprendizaje del español como lengua extranjera. Madrid: EDELSA.

FINCH, G. (2003). Word of Mouth: A New Introduction to Language and Communication. Basingstoke, UK: Palgrave Macmillan.

FIRTH, A. \& WAGNER, J. (1997). “On discourse, communication and (some) fundamental concepts in SLA research" The modern language Journal, 81-3: 285-300. Retrieved [15/06/2010] from http://newcastle.academia.edu/AlanFirth/Papers/124386/On -Discourse--communication-and--some--fundamental-conceptsin-SLA-research 
FISCHER K. \& DRESCHER M. (1996). "Methods for the description of discourse particles: contrastive analysis". Language Sciences. 18-3/4: 853-861.

FITIKIDES, T. (1936). Common mistakes in English. (6 Ed.). London: Longman.

Foley, W.A. \& Van Valin, R.D. JR. (1984). Functional Syntax and Universal Grammar. Cambridge: Cambridge University Press.

ForTANET-Gómez, I. \& RaISANEn C.A. (Eds.). (2008). ESP in Higher European Education: Teaching Language and Content. Amsterdam: John Benjamins Publishing.

FouCAULT, M. (1972). The Archaeology of Knowledge. London: Tavistock.

FREDDI, M. (2005). "Arguing linguistics: Corpus investigation of one functional variety of academic discourse". Journal of English for Academic Purposes, 4: 5-26.

FRENCH, F. G. (1949) Common Errors in English. London: Oxford University Press.

FriedLANDER, A. (1990) "Composing in English: effects of a first language on writing in English as a second language" in B. Kroll, (Ed.). Second Language Writing. Research Insights for the Classroom. Cambridge: Cambridge University Press: 109-125.

FUKUSHIMA, S. (1990). "Offers and requests: Performance by Japanese learners of English”. World Englishes, 9: 317-325.

FULCHER G. \& DAVIDSON. F. (2007). Language Testing and Assessment: An Advanced Resource Book. London and New York: Routledge.

GAO, S. (2009). "Policies for Teachers towards Errors in College English Writing". International Education Studies, 2, 2. Retrieved [01/09/2009] from www.ccsenet.org/journal.html

García Velasco, D. \& Portero Muñoz, C. (2002). "Understood objects in functional grammar". Working Papers in Functional Grammar. 76: $1-24$. 
GARSIDE R. \& SMITH N. (1997). "A hybrid grammatical tagger: CLAWS4" in R. Garside et al. (Eds.). Corpus Annotation: linguistic information from computer text corpora. London: Longman: 102-121.

GASKELL, D. \& CoBB, T. (2004). "Can learners use concordance feedback for writing errors?" System, 32: 301-319.

GEA, M.L. (2005). "A practical study of genre-based instruction in academic writing at University" in M.L. Carrió (Coord.). Perspectivas interdisciplinares de la lingüística aplicada, 2. Valencia: Asociación Española de Lingüística Aplicada: 252262.

GeE, J.P. (1999). Discourse Analysis. Theory and Method. London: Routledge.

GonZalvez-GarciA, F. (2009). "The family of object-related depictives in English and Spanish: towards a usage-based constructionist analysis". Language Sciences, 31: 663-723.

GRICE, H.P. (1975). "Logic and conversation" in P. Cole \& J. Morgan (Eds.). Syntax and Semantics, 3. New York: Academic Press: 41-58.

GRICE, H.P. (1989). Studies in the Way of Words. Cambridge: Harvard University Press.

Gros, B. (1997). Diseño y programas educativos. Pautas pedagógicas para la elaboración de software. Barcelona: Ariel.

GRUNDI, P. (2002). "The sociopragmatics of writing". Retrieved [30/11/10] from http://www.baleap.org.uk/pimreports/ 2002/heriotwatt/grundy.htm

Guo, T. \& ZHOU, L. (2008) “Studies on Contrastive Analysis”. International Forum of Teaching and Studies, 4-1: 62-75.

HAAN, P. DE AND VAN ESCH, K. (2005). "The development of writing in English and Spanish as foreign languages". Assessing writing, 10: 100-116. 
HABERMAS, J. (1970). "Introductory remarks to a theory of communicative competence". Inquiri 13.3. Reprinted in H.P. Dreitzel (Ed.). Recent sociology, 2. London: Macmillan.

Halbach A., Lázaro Lafuente, A. \& Pérez Guerra, J. (2010). La acreditación del nivel de lengua inglesa en las universidades españolas. Madrid: British Council.

HaLlidAY, M.A.K., (1967). "Notes on transitivity and theme in English". Journal of Linguistics, 3-12: 37-81.

HaLLIDAY, M.A.K. (1984). An Introduction to Functional Grammar. London: Edward Arnold.

HaLLIDAY, M.A.K. \& HASAN R. (1976). Cohesion in English. London: Longman.

HAMID, O. (2007). "Identifying second language errors: how plausible are plausible reconstructions?" ELT Journal, 61-2: 107-116.

HAMILTON, R.P. (2001). "The insignificance of learners' errors: a philosophical investigation of the interlanguage hypothesis". Language \& Communication, 21: 73-88.

HARUMITSU, M. (1988). "Interlanguage Analysis for Foreign Language Teaching”. Kanagawa University Studies in Language, 11: 13-18.

HAUGEN, E. (1950). “The analysis of linguistic borrowing”. Language, 26: 210-231.

HAWKEY, R. (2009). "Impact of a Blended Learning course: observation and stakeholder views". Research Notes, 36: 26-28.

HAWTHORN, J. (1992). A Concise Glossary of Contemporary Literary Theory. London: Edward Arnold.

Heine, B., Claudi U. \& Hünnemeyer, F. (1991). Grammaticalization: A Conceptual Framework. Chicago: University of Chicago Press.

HILL, Robert J. (1982). A dictionary of false friends. Hong-Kong: The Macmillan Press Ltd. 
HILLOCKS, G. JR. (2002). The Testing Trap. How state writing assessments control learning. New York and London: Teachers college, Columbia University.

HINKEL, E. (2009). "The effects of essay topics on modal verb uses in L1 and L2 academic writing". Journal of Pragmatics, 41: 667-683.

Holmes, J. \& RAmos R. (1993). "False Friends and Reckless Guessers" Second Language Reading and Vocabulary Learning: 86-108.

HouSE, J. (1986). “Learning to talk: Talking to learn. An investigation of learner performance in two types of discourse" in G. Kasper (Ed.). Learning, teaching and communication in the foreign language classroom. Aarhus: Aarhus University Press: 43-57.

Hubert, M. \& Bonzo J.D. (2010). “Does second language writing research impact U.S. university foreign language instruction?" System, 38: 517-528.

Hughes, A. (1989). Testing for language teachers. Cambridge: Cambridge University Press.

Hunston, S. (2002). Corpora in Applied Linguistics. Cambridge: Cambridge University Press.

Hutchinson, T. \& Waters, A. (1987). English for Specific Purposes. Cambridge: Cambridge University Press.

HymeS, D. (1972). "On communicative competence" in J. Pride \& J. Holmes (Eds.). Sociolinguistics. Harmondsworth: Penguin Books.

IGLESIAS RÁBADE, L. (Ed.). (1999). Análisis de los errores del examen de inglés en las Pruebas de Acceso a la Universidad en el distrito universitario de Galicia. Santiago de Compostela: Servizo de Publicacións e intercambio Científico, Universidade de Santiago de Compostela.

JACKENDOFF, R. (1992). Languages of the Mind. Cambridge: MIT Press. 
JAIN, M. (1974). "Error Analysis: Source, Cause and Significance" in J. Richards (Ed.). Error analysis: Perspectives on Second Language Acquisition: 189-215.

JAKOBOVITS, L.A. (1970). Foreign language learning. Rowley: Newbury House.

JAMES, C. (1980). Contrastive analysis. London: Longman.

JAMES, C. (1998). Errors in Language Learning and Use. London: Longman.

JAMES, C. (2008). “Cross-linguistic Awareness: A New Role for Contrastive Analysis". Linguanet, 1.

JANNEY R.W. \& ARNDT H. (1992). "Intracultural Tact vs Intercultural Tact” in R.J. Watts, S. Ide \& K. Enlich (Eds.). Politeness in Language. Studies in its History, Theory and Practice. Berlin: Mouton de Gruyter: 2-41.

JÄRVINEN, H.M. (2004). "The Common European Framework in teaching writing" in K. Mäkinen, P. Kaikkonen \& V. Kohonen (Eds.). Future perspectives in foreign language education. Oulu: Oulu University Press. Retrieved [14/01/2010] from http://www.coe.int/T/DG4/Portfolio/?L=E\&M=/documents int ro/common framework.html

JAWORSKI, A. \& COUPLAND, N. (2006). "Introduction: Perspectives on discourse analysis" in A. Jaworski \& N. Coupland (Eds.). The discourse reader. London: Routledge.

JOHANSSON, S. (1975). "The Uses of Error Analysis and Contrastive Analysis (II)". English Language Teaching, 29-4: 330-336.

JONES, R. (1979). "Performance testing of second language proficiency" in E. Briere \& F. Hinofotis (Eds.), Concepts in language testing. Washington, DC: TESOL: 50-57. 
KACHRU, B. (1985). "Standards, codification and sociolinguistic realism: the English language in the Outer Circle" in R. Quirk, \& H.G. Widdowson (Eds.). English in the World: Teaching and Learning the Language and Literatures. Cambridge: Cambridge University Press: 11-30.

KANAGI, R. (1999). "Interactional routines as a mechanism for L2 acquisition and socialization in an immersion context." Journal of Pragmatics, 31: 1467-92.

KAPPEL J. \& LOCHTMAN K. (2009). The World a Global Village: Intercultural Competence in English Foreign Language Teaching. Brussels: VUB PRESS.

KARRA, M. (2006). “Second Language Acquisition: Learners' Errors and Error Correction in Language Teaching". Retrieved [20/07/2009] from http://hin.proz.com/doc/633.

KASPER, G. (1985). "Repair in foreign language teaching". Studies in Second Language Acquisition, 7: 200-15.

KASPER, G. (1997). Can pragmatic competence be taught? Retrieved [03/02/2010] from http://www.nflrc.hawaii.edu/NetWorks/NW06/

KASPER, G. (2001). "Classroom research on interlanguage Pragmatics" in K.R. Rose \& G. Kasper, (Eds.). Pragmatics in Language Teaching. Cambridge: Cambridge University Press.

KASPER, G. \& Rose, K.R. (2001). "Preface to Pragmatics in Language teaching" in Rose K.R. \& Kasper G. (Eds.). Pragmatics in Language Teaching. Cambridge: Cambridge University Press.

KASPER, G. \& RoSe, K. R. (2002). Pragmatic development in a second language. Oxford: Blackwell.

KASPER, G. \& SCHMIDT, R. (1996). "Developmental issues in interlanguage Pragmatics". Studies in Second language Acquisition, 18: 149-69.

KEMPSON R. (2001). "Pragmatics: Language and Communication” in M. Aronoff \& J. Rees-Miller, (Eds.). The Handbook of Linguistics. Oxford: Blackwell Publishers. 
Khalifa, H., Robinson, M. \& HARVEY S. (2010). "Working together: The case of the English diagnostic test and the Chilean Ministry of Education". Research Notes, 40: 22-26.

KIRK-GREENE, CWE (1992). NTC's Dictionary of Faux Amis. Lincolnwood: National Textbook Company.

KIRKGÖZ Y. (2010). "An analysis of written errors of Turkish adult learners of English". Procedia Social and Behavioral Sciences, 2: $4352-4358$.

KoHN, K. (1986). "The analysis of transfer" in E. Kellerman \& M. Sharwood-Smith, (Eds.). Crosslinguistic Influence in Second Language Acquisition. Oxford: Pergamon: 21-34.

KRASHEN, S. (1981). Second Language Acquisition and Second Language Learning. Oxford: Pergamon.

KURTES, S. (2005). "Contrastive linguistics: a 21st century perspective” in S. Marmaridou, K. Nikiforidou \& E. Antonopoulou, (Eds.). Reviewing linguistic thought: converging trends for the 21st century. Berlin: Mouton de Gruyter: 255-278.

KURTES, S. (2006). "Contrastive Analysis" An encyclopaedia of the Arts, 49: 830-839.

LADO, R. (1957). Linguistics across cultures. Ann Arbor: University of Michigan Press.

LANDONE, E. (2009). "Reflexiones sobre la cortesía verbal en la enseñanza/aprendizaje del ELE”. Revista didáctica ELE, 8.

LARDIERE, D. (2009). "Some thoughts on the contrastive analysis of features in second language acquisition". Second language Research, 25-2: 173-227.

LaRSEN-Freeman, D. (1997). "Chaos/Complexity Science and Second Language acquisition”. Applied Linguistics, 18-2: 141-65.

LARSEN-FreEmAN, D. \& LONG, M. (1991). An Introduction to second language acquisition research. New York: Longman. 
LASCARIDES, A. \& ASHER, N. (1993). "Temporal interpretation, discourse relations, and commonsense entailment". Linguistics and Philosophy, 16: 437-93.

LEE, I. (1997). “ESL learners' performance in error correction in writing: some implications for teaching”. System, 25-4: 465-477.

LEE, I. (2004). "Error correction in L2 secondary writing classrooms: the case of Hong Kong". Journal of Second Language Writing, 13: 285-312.

LEECH G. (1997). "Introducing corpus annotation” in R. Garside, G. Leech \& T. McEnery (Eds.). Corpus Annotation: linguistic information from computer text corpora. London: Longman: 1-18.

LeVInson, S.C. (2000). Presumptive Meanings: The Theory of Generalized Conversational Implicature. Cambridge: MIT Press.

LeVISON, M. LeSSARD, G. \& WALKer D. (2000). "A multi-level approach to the detection of second language learner errors". Literary and Linguistic Computing, 15-3: 313- 322.

LEWANDOWSKı, T. (1986). Diccionario de lingüística. Madrid: Cátedra.

$\mathrm{LI}, \mathrm{X}$. (2008). "From contrastive rhetoric to intercultural rhetoric" in U. Connor (Ed.). Contrastive Rhetoric: Reaching to Intercultural Rhetoric. Amsterdam: John Benjamins Publishing Company.

LOI, C.K. \& SweEtNAM, M. (2010). "Cultural differences in the organization of research article introductions from the field of educational psychology: English and Chinese". Journal of Pragmatics, 42: 2814-2825.

LONG, M.H., AdAMS, L., McLeAn, M. \& CASTAÑos, F. (1976). Doing things with words: Verbal interaction in lockstep and small group classroom situations. In J. Fanselow \& R. Crymes (Eds.). TESOL '76. Washington: TESOL: 137-53. 
LONG, M. (1996). "The role of the linguistic environment in second language acquisition" in W.Ritchie, \& T. Bhatia, (Eds.). Handbook of Second Language Acquisition. San Diego: Academic Press: 413-468.

Martinet, A. (1960). Éléments de linguistique générale. Paris: Masson \& Armand Colin Éditeurs.

MARTINEZ, A. (2004). The effect of instruction on the development of pragmatic competence in the English as a foreign language context: a study based on suggestions. Unpublished PhD Dissertation. Universitat Jaume I. Retrieved [10/01/2010] from http://www.tesisenxarxa.net/TDX-0126105-123437/

McEnery, T. \& WiLson, A. (1996). Corpus Linguistics. Edinburgh: Edinburgh University.

McEnery, T. \& Wilson, A. (2001). Corpus Linguistics. Web pages to be used to supplement the book. Retrieved [02/02/2011] from http://www.sal.tohoku.ac.jp/ling/corpus2/.

McNAmARA, T. (1996). Measuring second language performance. London: Longman.

Martín Martín, P. (2003). "A genre analysis of English and Spanish research paper abstracts in experimental social sciences". English for Specific Purposes, 22: 25-43.

MelLes, G. (1997). "Enfocando la competencia lingüística: Concienciación gramatical”. Hispania, 80-4: 848-58.

MeY, J.L., 1993. Pragmatics. An Introduction. Oxford: Blackwell.

MeY, J.L. \& TAlbOt, M.M. (1988). "Computation and the Soul” Journal of Pragmatics, 12-5/6: 743-789.

MILROY, L. \& MILROY, J. (1992). "Social network and social class: toward an integrated sociolinguistic model". Language in Society, 26: 1-26. 
Montalt, V. (2005). Manual de traducció científicotècnica. Vic: Eumo Editorial.

MoRENO, A. I. (1997). "Genre constrains across languages: Casual metatext in Spanish and English RAs". English for Specific Purposes, 16-3: 161-179.

Moreno, A. I. \& SuÁREZ, L. (2008). "A study of critical attitude across English and Spanish academic book reviews". Journal of English for Academic Purposes, 7: 15-26.

MuÑIZ, R. \& CARRIÓ PASTOR, M.L. (2007). "Variaciones culturales en la correspondencia comercial en inglés". Revista de innovación e investigación en la clase de lenguas: Encuentro, 16-1: 76-81.

NÉMETH, E. \& BıBOK, K. (2010). “Interaction between grammar and Pragmatics: The case of implicit arguments, implicit predicates and co-composition in Hungarian". Journal of Pragmatics, 422: 501-524.

NiIMURA T. \& HAYASH B. (1996). "Contrastive Analysis of English and Japanese Demonstratives from the perspective of L1 and L2 Acquisition". Language Sciences, 18-3/4: 811-834.

NiR, B. \& Berman, R. (2010). "Complex syntax as a window on contrastive rhetoric". Journal of Pragmatics, 42: 744-765

NunAN, D. (1988). The Learner-Centred Curriculum: A Study in Second Language Teaching. Cambridge: Cambridge University Press.

NunAN, D. (1989). Designing Tasks for the Communicative Classroom. New York: Cambridge University Press.

NunAN, D. (1992). (Ed.). Collaborative language learning and teaching. Cambridge: Cambridge University Press.

NunAN, D. (1993). Introducing Discourse Analysis. London: Penguin English.

OduIN, T. (1989). Language Transfer. Cross-linguistic influence in language learning. Cambridge: Cambridge University Press. 
O'Grady, W., YamashitA, Y. \& LeE, S. (2005). "A note on canonical word order". Applied Linguistics, 26-3: 453-58.

OHTA, A. (1994). "Socializing the expression of affect: An overview of affective particle use in the Japanese as a foreign language classroom". Issues in Applied Linguistics, 5: 303-325.

OLLER, J.W. (1972). "Contrastive analysis, difficulty and predictability". Foreign Language Annals, 6-1: 95-106.

OLSEN, S. (1999). "Errors and compensatory strategies: a study of grammar and vocabulary in texts written by Norwegian learners of English". System, 27: 191-205.

OzTURK, I. (2007). "The textual organisation of research article introductions in applied linguistics: Variability within a single discipline". English for Specific Purposes, 26: 25-38.

PAlACIOS, I. \& Alonso, R. (2005). "Lexis and leaner corpora. A study of English/Spanish false friends on the basis of the data provided by SULEC (Santiago University Learner of English Corpus)" in Studies in contrastive linguistics. Proceedings of the $4^{\text {th }}$ International Contrastive Linguistics Conference. Santiago de Compostela: Universidad de Santiago de Compostela.

Pallotti, G. (2007). "An Operational Definition of the Emergence Criterion”. Applied Linguistics, 28-3: 361-382.

Pietarinen, A.V. (2004). "Grice in the wake of Peirce". Pragmatics \& Cognition, 12-2: 295-315.

PISANSKI PETERLIN A. (2005). "Text-organising metatext in research articles: an English-Slovene contrastive analysis". English for Specific Purposes, 24: 307-319.

PORTER, P.A., (1986). "How learners talk to each other: Input and interaction in task-centered discussion" in R.R. Day (Ed.). Talking to learn: Conversation in Second Language acquisition. Rowley: Newbury House: 200-222. 
RANDALL, S. (2002). “Cambridge ESOL's growing impact on English language teaching and learning in national education projects". Research Notes in Cambridge ESOL, 40: 2-3.

ReEs-Miller, J. (2001). “Applied Linguistics” in A. Aronoff, \& J. Rees-Miller (Eds.). The Handbook of Linguistics. Oxford: Blackwell Publishers: 637-646.

REID, J. (1998). "Responding to ESL student language problems: Error analysis and revision plans" in P. Byrd \& J. Reid, (Eds.). Grammar in the composition classroom. Boston: Heinle \& Heinle: 118-137.

Reuer V. (2003). "Error Recognition and Feedback with Lexical Functional Grammar". CALICO Journal, 20-3: 497-512.

RICHARDS, J.C. (1971). "A non-contrastive approach to error analysis". English Language Teaching Journal, 25: 204-19.

RichaRDS, J.C. (1974). Error Analysis: Perspective on Second Language Acquisition. London: Longman.

RICHARDS, J.C. \& Rodgers, T.S. (2001). Approaches and methods in language teaching. Cambridge: Cambridge University Press.

RIFKIN, B. \& RoBeRTS, F.D. (1995). "Error gravity: a critical review of research design". Language Learning, 45-3: 511-537.

RIVERS, W.M. (1964). The Psychologist and the Foreign Language Teacher. Chicago: University of Chicago Press.

RoBerts, C. (1998). "Awareness in intercultural communication". Language Awareness, 7-2/3: 109-127.

Rodríguez Aguado, J.I. (2004). Análisis de errores en el ejercicio de redacción en las Pruebas de Acceso a la Universidad. Asignatura, lengua extranjera, inglés. Unpublished PhD. Universidad de Valladolid. 
ROEHR, K. (2007). "Metalinguistic Knowledge and Language Ability in University-Level L2 Learners”. Applied Linguistics, 29-2: 173199.

RumelHaRT, D.E. \& McClelland, J.L. (1986). "PDP models and general issues in cognitive science" in D.E. Rumelhart, J.L. McClelland, \& the PDP Research Group (Eds.). Parallel distributed processing: Explorations in the microstructure of cognition. 1: Foundations. Cambridge: Bradford Books/MIT Press.

RutheRford, W.E. \& ShARWOOd SMith, M. (Eds.). (1988). Grammar and Second Language Teaching: A Book of Readings. New York: Newbury House Publishers.

Salamoura, A. (2008). "Aligning English Profile research data to the CEFR". Research Notes in Cambridge ESOL, 33: 5-7.

SALEM L., (2007). "The lexico-grammatical continuum viewed through student error". English Language Teaching Journal, 61-3: 211219.

SAMRAJ, B. (2002). "Introductions in research articles: Variations across disciplines". English for Specific Purposes, 21: 1-17.

SAMRAJ, B. (2004). "Discourse features of the student-produced academic research paper: Variation across disciplinary courses". Journal of English for Academic Purposes, 3: 5-22.

SAMRAJ, B. (2005). "An exploration of a genre set: Research article abstracts and introductions in two disciplines". English for Specific Purposes, 24: 141-156.

SAmRAJ, B. \& Monk, L. (2008). "The statement of purpose in graduate program applications: Genre structure and disciplinary variation". English for Specific Purposes, 27: 193-211.

Santos Gargallo, I. (1993). Análisis Contrastivo, Análisis de Errores e Interlengua en el marco de la Lingüística Contrastiva. Madrid: Síntesis. 
SANDELOWSKI, M. (2003). "Tables or tableaux? The challenges of writing and reading mixed methods studies" in A. Tashakkori and C. Teddlie (Eds.). Handbook of mixed methods in social \& behavioral research. Sage: Thousand Oaks.

SAVIGNON, S.J. (1972). Communicative competence: an experiment in foreign language teaching. Philadelphia: Center for Curriculum Development.

SavignoN, S.J. (Ed.). (2002). Interpreting Communicative Language Teaching: Contexts and Concerns in Teacher Education. New Haven: Yale University Press.

SCHACHTER, J. (1996). "Learning and triggering in adult L2 acquisition" in G. Brown, K. Malmkjaer \& J. Williams (Eds.). Performance and competence in Second Language Acquisition. Cambridge: Cambridge University Press.

SCHLEEF, E. (2009). "A cross-cultural investigation of German and American academic style". Journal of Pragmatics, 41: 11041124.

SEARLE, J.R. (1969). Speech acts: an essay in the philosophy of language. Cambridge: Cambridge University Press.

SEARLE, J.R. (1985). Expression and meaning: studies in the theory of speech acts. Cambridge: Cambridge University.

SeLINKER, L. (1972). "Interlanguage". International Review of Applied Linguistics, 10-3: 209-31.

Sharwood, M. \& Truscott, J. (2005). "Stages or Continua in Second Language Acquisition”. Applied Linguistics, 26-2: 219-240.

SHARWOOD-SMith, M. (1988). "Consciousness Raising and the Second Language Learner" in W. Rutherford \& M. Sharwood-Smith (Eds.). Grammar and Second Language Teaching: $A$ book of Readings. New York: Newbury House: 51-60. 
SHEEN, R. (1996). "The advantage of exploiting contrastive analysis in teaching and learning a foreign language". International Review of Applied Linguistics, 34-3: 183-197.

SIMPSON, J.M. (2000). "Topical structure analysis of academic paragraphs in English and Spanish". Journal of Second Language Writing, 9-3: 239-309.

SINCLAIR, J.M. (1992). "The automatic analysis of corpora” in J. Svartvik, (Ed.). Directions in corpus linguistics. Proceedings of Nobel Symposium 82. Stockholm. Berlin: Mouton de Gruyter: 379397.

SinclaiR, J. (2005). "Corpus and Text - Basic Principles" in M. Wynne (Ed.). Developing Linguistic Corpora: a Guide to Good Practice. Oxford: Oxbow Books: 1-16. Retrieved [26/03/2007] from http://ahds.ac.uk/linguistic-corpora/.

SINCLAIR, J. (2006). Linear Unit Grammar: Integrating Speech and Writing. Amsterdam: John Benjamins Publishing Company.

SinclaiR, J. \& COULTHARD, M. (1975). Toward an Analysis of Discourse: the English Used by Teachers and Pupils. Oxford: Oxford University Press.

SKEHAN, P. (1998). A Cognitive Approach to Language Learning. Oxford: Oxford University Press.

SLOBIN, D.I. (1996). "From thought and language to thinking for speaking" in J.J. Gumperz and S.C. Levinson (Eds.). Rethinking Linguistic Relativity: Studies in the Social and Cultural Foundations of Language, 17. Cambridge: Cambridge University Press: 70-96.

SPERBER, D. \& WILSON, D. (1995). Relevance: Communication and Cognition. Oxford: Blackwell.

SPERBER, D. \& WILSON, D. (1997). "Remarks on relevance theory and the social sciences”. Multilingua, 16: 145-51. 
StRAuSS, A.L. \& CORBIN, J. (1990). Basics of Qualitative Research: Grounded Theory, procedures and techniques. Newbury Park: Sage Publications

SWALES, J.M. (1990). Genre analysis. English in academic and research settings. Cambridge: Cambridge University Press.

SWALES, J.M. (2004). Research genres: Explorations and applications. Cambridge: Cambridge University Press.

TAKAHASHI S. (1996). "Pragmatic Transferability". Studies in Second Language Acquisition, 18: 189-223.

TAKAHASHI, S. (2005) "Pragmalinguistic Awareness: is it related to motivation and proficiency?" Applied Linguistics, 26-1: 90120.

TANAKA, N. (1988). "Politeness: Some problems for Japanese speakers of English". JALT Journal, 9: 81-102.

TAYLOR, G. (1986). "Errors and explanations". Applied Linguistics, 7: 144166.

TERRELL, T. (1991). "The role of Grammar Instruction in a Communicative Approach”. Modern Language Journal, 75-1: 52-63.

TRIMBLE, L. (1985). English for Science and Technology: A Discourse Approach. Cambridge: Cambridge University Press.

TRUSCOTT, J. (1996). "The case against grammar correction in L2 writing classes”. Language Learning, 46-2: 327-369.

TRUSCOTT, J. (1998). "Noticing in second language acquisition: a critical review" Second language Research, 14-2:103-135.

TURTON, N. (1995). ABC of Common Grammatical Errors: For Learners and Teachers of English (ELT). London: Macmillan Educational.

VAleRo-GARCÉS, C. (1996). "Contrastive ESP rhetoric: Metatex in SpanishEnglish economics texts”. English for Specific Purposes, 15-4: 279-294. 
VAN DIJK T.A. (2004). "Ideology and Discourse Analysis". Ideology Symposium Oxford. Retrieved [15/07/2009] from http://www.discursos.org/unpublished\%20articles/ldeology\% 20and\%20discourse\%20analysis.htm.

VAN Eemeren, F.H. (1999). "Argumentation: an overview of theoretical approaches and research themes. A prepublication". Retrieved [27/01/2010] from http://argumentation.ru/2002 1/ papers/1_2002p4.html.

VAN EK, J.A. (1975). "The Threshold Level in a European Unit/Credit System for Modern Language Learning by Adults". Systems Development in Adult Language Learning. Strasbourg: Council of Europe.

VAN VALIN, R.D. JR. (1993). "A synopsis of role and reference grammar" in R.D. Van Valin Jr. (Ed.). Advances in Role and Reference Grammar. Amsterdam and Philadelphia: John Benjamins: 1164.

Van Valin, R.D. JR. (2001). "Functional Linguistics" in A. Aronoff, \& J. Rees-Miller, (Eds.). The Handbook of Linguistics. Oxford: Blackwell Publishers: 319-337.

VAN VAlin, R.D. JR. \& LAPolLA, R.J. (1997). Syntax: Structure, Meaning and Function. Cambridge: Cambridge University Press.

VanPatten, B. (1996). Input Processing and Grammar Instruction in Second Language Acquisition. Norwood: Ablex.

VanPatten, B. (2002). "Processing instruction: an update". Language Learning, 52: 755-803.

VASSILEVA, I. (2001). "Commitment and detachment in English and Bulgarian academic writing". English for Specific Purposes, 20: 83-102.

VÁZQUEZ, G. (1999). ¿Errores? ¡Sin falta! Madrid: Edelsa.

Verschueren, J. (1999). Understanding Pragmatics. New York: Arnold Publishers. 
WANG M.L. (2007). “Pragmatic Errors in English Learners' Letter Writing”. Sino-US English Teaching, 4-2: 39-43.

WARDHAUGH, R. (1970). "The Contrastive Analysis Hypothesis". TESOL Quarterly, 4-2: 123-130.

WeBber, P. (1993). "Writing medical articles: a discussion of common errors made by L2 authors and some particular features of discourse". UNESCO-ALSED LSP Newsletter, 15-2: 38-49.

WEIR, C.J. (2005). "Limitations of the Common European Framework for developing comparable examinations and tests". Language testing, 22: 281-300.

WeLLS, G. (1985). Language Development in the Pre-school Years. Cambridge: Cambridge University Press.

WHITMAN, R.L. \& JACKSON, K.L., (1972). “The unpredictability of contrastive analysis". Language Learning, 22: 29-42.

WidDowson, H.G. (1978). Teaching language as communication. Oxford: Oxford University Press.

Widdowson H.G. (1979). Explorations in Applied Linguistics. Oxford: Oxford University Press.

Widdowson, H. G. (1983). Learning Purpose and Language Use. Oxford: Oxford University Press.

Widdowson, H.G. (1996). Linguistics. Oxford: Oxford University Press

WIDDowson, H.G. (1998). "Retuning, calling the tune, and paying the piper: a reaction to Rampton" International Journal of Applied Linguistics, 8: 131-40.

WILKINS, D.A. (1976). Notional Syllabuses. London: Oxford University Press.

Wilson, D. \& Sperber, D. (1998) "Pragmatics and time” in R. Carston \& S. Uchida (Eds.). Relevance theory: Applications and implications. Amsterdam: John Benjamins: 1-22. 
WiLSON, D. \& SPERBER, D. (2002). "Truthfulness and relevance". Mind, 111: 583-632.

Wilson, D. \& Sperber, D. (2004). "Relevance Theory" in L.R. Horn \& G. Ward (Eds.). The Handbook of Pragmatics. Oxford: Blackwell: 607-632. Retrieved [28/01/2010] from www.phon.ucl.ac.uk/ .../9b\%20Wilson\%20\&\%20Sperber\%20Relevance\%20theory\%20U CLWPL.doc

WISHNOFF, J. (2000). “Hedging Your Bets: L2 Learners' acquisition of pragmatic devices in academic writing and computer-mediated discourse". Second Language Studies, 19-1: 119-148.

WITTGENSTEIN, L. (1968). Los cuadernos azul y marrón. Madrid: TECNOS.

XIE, F. \& JIANG X.M. (2007). "Error analysis and the EFL classroom teaching". US-China Education Review, 4-9: 10-14.

YAKHONTOVA, T. (2006). "Cultural and disciplinary variation in academic discourse: The issue of influencing factors". Journal of English for Academic Purposes, 5: 153-167.

YALDEN, J. (1987). The communicative syllabus: Evolution, Design and Implementation. London: Prentice-Hall International.

YATES, R. \& KENKEL, J. (2002). "Responding to sentence-level errors in writing". Journal of Second Language Writing, 11-1: 29- 47.

YEN-FEN LIAO (2004) "Issues of Validity and Reliability in Second Language Performance Assessment". Working Papers in TESOL \& Applied Linguistics, 4-2: 1-4.

YULE, G. (1996). Pragmatics. Oxford: Oxford University Press. 


\section{SUMMARIES}





\section{SUMMARIES}

\subsection{SUMMARY}

Linguistic error has proven to be a recurrent area of interest for researchers. There exist several types of approaches to error; some studies have focused on specific errors, such as grammatical errors, others on more general or exogenous issues, such as the perception of error of the group object of study, etc. From the point of view of methodology, some have been dedicated to the definition and description of error, while others have studied the identification of erroneous uses of language. Several proposals for error categorisation have also been propounded.

In the case of error production in languages foreign to the speaker, the learning factor must also be included. Some authors have focused on the underlying reasons, questioning if the cause for errors rests upon an inadequate teaching method, or the actual teacher, or even if the cause is intrinsic to any learnt language, as opposed to the Mother Tongue. 
From the principle that it is possible to improve the language proficiency level of students by looking at the errors produced, this doctoral dissertation studies pragmatic error in the production of written English.

In addition, it includes pedagogic perspectives that introduce a Second Language to potential speakers and the European Framework of Reference.

The thesis is structured as follows: the first part is dedicated to a theoretical justification of the research, with an introduction to Pragmatics, Error Analysis, Contrastive Analysis, Second Language Acquisition -in particular the Communicative Approach- and the European Framework for Languages. The third chapter is dedicated to the objectives. Chapter 4 explains the methodology used for data processing and analysis. The results are explained in chapter 5 and chapter 6 presents the conclusions derived from these.

To begin with, a proposal for error analysis and identification is presented. This takes into account error distribution and classification and language levels proposed in the Common European Framework of Reference for Languages as an open tool for the analysis of errors investigated. Then, once the results obtained from this classification, and from real texts produced by students of English language are known, a hierarchic taxonomy of the errors found is proposed. A correspondence between the errors and the B1 language level (CEFR) is established. 


\subsection{RESUM}

L'error lingüístic ha estat un àrea d'interés recurrent per als investigadors. N'hi ha tot tipus d'enfocament envers l'error; alguns estudis s'han centrat en errors específics, com ara gramaticals, altres en qüestions més generals, o exògenes, com ara la percepció de l'error per part del grup objecte d'estudi, etc. Des del punt de vista metodològic, alguns s'han dedicat a la definició i descripció de l'error, uns altres a la identificació d'usos erronis de la llengua; alguns autors han fet la distinció entre categories d'errors.

En el cas de la producció d'errors en llengües estrangeres al parlant, també cal incloure el factor aprenentatge. Alguns autors se n'han centrat en les raons subjacents, qüestionant si la raó dels errors cal buscar-la en un ensenyament inapropiat, o en els professors, o bé si és intrínsec al llenguatge aprés, en oposició al llenguatge nadiu.

Des del plantejament que es pot millorar el nivell de coneixement de llengua dels estudiants a partir dels errors que produeixen, la tesi doctoral estudia l'error pragmàtic en la producció escrita en anglés. A més, inclou les perspectives pedagògiques que introdueixen la segona llengua als parlants potencials, i el marc de referència europeu. 
La tesi té la següent estructura: la primera part està dedicada a la justificació teòrica del treball, amb una introducció a la Pragmàtica, l'Anàlisi d'Errors, l'Anàlisi Contrastiva, I'Adquisició de la Segona Ilengua -en particular l'Enfocament Comunicatiu, i el Marc Europeu per a les Llengües. El tercer capítol està dedicat als objectius. El capítol 4 explica la metodologia utilitzada per al tractament de les dades. Els resultats estan explicats al capítol 5, i les conclusions que se n'extrauen al capítol 6.

Primer s'introdueix una proposta per a l'anàlisi i identificació d'errors, tot tenint en compte la distribució i classificació d'errors i nivells de llengua establerts pel Marc Comú Europeu de Referència per a les Llengües com a eina oberta per a la categorització dels errors analitzats. Una vegada s'han obtingut els resultats a partir d'aquesta categorització i de texts reals produïts per estudiants d'anglés, es proposa una taxonomia jeràrquica dels errors trobats. S'ha establert una correspondència entre els errors, i el nivell B1 de llengua establert al CEFR. 


\subsection{RESUMEN}

El error lingüístico ha sido una recurrente área de interés para los investigadores. Conocemos de todo tipo de aproximaciones al error; algunos estudios se han centrado en errores específicos, como los gramaticales, otros en cuestiones más generales, o exógenas, como por ejemplo la percepción del error por parte del grupo objeto de estudio, etc. Desde el punto de vista de la metodología, algunos se han dedicado a la definición y descripción del error, otros, a la identificación de usos erróneos de la lengua; también hay propuestas de categorías de errores. En el caso de la producción de errores en lenguas extranjeras al hablante, también hay que incluir el factor aprendizaje. Algunos autores se han centrado en las razones subyacentes, cuestionando si hay que buscar la causa de los errores en una enseñanza inapropiada, o en el profesorado, o bien si es intrínseca al lenguaje aprendido, en oposición a la lengua materna.

Desde el planteamiento de que es posible mejorar el nivel de conocimiento de la lengua de los estudiantes a partir de los errores que producen, la tesis doctoral estudia el error pragmático en la producción escrita en inglés. Asimismo, incluye las perspectivas pedagógicas que 
introducen la segunda lengua a los hablantes potenciales y el marco de referencia europeo.

La tesis está estructurada de la siguiente manera: la primera parte está dedicada a la justificación teórica del trabajo, con una introducción a la Pragmática, el Análisis de Errores, el Análisis Contrastivo, la Adquisición de la Segunda Lengua -en particular el Enfoque Comunicativo- y el Marco Europeo para las Lenguas. El tercer capítulo está dedicado a los objetivos. El capítulo 4 explica la metodología utilizada para el tratamiento de los datos. Los resultados se explican en el capítulo 5 y las conclusiones en el 6.

Primero se introduce una propuesta para el análisis y la identificación de errores que tiene en cuenta la distribución y clasificación de errores y niveles de lengua establecidos en el Marco Común Europeo de Referencia para las Lenguas como herramienta abierta para la categorización de los errores analizados. Una vez obtenidos los resultados a partir de esta categorización y de textos reales producidos por estudiantes de inglés, se propone una taxonomía jerárquica de los errores hallados. Se establece una correspondencia entre los errores y el nivel B1 de lengua establecido en el CEFR. 
ANNEXES 



\section{ANNEXES}

In $C D$

9.1. Assignments.

9.2. Texts produced by the students.

9.3. Analysis grid with examples.

9.4. Correction.

9.5. Results per text.

9.6. Statistical analyses.

9.7. Qualitative analysis. 

